\title{
CONTACT ANGLES AND SURFACE ENERGETICS
}

by

Daniel Yu Hing Kwok

\begin{abstract}
A thesis submitted in conformity with the requirements
for the Degree of Doctor of Philosophy

Graduate Department of Mechanical and Industrial Engineering University of Toronto
\end{abstract}

() Copyright by Daniel Yu Hing Kwok 1998 
National Library of Canada

Acquisitions and Bibliographic Services

395 Wellington Street Ottawa ON K1A ON4 Canada
Bibliothèque nationale du Canada

Acquisitions et services bibliographiques

395. ne Wellington Ottawa ON K1A ON4 Canada
The author has granted a nonexclusive licence allowing the National Library of Canada to reproduce, loan, distribute or sell copies of this thesis in microform, paper or electronic formats.

The author retains ownership of the copyright in this thesis. Neither the thesis nor substantial extracts from it may be printed or otherwise reproduced without the author's permission.
L'auteur a accordé une licence non exclusive permettant à la Bibliothèque nationale du Canada de reproduire, prêter, distribuer ou vendre des copies de cette thèse sous la forme de microfiche/film, de reproduction sur papier ou sur format électronique.

L'auteur conserve la propriété du droit d'auteur qui protège cette thèse. $\mathrm{Ni}$ la thèse ni des extraits substantiels de celle-ci ne doivent être imprimés ou autrement reproduits sans son autorisation. 
Thesis Title: $\quad$ Contact Angles and Surface Energetics

Degree and Year: Doctor of Philosophy, 1998

Name: $\quad$ Daniel Yu Hing Kwok

Department: $\quad$ Graduate Department of Mechanical and Industrial Engineering

University: University of Toronto

\begin{abstract}
Low-rate dynamic contact angles of a large number of liquids are measured on various solid surfaces by Axisymmetric Drop Shape Analysis - Profile (ADSA-P). It is found that not all experimental contact angles can be used for energetic calculations: In a specific case, slip and stick contact angle behaviour occurs where the contact angle fluctuates by as much as $35^{\circ}$. Thus, circumspection is necessary in the decision whether or not the experimental contact angles can be used to interpret surface energetics in conjunction with Young's equation and whether the solid-liquid systems violate the basic assumptions made in all contact angle approaches. It is shown that if one omits the inconclusive contact angle measurements, the liquid-vapour surface tension times cosine of the contact angle changes smoothly with the liquid-vapour surface tension, i.e. $\gamma_{l v} \cos \theta$ depends only on $\gamma_{l}$ for a given solid surface (or solid surface tension). Changing the solid surface (and hence $\gamma_{s v}$ ) shifts the curves in a very regular manner. Thus, $\gamma_{l v} \cos \theta$ depends only on $\gamma_{l v}$ and $\gamma_{s v}$. Intermolecular forces do not have an additional and independent effect on the contact angles. Because of Young's equation, the solid-liquid surface tension $\gamma_{s l}$ can be expressed as a function of only $\gamma_{\nu}$
\end{abstract}


and $\gamma_{s v}$.

Goniometer and ADSA-P contact angle measurements are also compared: they are shown to be essentially identical for solid-liquid systems which have constant contact angles. In the specific case of the slip/stick of the three-phase contact line using a goniometer technique, the observed static advancing angle corresponds to the maximum angle of the entire slip/stick behaviour, as registered by the automated ADSA-P technique. Thus, conventional goniometer measurements may produce a mixture of meaningful and meaningless contact angles, with no criteria to distinguish between the two. This provides partial explanation of the contact angle controversy in the literature.

A large amount of dynamic contact angle data is generated. An equation which follows these experimental patterns and which allows the determination of solid surface tensions is discussed. 


\section{ACKNOWLEDGEMENTS}

I would like to express my sincere gratitude to my supervisor Professor A. W. Neumann for his valuable advice and assistance throughout this study. He led me into this interesting and challenging areas of contact angles and surface thermodynamics.

I would like to thank my parents for their continued support and encouragement throughout my study in Canada.

I am indebted to Miss Yvonne Chung. Yvonne's encouragement, support, and patience are a real contribution to my study.

Thanks are due Professor H. -J. Jacobasch, Dr. K. Grundke, and Dr. T. Gietzelt at the Institute of Polymer Research Dresden (Germany) for their collaboration.

Thanks are due Professor D. Li for his valuable advice and insight in surface thermodynamics.

I would also like to thank my laboratory colleagues for their help and advice, especially Z. Policova. 


\section{TABLE OF CONTENTS}

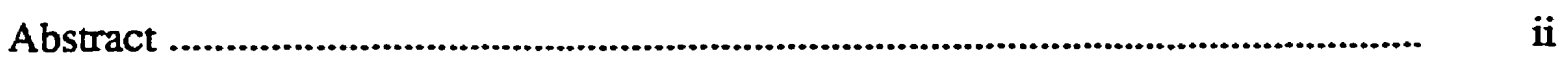

Acknowledgements ........................................................................................ iv

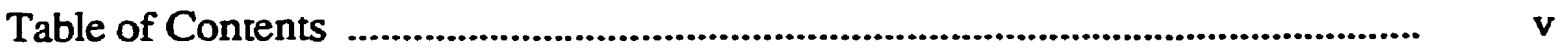

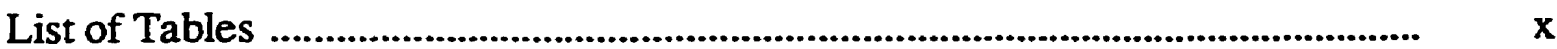

List of Figures ............................................................................................... xiv

List of Appendices ....................................................................................... xvii

Chapter 1. Introduction .............................................................................

Chapter 2. Experimental Contact Angle Patterns ................................................... 10

Chapter 3. Experimental Contact Angle Patterns from a Goniometer .................... 15

3.1 Materials (Solid Surfaces and Liquids) ............................................... 15

3.2 Experimental Procedures ..................................................................... 17

3.3 Results and Discussion ..................................................................... 18

Chapter 4. Axisymmetric Drop Shape Analysis - Profile (ADSA-P) ..................... 24

4.1 ADSA Methodology ........................................................................ 24

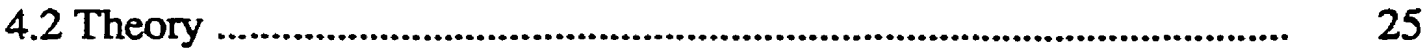

4.3 Drop Profile Coordinates ..................................................................... 27

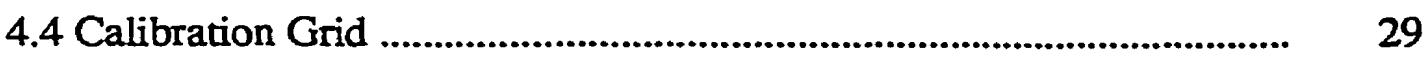

Chapter 5. Low-Rate Dynamic Contact Angles from ADSA-P .............................. 34

5.1 Experimental Procedures .................................................................... 34 
5.2 Inert (Non-polar) Surfaces: FC-722-Coated Mica

5.2.1 Materials (Solid Surfaces and Liquids) ................................. 37

5.2.2 Results and Discussion ...................................................... 38

5.3 Non-Inert (Polar) Surfaces: Poly(propene-alt-N-(n-propyl)-

maleimide) and Poly(propene-ait- $\mathrm{N}$-(n-hexyl)maleimide)

5.3.1 Materials (Solid Surfaces and Liquids) ................................ 42

5.3.2 Results and Discussion ......................................................... 43

5.4 Other Non-Polar and Polar Surfaces ..................................................... 50

Chapter 6. Universality of Contact Angle Patterns ................................................ 84

6.1 Reasons of Deviation from Smoothness .............................................. 86

Chapter 7. Criteria for Calculations of Surface Energetics ...................................... 91

7.1 Accepted Assumptions for Calculations of Surface

Energetics

7.2 Experimental Criteria ........................................................................... 95

Chapter 8. Contact Angle Interpretation ............................................................. 103

8.1 Surface Tension Component Approaches .............................................. 104

8.1.1 Fowkes Approach ............................................................... 104

8.1.2 Owens-Wendt-Kaelble Approach ....................................... 106

8.1.3 Lifshitz - van der Waals / Acid-Base (van Oss)

Approach …....................................................................... 108

8.2 Equation of State Approach .............................................................. 110 


\subsubsection{Equation of State Approach: Modified Berthelot's}

Rule

Chapter 9. Applications

9.1 Evaluation of Existing Contact Angle Data

9.2 Predictive Power of the Equation of State Approach

Chapter 10. Conclusions

Chapter 11. Perspective

Chapter 12. Future Work

References

Appendix A. Statistical Criteria for Averaging of Contact Angle Data

Appendix B. Low-Rate Dynamic Contact Angles on a Fluorocarbon

FC-725-Coated Silicon Wafer Surface

B.1 Materials (Solid Surfaces and Liquids)

B.2 Results

Appendix C. Low-Rate Dynamic Contact Angles on a

Poly(n-butyl methacrylate) Solid Surface

C. 1 Materials (Solid Surfaces and Liquids)

178

C.2 Results

Appendix D. Low-Rate Dynamic Contact Angles on a Polystyrene 
D.1 Materials (Solid Surfaces and Liquids)

D.2 Results

Appendix E. Low-Rate Dynamic Contact Angles on a Poly(styrene-

(hexyl/10-carboxydecyl 90:10)-maleimide) Solid Surface

E.1 Materials (Solid Surfaces and Liquids)

E.2 Results

Appendix F. Low-Rate Dynamic Contact Angles on a Poly(methyl methacrylate/n-butyl methacrylate) Solid Surface

F.1 Materials (Solid Surfaces and Liquids)

F.2 Results

Appendix G. Low-Rate Dynamic Contact Angles on a Poly(methyl

methacrylate) Solid Surface

G.1 Materials (Solid Surfaces and Liquids)

G.2 Results

Appendix H. Low-Rate Dynamic Contact Angles on Poly(propene-alt-N(n-alkyl)maleimide) Solid Surfaces

H.1 Materials (Solid Surfaces and Liquids)

H.2 Results

Appendix I. Low-Rate Dynamic Contact Angles on a Poly(propene-alt-Nmethylmaleimide) Solid Surface 
Appendix J. Alternative Formulations of an Equation of State Approach for Solid Surface Tensions 


\section{LIST OF TABLES}

Table 3.1: Suppliers and surface tensions of the liquids used for the contact angle measurements on poly(propene-alt- $N-(n-$ propyl)maleimide) and poly(propene-alt $-N-(n$-hexyl)maleimide) copolymers.

Table 3.2: Summary of the static contact angles measured by a conventional goniometer technique on poly(propene-alt- $N$-( $n$-propyl)maleimide) and poly(propene-alt- $N$-( $n$-hexyl)maleimide) copolymers.

Table 5.1: Suppliers and surface tensions of the liquids used for the low-rate dynamic contact angle measurements on a FC-722-coated mica.

Table 5.2: Low-rate dynamic (advancing) contact angles of different liquids on a FC-722-coated mica.

Table 5.3: Low-rate dynamic (advancing) contact angles of different liquids on a poly (propene-alt- $N$-( $n$-propyl)maleimide) copolymer surface.

Table 5.4: Summary of the low-rate dynamic (advancing) contact angles measured by ADSA-P on a poly(propene-alt- $N-(n-$ propyl)maleimide) copolymer surface.

Table 5.5: Low-rate dynamic (advancing) contact angles of different liquids on a poly(propene-alt- $N$-( $n$-hexyl)maleimide) copolymer surface.

Table 5.6: Summary of the low-rate dynamic (advancing) contact angles measured by ADSA-P on a poly(propene-alt $-N-(n-$ hexyl)maleimide) copolymer surface.

Table 5.7: Comparison between the advancing contact angles measured by ADSA-P and a goniometer on the poly(propene-alt $-N-(n-$ propyl)maleimide) copolymer surface.

Table 5.8: Comparison between the advancing contact angles measured by ADSA-P and a goniometer on the poly(propene-alt $-N-(n-$ hexyl)maleimide) copolymer surface. 
Table 8.1: Calculated solid surface tension components for FC-721 using three simultaneous equations of Eq.(8.11), the van Oss approach, from contact angles of three polar liquids.

Table 8.2: Calculated solid surface tension components for FC-721 using three simultaneous equations of Eq.(8.11), the van Oss approach, from contact angles of one non-polar and two polar liquids.

Table 8.3: Calculated $\gamma_{s v}$ values of the FC-722-coated mica from Antonow's and Berthelot's rules.

Table 8.4: Summary of the dynamic contact angles of various solids by ADSA-P and capillary rise technique, together with the $\gamma_{s v}$ values calculated from the equation of state approach.

Table 8.5: Averaged $\gamma_{s v}$ values reproduced from Table 8.4; $\gamma_{s v}$ and $\beta$ values determined by a two-variable least-square fit are also given.

Table 9.1: Summary of the static contact angles of various solids from Zisman et al. by a conventional goniometer technique. The $\gamma_{s v}$ values were calculated from the equation of state approach.

Table 9.2: Averaged $\gamma_{s v}$ values from Table 9.1 calculated from the equation of state approach.

124

Table 9.3: Comparison between the measured and predicted contact angles and liquid surface tensions on a FC-722-coated mica.

Table A.1: Summary of the correlation analysis to study whether or not averaging the contact angles over time is allowed.

Table B.1: Suppliers and surface tensions of the liquids used for contact angle measurements on a FC-725-coated silicon wafer surface.

Table B.2: Low-rate dynamic (advancing) contact angles of different liquids on a FC-725-coated silicon wafer surface.

Table B.3: Summary of the low-rate dynamic (advancing) contact angles measured by ADSA-P on a FC-725-coated silicon wafer surface.

Table C.1: Suppliers and surface tensions of the liquids used for contact angle measurements on a poly( $n$-butyl methacrylate)-coated silicon wafer surface. 
Table C.2: Low-rate dynamic (advancing) contact angles of different liquids on a poly ( $n$-butyl methacrylate)-coated silicon wafer surface.

Table C.3: Summary of the low-rate dynamic (advancing) contact angles measured by ADSA-P on a poly ( $n$-butyl methacrylate)-coated silicon wafer surface.

Table D.1: Suppliers and surface tensions of the liquids used for contact angle measurements on a polystyrene-coated silicon wafer surface.

Table D.2: Low-rate dynamic (advancing) contact angles of different liquids on a polystyrene-coated silicon wafer surface.

Table D.3: Summary of the low-rate dynamic (advancing) contact angles measured by ADSA-P on a polystyrene-coated silicon wafer surface.

Table E.1: Suppliers and surface tensions of the liquids used for contact angle measurements on a poly(styrene-(hexyl/10-carboxydecyl 90:10)-maleimide)-coated silicon wafer surface.

Table E.2: Low-rate dynamic (advancing) contact angles of different liquids on a poly(styrene-(hexyl/10-carboxydecyl 90:10)maleimide)-coated silicon wafer surface.

Table E.3: Summary of the low-rate dynamic (advancing) contact angles measured by ADSA-P on a poly(styrene-(hexyl/10carboxydecyl 90:10)-maleimide)-coated silicon wafer surface.

Table F.1: Suppliers and surface tensions of the liquids used for contact angle measurements on a poly (methyl methacrylate/ $n$-butyl methacrylate)-coated silicon wafer surface.

Table F.2: Low-rate dynamic (advancing) contact angles of different liquids on a poly(methyl methacrylate/n-butyl methacrylate)coated silicon wafer surface.

Table F.3: Summary of the low-rate dynamic (advancing) contact angles measured by ADSA-P on a poly (methyl methacrylate/n-butyl methacrylate)-coated silicon wafer surface. 
Table G.1: Suppliers and surface tensions of the liquids used for contact angle measurements on a poly(methyl methacrylate)-coated silicon wafer surface.

Table G.2: Low-rate dynamic (advancing) contact angles of different liquids on a poly(methyl methacrylate)-coated silicon wafer surface.

Table H.1: Suppliers and surface tensions of the liquids used for contact angle measurements on poly (propene-alt $-N-(n-$ propyl)maleimide)- and poly(propene-alt $-N-(n-$ hexyl)maleimide)-coated silicon wafer surfaces.

Table H.2: Low-rate dynamic (advancing) contact angles of different liquids on poly(propene-alt-N-(n-hexyl)maleimide)and poly(propene-alt- $N$-( $n$-propyl)maleimide)-coated silicon wafer surfaces.

Table H.3: Summary of the low-rate dynamic (advancing) contact angles measured by ADSA-P on poly (propene-alt- $N$ - $(n$-hexyl)maleimide)- and poly(propene-alt- $N$-( $n$-propyl)maleimide)coated silicon wafer surfaces.

Table I.1: Suppliers and surface tensions of the liquids used for contact angle measurements on a poly (propene-alt- $N$-methylmaleimide)coated silicon wafer surface.

Table I.2: Low-rate dynamic (advancing) contact angles of different liquids on a poly(propene-alt- $N$-methylmaleimide)-coated silicon wafer surface.

Table 1.3: Summary of the low-rate dynamic (advancing) contact angles measured by ADSA-P on a poly (propene-alt- $N$ methylmaleimide)-coated silicon wafer surface.

Table J.1: $\quad \gamma_{s v}$ and $\beta$ values determined by a two-variable least-square fit for the two equation-of-state formulations. 


\section{LIST OF FIGURES}

Figure 1.1: Schematic of a sessile-drop contact angle system. 9

$\begin{array}{lll}\text { Figure 2.1: } & \gamma_{l v} \cos \theta \text { vs. } \gamma_{l \nu} \text { for three well-prepared inert solid surfaces: } & 14\end{array}$ FC-721-coated mica, heat-pressed Teflon FEP (fluorinated ethylene propylene), and poly(ethylene terephthalate) PET.

Figure 3.1: Chemical structure for poly(propene-alt- $N$-( $n$-propyl)maleimide) 20 and poly(propene-alt- $N$-( $n$-hexyl)maleimide) copolymers.

Figure 3.2: $\quad \gamma_{l \nu} \cos \theta$ vs. $\gamma_{l \nu}$ for poly(propene-alt- $N$-( $n$-propyl)maleimide) and poly(propene-alt- $N$-(n-hexyl)maleimide) copolymers from goniometer contact angles.

Figure 4.1: Definition of the coordinate system for ADSA-P.

Figure 4.2: Schematic of the ADSA-P set-up for sessile and pendant drop measurements.

Figure 4.3: A computer picture of a doubly-distilled water sessile drop on a poly(methyl methacrylate)-coated silicon wafer surface, reproduced by a laser printer.

Figure 4.4: A computer picture of a calibration grid, reproduced by a laser printer.

Figure 5.1: Schematic of a motorized syringe mechanism for dynamic contact angle measurements.

Figure 5.2: Low-rate dynamic contact angles of water on a FC-722-coated mica.

Figure 5.3: Dynamic and static contact angles of cis-decalin on a FC-722coated mica.

Figure 5.4: $\quad \gamma_{l v} \cos \theta$ vs. $\gamma_{l l}$ for the dynamic contact angles of the 17 liquids on a FC-722-coated mica.

Figure 5.5: Low-rate dynamic contact angles of water on a poly(propenealt $-N$-(n-propyl)maleimide) copolymer.

Figure 5.6: Low-rate dynamic contact angles of glycerol on a poly(propene- 57 alt- $N$-( $n$-propyl)maleimide) copolymer. 
Figure 5.7: Low-rate dynamic contact angles of formamide on a poly(propene-alt- $N$-( $n$-propyl)maleimide) copolymer.

Figure 5.8: Low-rate dynamic contact angles of ethylene glycol on a poly(propene-alt- $N$-( $n$-propyl)maleimide) copolymer.

Figure 5.9: Low-rate dynamic contact angles of diiodomethane on a poly(propene-alt- $N$-( $n$-hexyl)maleimide) copolymer.

Figure 5.10: $\gamma_{l \nu} \cos \theta$ vs. $\gamma_{L v}$ for the poly(propene-alt- $N$-( $n$-propyl)maleimide) 61 and poly(propene-alt- $N$-( $n$-hexyl)maleimide) copolymers.

Figure 5.11: $\gamma_{l \nu} \cos \theta$ vs. $\gamma_{l v}$ for a FC-725-coated silicon wafer surface.

62

Figure 5.12: $\gamma_{l \nu} \cos \theta$ vs. $\gamma_{l v}$ for a poly ( $n$-butyl methacrylate) PnBMAcoated silicon wafer surface.

Figure 5.13: $\quad \gamma_{l \nu} \cos \theta$ vs. $\gamma_{l v}$ for a polystyrene PS-coated silicon

64 wafer surface.

Figure 5.14: $\quad \gamma_{l \nu} \cos \theta$ vs. $\gamma_{l \nu}$ for a poly(styrene-(hexyl/10-carboxydecyl

65 90:10)-maleimide)-coated silicon wafer surface.

Figure 5.15: $\gamma_{l v} \cos \theta$ vs. $\gamma_{l v}$ for a poly (methyl methacrylate/ $n$-butyl

66

methacrylate) $\mathrm{P}(\mathrm{MMA} / n \mathrm{BMA})$-coated silicon wafer surface.

Figure 5.16: $\gamma_{l v} \cos \theta$ vs. $\gamma_{l v}$ for a poly(methyl methacrylate) PMMA-

67 coated silicon wafer surface.

Figure 5.17: $\quad \gamma_{l v} \cos \theta$ vs. $\gamma_{l v}$ for a poly(propene-alt-N-methylmaleimide)-

68 coated silicon wafer surface.

Figure 6.1: $\quad \gamma_{l \nu} \cos \theta$ vs. $\gamma_{l v}$ for various solid surfaces.

Figure 6.2: $\quad \gamma_{l v} \cos \theta$ vs. $\gamma_{l v}$ for three methacrylate polymer-coated 90 silicon wafer surfaces.

Figure 7.1: $\quad \gamma_{l \nu} \cos \theta$ vs. $\gamma_{l v}$ for a PET surface 100

Figure 7.2: Low-rate dynamic contact angles of water on a octadecanethiol $\left(\mathrm{HS}\left(\mathrm{CH}_{2}\right) \mathrm{CH}_{3}\right) \mathrm{SAM}$ on a gold substrate.

101

Figure 7.3: $\quad \gamma_{l v} \cos \theta$ vs. $\gamma_{l v}$ for a octadecanethiol $\left(\mathrm{HS}\left(\mathrm{CH}_{2}\right)_{17} \mathrm{CH}_{3}\right)$ 102 SAM on a gold substrate and a hexatriacontane surface. 
Figure 9.1: $\quad \gamma_{l v} \cos \theta$ vs. $\gamma_{l v}$ generated from the equation of state approach, Eq. (8.35), from $\gamma_{s \nu}=16.0 \mathrm{~mJ} / \mathrm{m}^{2}$ to $\gamma_{s \nu}=45.0 \mathrm{~mJ} / \mathrm{m}^{2}$, in $1.0 \mathrm{~mJ} / \mathrm{m}^{2}$ increments.

Figure 9.2: $\quad \gamma_{l v} \cos \theta$ vs. $\gamma_{l \nu}$ for 80:20 tetrafluoroethylene and chlorotrifluoroethylene, 50:50 tetrafluoroethylene-ethylene, and nylon $(6,6)$ surfaces as well as the theoretical constant $\gamma_{s v}$ curves from Figure 9.1.

Figure 9.3: $\quad \gamma_{l \nu} \cos \theta$ vs. $\gamma_{l \nu}$ for 80:20 tetrafluoroethylene and chlorotrifluoroethylene, 50:50 tetrafluoroethylene-ethylene, and and nylon $(6,6)$ surfaces as well as the theoretical constant $\gamma_{s v}$ curves from Figure 9.1. Contact angle data which are clearly outside a constant $\gamma_{s \nu}$ curve by more than $\pm 1.0 \mathrm{~mJ} / \mathrm{m}^{2}$ are discarded (solid symbols).

Figure J.1: $\quad \gamma_{l v} \cos \theta$ vs. $\gamma_{l v}$ for a FC-725-coated silicon wafer surface. The curve is a best fit of Eq.(J.6) to the experimental data.

Figure J.2: $\quad \gamma_{l \nu} \cos \theta$ vs. $\gamma_{l \nu}$ for a poly $(n$-butyl methacrylate) PnBMA225 coated-silicon wafer surface. The curve is a best fit of Eq.(J.6) to the experimental data.

Figure J.3: $\quad \gamma_{l v} \cos \theta$ vs. $\gamma_{l \nu}$ for a polystyrene PS-coated silicon wafer surface. The curve is a best fit of Eq.(J.6) to the experimental data.

Figure J.4: $\quad \gamma_{l \nu} \cos \theta$ vs. $\gamma_{l \nu}$ for a poly(styrene-(hexyl/10-carboxydecyl 90:10)-maleimide)-coated silicon wafer surface. The curve is a best fit of Eq.(J.6) to the experimental data.

Figure J.5: $\quad \gamma_{l v} \cos \theta$ vs. $\gamma_{l v}$ for a poly (methyl methacrylate/ $n$-butyl methacrylate) $\mathrm{P}(\mathrm{MMA} / n \mathrm{BMA})$-coated silicon wafer surface. The curve is a best fit of Eq.(J.6) to the experimental data.

Figure J.6: $\quad \gamma_{l v} \cos \theta$ vs. $\gamma_{l \nu}$ for a poly(methyl methacrylate) PMMAcoated silicon wafer surface. The curve is a best fit of Eq.(J.6) to the experimental data. 


\section{LIST OF APPENDICES}

Appendix A. Statistical criteria for averaging of contact angle data 164

Appendix B. Low-rate dynamic contact angles on a fluorocarbon FC-725- 168 coated silicon wafer surface

Appendix C. Low-rate dynamic contact angles on a poly(n-butyl

178 methacrylate) solid surface

Appendix D. Low-rate dynamic contact angles on a polystyrene solid

185 surface

Appendix E. Low-rate dynamic contact angles on a poly(styrene(hexyl/10-carboxydecyl 90:10)-maleimide) solid surface

Appendix F. Low-rate dynamic contact angles on a poly(methyl methacrylate/n-butyl methacrylate) solid surface methacrylate) solid surface (n-alkyl)maleimide) solid surface methylmaleimide) solid surface

Appendix J. Alternative formulations of an equation of state approach for solid surface tensions 


\section{CHAPTER 1}

\section{INTRODUCTION}

The determination of solid-vapour $\left(\gamma_{s v}\right)$ and solid-liquid $\left(\gamma_{s l}\right)$ interfacial tensions is of importance in a wide range of problems in pure and applied science. Because of the difficulties involved in measuring directly the surface tension involving a solid phase, indirect approaches are called for: Several independent approaches have been used to estimate solid surface tensions, including direct force measurements [1-9], contact angles [10-17], capillary penetration into columns of particle powder [18-21], sedimentation of particles [22-25], solidification front interaction with particles [26-33], film flotation [34-38], gradient theory [39-42], Lifshitz theory of van der Waals forces [42-45], and theory of molecular interactions [46-49]. Among these methods, contact angle measurements are believed to be the simpliest.

Contact angle measurement is easily performed by establishing the tangent (angle) of a liquid drop with a solid surface at the base. The attractiveness of using contact angles $\theta$ to estimate the solid-vapour and solid-liquid interfacial tensions is due to the relative ease with which contact angles can be measured on suitably prepared solid surfaces. It will become apparent later that this seeming simplicity is, however, very misleading. 
The possibility of estimating solid surface tensions from contact angles relies on a relation which has been recognized by Young [50] in 1805. The contact angle of a liquid drop on a solid surface is defined by the mechanical equilibrium of the drop under the action of three interfacial tensions (Figure 1.1): solid-vapour, $\gamma_{s v}$, solid-liquid, $\gamma_{s l}$, and liquid-vapour, $\gamma_{l v}$. This equilibrium relation is known as Young's equation:

$$
\gamma_{l \nu} \cos \theta_{Y}=\gamma_{s \nu}-\gamma_{s l}
$$

where $\theta_{Y}$ is the Young contact angle, i.e. a contact angle which can be inserted into Young's equation. It will become apparent later that the experimentally accessible contact angles may or may not be equal to $\theta_{Y}$.

Young's equation (1.1) contains only two measurable quantities, the contact angle $\theta$ and the liquid-vapour surface tension, $\gamma_{l v}$. In order to determine $\gamma_{s v}$ and $\gamma_{s l}$, an additional relation relating these quantities must be sought. Nevertheless, Eq.(1.1) suggests that the observation of the equilibrium contact angles of liquids on solids may be a starting point for investigating the solid surface tensions, $\gamma_{s v}$ and $\gamma_{s l}$. This has inspired many studies which attempt to develop methodologies to determine solid surface tensions. A common feature of these approaches is the assumption that contact angle measurement is a trivial task.

Since $\gamma_{l v}, \gamma_{s v}$ and $\gamma_{s l}$ are thermodynamic properties of the liquid and solid, Eq.(1.1) implies a single, unique contact angle; in practice, however, contact angle phenomena are complicated [51-53]. In particular, the contact angle made by an 
advancing liquid $\left(\theta_{a}\right)$ and that made by a receding liquid $\left(\theta_{r}\right)$ are not identical; nearly all solid surfaces exhibit contact angle hysteresis, $H$ (the difference between $\theta_{a}$ and $\left.\theta_{r}\right)$ :

$$
H=\theta_{a}-\theta_{r}
$$

Contact angle hysteresis can be due to roughness and heterogeneity of a solid surface. If roughness is the primary cause, then the measured contact angles are meaningless in terms of Young's equation. On very rough surfaces, contact angles are larger than on chemically identical, smooth surfaces [21]. Obviously, interpreting such angles in terms of Eq.(1.1) would lead to erroneous results because the contact angle would inevitably reflect surface topography, rather than exclusively surface energetics.

Because of these various complexities, models have been employed to gain a deeper understanding of the thermodynamic status of contact angles. In general, it has been found that the experimentally observed apparent contact angle, $\theta$, may or may not be equal to the Young contact angle, $\theta_{Y}[51,52]$ :

(1) On ideal solid surfaces, there is no contact angle hysteresis and the experimentally observed contact angle is equal to $\theta_{Y}$.

(2) On smooth, but chemically heterogeneous solid surfaces, $\theta$ is not necessarily equal to the thermodynamic equilibrium angle. Nevertheless, the experimental 
advancing contact angle, $\theta_{a}$, can be expected to be a good approximation of $\theta_{Y}$. This has been illustrated using a model of a vertical surface consisting of heterogeneous and smooth strips $[51,52]$. Therefore, care must be exercised to ensure that the experimental apparent contact angle, $\theta$, is the advancing contact angle in order to be inserted into the Young equation. While the receding angle on a heterogeneous and smooth surface can also be a Young angle, it is usually found to be non-reproducible often because of sorption of the liquid into the solid and swelling of the solid by the liquid [54].

(3) On rough solid surfaces, no such equality between $\theta_{a}$ and $\theta_{Y}$ exists: all contact angles on rough surfaces are meaningless in terms of Young's equation.

The thermodynamic equilibrium angles on rough and heterogeneous surfaces are the so-called Wenzel [55] and Cassie [56-58] angles, respectively. They are not equal to $\theta_{Y}$ [51,52]; furthermore, they are not experimentally accessible quantities.

There are as yet no general criteria to answer the question of how smooth a solid surface has to be for surface roughness not to have an effect on the contact angle. This and similar problems can be linked to line tension, which has its own complexities [59]. It is, therefore, of utmost importance to prepare solid surfaces as smooth as possible so that the experimental advancing angles can be a good approximation of $\theta_{Y}$. In addition to these complexities, penetration of the liquid into 
the solid, swelling of the solid by the liquid, and chemical reactions can all play a role. For example, swelling of a solid by a liquid [54] can change the chemistry of the solid in an unknown manner and hence affect the values of $\gamma_{s v}$, and/or $\gamma_{s l}$. Therefore, it is also important to ensure that the solid surfaces are as inert as possible in order to minimize such effects, by appropriate choice of the liquid.

Several contact angle approaches [10-17], of current interest, were largely inspired by the idea of using Young's equation for the determination of surface energetics. While these approaches are, logically and conceptually, mutually exclusive, they share, nevertheless, some basic assumptions:

(1) All approaches rely on the validity and applicability of Young's equation for surface energetics from experimental contact angles.

(2) Pure liquids are always used; surfactant solutions or mixtures of liquids should not be used, since they would introduce complications due to preferential adsorption.

(3) The values of $\gamma_{l v}, \gamma_{s v}$, (and $\gamma_{s l}$ ) are assumed to be constant during the experiment, i.e. there should be no physical or chemical reaction between a solid and a liquid.

(4) The liquid surface tensions of the testing liquids should be higher than the anticipated solid surface tension. 
(5) The values of $\gamma_{s v}$ going from liquid to liquid are also assumed to be constant, i.e. independent of the liquids used.

With respect to the first assumption, one requires the solid surfaces to be rigid, smooth and homogeneous so that Young's equation is the appropriate equilibrium condition; the experimentally observed contact angles should also be advancing contact angles. However, many attempts have been made in the literature to interpret surface energetics of solids, which are not rigid (e.g. gels $[17,60])$ and not smooth (e.g. biological surfaces $[17,61-65]$ ), in conjunction with Young's equation. Clearly, these results are open to question, since Young's equation may not be valid or applicable in these situations. With respect to the other assumptions, the solid surfaces should be as inert as possible so that effects such as swelling and chemical reactions are minimized.

In order to assure that the experimentally measured contact angles do not violate any of the above assumptions, one requires careful experimentation and suitable methodology. However, contact angles are typically measured simply by depositing a drop of liquid on a given solid surface, and manually placing a tangent to the drop at its base using a so-called goniometer-sessile drop technique $[66,67]$. Apart from the subjectivity of the technique, it normally yields contact angle accuracy of no better than $\pm 2^{\circ}$. More important, the technique cannot be expected to reflect the complexities of solid-liquid interactions. It will become apparent in this thesis that much of the controversy with respect to the interpretation of contact 
angles in terms of surface energetics lies in the fact that not enough attention is given to the readily accepted assumptions.

In this thesis, the correlation of contact angles with solid surface tensions will be explored, based on over 600 freshly prepared solid surfaces and 50,000 drop images acquired and analyzed: Chapter 2 illustrates the experimental contact angle patterns on inert solid surfaces using an automated axisymmetric drop shape analysis; these results will be contrasted with the patterns obtained on non-inert solid surfaces using a conventional goniometer-sessile drop technique in Chapter 3. It will be apparent that, by using the automated axisymmetric drop shape analysis - profile (ADSA-P) and the appropriate experimental procedures described in Chapter 4, the apparent discrepancy between the two contact angle patterns indeed is shown to come from the fact that some (or all) of the widely accepted assumptions are violated, because the goniometer procedure does not have a built-in quality control mechanism. Chapter 5 illustrates the low-rate dynamic contact angle results for various solid surfaces, as obtained by ADSA-P. The universality of the contact angle patterns will be discussed in Chapter 6. Chapter 7 presents a detailed discussion of the criteria for calculations of surface energetics. An equation which follows these experimental patterns and which allows the determination of solid surface tensions from contact angles will be sought in Chapter 8. Applications of the equation developed in Chapter 8 will be discussed in Chapter 9; contact angle data from Zisman et al. on several solid surfaces will be evaluated for energetic calculations. 
The conclusions of this thesis, a perspective, and future work will be given, respectively, in Chapters 10, 11, and 12. 


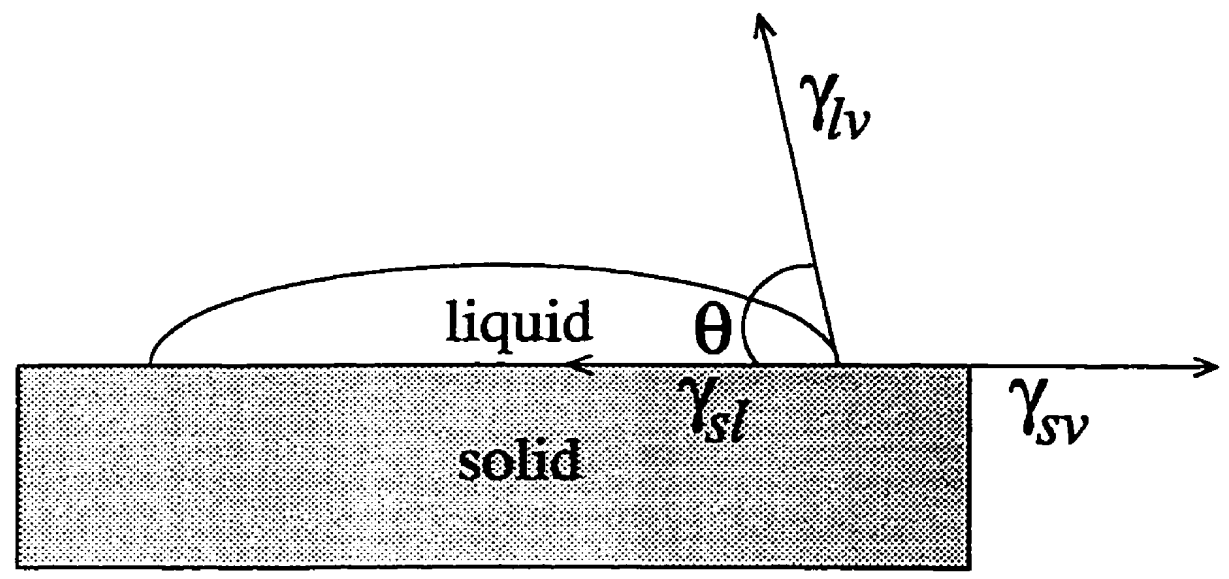

$$
\gamma_{l v} \cos \theta_{Y}=\gamma_{s v}-\gamma_{s l}
$$

$\gamma_{l v}$ : liquid-vapour surface tension

$\gamma_{s v}$ : solid-vapour surface tension

$\gamma_{s l}$ : solid-liquid surface tension

$\theta_{Y}$ : Young contact angle

Figure 1.1 Schematic of a sessile-drop contact angle system 


\section{CHAPTER 2}

\section{EXPERIMENTAL CONTACT ANGLE PATTERNS}

On carefully prepared solid surfaces, $\mathrm{Li}$ et al. $[68,69]$ have performed static (advancing) contact angle experiments using an automated axisymmetric drop shape analysis - profile (ADSA-P). The technique of ADSA-P will be described in Chapter 4. It has been found $[68,69]$ that a contact angle accuracy of better than $\pm 0.3^{\circ}$ can be obtained on well-prepared solid surfaces.

In the experiments of $\mathrm{Li}$ et al., static (advancing) contact angles were measured by supplying test liquids from below the surface into the sessile drop, using a motor-driven syringe device. A hole of about $1 \mathrm{~mm}$ in the centre of each solid surface was required to facilitate such procedures. Liquid was pumped slowly into the drop from below the surface until the three-phase contact radius was about 0.4 $\mathrm{cm}$. After the motor was stopped, the sessile drop was allowed to relax for approximately $30 \mathrm{sec}$. to reach equilibrium. Then 3 pictures of this sessile drop were taken successively at intervals of $30 \mathrm{sec}$. More liquid was then pumped into the drop until it reached another desired size, and the above procedure was repeated [68]. These procedures ensure that the measured static contact angles are indeed the advancing contact angles.

Three carefully prepared solid surfaces were used in Li et al.'s study: they are FC-721-coated mica, Teflon FEP (fluorinated ethylene propylene) heat-pressed 
against quartz glass slides and poly(ethylene terephthalate) PET. FC-721 is a $3 \mathrm{M}$ "Fluorad" brand antimigration coating designed to prevent the creep of lubricating oils out of bearings. The FC-721-coated mica was prepared by a dip-coating technique. Teflon FEP (fiuorinated ethylene propylene) surfaces were prepared by a heat-pressing method. The material was cut to $2 \times 4 \mathrm{~cm}$, sandwiched between two glass slides, and heat-pressed by a jig in an oven. Poly(ethylene terephthalate) PET is the condensation product of ethylene glycol and terephthalic acid. The surfaces of PET films were exceedingly smooth as received and cleaned before measurement. Details of the solid surface preparation can be found elsewhere [68].

Figure 2.1 shows these contact angle results in a plot of $\gamma_{l v} \cos \theta$ vs. $\gamma_{t v}$, for a large number of pure liquids with different molecular properties. It can be seen that, for a given solid surface, $\gamma_{l \nu} \cos \theta$ changes smoothly and systematically with $\gamma_{l \nu}$. Since the solid surface tension, $\gamma_{s v}$, of a given solid surface is expected to be constant, i.e. independent of the choice of the testing liquid used, Figure 2.1 implies that $\gamma_{l \nu} \cos \theta$ depends only on $\gamma_{L \nu}$ at constant $\gamma_{s \nu}$. Replacing the solid surface from the hydrophobic FC-721 surface to the hydrophilic PET surface shifts the curve in a very regular manner. Thus, one has to conclude that the values of $\gamma_{l \nu} \cos \theta$ depend only on $\gamma_{k}$ and $\gamma_{s v}$, independent of any specific intermolecular forces of the liquids and solids [68-70]:

$$
\gamma_{l \nu} \cos \theta=f\left(\gamma_{l v}, \gamma_{s v}\right)
$$

where $f$ is an as yet unknown function. Because of Young's equation, the 
experimental contact angle patterns in Figure 2.1 imply, in light of Eq.(2.1), that the solid-liquid interfacial tension $\gamma_{s l}$ depends only on the liquid-vapour $\gamma_{b}$ and solidvapour $\gamma_{s v}$ surface tensions: combining Young's equation with Eq.(2.1) yields

$$
\gamma_{s v}-\gamma_{s l}=f\left(\gamma_{l v}, \gamma_{s v}\right)
$$

and hence

$$
\gamma_{s l}=\gamma_{s v}-f\left(\gamma_{k}, \gamma_{s v}\right)=F\left(\gamma_{L}, \gamma_{s v}\right)
$$

where $F$ is as yet another unknown function. This is indeed in agreement with thermodynamics [71] and the thermodynamic phase rule for capillary systems [7275] which states that there are only two degrees of freedom for such solid-liquid systems. Thus, one can simply change the contact angle by changing either $\gamma_{t v}$ or $\gamma_{s v}$. While the specific intermolecular forces determine the primary surface tensions of liquids and solids, they do not have any additional and independent effects on the contact angles, in the context of Young's equation. In principle, a plot of $\cos \theta$ vs. $\gamma_{l v}$, rather than $\gamma_{l v} \cos \theta$ vs. $\gamma_{l v}$, can also be used to deduce the functional dependence of Eq.(2.3). Historically, a plot of $\gamma_{l \nu} \cos \theta$ vs. $\gamma_{l \nu}$ has been used in conjunction with Young's equation to argue the fact that as $\gamma_{l \nu} \cos \theta$ increases and approaches $\gamma_{s v}, \gamma_{s l}$ approaches zero [13,14].

It is to be noted that the experimental contact angle patterns shown in Figure 2.1 do not always appear in the literature: curves far less smooth or no unique curves at all are very frequently reported (see Chapter 3 ). Such patterns can have a variety of causes. Accurate contact angle measurements require extreme 
experimental care. Even very minor vibrations can cause advancing contact angles to decrease, resulting in errors of several degrees. Surface roughness can affect the contact angles and make Young's equation inapplicable. Swelling of the solid by the liquid [54] can change the chemistry of the solid and hence the values of $\gamma_{s v}$ and $\theta$ in an unpredictable manner. Non-constancy of $\gamma_{l v}, \gamma_{s v}$ and $\gamma_{s l}$ during the experiment, and non-constancy of $\gamma_{s v}$ from liquid to liquid can produce scatter in plots of the type of Figure 2.1 easily.

It will be shown below in Chapter 3 that the present controversy with respect to the experimental contact angle patterns arises from the fact that these patterns are often complex, and cannot be unraveled by the simple goniometer techniques: an example of the experimental patterns, which are very different from those of Figure 2.1, will be illustrated, simply by measuring advancing contact angles by a goniometer technique. 


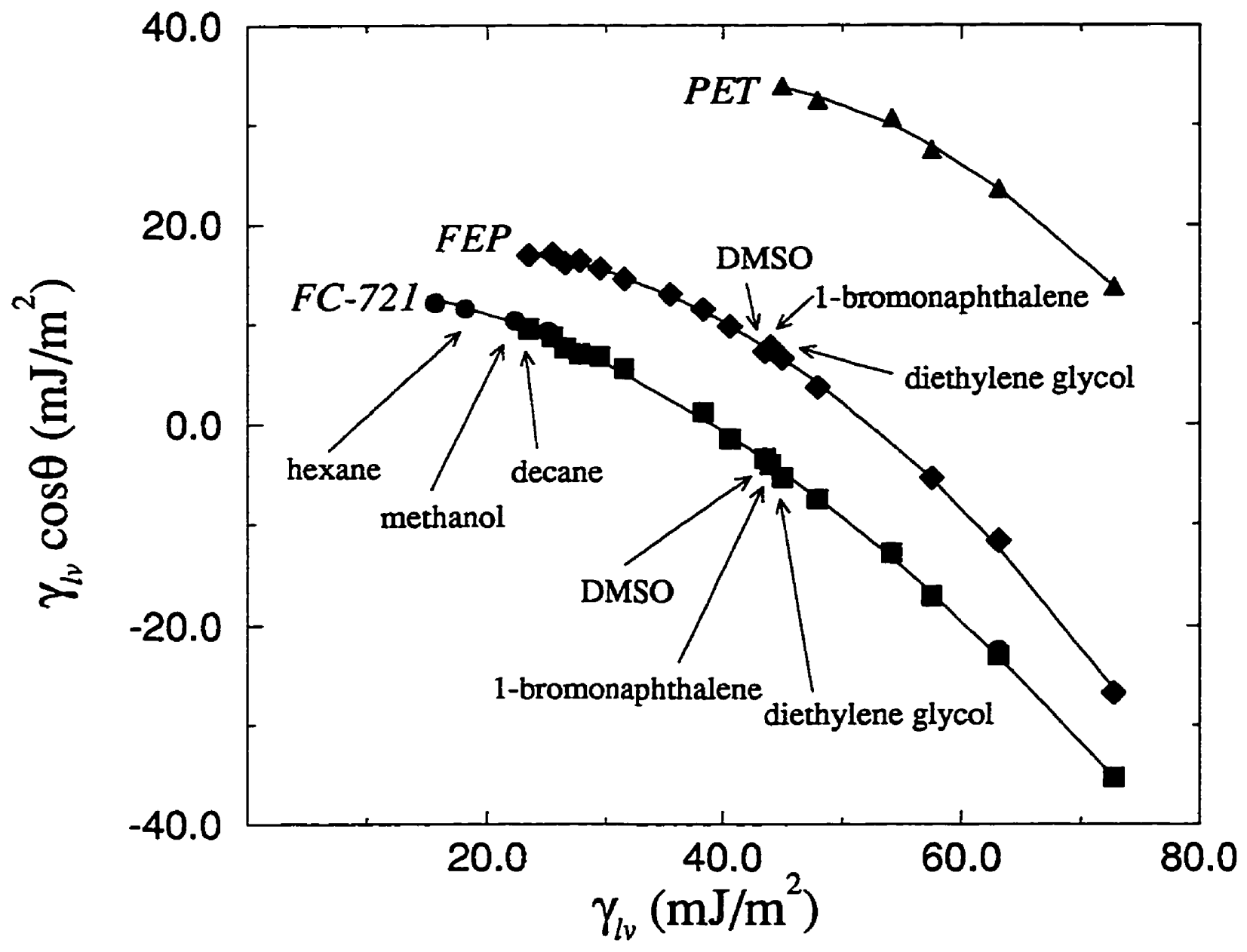

- FC-721-coated mica [68]

- FC-721-coated mica [69]

$\bullet$ FEP [68]

$\triangle$ PET [68]

Figure $2.1 \gamma_{l} \cos \theta$ vs. $\gamma_{l v}$ for three well-prepared inert solid surfaces: FC-721coated mica, heat-pressed Tefion FEP (fluorinated ethylene propylene), and poly(ethylene terephthalate) PET. The smoothness of the curves suggests that $\gamma_{h v} \cos \theta$ depends only on $\gamma_{i v}$ and $\gamma_{s \nu}$. 


\section{CHAPTER 3}

\section{EXPERIMENTAL CONTACT ANGLE PATTERNS \\ FROM A GONIOMETER}

In order to compare the experimental contact angle patterns obtained by a goniometer with those by an automated ADSA-P technique shown in Figure 2.1, two well-defined copolymers were selected. These copolymers were selected purposely to be not as inert as the FC-721-coated mica, Tefion FEP, and PET surfaces used by Li et al.

\subsection{Materials (Solid Surfaces and Liquids)}

Two copolymers, poly(propene-alt- $N$-( $n$-propyl)maleimide) and poly(propenealt- $N$-( $n$-hexyl)maleimide), i.e. copolymers with different side chains, were used for contact angle measurements (see Figure 3.1 for chemical structure). The copolymers were prepared by polymer analogous reactions $[76,77]$ of alternating poly(propenemaleic anhydride) copolymer with propyl- or hexyl-amine at the Institute of Polymer Research Dresden (Germany). The molecular weights of the poly(propene-maleic anhydride) copolymer determined by gel permeation chromatography are $\mathbf{M}_{w}=$ $27300 \mathrm{~g} / \mathrm{mol}$ and $M_{n}=9700 \mathrm{~g} / \mathrm{mol}$, respectively. For calibration a poly(propenemaleic anhydride) copolymer was used with known molecular weight $\left(M_{w}=62500\right.$ $\mathrm{g} / \mathrm{mol}, \mathrm{M}_{n}=16100 \mathrm{~g} / \mathrm{mol}$ ). It should be noted that excess of primary amines was 
used in the preparation of the copolymers; the maleimides are expected to convert $100 \%$ to the propyl- and hexyl-maleimides. Subsequently, the copolymers were dissolved in tetrahydrofuran and precipitated using hexane. The above procedures were repeated several times.

For each copolymer, a $2 \%$ solution was prepared using tetrahydrofuran (Sigma-Aldrich; $99.9+\%$ HPLC) as the solvent. Silicon wafers $\langle 100\rangle$ (Silicon Sense, Naschua, N.H., U.S.A.; thickness: $525 \pm 50$ micron) were selected as the substrate for the copolymer coating. The silicon wafer surfaces were obtained as circular discs of about $10 \mathrm{~cm}$ diameter and were cut into rectangular shapes of about $2 \times 3 \mathrm{~cm}^{2}$. Each rectangular silicon wafer surface was first cleaned with ethanol (Commercial Alcohol Inc., Toronto; >99\% purity from a 25L metal tank), acetone (BDH Inc., Toronto; $99.5 \%$ purity from a $4 \mathrm{~L}$ bottle), and then soaked in chromic acid for at least $24 \mathrm{hr}$. Chromerge acid, for glassware cleaning, was obtained by mixing a bottle of $25 \mathrm{ml}$ chromium trioxide supplied by VWR Scientific Company with $4.08 \mathrm{~kg}$ of concentrated sulphuric acid in technical grade. The cleaned wafer surfaces were rinsed with doubly-distilled water (deionized with a Sybron Barnstead MEGA-PURE system), and dried under a heat lamp before the copolymer coating. A few drops of the $2 \%$ copolymer/tetrahydrofuran solution were deposited on the dried silicon wafers inside Petri glass dishes (Canlab, Mississauga, Ont.: cat.\# D2005-1) overnight; the solution spread and a thin layer of the copolymer formed on the wafer surface after tetrahydrofuran has evaporated. This preparation produced good quality coated surfaces, as manifested by light fringes, due to refraction at these 
surfaces, suggesting that roughness is in the order of nanometers or less. It should be noted that if preparation of the solid surfaces and liquids for contact angle measurements is less careful, impurities can easily contaminate the testing liquids and solids. This would inevitably result in the contact angle measurements of contaminated liquids and solids, rather than the presumed pure liquids and solids.

Thirteen liquids were chosen in this study. Selection of these liquids was based on the following criteria: (1) liquids should include a wide range of intermolecular forces; (2) liquids should be non-toxic; and (3) the liquid surface tension should be higher than the anticipated solid surface tension $[10,13,21]$. They are, in the order of increasing surface tension, cis-decalin, 2,5-dichlorotoluene, ethyl cinnamate, dibenzylamine, dimethyl sulfoxide (DMSO), 1-bromonaphthalene, diethylene glycol, ethylene glycol, diiodomethane, 2,2'-thiodiethanol, formamide, glycerol and water. The physical properties and surface tensions of these liquids are shown in Table 3.1, for room temperature, $23.0 \pm 0.5^{\circ} \mathrm{C}$. The surface tensions of these liquids were determined independently by a pendant drop method using ADSA-P.

\subsection{Experimental Procedures}

The procedures to measure the advancing contact angles using a goniometersessile drop technique are the same as those typically used in the literature: a sessile drop of about $0.4-0.5 \mathrm{~cm}$ radius was formed from above through a Teflon capillary. The three-phase contact line of the drop was then slowly advanced by supplying more liquid from above through the capillary which was always kept in contact with 
the drop. The maximum (advancing) contact angles were measured carefully from the left and right side of the drop and subsequently averaged. The above procedures were repeated for 5 drops on 5 new surfaces. All readings were then averaged to give an averaged contact angle. The contact angle results are given in Table 3.2, for room temperature, $23.0 \pm 0.5^{\circ} \mathrm{C}$.

\subsection{Results and Discussion}

Figure 3.2 shows the contact angle results for the two copolymers from the goniometer-sessile drop measurements in a plot of $\gamma_{l v} \cos \theta$ vs. $\gamma_{l v}$. Contrary to the contact angle patterns shown in Figure 2.1, considerable scatter is apparent. It should be noted that this scatter is much larger than the error limits calculated from the goniometer contact angle accuracy of $\pm 2^{\circ}$. Thus, the cause of such scatter cannot be the subjectivity/accuracy of the goniometer technique.

On a given solid, say the poly(propene-alt- $N$-( $n$-hexyl)maleimide) copolymer, $\gamma_{s v}$ is expected to be constant; since the values of $\gamma_{k v} \cos \theta$ here do not appear to give a smooth and systematic change with $\gamma_{l \nu}$, one might argue that $\gamma_{l} \cos \theta$ cannot be a simple function $g$ of only $\gamma_{L v}$ and $\gamma_{S v}$, but has to depend also on the various specific intermolecular forces of the liquids and solids:

$$
\gamma_{l v} \cos \theta=g\left(\gamma_{\nu}, \gamma_{s \nu}, \ldots\right)
$$

Thus, because of Young's equation, this scatter would seem to favour the stipulation of the surface tension component approaches $[11,15-17,78-80]$ that $\gamma_{s l}$ depends not 
only on $\gamma_{l \nu}$ and $\gamma_{s \nu}$, but also on the specific intermolecular forces:

$$
\gamma_{s v}-\gamma_{s l}=g\left(\gamma_{l v}, \gamma_{s v}, \ldots\right)
$$

and hence

$$
\gamma_{s l}=\gamma_{s v}-g\left(\gamma_{k v}, \gamma_{s v}, \ldots\right)=G\left(\gamma_{l v}, \gamma_{s v}, \ldots\right)
$$

where $G$ is an unknown function. It is to be noted that while the contact angle patterns in Figure 3.2 can be easily found in the literature, they do not really support the above stipulation of the surface tension component approaches $[11,15-17,78-80]$. In Chapter 5, it will be shown that this scatter indecd comes from the fact that many of the experimental contact angles in Figure 3.2 have violated some (or all) assumptions usually made and summarized in Chapter 7. Thus, the apparent additional degrees of freedom (inferred from the scatter) do not come from the putative independent effect of intermolecular forces on the contact angles: $\gamma_{l \nu} \cos \theta$ can be shown to change smoothly and systematically with $\gamma_{l v}$ if suitable experimental techniques and procedures are employed, such as those described in Chapters 4 and 5. 


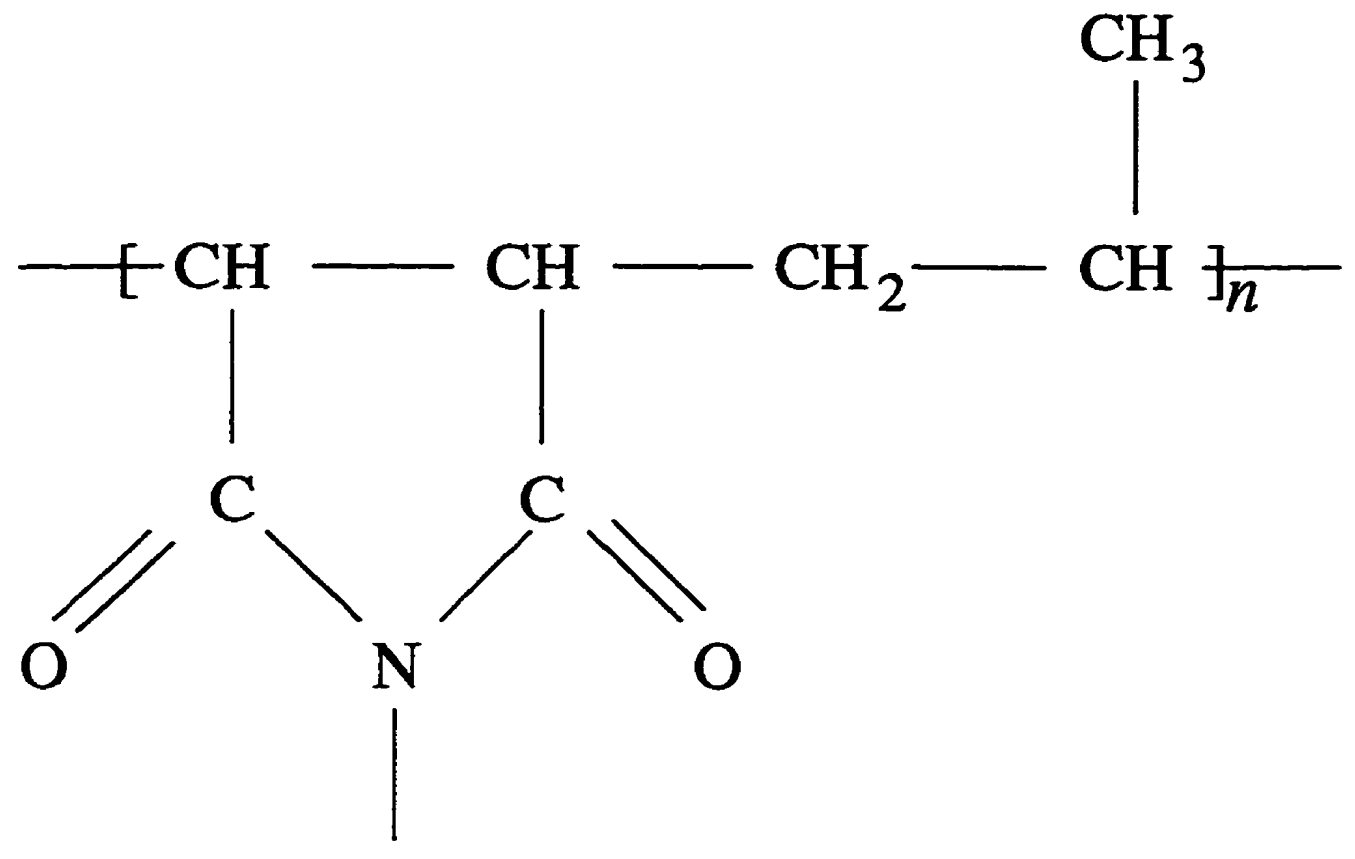

$\left(\mathrm{CH}_{2}\right)_{\mathrm{m}}$

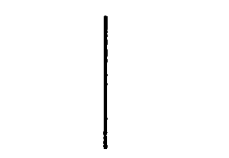

$\mathrm{CH}_{3}$

$$
\begin{aligned}
& \text { poly(propene-alt- } N \text {-(n-alkyl)maleimide) } \\
& \text { or } \begin{array}{rl}
\mathrm{m}=2 & n \text { - propyl } \\
\mathrm{m}=5 & n \text {-hexyl }
\end{array}
\end{aligned}
$$

Figure 3.1 Chemical structure for poly(propene-alt- $N$-( $n$-propyl)maleimide) and poly(propene-alt- $N$-( $n$-hexyl)maleimide) copolymers. 


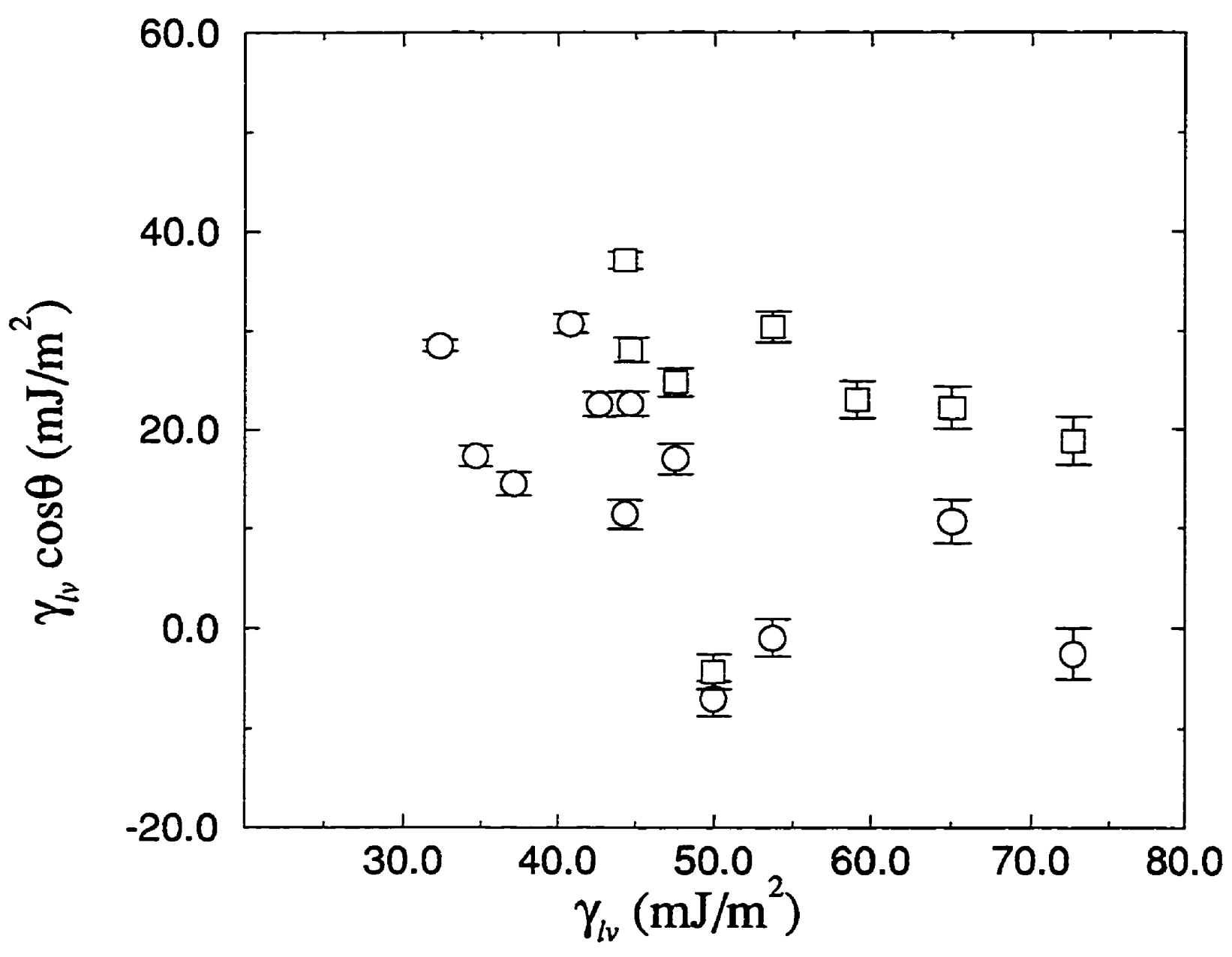

Opoly(propene-alt- $N$-( $n$-hexyl)maleimide); goniometer $\square$ poly(propene-alt- $N$-( $n$-propyl)maleimide); goniometer

Figure $3.2 \gamma_{h} \cos \theta$ vs. $\gamma_{l \nu}$ for poly(propene-alt- $N$-( $n$-propyl)maleimide) and poly(propene-alt- $N$-( $n$-hexyl)maleimide) copolymers. These angles are advancing contact angles measured by a conventional goniometric technique. Due to the scatter, one might argue that $\gamma_{l v} \cos \theta$ cannot be a simple function of $\gamma_{l v}$ and $\gamma_{s v}$. 
Table 3.1: Suppliers and surface tensions of the liquids used for the contact angle measurements on the poly(propene-alt- $N$-( $n$-propyl)maleimide) and poly(propene-alt $-N-(n-$ hexyl)maleimide) copolymers. The surface tensions were measured at $23.0 \pm 0.5^{\circ} \mathrm{C}$

\begin{tabular}{|c|c|c|c|c|c|}
\hline liquid & supplier & $\%$ purity & $\begin{array}{l}\text { density } \\
\left(\mathrm{g} / \mathrm{cm}^{3}\right)\end{array}$ & $\begin{array}{c}\text { surface tension } \\
\gamma_{t v}\left(\mathrm{~mJ} / \mathrm{m}^{2}\right)\end{array}$ & $\begin{array}{l}\text { no. of } \\
\text { drops }\end{array}$ \\
\hline cis-decalin & aldrich & 99 & 0.897 & $32.32 \pm 0.01$ & 7 \\
\hline 2,5-dichlorotoluene & aldrich & 98 & 1.254 & $34.64 \pm 0.003$ & 10 \\
\hline ethyl cinnamate & aldrich & 99 & 1.049 & $37.17 \pm 0.02$ & 10 \\
\hline dibenzylamine & aldrich & 97 & 1.026 & $40.80 \pm 0.06$ & 9 \\
\hline $\begin{array}{l}\text { dimethyl sulfoxide } \\
\text { (DMSO) }\end{array}$ & $\begin{array}{l}\text { sigma- } \\
\text { aldrich }\end{array}$ & $\begin{array}{l}99.9 \\
\text { (HPLC) }\end{array}$ & 1.101 & $42.68 \pm 0.09$ & 10 \\
\hline 1-bromonaphthalene & aldrich & 98 & 1.489 & $44.31 \pm 0.05$ & 7 \\
\hline diethylene glycol & aldrich & 99 & 1.118 & $44.68 \pm 0.03$ & 9 \\
\hline ethylene glycol & aldrich & $99+$ & 1.113 & $47.55 \pm 0.02$ & 10 \\
\hline diiodomethane & aldrich & 99 & 3.325 & $49.98 \pm 0.02$ & 10 \\
\hline 2,2'-thiodiethanol & aldrich & $99+$ & 1.221 & $53.77 \pm 0.03$ & 10 \\
\hline formamide & aldrich & $99.5+$ & 1.134 & $59.08 \pm 0.01$ & 10 \\
\hline glycerol & $\begin{array}{l}\text { baker } \\
\text { analyzed }\end{array}$ & 99.8 & 1.258 & $65.02 \pm 0.04$ & 8 \\
\hline water & LAST $^{+}$ & $\begin{array}{l}\text { doubly } \\
\text { distilled }\end{array}$ & 0.997 & $72.7 \pm 0.09$ & 10 \\
\hline
\end{tabular}

'Laboratory of Applied Surface Thermodynamics 
Table 3.2: Summary of the static contact angles measured by a conventional goniometer technique on poly(propene-alt- $N$-( $n$-propyl)maleimide) and poly(propene-alt $-N-(n-$ hexyl)maleimide), with $\pm 2^{\circ}$ accuracy

\begin{tabular}{|c|c|c|}
\hline \multirow[t]{2}{*}{ liquid } & \multicolumn{2}{|c|}{ contact angle $\theta$ (deg.) } \\
\hline & $\begin{array}{l}\text { poly(propene-alt }-N-(n- \\
\text { propyl)maleimide) }\end{array}$ & $\begin{array}{l}\text { poly(propene-alt }-N-(n- \\
\text { hexyl)maleimide) }\end{array}$ \\
\hline cis-decalin & -.--- & 28.0 \\
\hline 2,5-dichlorotoluene & ---- & 60.0 \\
\hline ethyl cinnamate & ----- & 67.0 \\
\hline dibenzylamine & ----- & 41.0 \\
\hline dimethyl sulfoxide (DMSO) & -..-- & 58.0 \\
\hline 1-bromonaphthalene & 33.0 & 75.0 \\
\hline diethylene glycol & 51.0 & 59.5 \\
\hline ethylene glycol & 58.5 & 69.0 \\
\hline diiodomethane & 95.0 & 98.0 \\
\hline $2,2^{\prime}$-thiodiethanol & 55.5 & 91.0 \\
\hline formamide & 67.0 & $\begin{array}{l}\text { dissolved the polymer } \\
\text { on contact }\end{array}$ \\
\hline glycerol & 70.0 & 80.5 \\
\hline water & 75.0 & 92.0 \\
\hline
\end{tabular}




\section{CHAPTER 4}

\section{AXISYMMETRIC DROP SHAPE ANALYSIS \\ - PROFILE (ADSA-P)}

\subsection{ADSA Methodology}

ADSA-P is a technique to determine liquid-fluid interfacial tensions and contact angles from the shape of axisymmetric menisci, i.e., from sessile as well as pendant drops. Assuming that the experimental drop is Laplacian and axisymmetric, ADSA-P finds the theoretical profile that best matches the drop profile extracted from the image of a real drop, from which the surface tension, contact angle, drop volume and surface area can be computed. The strategy employed is to fit the shape of an experimental drop to a theoretical drop profile according to the Laplace equation of capillarity, using surface/interfacial tension as an adjustable parameter. The best fit identifies the correct surface/interfacial tension from which the contact angle can be determined by a numerical integration of the Laplace equation (4.1). Details of the methodology can be found elsewhere [81-84].

ADSA-P has been used to perform accurate measurements of the surface tensions and contact angles in a variety of situations $[68,69,77,84-94]$. It can be used for both air-liquid and liquid-liquid systems [85]; it is particularly suited for the study of time- [87], temperature- [94] and pressure-dependence [88] of interfacial tensions and contact angles. 


\subsection{Theory}

Axisymmetric drop shape analysis - profile (ADSA-P) is a technique to determine liquid-fluid interfacial tensions and contact angles from the shape of axisymmetric menisci, i.e., from sessile as well as pendant drops. The strategy employed is to construct an objective function which expresses the deviation of the physically observed curve from a theoretical Laplacian curve, i.e., a curve satisfying the Laplace equation of capillarity:

$$
\gamma\left(\frac{1}{R_{1}}+\frac{1}{R_{2}}\right]=\Delta P
$$

where $R_{1}$ and $R_{2}$ are the principal radii of curvature of the drop, and $\Delta P$ is the pressure difference across the curved interface. This is a mechanical equilibrium condition between two fluid phases separated by a curved interface. It represents a balance between two opposing forces: the surface tension of the interface and gravity. While the former tends to make the drop spherical, the latter pulls the drop downward. If gravity is the only external force, then $\Delta P$ can be expressed as

$$
\Delta P=\Delta P_{0}+\Delta \rho g z
$$

where $\Delta P_{0}$ is the reference pressure at any arbitrary reference plane, $\Delta p$ is the density difference between the fluids, $g$ is the gravitational acceleration, and $z$ is the vertical height above the reference plane. 
If the origin of the coordinate system is placed at the apex point of the drop and the $x$-axis is tangent to the origin and normal to the axis of symmetry, as shown in Figure 4.1, Eq.(4.2) can then be written as

$$
\gamma\left[\frac{1}{R_{1}}+\frac{\sin \phi}{x}\right]=2 \frac{\gamma}{R_{0}}+(\Delta \rho) g z
$$

As indicated in Figure 4.1, the radius, $R_{1}$, turns in the plane of the paper, $R_{2}=\frac{x}{\sin \phi}$ rotates in the plane perpendicular to the plane of the paper and about the axis of symmetry and $R_{0}$ is the radius of curvature at the origin $\left(R_{1}=R_{2}=R_{0}\right.$ at the origin); $\phi$ is the turning angle measured between the tangent to the interface at $(x, z)$ and the horizontal plane through the same point $(x, z)$ and represents the contact angle at the point where the liquid touches the solid surface. Since the drop is axisymmetric, the interface can be described by the meridian section alone, shown in Figure 4.1. If the interface is given by

$$
u=u(x, z)
$$

the meridian curve can be represented by

$$
x=x(s) \quad z=z(s)
$$

where $s$ is the arc length parameter measured from the origin. The Laplace equation, i.e., Eq.(4.3), is then parameterized and results in a set of three first order differential equations and three boundary conditions $[81,84]$ as follows: 


$$
\begin{gathered}
\frac{d x}{d s}=\cos \phi \\
\frac{d z}{d s}=\sin \phi \\
\frac{d \phi}{d s}=\frac{2}{R_{0}}+\frac{(\Delta \rho) g}{\gamma} z-\frac{\sin \phi}{x} \\
x(0)=z(0)=\phi(0)=0
\end{gathered}
$$

By simultaneously integrating the system of equations, the theoretical drop profiles are matched with the experimental drop profiles, where the former are calculated with the surface tension as one of the adjustable parameters. The best match identifies the correct, i.e., operative surface tension. Details of these mathematical procedures can be found elsewhere $[81,84]$.

Apart from local gravity and densities of liquid and fluid phases, the only input information required by ADSA-P is several arbitrary but accurate coordinate points selected from the drop profile. The output of the ADSA-P program provides the values of surface tension, drop volume, surface area, and in the case of a sessile drop, radius of the three-phase contact line and contact angle.

\subsection{Drop Profile Coordinates}

To compare the theoretical and the experimental drop profiles, ADSA requires a set of arbitrary, but accurate, coordinates along the experimental drop profile. This procedure has been automated by Cheng et al. $[82,83]$. A schematic of the ADSA set-up is shown in Figure 4.2. A high resolution camera (Cohu $4800 \mathrm{CCD}$ 
monochrome camera) is mounted on a Wild-Heerbrugg M7S microscope. The video signal of the pendant or sessile drop is transmitted to a digital video processor, which performs the frame grabbing and digitization of the image with 256 gray levels for each pixel, where 0 represents black and 255 represents white. A SPARCstation computer can be used to acquire images from the image processor and to perform the image analysis and computation.

To accurately determine the edge of the drop profile, a SOBEL $3 \times 3$ pixel operator is used [82-84]. The edge of the drop is found by choosing a pixel with the steepest gradient moving from outside of the drop to the inside. Once the drop profile coordinates are known, ADSA selects 20 points along the edge of the profile randomly. The system of differential equations can then be solved for the correct surface tension $\gamma$. This procedure is then repeated 10 times and the results are averaged to give the $95 \%$ confidence limits. A computer image of a doubly-distilled water sessile drop on a poly(methyl methacrylate)-coated silicon wafer surface is given in Figure 4.3. From the profile of this drop, the surface tension calculated from ADSA-P is found to be $70.64 \pm 0.52 \mathrm{~mJ} / \mathrm{m}^{2}$, from which a contact angle of $73.44 \pm 0.12^{\circ}$ is obtained. It has been found that, since ADSA assumes an axisymmetric drop shape, the values of liquid surface tension measured from sessile drops are very sensitive to even a very small deviation from axial symmetry, which may be due to surface imperfection, such as roughness and heterogeneity; contact angles are less sensitive. Therefore, the liquid surface tensions used in this thesis were independently measured by applying ADSA-P to a pendant drop. 


\subsection{Calibration Grid}

Since ADSA determines the surface tension and contact angle of a drop based on its profile, it is important to correct for the optical distortion due to the microscope lens, using a grid pattern on a $5 \times 5 \mathrm{~cm}^{2}$ optical glass. The size of the squares of this grid is $0.25 \times 0.25 \mathrm{~mm}^{2}$. It is mounted on an aluminum cell. Before experiment is started, the cell is placed at a position parallel to the camera. By taking the image of a calibration grid and knowing what the spacing between grid lines is, the optical distortion caused by the lenses of the microscope can be corrected [82-84]. A computer image of a $0.25 \times 0.25 \mathrm{~mm}^{2}$ calibration grid is shown in Figure 4.4.

A good calibration grid picture should be clean; dirt on the lines in Figure 4.4 will reduce the accuracy of the surface tension/contact angle measurements. Therefore, special cleaning tissue was used to remove dust from the calibration grid. 


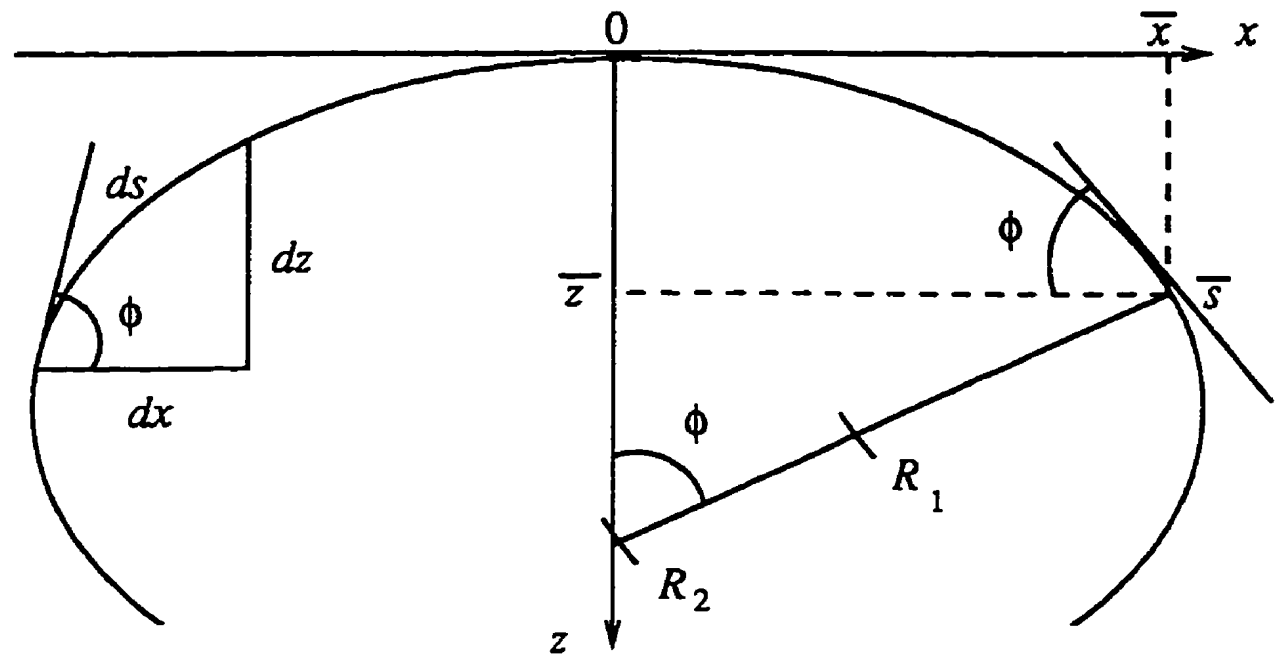

Figure 4.1 Definition of the coordinate system. $R_{1}$ and $R_{2}$ are the two principal radii of curvature of the drop. 


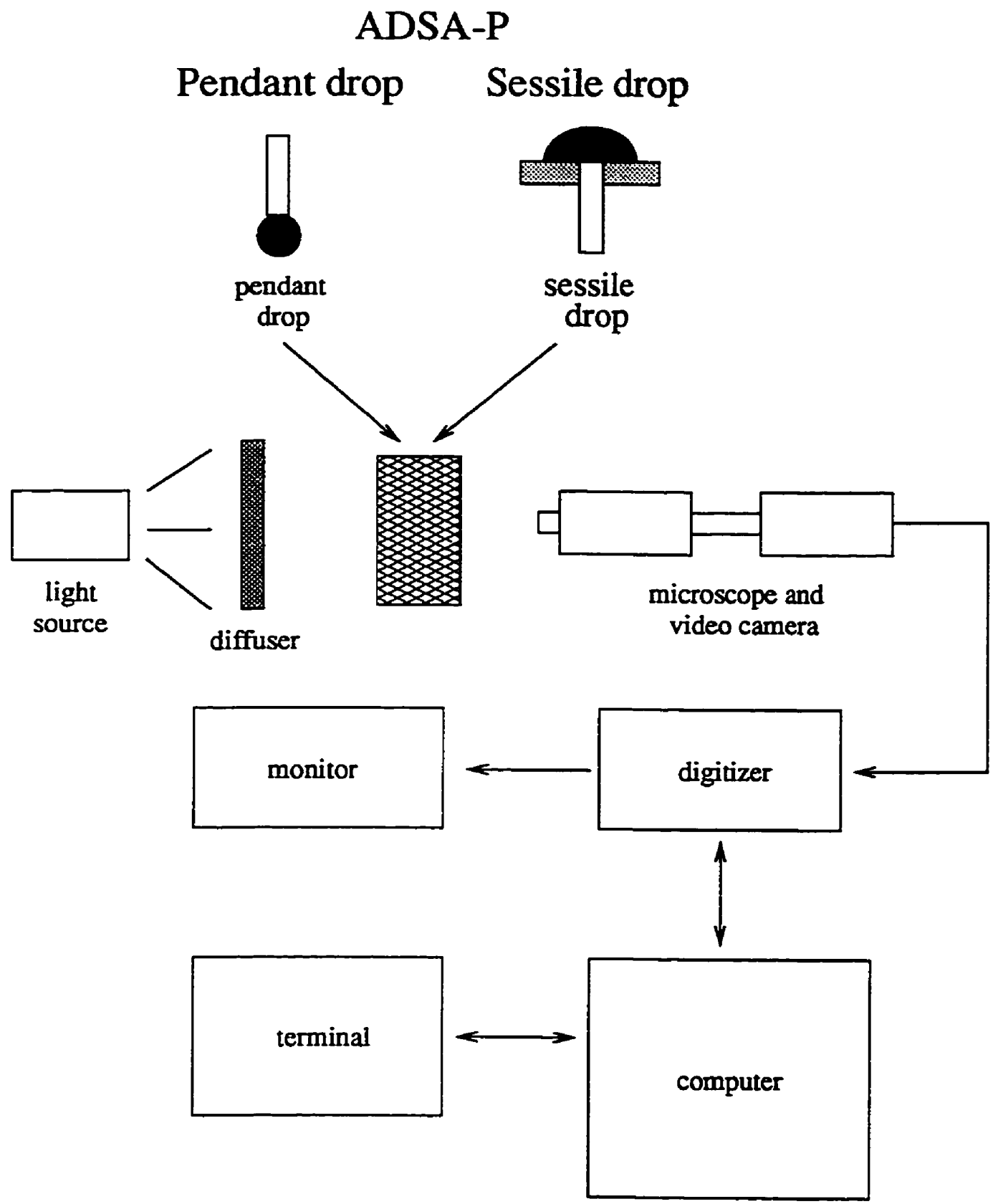

Figure 4.2 Schematic of the ADSA-P set-up for sessile and pendant drop measurements. 


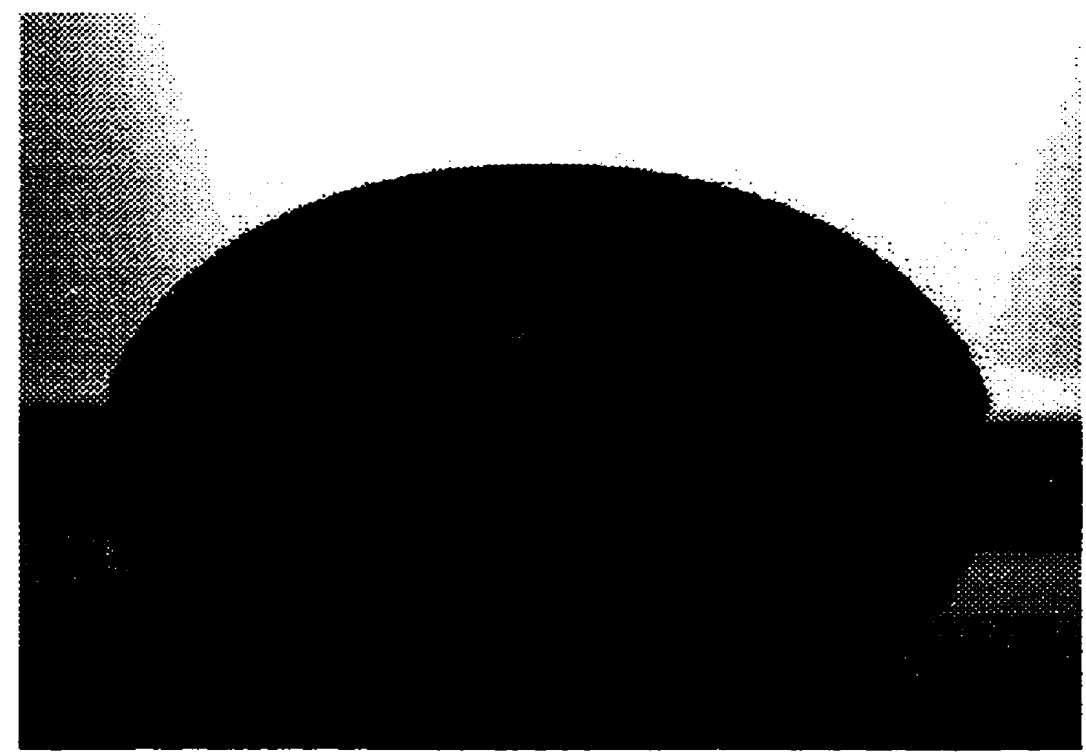

liquid surface tension

$\gamma_{l v}=70.64 \pm 0.52 \mathrm{~mJ} / \mathrm{m}^{2}$

contact angle

$\theta=73.44 \pm 0.12^{\circ}$

three-phase contact radius

$R=0.4897 \pm 0.0002 \mathrm{~cm}$

drop volume

$V=0.1234 \pm 0.0001 \mathrm{~cm}^{3}$

drop surface area

$A=1.0270 \pm 0.0005 \mathrm{~cm}^{2}$

Figure 4.3 A computer picture of a doubly-distilled water sessile drop on a poly(methyl methacrylate)-coated silicon wafer surface, reproduced by a laser printer. From this profile, ADSA-P determines the surface tension and contact angle to be $70.6 \pm 0.5 \mathrm{~mJ} / \mathrm{m}^{2}$ and $73.4 \pm 0.1^{\circ}$, respectively. 


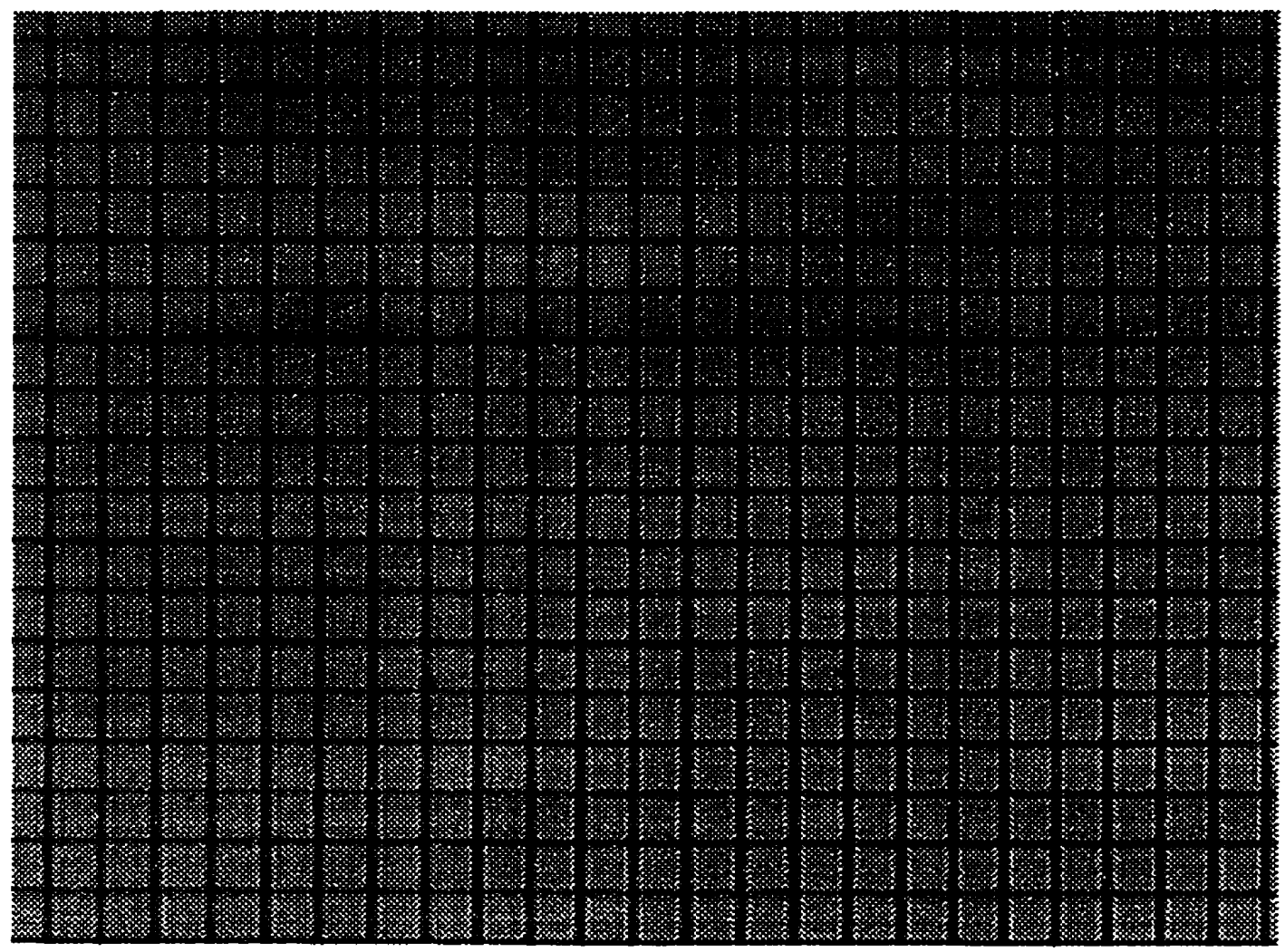

Figure 4.4 A computer picture of a calibration grid, reproduced by a laser printer. The size of the squares is $0.25 \times 0.25 \mathrm{~mm}^{2}$. 


\title{
CHAPTER 5
}

\section{LOW-RATE DYNAMIC CONTACT ANGLES \\ FROM ADSA-P}

\begin{abstract}
ADSA-P determines not only the contact angle, but also the liquid surface tension, drop volume, and three-phase contact radius of a given sessile drop picture (see Figure 4.3); continuous measurements of the contact angles as the drop front slowly advances over the solid surface of interest are possible. It will be shown that the results obtained from such procedures allow explanation of the apparent discrepancy between the two types of contact angle patterns in Figure 2.1 on the one hand and those of Figure 3.2 on the other.
\end{abstract}

\subsection{Experimental Procedures}

Sessile drop contact angle measurements using ADSA-P were performed dynamically, by using a motor driven syringe to pump liquid steadily into the sessile drop from below the surface [95]. A quartz cuvette $\left(5 \times 5 \times 5 \mathrm{~cm}^{3}\right)$ from Hellma (Concord, Ont.) was used to enclose the drop from its environment. It has been found that there are virtually no difference between the measured contact angles with or without a cuvette. The dynamic advancing and receding contact angle measurements can be performed, respectively, by pushing or pulling the syringe plunger of a motorized syringe mechanism, leading to an increase or decrease in 
drop volume. A schematic of this mechanism is shown in Figure 5.1. Normally, at least $\mathbf{5}$ and up to 10 dynamic contact angle measurements were performed on a new solid surface each time, at velocities of the three-phase contact line in the range from 0.1 to $1.5 \mathrm{~mm} / \mathrm{min}$. It will become apparent later that low-rate dynamic contact angles in this velocity range are essentially identical to the static contact angles for relatively smooth surfaces. In this thesis, all contact angles were measured at $23.0 \pm$ $0.5^{\circ} \mathrm{C}$.

In these dynamic procedures, liquid is supplied into the sessile drop from below the solid surface using a motorized syringe device [95]. In order to facilitate such an experimental procedure, a hole of about $1 \mathrm{~mm}$ diameter on the solid surface is required. The strategy of pumping liquid from below the surface was pioneered by Oliver et al. $[96,97]$ because of its potential for avoiding drop vibrations and for measuring true advancing contact angles without disturbing the drop profile. In order to avoid leakage between a stainless steel needle (Chromatographic Specialities, Brockville, Ont.; N723 needles pt.\# 3, 2" long, 23 GA, cat.\# H91023) and the hole (on the surface), Tefion tape (Labcor, Anjou, Quebec; cat.\# H-08782-27) was wrapped around the end of the needle before insertion into the hole. In the literature, it is customary to first deposit a drop of liquid on a given solid surface using a syringe or a Tefion needle; the drop is then made to advance by supplying more liquid from above using a syringe or a needle in contact with the drop. Such experimental procedures cannot be used for ADSA-P since ADSA determines the contact angles and surface tensions based on the complete and undisturbed drop 
profile.

In actual experiments, an initial liquid drop of about $0.3 \mathrm{~cm}$ radius was carefully deposited from above using a gas-tight Hamilton syringe (Chromatographic Specialities, Brockville, Ont.: 81201, 1750LT, cat.\# 063283) with a stainless steel needle (Chromatographic Specialities, Brockville, Ont.; N722 needles pt\# 3,2" long, 22 GA, cat.\# H91022), covering the hole on the surface. This is to ensure that the drop will increase axisymmetrically in the centre of the image field when liquid is supplied from the bottom of the surface and will not hinge on the lip of the hole. The motor in the motorized syringe mechanism was then set to a specific speed, by adjusting the voltage from a voltage controller. Such a syringe mechanism pushes the syringe plunger (Chromatographic Specialities, Brockville, Ont.; gas-tight Hamilton syringe: 81201, 1750LT, cat.\# 063283), leading to an increase in drop volume and hence the three-phase contact radius. A sequence of pictures of the growing drop was then recorded by the computer typically at a rate of 1 picture every 2 seconds, until the three-phase contact radius was about $0.5 \mathrm{~cm}$ or larger. For each low-rate dynamic contact angle experiment, at least $\mathbf{5 0}$ and up to 500 images were normally taken. Since ADSA-P determines the contact angle and the three-phase contact radius simultaneously for each image, the advancing dynamic contact angles as a function of the three-phase contact radius (i.e. location on the surface) can be obtained. In addition, the change in the contact angle, drop volume, drop surface area, and the three-phase contact radius can also be studied as a function of time. The actual rate of advancing can be determined by linear 
regression, by plotting the three-phase contact radius over time. For each liquid, different rates of advancing were studied, by adjusting the speed of the pumping mechanism [95].

It should be noted that measuring contact angles as a function of the threephase contact radius has an additional advantage: the quality of the surface is observed indirectly in the measured contact angles. If a solid surface is not very smooth, irregular and inconsistent contact angle values will be seen as a function of the three-phase contact radius. When the measured contact angles are essentially constant as a function of surface location, the mean contact angle for a specific rate of advancing can be obtained by averaging the contact angles, after the three-phase contact radius reaches 0.3 to $0.5 \mathrm{~cm}$ (see later). The purpose of choosing these relatively large drops is to avoid any possible line tension effects on the measured contact angles $[59,98,99]$.

\subsection{Inert (Non-Polar) Surfaces: FC-722-Coated Mica Surface}

\subsubsection{Materials (Solid Surfaces and Liquids)}

A fluorocarbon, FC-722, dip-coated onto mica surfaces was chosen as the substrate for the dynamic contact angle experiments. FC-722 is a fluorochemical coating available from 3M (London, Ont.: I.D.\# 98-0211-5542-3) and is chemically very similar to the FC-721 used in earlier studies. They were prepared by the same dip-coating procedures described elsewhere $[68,69]$, using freshly cleaved mica surfaces. The mica surfaces were obtained originally as sheets from Asheville- 
Schoonmaker Mica Co. (Newport News, VA, U.S.A.).

Before dip-coating, the mica surfaces were prepared in the following

procedures: (1) mica sheets were cut into small mica plates of about $2 \times 3 \mathrm{~cm}^{2}$; (2) a hole of about $1 \mathrm{~mm}$ in diameter was made, by drilling, in the centre of each mica surface; (3) each mica surface was then cleaved by a sharp knife, cleaned with ethanol (Commercial Alcohol Inc., Toronto; >99\% purity from a 25L metal tank), and acetone (BDH Inc., Toronto; $99.5 \%$ purity from a $4 \mathrm{~L}$ bottle), and dried in the air before dip-coating.

Seventeen liquids were chosen for the contact angle measurements [95]. These liquids, together with the surface tensions, are given in Table 5.1. The surface tensions of these liquids were determined independently by applying ADSA-P to pendant drops at room temperature, $23.0 \pm 0.5^{\circ} \mathrm{C}$. Selection of these liquids was based on the criteria described in Chapter 3 (section 3.1).

\subsubsection{Results and Discussion}

Figure 5.2 shows a typical example of a low-rate dynamic contact angle experiment: water on a FC-722 surface. As can be seen in this figure, increasing the drop volume $V$ linearly from $0.18 \mathrm{~cm}^{3}$ to $0.22 \mathrm{~cm}^{3}$, by the motorized syringe mechanism, increases the contact angle $\theta$ from about $108^{\circ}$ to $119^{\circ}$ at essentially constant three-phase contact radius $R$. This is due to the fact that even carefully putting an initial drop from above on a solid surface can result in a contact angle 
somewhere between advancing and receding. Therefore, it takes addition of a certain amount of liquid for the initial drop front to start advancing. Further increase in the drop volume causes the three-phase contact line to advance, with $\theta$ essentially constant as $R$ increases. Increasing the drop volume in this manner ensures the measured $\theta$ to be an advancing contact angle. The rate of advancing for this experiment can be determined by linear regression from the linear region of the plot of the three-phase contact radius over time: It was found that the drop periphery was being advanced at a rate of $0.14 \mathrm{~mm} /$ minute, in the specific example given in Figure 5.2. The regression coefficient for the rate of advancing was found to be 0.999; this indicates that the rate of change of the three-phase contact line was very constant, even though it was controlled simply by manipulating the drop volume.

As can be seen in Figure 5.2, the measured contact angles are essentially constant as $R$ increases. This indicates good surface quality of the solid used in this experiment. It turns out that averaging the measured contact angles after $R$ reaches $0.50 \mathrm{~cm}$ is convenient, since the drop is guaranteed to be in the advancing mode and that line tension effects are negligible $[59,98,99]$. Averaging the measured contact angles, after $R$ reaches $0.50 \mathrm{~cm}$, yields a mean contact angle of $118.4^{\circ}$ for water. While a three-phase contact radius of $0.50 \mathrm{~cm}$ may seem to be an arbitrary value, it turns out that there is virtually no difference between averaging $\theta$ for $R$ larger than $0.48 \mathrm{~cm}$ and $0.54 \mathrm{~cm}$; the contact angles are essentially constant after $R=0.50 \mathrm{~cm}$. Similar results were also obtained for other liquids [95]. 
Dynamic/static contact angle experiments have also been performed: A liquid drop is first selected to advance at a specific rate of advancing and then stopped, while a sequence of images is recorded. A typical experiment is shown in Figure 5.3 for cis-decalin. As drop volume increases from $0.05 \mathrm{~cm}^{3}$ to $0.07 \mathrm{~cm}^{3}$, the threephase contact line advances from about $0.36 \mathrm{~cm}$ to $0.41 \mathrm{~cm}$ at a rate of 0.41 $\mathrm{mm} /$ minute. A sequence of drop images was acquired after the motor was stopped at $R=0.41 \mathrm{~cm}$. As can be seen in Figure 5.3, the contact angle is independent of the low rate of advancing; this result suggests that the low-rate dynamic contact angle $\theta_{d y n}$ is identical to the static contact angle $\theta_{\text {stat }}$. This result re-confirms validity of the experimental protocol used by $\mathrm{Li}$ et al. $[68,69]$ to measure static contact angles and is also in good agreement with recent work to determine low-rate dynamic contact angles by the automated capillary rise technique $[100,101]$.

A summary of the low rate-dynamic contact angles for the seventeen liquids is shown in Table 5.2: With each liquid, ten different measurements (i.e. ten different rates of advancing on ten new surfaces) were performed. It can be seen that these dynamic contact angles are essentially independent of the velocity of the three-phase contact line, as is, in principle, obvious from Figure 5.3. Since the low-rate dynamic contact angles in Table 5.2 are essentially independent of the velocity of the threephase contact line, a mean dynamic contact angle for each pure liquid was determined by averaging the contact angles at the ten different rates of advancing.

Figure 5.4 shows all experimental contact angle results at very slow motion of the three-phase contact line in a plot of $\gamma_{l v} \cos \theta$ vs. $\gamma_{l v}$. This result reconfirms the 
finding of $\mathrm{Li}$ et al. shown in Figure 2.1 that, at constant $\gamma_{s v}, \gamma_{\nu} \cos \theta$ changes smoothly with $\gamma_{l v}$, independent of the liquid properties. Clearly, if there are any additional and independent effects of intermolecular forces on the contact angles, the data points for the polar liquids (1-pentanol, 1-decanol, DMSO, 2,2'-thiodiethanol, diethylene glycol, ethylene glycol, glycerol, and water) in Figure 5.4 would not fall completely on a smooth curve along with the non-polar liquids. It can be seen that the data point for 1-pentanol is slightly below the curve; 1-decanol is again slightly below; DMSO is above and ethylene glycol is on the curve: there is no evidence of any systematic deviation of the polar liquids away from such a curve. This question will also be addressed in Chapter 6.

It should be noted that in these low-rate dynamic contact angle experiments, images of an advancing drop (and hence information such as surface tension and contact angle) are recorded continuously as drop volume is steadily increased from below the surface. The procedures used here are different from those by $\mathrm{Li}$ et al. $[68,69]$ in that the contact angles measured by Li et al. were static angles, i.e. contact angles at zero velocity of the three-phase contact line.

\subsection{Non-Inert (Polar) Surfaces: Poly(propene-alt-N-(n-propyl)maleimide) and Poly(propene-alt- $\mathrm{N}$-(n-hexyl)maleimide)}

Experience has shown that non-polar surfaces, such as Teflon and fluorocarbons, often are quite inert with respect to many liquids; however, polar surfaces often are less inert and hence may show different contact angle patterns, 
due to such causes as chemical reaction and/or swelling and dissolution of the solid by the liquid. Since low-rate dynamic contact angle experiments when interpreted by ADSA-P have many advantages over the conventional way of manually putting tangents to the sessile drops, ADSA-P is employed here to measure low-rate dynamic contact angles on the copolymers, poly(propene-alt- $N-(n-$ propyl)maleimide) and poly(propene-alt- $N$-( $n$-hexyl)maleimide), in order to elucidate the discrepancies between the results in Figures 2.1 and 5.4 on the one hand, and those in Figure 3.2 by a goniometer on the other. It will become apparent that a goniometer technique is liable to produce a mixture of meaningful and meaningless angles, with no criteria to distinguish between the two. If one disregards the meaningless angles to be identified by dynamic ADSA measurements, the results are in harmony with those patterns shown in Figures 2.1 and 5.4 , as will be shown below.

\subsubsection{Materials (Solid Surfaces and Liquids)}

Eight liquids were selected for the contact angle measurements on poly(propene-alt- $N$-( $n$-propyl)maleimide) and thirteen liquids on poly(propene-alt$N$-( $n$-hexyl)maleimide) [77]. The chemical structure of these copolymers has been described in Chapter 3; the surface tensions and physical properties of the testing liquids have been summarized in Table 3.1.

Silicon wafer $<100>$ (Silicon Sense, Naschua, N.H., U.S.A.; thickness: $525 \pm$ 50 micron) was selected as the substrate for the copolymer coating. They were 
obtained as circular discs of about $10 \mathrm{~cm}$ diameter and were cut into rectangular size of about $2 \times 3 \mathrm{~cm}^{2}$. The general procedures to prepare the solid surfaces are similar to those described in Chapter 3 (section 3.1). Before soaking the rectangular wafer surfaces into chromic acid, a hole of about $1 \mathrm{~mm}$ diameter was made by drilling, using a diamond drill bit from Lunzer (New York; SMS-0.027). For each copolymer, a $2 \%$ solution was prepared using tetrahydrofuran (Sigma-Aldrich; $99.9+\%$ HPLC) as the solvent. A few drops of the $2 \%$ copolymer/tetrahydrofuran solution were deposited on the dried silicon wafers inside Petri glass dishes (Canlab, Mississauga, Ont.: cat.\# D2005-1) overnight; the solution spread and a thin layer of the copolymer formed on the wafer surface after tetrahydrofuran evaporated. This procedure produced good quality coated surfaces. Such polymer-coated surfaces have been studied by Atomic Force Microscopy [102]. It was found that surface roughness of the surfaces prepared by this procedure is in the order of nanometer.

\subsubsection{Results and Discussion}

Figure 5.5 shows a typical example of water on the poly(propene-alt- $N-(n-$ propyl)maleimide) copolymer. As described above, in order to avoid that the drop hinges at the edge of the hole, a small drop is deposited from above, covering the hole completely. This leads to an initial contact angle different from the advancing angle: increasing the drop volume, $V$, linearly from $0.10 \mathrm{~cm}^{3}$ to about $0.12 \mathrm{~cm}^{3}$ increases the apparent contact angle, $\theta$, from about $72^{\circ}$ to $77^{\circ}$ at essentially constant three-phase radius, $R$. This is due to the fact that even carefully putting an initial 
water drop from above on a solid surface can result in a contact angle somewhere between advancing and receding. This effect can be pronounced for liquids, such as water, which evaporate fast. Thus, it takes time for the initial drop front to start advancing. Further increase in the drop volume causes the three-phase contact line to advance, with $\theta$ essentially constant as $R$ increases. Increasing the drop volume in this manner ensures the measured $\theta$ to be an advancing contact angle. In this specific example, the measured contact angles are essentially constant as $R$ increases. This indicates good quality of the surfaces used. A mean contact angle of $77.33 \pm$ $0.06^{\circ}$ was obtained for this experiment. A total of nine experiments at different rates of advancing were performed, each on a newly prepared surface. The results of these low-rate dynamic contact angles are given in Table 5.3, together with similar results for other liquids. Since the contact angle results of water at different rates of advancing (in Table 5.3) are essentially constant, they can be averaged and result in a final value for $\theta$ of $77.51 \pm 0.27^{\circ}$.

Another contact angle result is shown in Figure 5.6 for glycerol on the same copolymer. Because the contact angles are essentially constant for all experiments, they can be averaged, resulting in a mean contact angle of $70.82 \pm 0.05^{\circ}$, at a rate of advancing of $0.16 \mathrm{~mm} / \mathrm{min}$. A total of 8 experiments (for 8 different rates of advancing) were performed on a new solid surface each time. These results are also summarized in Table 5.3. The results obtained for 2,2'-thiodiethanol and 1bromonaphthalene are similar to those shown in Figure 5.6; they are also given in Table 5.3. 
Unfortunately, not all liquids yield essentially constant advancing contact angles. Figure 5.7 shows the results of formamide on the same copolymer. It can be seen that as drop volume increases initially, contact angle increases from $60^{\circ}$ to $63^{\circ}$ at essentially constant three-phase radius. As the drop volume continues to increase, $\theta$ suddenly decreases to $60^{\circ}$ and the three-phase contact line starts to move. As $R$ increases further, the contact angle decreases slowly from $60^{\circ}$ to $54^{\circ}$. The surface tension-time plot indicates that the surface tension of formamide decreases with time. This suggests that dissolution of the copolymer occurs, causing $\gamma_{l v}$ to change from that of the pure liquid. Similar behaviour can also be observed in other experiments [77]. It is an important question to ask which contact angles one should use for the interpretation in terms of surface energetics. Since chemical or physical reactions such as polymer dissolution change the liquid-vapour, solid-vapour and solid-liquid interface (interfacial tensions) in an unknown manner, the contact angle data in Figure 5.7 should be disregarded for the interpretation in terms of surface energetics. The criteria for rejecting angles for calculations of solid surface tensions will be discussed in detail in Chapter 7. Obviously, it is virtually impossible for goniometer measurements to detect the complexities shown in Figure 5.7, e.g. the decrease in $\gamma_{t}$. Thus, the contact angle obtained from a goniometer for this and similar solid-liquid systems cannot be meaningful.

The results of ethylene glycol are shown in Figure 5.8. It can be seen that the contact angle increases slowly from $54^{\circ}$ to $57^{\circ}$ as the three-phase contact line advances from $0.46 \mathrm{~cm}$ to $0.54 \mathrm{~cm}$. While the cause of this increase in the contact 
angle is unclear, it is suspected that the operative solid-liquid interfacial tension is changed slowly due to physico-chemical reaction: according to Young's equation, if the values of $\gamma_{v}$ and $\gamma_{s v}$ are constant, a change in the contact angle must be a consequence of a change in $\gamma_{s l}$. It should be noted that the observed trends in the contact angle may well start immediately after drop formation, not only after the measurement procedure was set in motion. Also, there is no reason to suspect that the change of contact angle with time (or radius) would cease once the measurement was terminated. More likely, such trends would continue. Because there is no unique apparent contact angle and it is unclear whether or not the solid-liquid interfacial tension will remain constant and whether Young's equation is applicable, these angles should be excluded from the interpretation in terms of surface energetics. However, one might consider averaging the contact angles larger than $R$ $=0.48 \mathrm{~cm}$, since $\gamma_{l \nu}$ seems to be constant and since the contact angle error after averaging would not be very large, i.e. $\theta=55.74 \pm 0.63^{\circ}$. It should be noted that such averaging is not allowed: apart from the experimental reasons given above, the question of whether averaging over some data is allowed or not has firm quantitative answers based on the laws of statistics. The statistical justification for disregarding this and other similar systems will be discussed in Appendix A. The main fact is that the statistical analysis rejects "averaging" of the above contact angle data over time by a very large margin.

A summary of the contact angle behaviour for all liquids on poly(propene-alt$N$-(n-propyl)maleimide) is shown in Table 5.4. While the contact angle data of 
formamide, diiodomethane, ethylene glycol, and diethylene glycol should be disregarded, the contact angles of water, glycerol, 2,2'-thiodiethanol, and 1bromonaphthalene can be used for the interpretation in terms of surface energetics.

A similar study was conducted for a second copolymer, poly(propene-alt $-N-(n-$ hexyl)maleimide). It was found that only the advancing contact angles of water, glycerol, diethylene glycol, and cis-decalin are essentially constant. These results are summarized in Table 5.5. The remaining liquids, formamide, 2,2'-thiodiethanol, diiodomethane, ethylene glycol, 1-bromonaphthalene, dimethyl sulfoxide (DMSO), dibenzylamine, ethyl cinnamare, and 2,5-dichlorotoluene all show very complex contact angle patterns which have to be excluded from the interpretation in terms of surface energetics and testing of approaches for interfacial tensions.

A different contact angle experiment is shown in Figure 5.9 for diiodomethane on the poly(propene-alt- $N$-( $n$-hexyl)maleimide): initially the apparent drop volume, as perceived by ADSA-P, increases linearly, and the contact angle increases from $88^{\circ}$ to $96^{\circ}$ at essentially constant three-phase radius. Suddenly, the drop front jumps to a new location as more liquid is supplied into the sessile drop. The resulting contact angle decreases sharply from $96^{\circ}$ to $88^{\circ}$. As more liquid is supplied into the sessile drop, the contact angle increases again. Such slip/stick behaviour could be due to non-inertness of the surface. Phenomenologically, an energy barrier for the drop front exists, resulting in sticking, which causes $\theta$ to increase at constant $R$. However, as more liquid is supplied into the sessile drop, the drop front possesses enough energy to overcome the energy barrier, resulting in slipping, which causes $\theta$ 
to decrease suddenly. It should be noted that as the drop front jumps from one location to the next, it is unlikely that the drop will remain axisymmetric. Such a non-axisymmetric drop will obviously not meet the basic assumptions underlying ADSA-P, causing possible errors, e.g., in the apparent surface tension and drop volume. This can be seen from the discontinuity of the apparent drop volume and apparent surface tension with time as the drop front sticks and slips. Similar behaviour can also be observed in other experiments [77]. Obviously, the observed contact angles cannot all be Young contact angles, since $\gamma_{l v}, \gamma_{s v}$ (and $\gamma_{s l}$ ) are constants, so that because of Young's equation, $\theta$ ought to be a constant. In addition, it is difficult to decide unambiguously at this moment whether or not Young's equation is applicable at all because of lack of understanding of the slip/stick mechanism. Therefore, these contact angles should not be used for the interpretation in terms of surface energetics. A summary of the contact angle behaviour for all 13 liquids on this copolymer is shown in Table 5.6.

While pronouned cases of slip/stick behaviour can indeed be observed by the goniometer, it is virtually impossible to record the entire slip/stick behaviour manually. In this case, the goniometer contact angle can be very subjective, depending on the skill of the experimentalist. It is expected that a contact angle thus recorded by the goniometer should agree with the maximum angles obtained by ADSA-P. Indeed, a contact angle of $98^{\circ}$ was observed (in Table 3.2), in reasonable agreement with the maxima in the entire slip/stick pattern of the ADSA-P results ( $\theta$ $\approx 96^{\circ}$ in Figure 5.9). In cases where the liquid-vapour surface tension of the sessile 
drop decreases due to, e.g., dissolution of the surface, only ADSA can detect changes in the liquid-vapour surface tension. The distinctions and differentiations made by ADSA-P are not possible in a goniometer study. Thus, circumspection is necessary in the decision whether or not experimental contact angles can be used in conjunction with Young's equation; contact angles from a conventional goniometer-sessile drop technique may produce contact angles which do not fulfill the basic assumptions made in all surface energetic approaches [10-17], e.g. constancy of $\gamma_{k}$ and applicability of Young's equation already mentioned in Chapter 1. These various assumptions will be discussed in detail in Chapter 7.

A comparison of the angles measured here and those by the goniometer technique in Chapter 3 are summarized in Tables 5.7 and 5.8. It can be seen that the goniometer angles correspond very well with those of ADSA-P only in situations where the contact angles are constant; in cases where complexities of contact angles arise, the goniometer contact angles correspond only to the maxima of the angles from ADSA-P. The picture emerging in Figure 3.2 changes drastically upon elimination of the angles shown to be meaningless in the ADSA-P study, see Figure 5.10. The curves in Figure 5.10 are in harmony with the results obtained for more inert polar and non-polar surfaces in Figures 2.1 and 5.4. Again, it can be concluded that $\gamma_{l \nu} \cos \theta$ changes smoothly and systematically with $\gamma_{\nu}$ at constant $\gamma_{s v}$. Because of Young's equation, a relation of the form of Eq.(2.3) can be deduced:

$$
\gamma_{s l}=F\left(\gamma_{l v}, \gamma_{s v}\right)
$$


Thus, the experimental procedures and techniques used are crucial in the collection of contact angle data for surface energetics; conventional goniometer techniques may produce contact angles which violate the basic assumptions made in all surface energetic approaches, e.g., constancy of $\gamma_{s \nu}$. In other words, the most serious shortcoming of goniometer studies is not subjectivity and lack of accuracy, but inability to distinguish between meaningful and meaningless contact angle measurements.

\subsection{Other Non-Polar and Polar Surfaces}

Due to the fact that contact angle patterns which are irrelevant to the determination of solid surface tensions can be identified with the above experimental procedures and technique, low-rate dynamic contact angles of a large number of liquids were studied extensively on various solid surfaces. They are FC-725-coated silicon wafer surface, poly(n-butyl methacrylate) PnBMA, polystyrene PS, poly(styrene-(hexyl/10-carboxydecyl 90:10)-maleimide) $\quad \mathrm{P}(\mathrm{S}-(\mathrm{H} / \mathrm{C} \quad$ 90:10)M), poly(methyl methacrylate/n-butyl methacrylate) $\mathrm{P}(\mathrm{MMA} / n \mathrm{BMA})$, poly(methyl methacrylate) PMMA, and poly(propene-alt- $N$-methylmaleimide). Details with respect to solid surface preparation and experimental results have been given in Appendices B-I.

Again, it was found that not all contact angles can be used for energetic purposes. For example, slip/stick of the three-phase contact line, $\gamma_{l}$ decreases, and $\theta$ decreases or increases as the drop front advances, and dissolution of the polymers by 
the liquids were observed. The meaningful angles for these polymers (copolymers) are plotted in Figures 5.11-5.17, in plots of $\gamma_{l \nu} \cos \theta$ vs. $\gamma_{l \nu}$. For a given solid surface, $\gamma_{s v}$ is expected to be constant and these results suggest that $\gamma_{k v} \cos \theta$ changes smoothly and systematically with $\gamma_{i v}$. Changing the solid surface (and hence $\gamma_{s v}$ ) shifts the curves in a regular manner: intermolecular forces do not have any additional and independent effects on the contact angles. The universality of these contact angle patterns will be discussed in Chapter 6. 


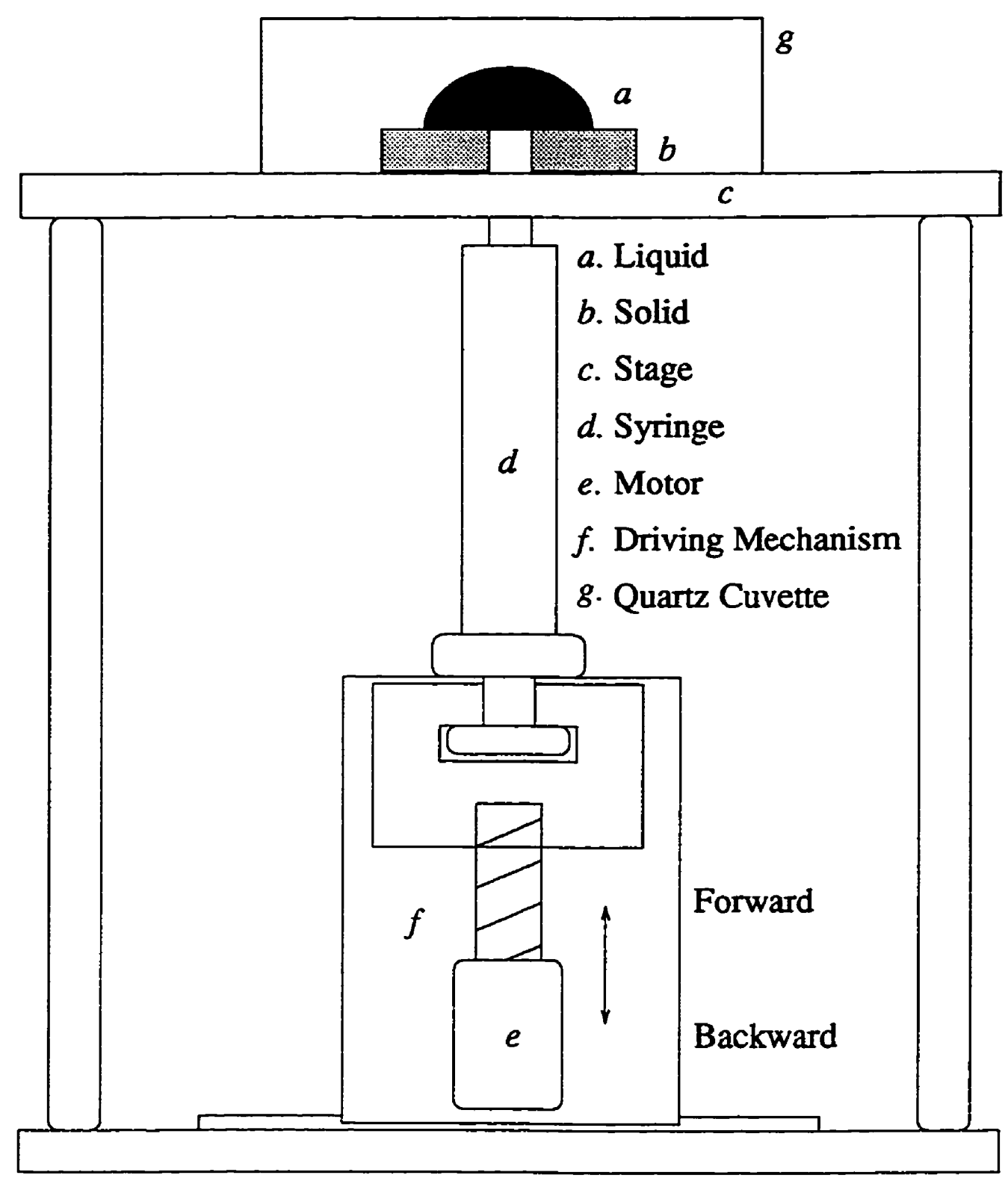

Figure 5.1 Schematic of a motorized syringe mechanism for dynamic contact angle measurements. 
low-rate dynamic contact angles:

water on a FC-722-coated mica
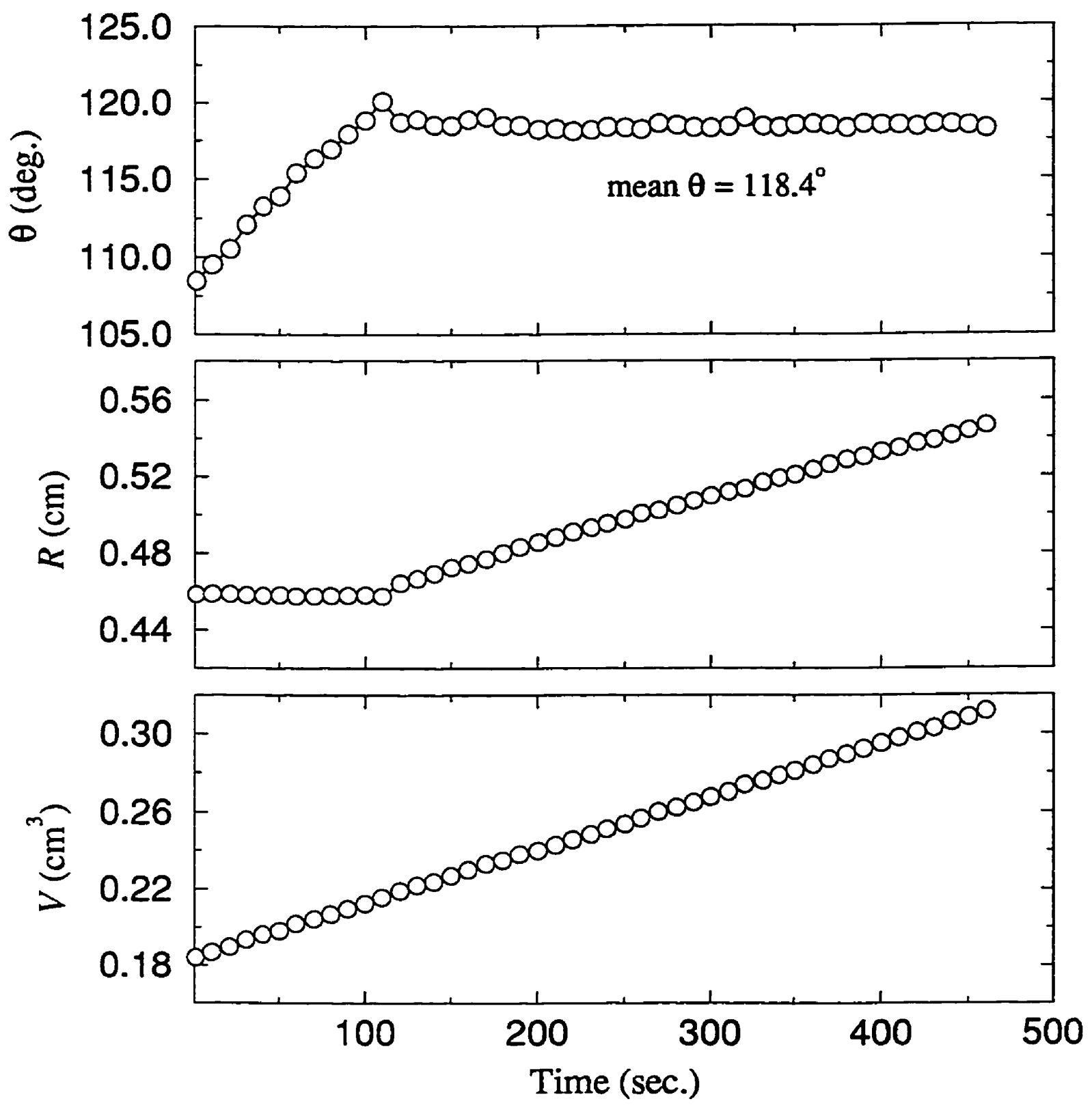

Figure 5.2 Low-rate dynamic contact angles of water on a FC-722-coated mica. A mean contact angle of $118.4^{\circ}$ is obtained for this experiment. 


\section{dynamic/static contact angles:}

cis-decalin on a FC-722-coated mica
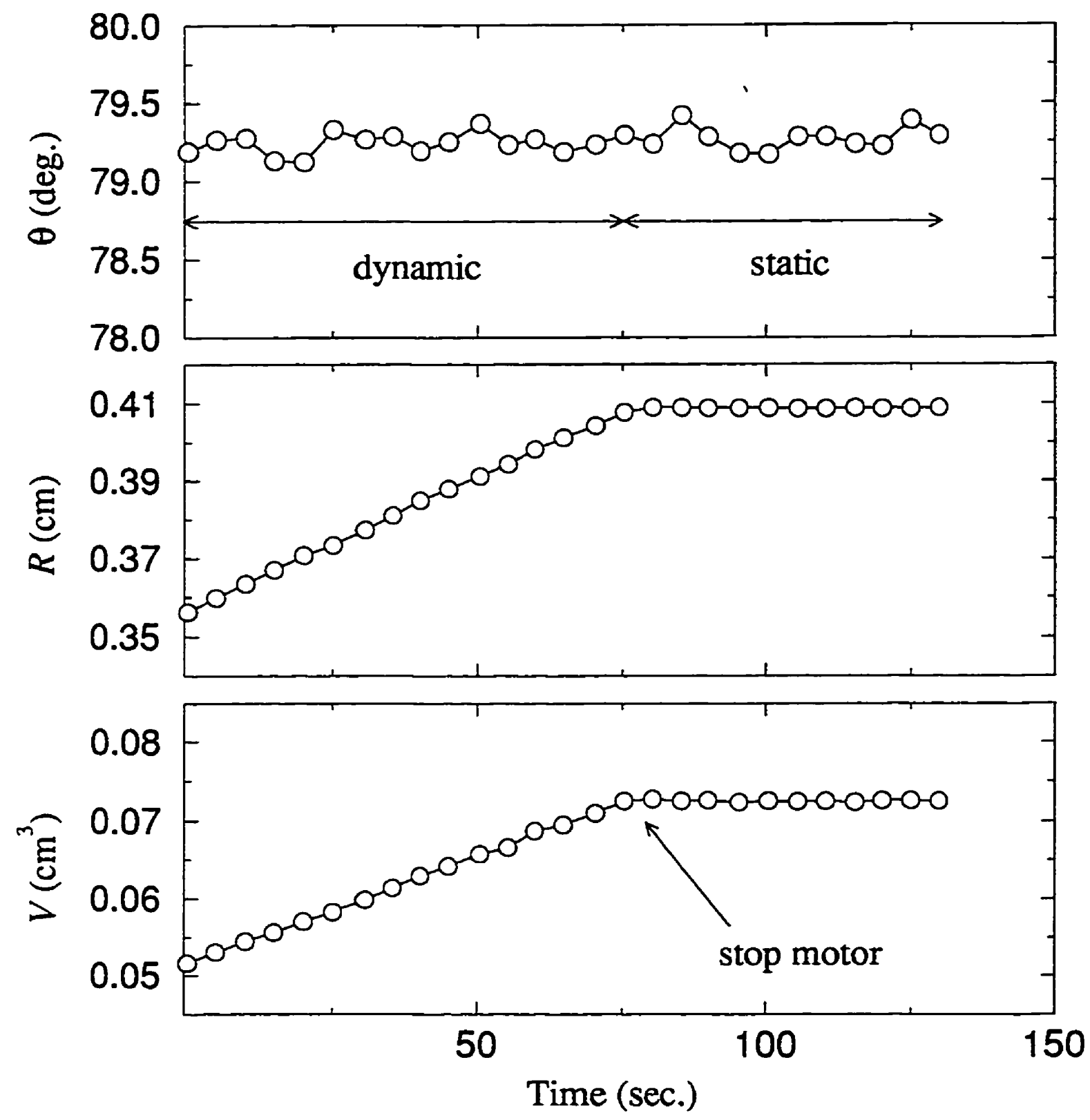

Figure 5.3 Dynamic and static contact angles of cis-decalin on a FC-722-coated mica. This result suggests that low-rate dynamic contact angle is identical to the static angle. 


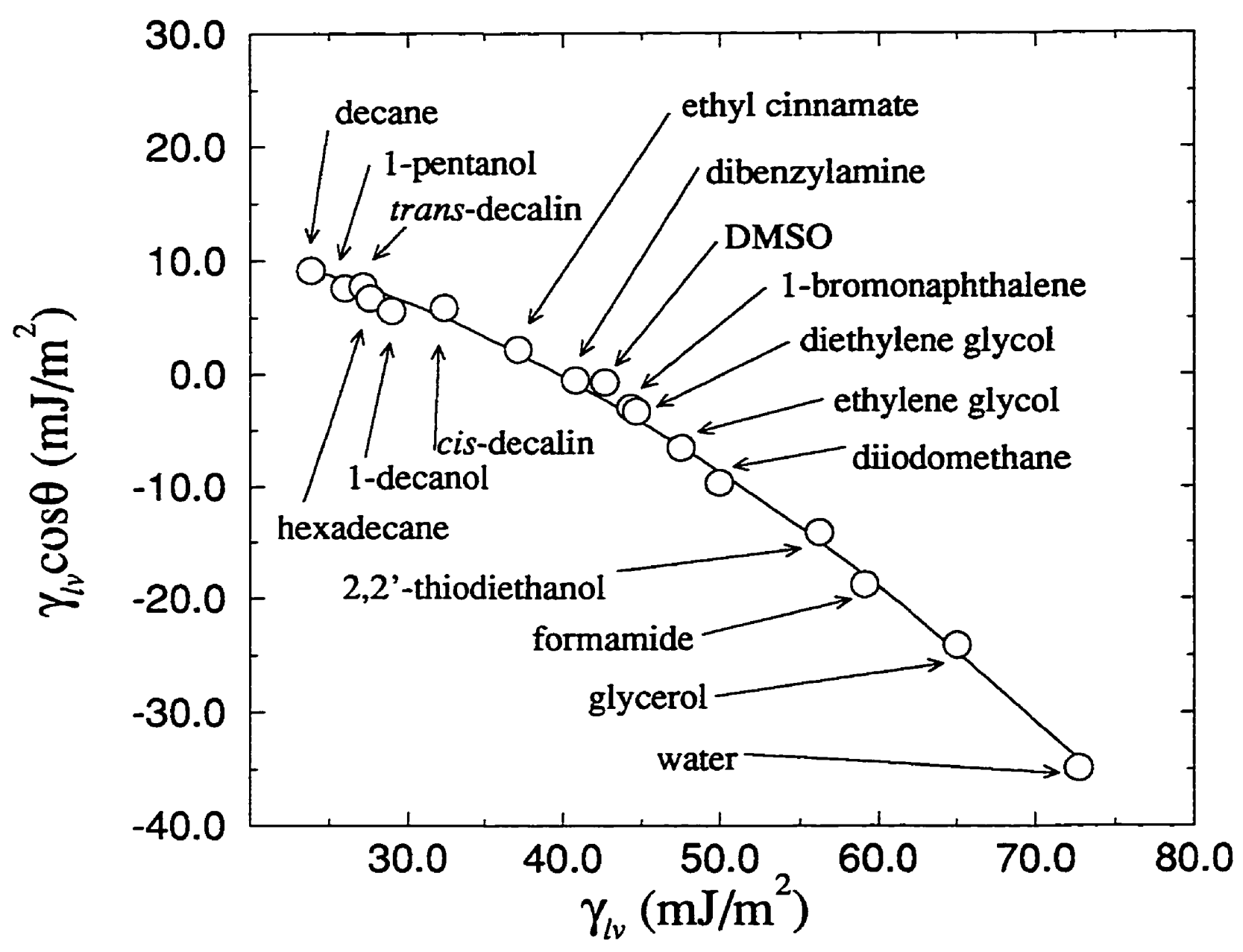

OFC-722-coated mica

Figure $5.4 \gamma_{l \nu} \cos \theta$ vs. $\gamma_{h \nu}$ for the dynamic contact angles of the 17 liquids on a FC-722-coated mica. This result reconfirms the finding of $\mathrm{Li}$ et al. shown in Figure 2.1 that at constant $\gamma_{s v}, \gamma_{l v} \cos \theta$ changes smoothly with $\gamma_{l v}$, independent of liquid properties. 
water on

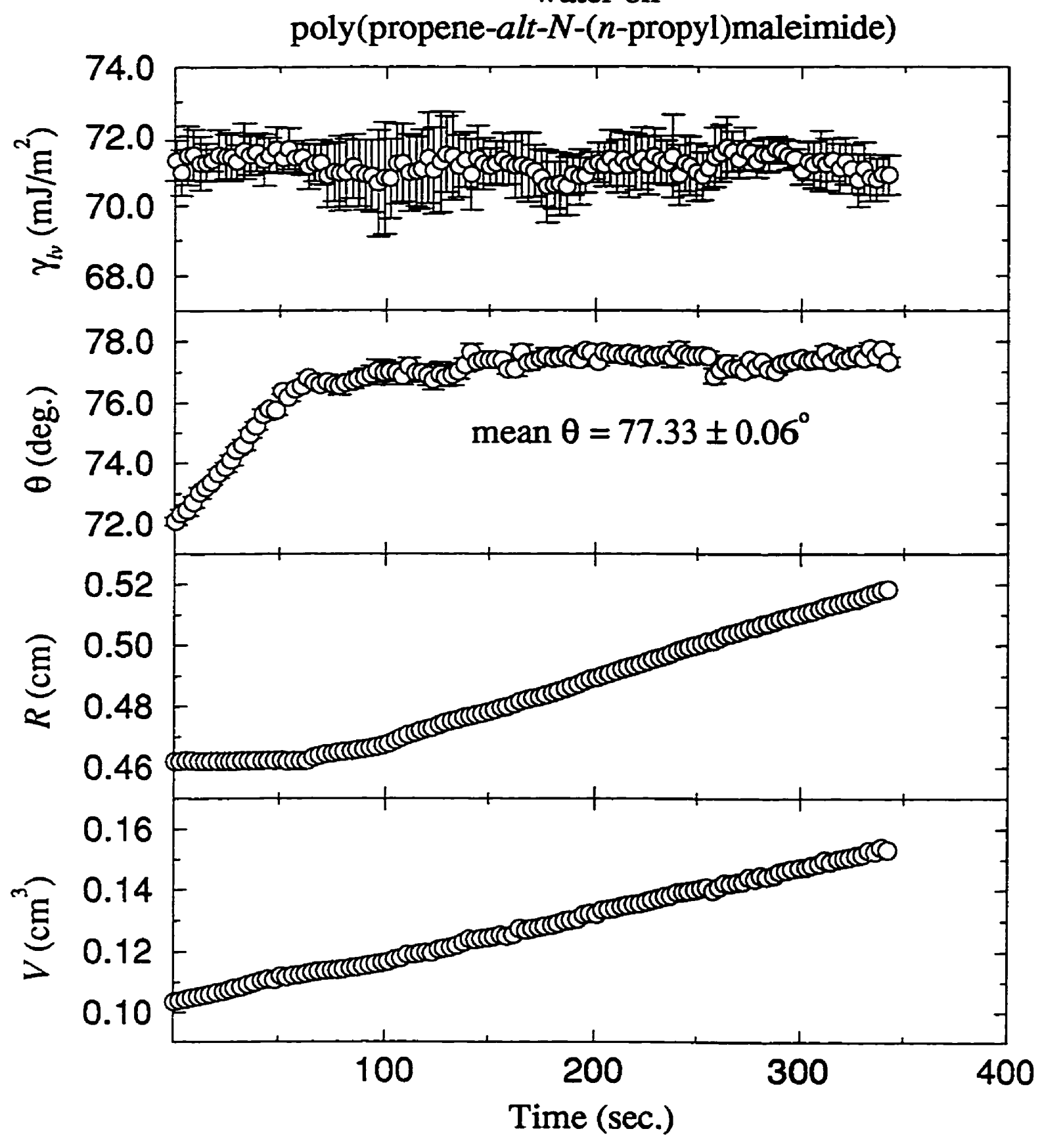

Figure 5.5 Low-rate dynamic contact angles of water on a poly(propene-alt- $N$ - $(n$ propyl)maleimide) copolymer. The initial increase in the contact angle at constant three-phase contact radius is due to that even carefully putting an initial drop from above can result in a contact angle somewhere between advancing and receding. Further increase in the drop volume causes the contact angle to increase. This procedure ensures the measured angle to be an advancing angle. A mean contact angle of $77.33 \pm 0.06^{\circ}$ is obtained. 


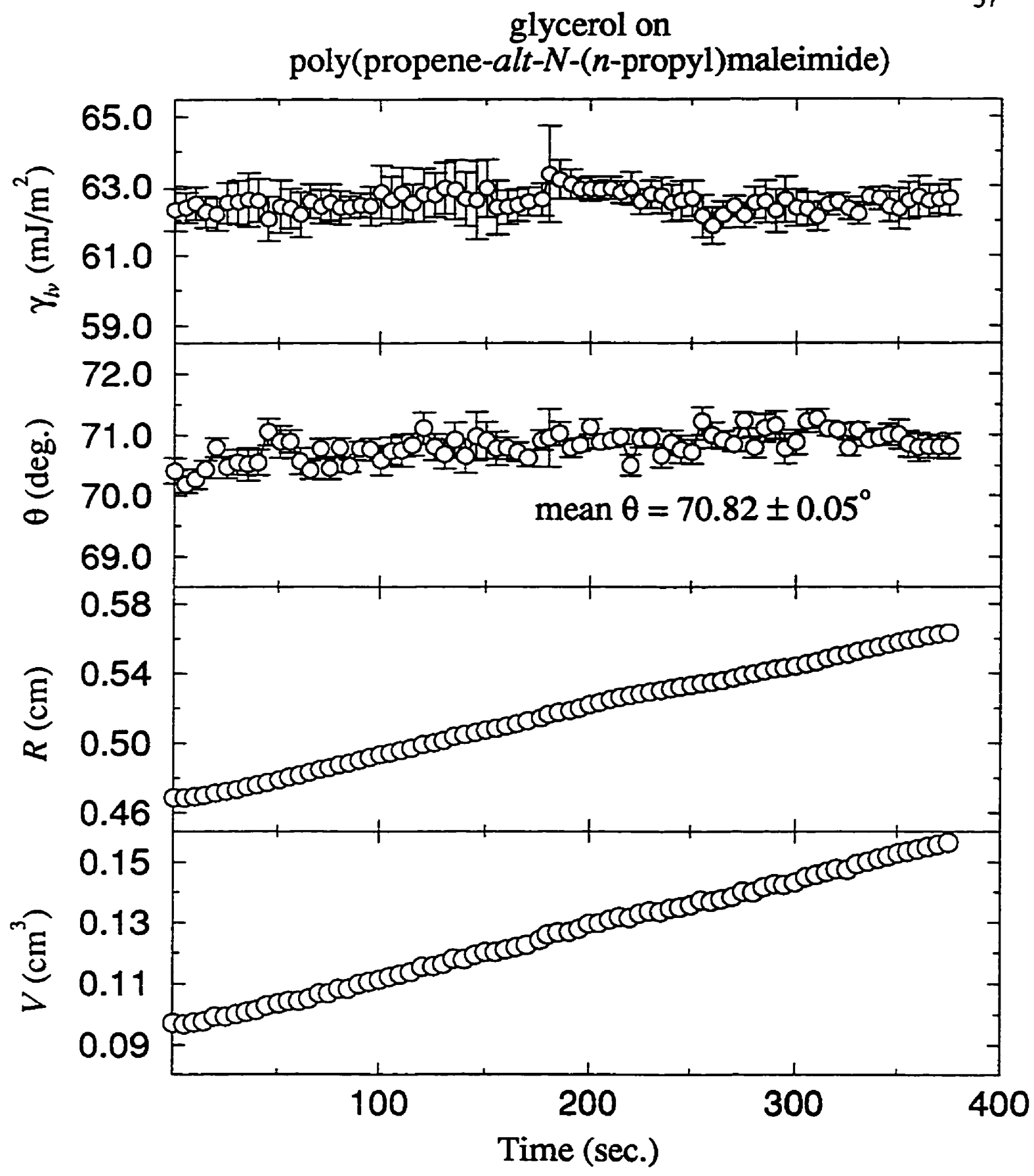

Figure 5.6 Low-rate dynamic contact angles of glycerol on a poly(propene-alt- $N$ (n-propyl)maleimide) copolymer. Since the advancing contact angles are essentially constant, they can be averaged, resulting in a mean contact angle of $70.82 \pm 0.05^{\circ}$. 
formamide on

poly(propene-alt- $N$-( $n$-propyl)maleimide)

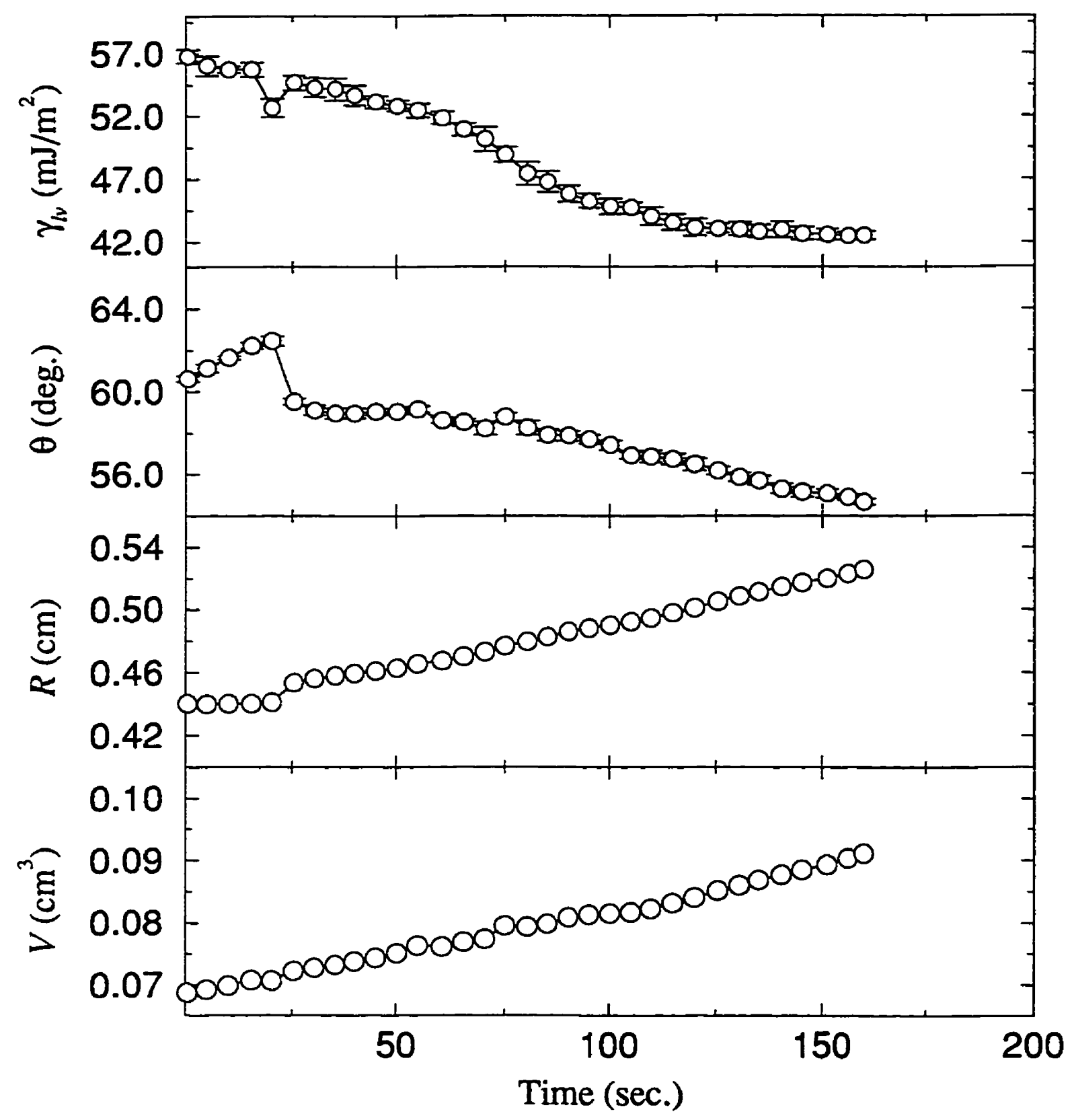

Figure 5.7 Low-rate dynamic contact angles of formamide on a poly(propene-alt$N$-(n-propyl)maleimide) copolymer. These angles should be disregarded for the interpretation in terms of surface energetics since $\theta$ is not constant and $\gamma_{l}$ is different from that of the pure liquid. It is virtually impossible for a goniometer technique to detect these complexities: the contact angle obtained from goniometer techniques cannot be meaningful for this and similar solid-liquid systems. 
ethylene glycol on poly(propene-alt- $N$-( $n$-propyl)maleimide)

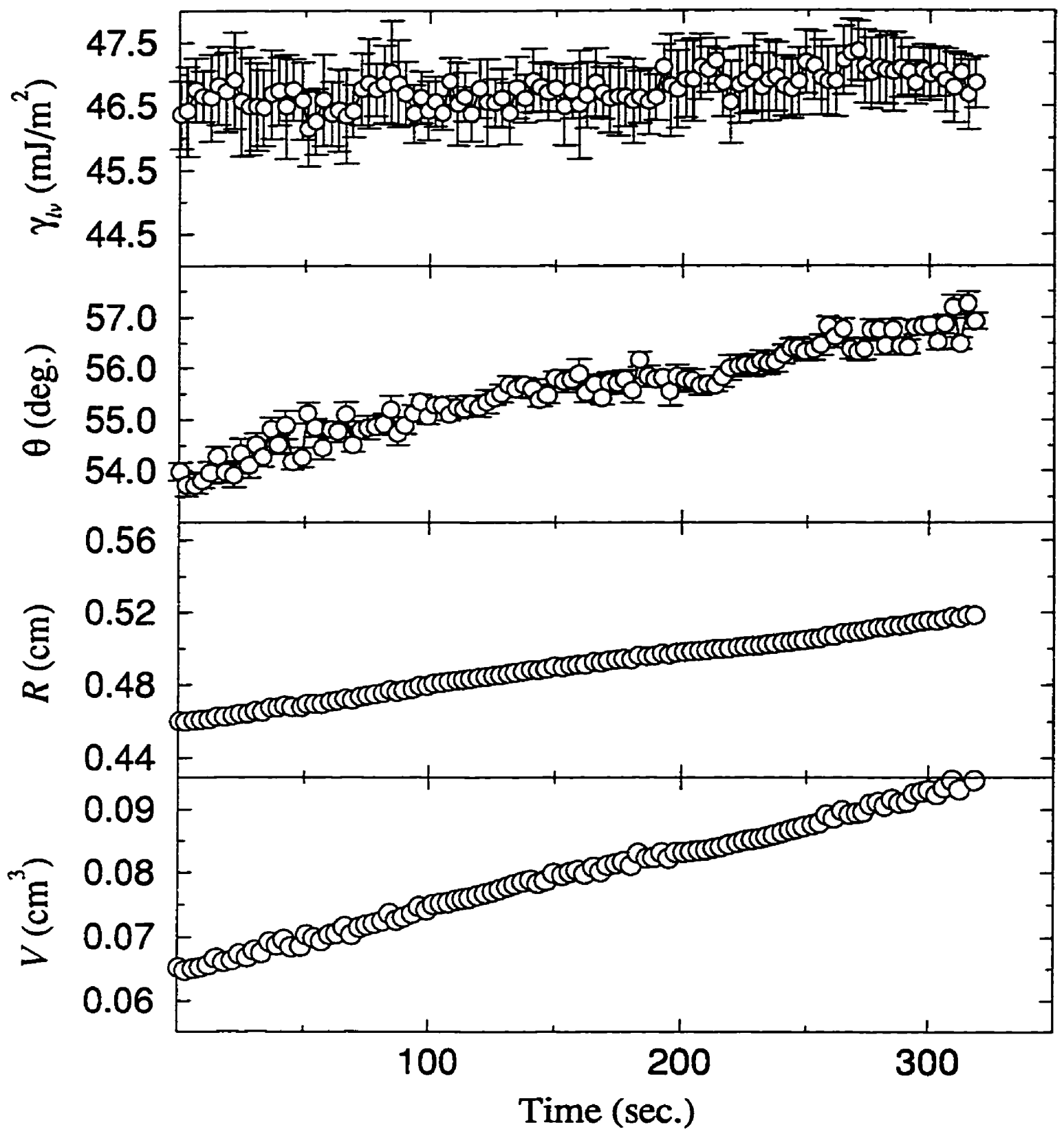

Figure 5.8 Low-rate dynamic contact angles of ethylene glycol on a poly(propene-alt- $N$-( $n$-propyl)maleimide) copolymer. These angles should be disregarded for the interpretation in terms of surface energetics since there is no apparent unique contact angle: according to Young's equation, if the values of $\gamma_{l v}$ and $\gamma_{s v}$ are constant, a change in the contact angle must be a consequence of a change in $\gamma_{s l}$. 
diiodomethane on poly(propene-alt- $N$-( $n$-hexyl)maleimide)

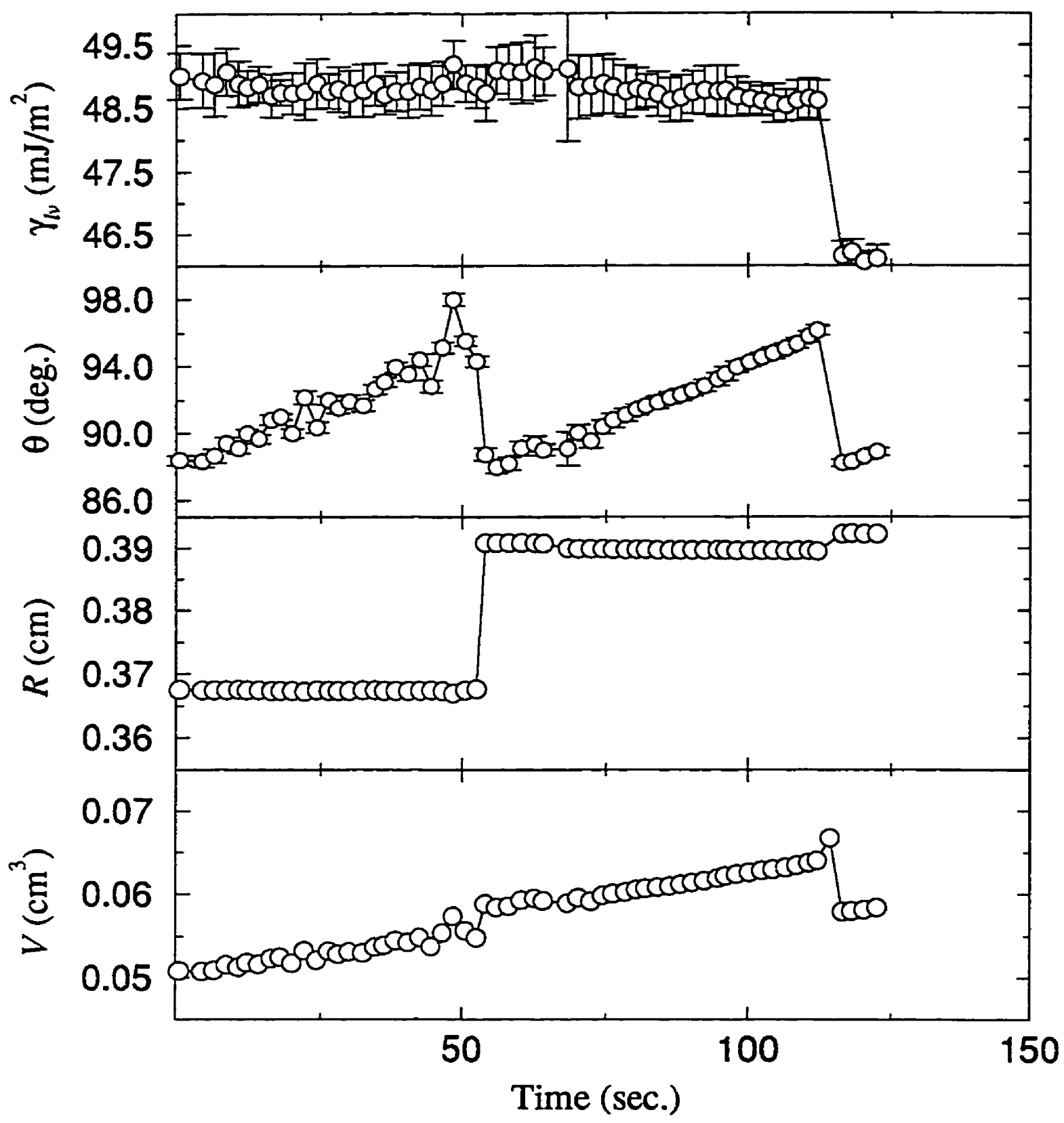

Figure 5.9 Low-rate dynamic contact angles of diiodomethane on a poly(propene-alt- $N$-( $n$-hexyl)maleimide) copolymer. These angles should be disregarded for the interpretation in terms of surface energetics since $\theta$ is not constant due to the slip/stick behaviour of the three-phase contact line. 


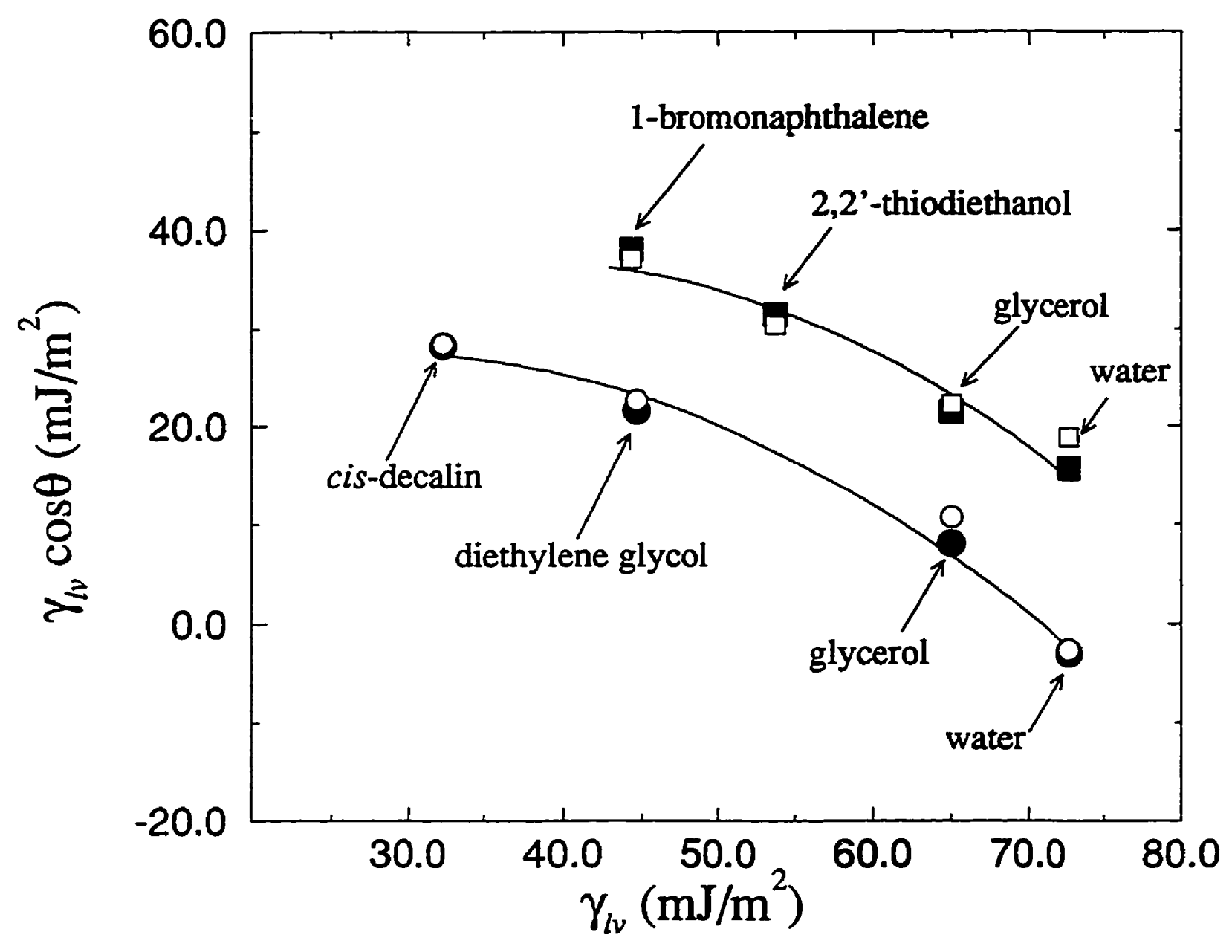

poly(propene-alt- $N$-(n-hexyl)maleimide); ADSA-P

poly(propene-alt- $N$-( $n$-propyl)maleimide); ADSA-P

O poly(propene-alt- $N$-( $n$-hexyl)maleimide); goniometer

$\square$ poly(propene-alt- $N$-( $n$-propyl)maleimide); goniometer

Figure $5.10 \gamma_{l v} \cos \theta$ vs. $\gamma_{l \nu}$ for the poly(propene-alt- $N$-( $n$-propyl)maleimide) and poly(propene-alt- $N$-( $n$-hexyl)maleimide) copolymers. Figure 3.2 changes drastically upon elimination of the angles shown to be meaningless using the dynamic contact angle procedures by ADSA-P. These results are in harmony with the results for more inert polar and non-polar surfaces shown in Figure 2.1. 


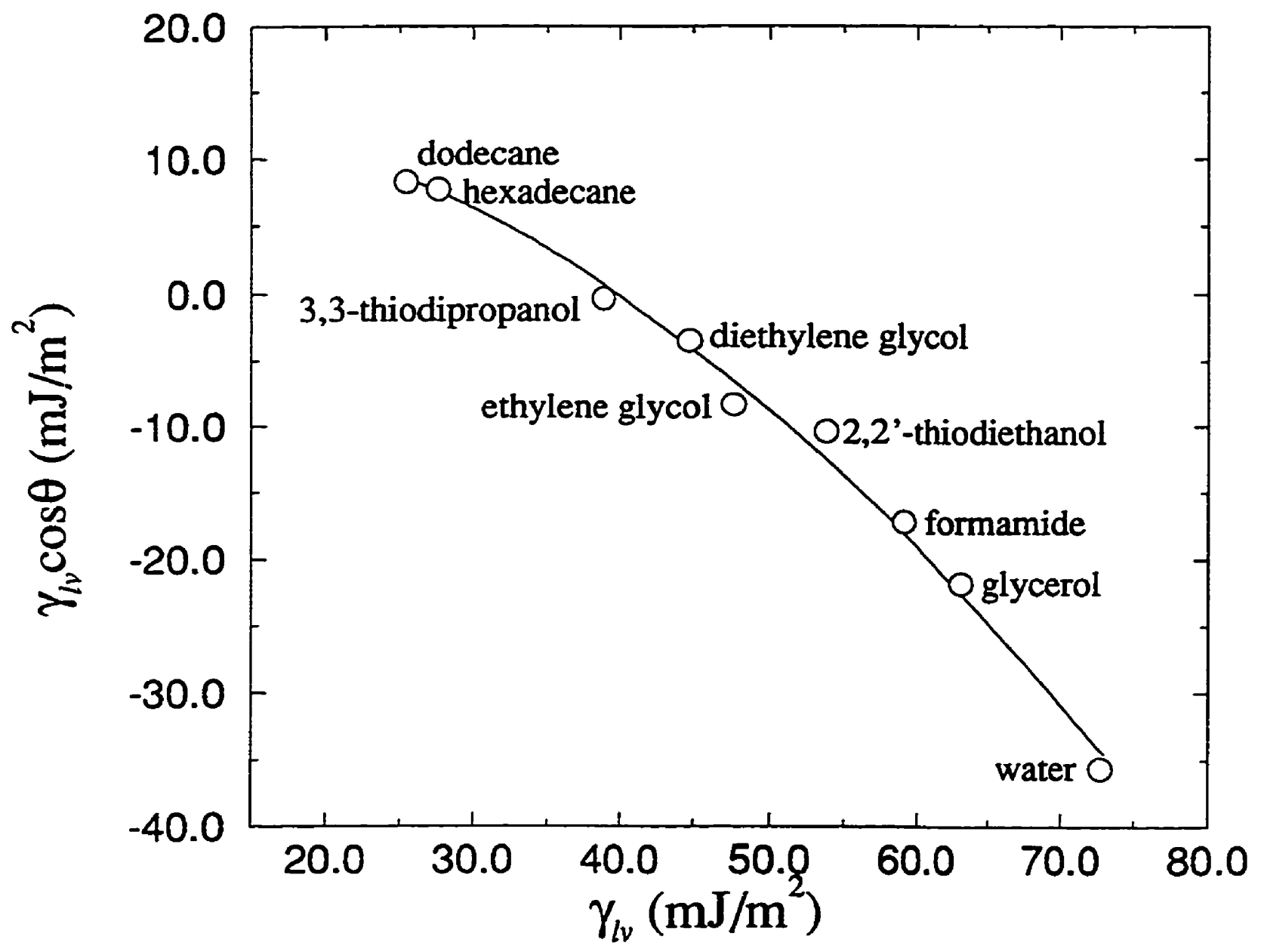

OFC-725-coated silicon wafer surface

Figure $5.11 \gamma_{L} \cos \theta$ vs. $\gamma_{L \nu}$ for a FC-725-coated silicon wafer surface. The contact angles are dynamic contact angles by ADSA-P. Results suggest that $\gamma_{l v} \cos \theta$ changes smoothly with $\gamma_{l}$ for a given solid surface. 


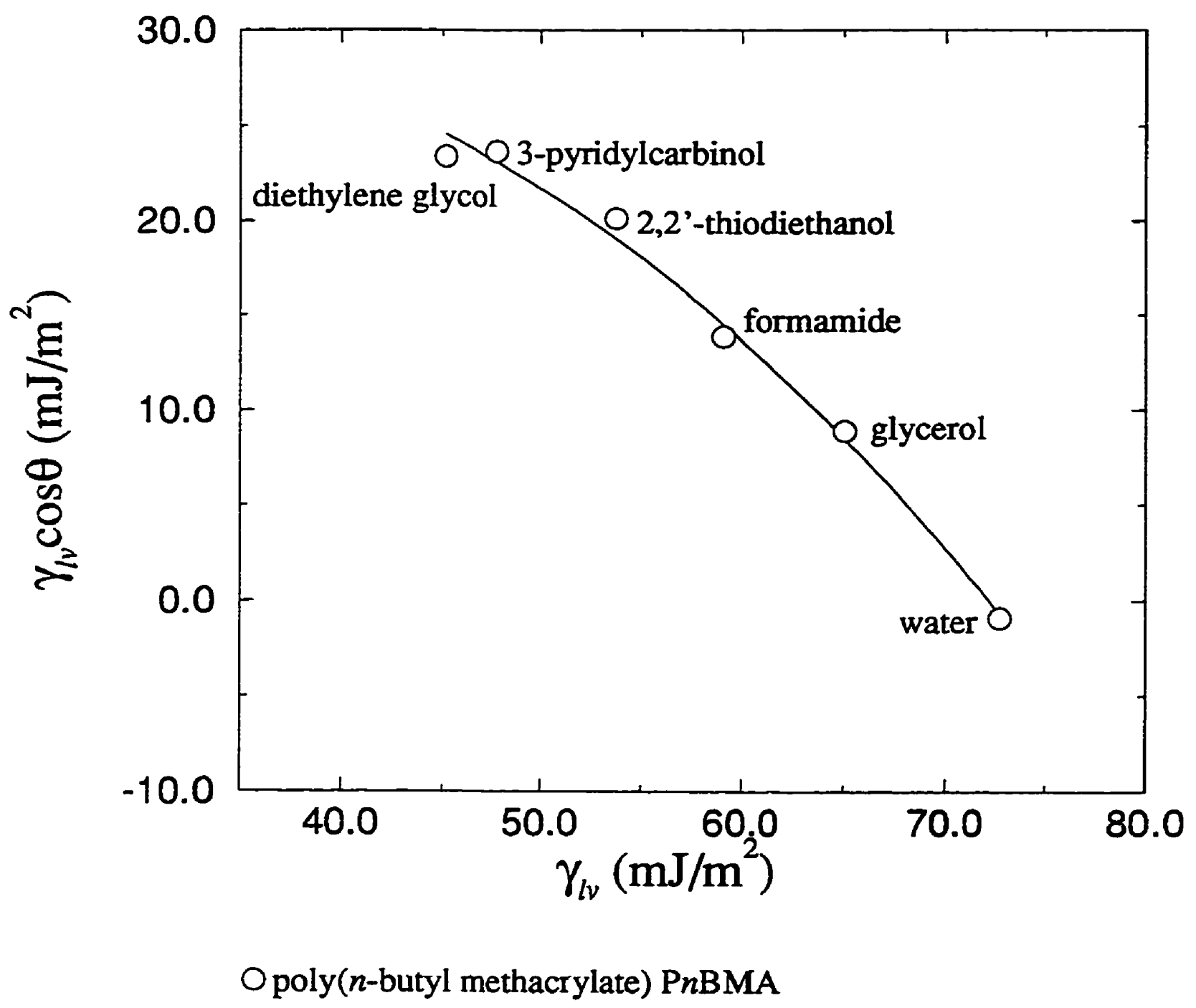

Figure $5.12 \gamma_{L} \cos \theta$ vs. $\gamma_{L}$ for a poly ( $n$-butyl methacrylate) PnBMA-coated silicon wafer surface. The contact angles are dynamic contact angles by ADSA-P. Results suggest that $\gamma_{l v} \cos \theta$ changes smoothly with $\gamma_{l v}$ for a given solid surface. 


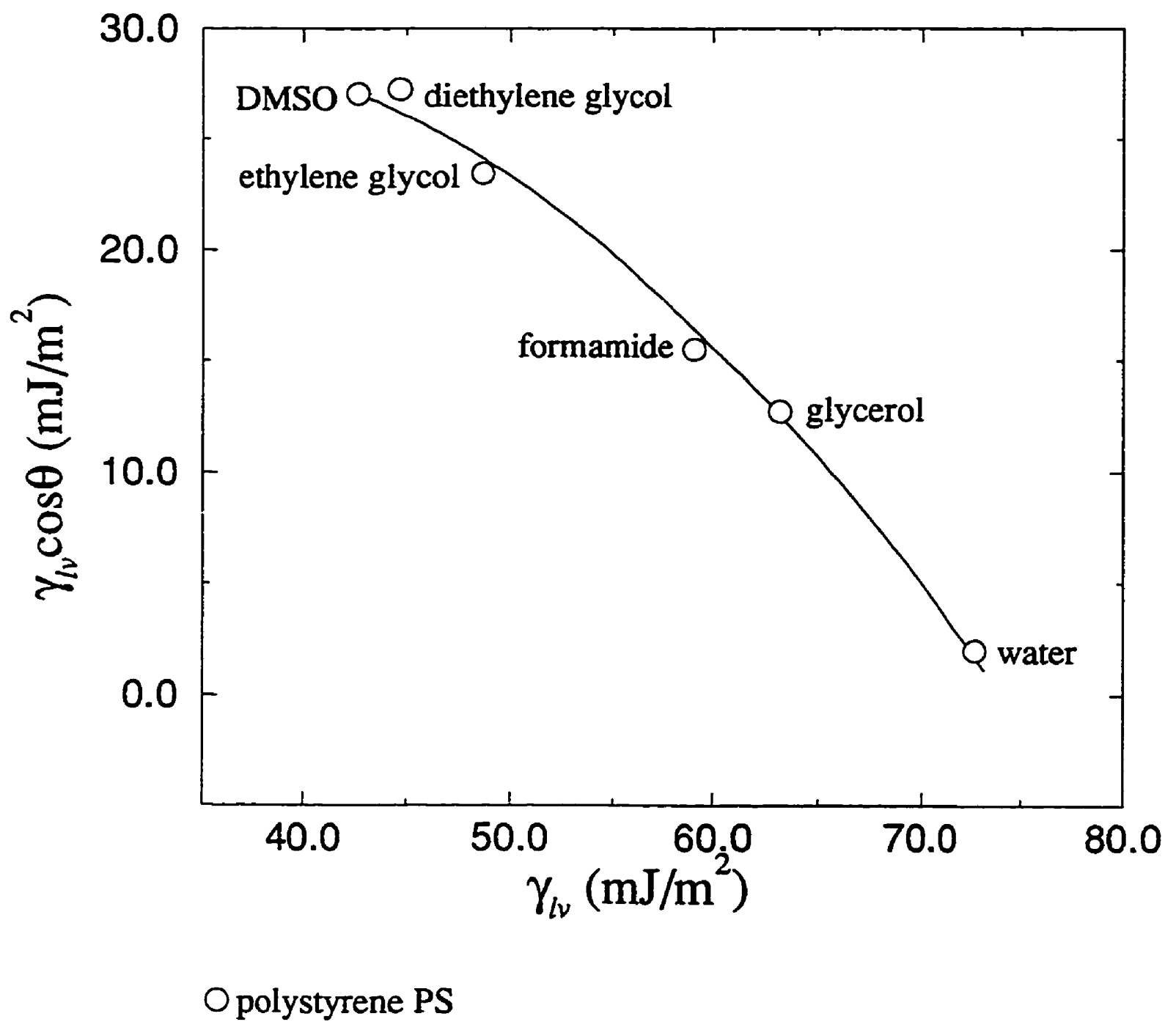

Figure $5.13 \gamma_{l \nu} \cos \theta$ vs. $\gamma_{l \nu}$ for a polystyrene PS-coated silicon wafer surface. The contact angles are dynamic contact angles by ADSA-P. Results suggest that $\gamma_{k} \cos \theta$ changes smoothly with $\gamma_{\nu}$ for a given solid surface. 


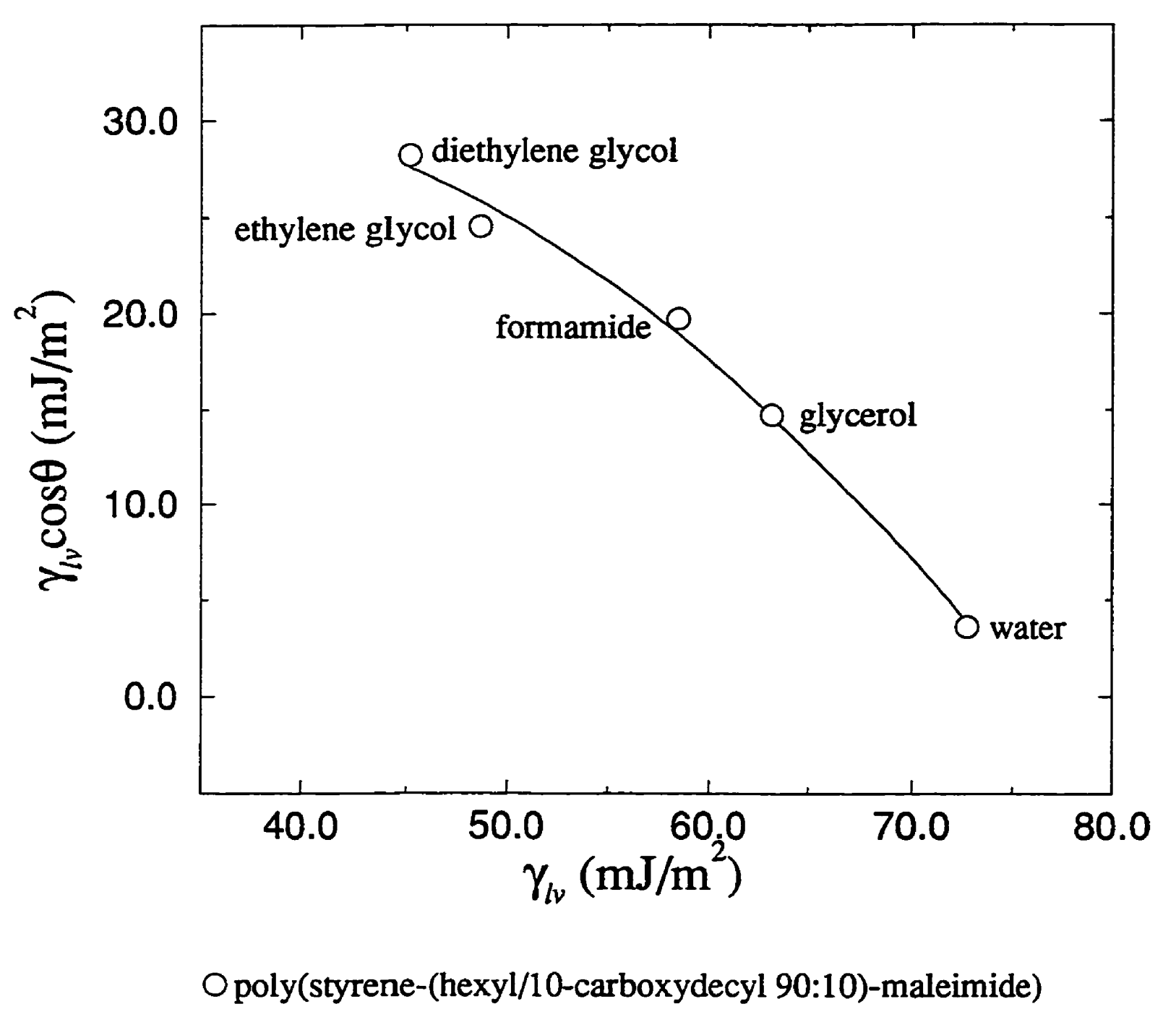

Figure $5.14 \gamma_{L \nu} \cos \theta$ vs. $\gamma_{L \nu}$ for a poly(styrene-(hexyl/10-carboxydecyl 90:10)maleimide)-coated silicon wafer surface. The contact angles are dynamic contact angles by ADSA-P. Results suggest that $\gamma_{l v} \cos \theta$ changes smoothly with $\gamma_{l v}$ for a given solid surface. 


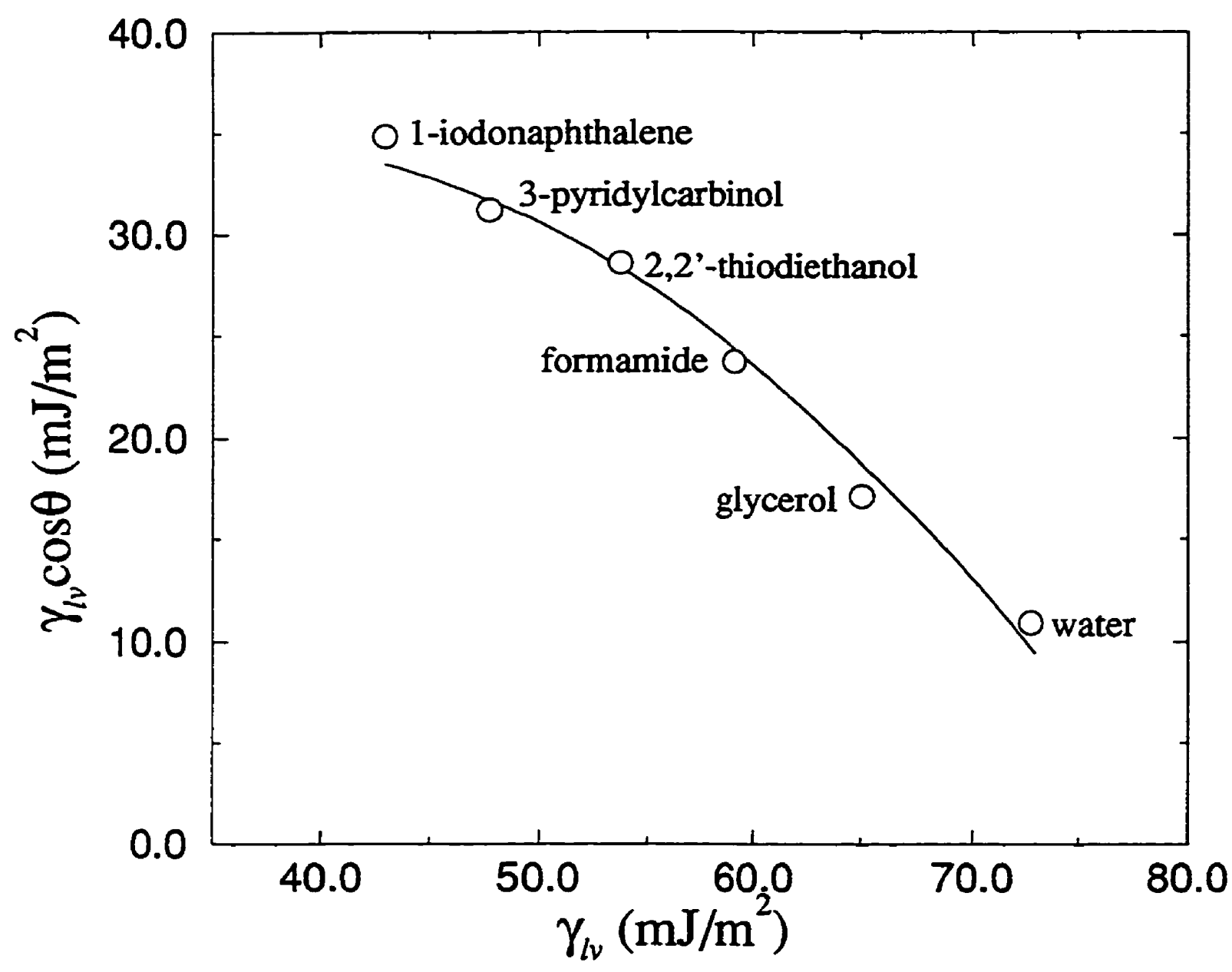

O poly(methyl methacrylate/n-butyl methacrylate)

Figure $5.15 \gamma_{l} \cos \theta$ vs. $\gamma_{k}$ for a poly(methyl methacrylate/ $n$-butyl methacrylate) $\mathrm{P}(\mathrm{MMA} / \mathrm{nBMA})$-coated silicon wafer surface. The contact angles are dynamic contact angles by ADSA-P. Results suggest that $\gamma_{l v} \cos \theta$ changes smoothly with $\gamma_{l v}$ for a given solid surface. 


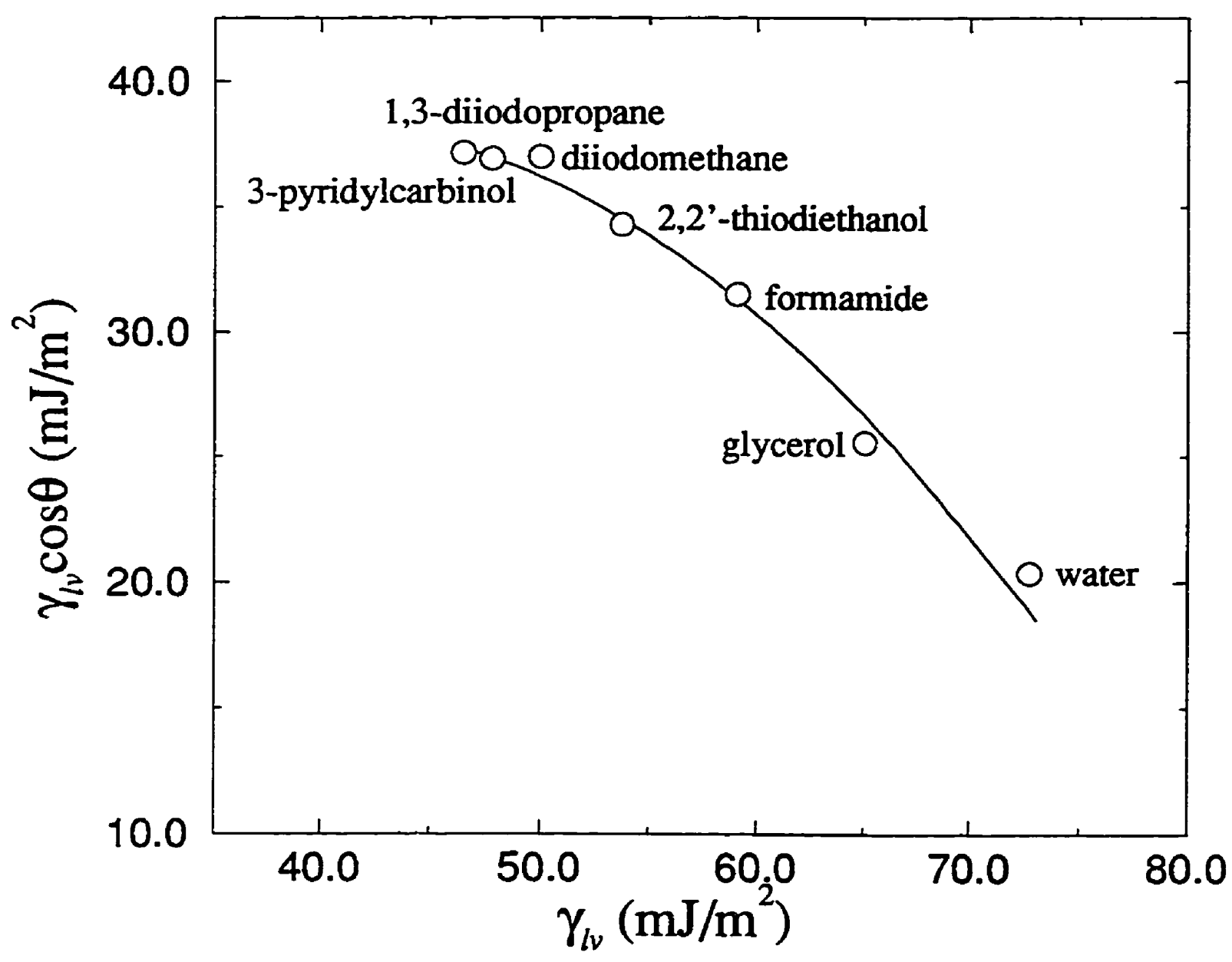

O poly(methyl methacrylate) PMMA

Figure $5.16 \gamma_{\nu} \cos \theta$ vs. $\gamma_{l \nu}$ for a poly(methyl methacrylate) PMMA-coated silicon wafer surface. The contact angles are dynamic contact angles by ADSA-P. Results suggest that $\gamma_{l} \cos \theta$ changes smoothly with $\gamma_{l}$ for a given solid surface. 


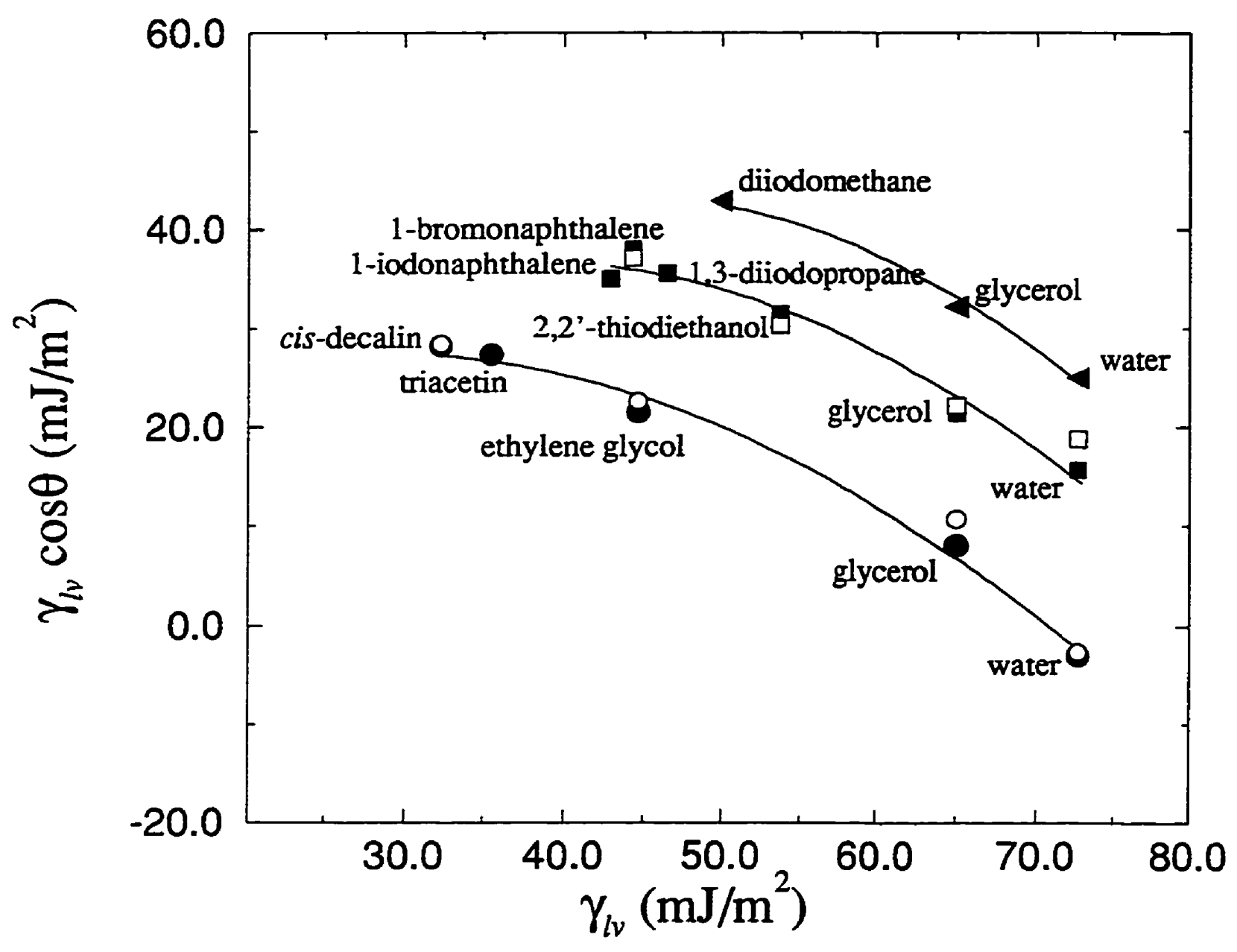

- poly(propene-alt- $N$-( $n$-hexyl)maleimide); ADSA-P $\circ$ poly(propene-alt- $N$-( $n$-hexyl)maleimide); goniometer - poly(propene-alt- $N$-( $n$-propyl)maleimide); ADSA-P $\square$ poly(propene-alt- $N$-( $n$-propyl)maleimide); goniometer $\checkmark$ poly(propene-alt- $N$-methylmaleimide); ADSA-P

Figure $5.17 \gamma_{l v} \cos \theta$ vs. $\gamma_{\nu}$ for a poly(propene-alt- $N$-alkylmaleimide)-coated silicon wafer surface. The contact angles are dynamic contact angles by ADSA-P. Results suggest that $\gamma_{l \nu} \cos \theta$ changes smoothly with $\gamma_{L \nu}$ for a given solid surface. 
Table 5.1: Suppliers and surface tensions of the liquids used for the low-rate dynamic contact angle measurements on a FC-722-coated mica. The surface tensions were measured at 23.0 $\pm 0.5^{\circ} \mathrm{C}$

\begin{tabular}{lllccc}
\hline liquid & supplier & $\%$ purity & $\begin{array}{c}\text { density } \\
\left(\mathrm{g} / \mathrm{cm}^{3}\right)\end{array}$ & $\begin{array}{c}\text { surface tension } \\
\gamma_{\nu}\left(\mathrm{mJ} / \mathrm{m}^{2}\right)\end{array}$ & $\begin{array}{c}\text { no. of } \\
\text { drops }\end{array}$ \\
\hline decane & caledon & 99.98 & 0.730 & $23.88 \pm 0.008$ & 10 \\
1-pentanol & aldrich & $99+$ & 0.811 & $26.01 \pm 0.09$ & 10 \\
trans-decalin & aldrich & 99 & 0.870 & $27.19 \pm 0.08$ & 10 \\
hexadecane & aldrich & $99+$ & 0.773 & $27.62 \pm 0.005$ & 10 \\
1-decanol & aldrich & $99+$ & 0.829 & $28.99 \pm 0.004$ & 10 \\
cis-decalin & aldrich & 99 & 0.897 & $32.32 \pm 0.01$ & 7 \\
ethyl cinnamate & aldrich & 99 & 1.049 & $37.17 \pm 0.02$ & 10 \\
dibenzylamine & aldrich & 97 & 1.026 & $40.80 \pm 0.06$ & 9 \\
dimethyl sulfoxide & sigma- & 99.9 & 1.101 & $42.68 \pm 0.09$ & 10 \\
(DMSO) & aldrich & $($ HPLC) & & & 7 \\
1-bromonaphthalene & aldrich & 98 & 1.489 & $44.31 \pm 0.05$ & 7 \\
diethylene glycol & aldrich & 99 & 1.118 & $44.68 \pm 0.03$ & 9 \\
ethylene glycol & aldrich & $99+$ & 1.113 & $47.55 \pm 0.02$ & 10 \\
diiodomethane & aldrich & 99 & 3.325 & $49.98 \pm 0.02$ & 10 \\
2,2'-thiodiethanol & aldrich & $99+$ & 1.221 & $56.26 \pm 0.004$ & 10 \\
formamide & aldrich & $99.5+$ & 1.134 & $59.08 \pm 0.01$ & 10 \\
glycerol & baker & 99.8 & 1.258 & $65.02 \pm 0.04$ & 8 \\
water & analyzed & & & & 10 \\
\hline & LAST & doubly & 0.997 & $72.7 \pm 0.09$ & 10 \\
\hline
\end{tabular}

'Laboratory of Applied Surface Thermodynamics 
Table 5.2: Low-rate dynamic (advancing) contact angles of different liquids on a FC-722coated mica. For each liquid, 10 different rates of advancing of the three-phase contact line were performed, each on a newly prepared solid surface. The error bars are $95 \%$ confidence limits

\begin{tabular}{cccccc}
\hline $\begin{array}{c}\text { decane } \\
\text { rate } \\
(\mathrm{mm} / \mathrm{min})\end{array}$ & $\begin{array}{c}\theta \\
\text { (deg.) }\end{array}$ & $\begin{array}{c}\text { 1-pentanol } \\
\text { rate }\end{array}$ & $\begin{array}{c}\theta \\
\text { (mm/min) }\end{array}$ & $\begin{array}{c}\text { trans-decalin } \\
\text { rate } \\
(\mathrm{mm} / \mathrm{min})\end{array}$ & $\begin{array}{c}\theta \\
\text { (deg.) }\end{array}$ \\
\hline 0.109 & 66.88 & 0.160 & 72.81 & 0.010 & 73.58 \\
0.115 & 67.51 & 0.162 & 72.29 & 0.062 & 73.94 \\
0.121 & 67.93 & 0.187 & 72.92 & 0.205 & 73.01 \\
0.194 & 67.64 & 0.202 & 72.63 & 0.212 & 72.78 \\
0.198 & 67.41 & 0.212 & 73.20 & 0.216 & 73.21 \\
0.213 & 66.74 & 0.236 & 72.63 & 0.227 & 73.40 \\
0.294 & 67.04 & 0.242 & 72.92 & 0.259 & 73.86 \\
0.296 & 66.90 & 0.286 & 74.20 & 0.309 & 73.17 \\
0.302 & 67.61 & 0.306 & 73.22 & 0.340 & 73.25 \\
0.303 & 67.93 & 0.313 & 72.71 & 0.379 & 73.54 \\
\hline Mean $\theta:$ & $67.36 \pm 0.31$ & & $72.95 \pm 0.37$ & & $73.38 \pm 0.26$ \\
\hline
\end{tabular}


Table 5.2: (cont'd)

\begin{tabular}{cccccc}
\hline $\begin{array}{c}\text { hexadecane } \\
\text { rate } \\
(\mathrm{mm} / \mathrm{min})\end{array}$ & $\begin{array}{c}\theta \\
\text { (deg.) }\end{array}$ & $\begin{array}{c}\text { 1-decanol } \\
\text { rate }\end{array}$ & $\begin{array}{c}\theta \\
(\mathrm{mm} / \mathrm{min})\end{array}$ & $\begin{array}{c}\text { cis-decalin } \\
\text { rate } \\
(\mathrm{mm} / \mathrm{min})\end{array}$ & $\begin{array}{c}\theta \\
(\mathrm{deg} .)\end{array}$ \\
\hline 0.089 & 76.08 & 0.078 & 78.77 & 0.101 & 79.34 \\
0.111 & 76.38 & 0.086 & 78.28 & 0.144 & 79.53 \\
0.151 & 76.21 & 0.089 & 79.65 & 0.178 & 79.49 \\
0.171 & 76.31 & 0.103 & 79.05 & 0.198 & 80.04 \\
0.208 & 75.93 & 0.112 & 78.26 & 0.258 & 79.26 \\
0.223 & 75.91 & 0.125 & 79.20 & 0.300 & 80.01 \\
0.230 & 76.19 & 0.127 & 78.77 & 0.384 & 79.57 \\
0.237 & 75.30 & 0.144 & 79.27 & 0.430 & 79.23 \\
0.421 & 75.24 & 0.157 & 78.46 & 0.450 & 79.58 \\
0.524 & 75.87 & 0.179 & 78.64 & 0.454 & 79.54 \\
\hline Mean $\theta:$ & $75.94 \pm 0.28$ & & $78.84 \pm 0.25$ & & $79.56 \pm 0.20$ \\
\hline
\end{tabular}


Table 5.2: (cont'd)

\begin{tabular}{cccccc}
\hline \multicolumn{2}{c}{ ethyl cinnamate } & \multicolumn{2}{c}{ dibenzylamine } & \multicolumn{3}{c}{$\begin{array}{c}\text { dimethyl sulfoxide } \\
\text { (DMSO) }\end{array}$} \\
$\begin{array}{c}\text { rate } \\
(\mathrm{mm} / \mathrm{min})\end{array}$ & $\begin{array}{c}\theta \\
(\text { deg. })\end{array}$ & $\begin{array}{c}\text { rate } \\
(\mathrm{mm} / \mathrm{min})\end{array}$ & $\begin{array}{c}\theta \\
\text { (deg.) }\end{array}$ & $\begin{array}{c}\text { rate } \\
(\mathrm{mm} / \mathrm{min})\end{array}$ & $\begin{array}{c}\theta \\
(\text { deg.) }\end{array}$ \\
\hline 0.065 & 86.45 & 0.053 & 91.09 & 0.033 & 91.71 \\
0.072 & 86.48 & 0.079 & 90.87 & 0.042 & 90.94 \\
0.077 & 86.27 & 0.080 & 90.85 & 0.088 & 91.52 \\
0.098 & 86.57 & 0.093 & 90.50 & 0.114 & 91.41 \\
0.113 & 86.73 & 0.112 & 90.23 & 0.129 & 90.64 \\
0.120 & 86.70 & 0.125 & 90.81 & 0.131 & 90.57 \\
0.147 & 86.40 & 0.153 & 90.85 & 0.132 & 90.84 \\
0.148 & 86.63 & 0.171 & 90.54 & 0.134 & 90.25 \\
0.149 & 86.41 & 0.194 & 90.68 & 0.178 & 91.02 \\
0.151 & 86.71 & 0.213 & 90.55 & 0.242 & 90.60 \\
\hline Mean $\theta:$ & $86.54 \pm 0.11$ & & $90.70 \pm 0.18$ & & $90.95 \pm 0.34$ \\
\hline
\end{tabular}


Table 5.2: (cont'd)

\begin{tabular}{|c|c|c|c|c|c|}
\hline \multicolumn{2}{|c|}{ 1-bromonaphthalene } & \multicolumn{2}{|c|}{ diethylene glycol } & \multicolumn{2}{|c|}{ ethylene glycol } \\
\hline $\begin{array}{c}\text { rate } \\
(\mathrm{mm} / \mathrm{min})\end{array}$ & $\begin{array}{c}\theta \\
\text { (deg.) }\end{array}$ & $\begin{array}{c}\text { rate } \\
(\mathrm{mm} / \mathrm{min})\end{array}$ & $\begin{array}{c}\theta \\
\text { (deg.) }\end{array}$ & $\begin{array}{c}\text { rate } \\
(\mathrm{mm} / \mathrm{min})\end{array}$ & $\begin{array}{c}\theta \\
\text { (deg.) }\end{array}$ \\
\hline 0.169 & 93.53 & 0.085 & 94.23 & 0.062 & 97.97 \\
\hline 0.178 & 94.25 & 0.090 & 94.16 & 0.071 & 97.30 \\
\hline 0.180 & 94.28 & 0.094 & 94.33 & 0.077 & 97.88 \\
\hline 0.192 & 93.66 & 0.106 & 94.01 & 0.096 & 97.60 \\
\hline 0.206 & 94.27 & 0.122 & 94.16 & 0.110 & 98.49 \\
\hline 0.236 & 93.28 & 0.128 & 94.13 & 0.154 & 97.60 \\
\hline 0.247 & 94.11 & 0.159 & 94.47 & 0.162 & 97.44 \\
\hline 0.251 & 93.55 & 0.186 & 94.16 & 0.203 & 98.81 \\
\hline 0.270 & 93.84 & 0.213 & 94.23 & 0.223 & 97.66 \\
\hline 0.278 & 93.34 & 0.219 & 94.23 & 0.290 & 97.98 \\
\hline Mean $\theta:$ & \pm 0.28 & & \pm 0.09 & & \pm 0.34 \\
\hline
\end{tabular}


Table 5.2: (cont'd)

\begin{tabular}{cccccc}
\hline \multicolumn{2}{c}{ diiodomethane } & \multicolumn{2}{c}{$2,2^{\prime}$-thiodiethanol } & \multicolumn{2}{c}{ formamide } \\
$\begin{array}{c}\text { rate } \\
(\mathrm{mm} / \mathrm{min})\end{array}$ & $\begin{array}{c}\theta \\
(\mathrm{deg})\end{array}$ & $\begin{array}{c}\text { rate } \\
(\mathrm{mm} / \mathrm{min})\end{array}$ & $\begin{array}{c}\theta \\
(\mathrm{deg} .)\end{array}$ & $\begin{array}{c}\text { rate } \\
(\mathrm{mm} / \mathrm{min})\end{array}$ & $\begin{array}{c}\theta \\
(\mathrm{deg} .)\end{array}$ \\
\hline 0.132 & 100.90 & 0.086 & 104.18 & 0.090 & 109.31 \\
0.154 & 101.10 & 0.112 & 104.56 & 0.104 & 107.09 \\
0.207 & 101.21 & 0.128 & 104.55 & 0.116 & 109.34 \\
0.220 & 101.78 & 0.167 & 104.18 & 0.124 & 107.53 \\
0.233 & 100.34 & 0.180 & 104.91 & 0.200 & 108.57 \\
0.243 & 101.11 & 0.243 & 104.68 & 0.260 & 108.82 \\
0.268 & 101.70 & 0.289 & 104.61 & 0.270 & 109.05 \\
0.277 & 101.32 & 0.305 & 104.97 & 0.295 & 108.79 \\
0.354 & 101.55 & 0.348 & 104.26 & 0.310 & 107.40 \\
0.444 & 101.74 & 0.373 & 104.71 & 0.350 & 109.01 \\
\hline Mean $\theta:$ & $101.18 \pm 0.42$ & & $104.56 \pm 0.20$ & & $108.49 \pm 0.60$ \\
\hline
\end{tabular}


Table 5.2: (cont'd)

\begin{tabular}{ccccc}
\hline & glycerol & & & water \\
rate & rate & $\theta$ \\
$(\mathrm{mm} / \mathrm{min})$ & $\begin{array}{c}\theta \\
(\text { deg. })\end{array}$ & $1 \mathrm{~mm} / \mathrm{min})$ & (deg.) \\
\hline 0.068 & 11.55 & 0.075 & 118.46 \\
0.120 & 111.34 & 0.094 & 118.71 \\
0.151 & 111.12 & 0.096 & 119.12 \\
0.153 & 111.52 & 0.104 & 118.15 \\
0.180 & 111.82 & 0.110 & 118.70 \\
0.219 & 111.00 & 0.113 & 119.26 \\
0.242 & 111.99 & 0.127 & 118.42 \\
0.250 & 112.03 & 0.128 & 118.74 \\
0.284 & 112.70 & 0.133 & 118.89 \\
\hline 0.285 & 112.22 & 0.143 & 118.41 \\
\hline Mean $\theta:$ & $111.73 \pm 0.38$ & & $118.69 \pm 0.24$ \\
\hline
\end{tabular}


Table 5.3: Low-rate dynamic (advancing) contact angles of different liquids on a poly (propene-alt- $N$-( $n$-propyl)maleimide) copolymer surface. For each liquid, at least 6 and up to 9 different rates of advancing of the three-phase contact line were performed, each on a newly prepared solid surface. The error bars are $95 \%$ confidence limits

\begin{tabular}{ccccc}
\hline $\begin{array}{c}\text { rate } \\
\text { (mm/min.) }\end{array}$ & $\begin{array}{c}\theta \\
(\text { deg. })\end{array}$ & $\begin{array}{c}\text { rate } \\
(\mathrm{mm} / \mathrm{min} .)\end{array}$ & $\begin{array}{c}\theta \\
\text { (deg.) }\end{array}$ \\
\hline 0.054 & 77.46 & 0.083 & 70.79 \\
0.064 & 78.08 & 0.115 & 70.94 \\
0.067 & 77.07 & 0.121 & 70.77 \\
0.068 & 77.79 & 0.157 & 70.82 \\
0.110 & 77.58 & 0.182 & 70.58 \\
0.114 & 76.98 & 0.192 & 70.35 \\
0.122 & 77.75 & 0.201 & 70.28 \\
0.126 & 77.33 & 0.228 & 70.83 \\
0.148 & 77.58 & $-1--$ & - \\
\hline Mean $\theta:$ & $77.51 \pm 0.27$ & & $70.67 \pm 0.20$ \\
\hline
\end{tabular}


Table 5.3: (cont'd)

\begin{tabular}{|c|c|c|c|}
\hline \multicolumn{2}{|c|}{ 2,2'-thiodiethanol } & \multicolumn{2}{|c|}{ 1-bromonaphthalene } \\
\hline $\begin{array}{c}\text { rate } \\
(\mathrm{mm} / \mathrm{min} .)\end{array}$ & $\begin{array}{c}\theta \\
\text { (deg.) }\end{array}$ & $\begin{array}{c}\text { rate } \\
(\mathrm{mm} / \mathrm{min} .)\end{array}$ & $\begin{array}{c}\theta \\
\text { (deg.) }\end{array}$ \\
\hline 0.090 & 53.92 & 0.484 & 30.85 \\
\hline 0.127 & 54.22 & 0.490 & 30.66 \\
\hline 0.128 & 54.21 & 0.499 & 30.55 \\
\hline 0.157 & 53.82 & 0.599 & 30.62 \\
\hline 0.234 & 54.12 & 0.532 & 30.93 \\
\hline 0.250 & 53.94 & 0.557 & 30.87 \\
\hline ----- & ----- & 0.570 & 30.67 \\
\hline -ב--- & ----- & 0.602 & 30.70 \\
\hline ----- & ----- & 0.633 & 30.90 \\
\hline Mean $\theta$ & $=0.18$ & & \pm 0.11 \\
\hline
\end{tabular}


Table 5.4: Summary of the low-rate dynamic (advancing) contact angles measured by ADSA$\mathrm{P}$ on a poly(propene-alt- $N$-( $n$-propyl)maleimide) copolymer surface

\begin{tabular}{lcc}
\hline liquid & $\begin{array}{c}\text { surface tension } \\
\gamma_{\nu}\left(\mathrm{mJ} / \mathrm{m}^{2}\right)\end{array}$ & $\begin{array}{c}\text { contact angle } \\
\theta \text { (deg.) }\end{array}$ \\
\hline 1-bromonaphthalene & 44.31 & 30.75 \\
diethylene glycol & 44.68 & $\theta \uparrow$ as $R \uparrow\left(45^{\circ} \rightarrow 49^{\circ}\right)$ \\
ethylene glycol & 47.55 & $\theta \uparrow$ as $R \uparrow\left(54^{\circ} \rightarrow 57^{\circ}\right)$ \\
diiodomethane & 49.98 & slip/stick $\left(45^{\circ} \rightarrow 80^{\circ}\right)$ \\
2,2'-thiodiethanol & 53.77 & 54.04 \\
formamide & 59.08 & $\theta \downarrow$ and $\gamma_{\nu} \downarrow$ as $R \uparrow\left(62^{\circ} \rightarrow 54^{\circ}\right)$ \\
glycerol & 65.02 & 70.67 \\
water & 72.70 & 77.51 \\
\hline
\end{tabular}


Table 5.5: Low-rate dynamic (advancing) contact angles of different liquids on poly(propenealt $-N$-( $n$-hexyl)maleimide) copolymer surface. For each liquid, at least 5 and up to 10 different rates of advancing of the three-phase contact line were performed, each on a newly prepared solid surface. The error bars are $95 \%$ confidence limits

\begin{tabular}{|c|c|c|c|}
\hline \multicolumn{2}{|c|}{ water } & \multicolumn{2}{|c|}{ glycerol } \\
\hline $\begin{array}{c}\text { rate } \\
(\mathrm{mm} / \mathrm{min} .)\end{array}$ & $\begin{array}{c}\theta \\
\text { (deg.) }\end{array}$ & $\begin{array}{c}\text { rate } \\
\text { (mm/min.) }\end{array}$ & $\begin{array}{c}\theta \\
\text { (deg.) }\end{array}$ \\
\hline 0.060 & 92.44 & 0.082 & 82.69 \\
\hline 0.068 & 92.31 & 0.106 & 82.97 \\
\hline 0.077 & 92.37 & 0.123 & 82.78 \\
\hline 0.127 & 91.91 & 0.145 & 83.22 \\
\hline 0.150 & 92.27 & 0.147 & 83.24 \\
\hline ----- & --.-- & 0.162 & 82.92 \\
\hline ----- & 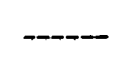 & 0.164 & 82.90 \\
\hline --.--- & ----- & 0.226 & 82.43 \\
\hline --- & -.- & 0.244 & 82.17 \\
\hline --.-- & $\cdots$ & 0.275 & 82.94 \\
\hline Mean $\theta:$ & $=0.26$ & & \pm 0.24 \\
\hline
\end{tabular}


Table 5.5: (cont'd)

\begin{tabular}{|c|c|c|c|}
\hline \multicolumn{2}{|c|}{ diethylene glycol } & \multicolumn{2}{|c|}{ cis-decalin } \\
\hline $\begin{array}{c}\text { rate } \\
(\mathrm{mm} / \mathrm{min} .)\end{array}$ & $\stackrel{\theta}{\theta}$ & $\begin{array}{c}\text { rate } \\
(\mathrm{mm} / \mathrm{min} .)\end{array}$ & $\begin{array}{c}\theta \\
\text { (deg.) }\end{array}$ \\
\hline 0.119 & 60.75 & 0.298 & 28.69 \\
\hline 0.124 & 60.43 & 0.335 & 28.19 \\
\hline 0.186 & 61.58 & 0.338 & 28.96 \\
\hline 0.222 & 61.18 & 0.408 & 28.59 \\
\hline 0.230 & 61.06 & 0.459 & 29.66 \\
\hline 0.257 & 61.45 & -..- & -- \\
\hline 0.305 & 61.21 & ---- & --- \\
\hline 0.325 & 60.84 & -..-- & --- \\
\hline 0.332 & 60.89 & ---- & - \\
\hline 0.345 & 60.96 & --.-- & ---- \\
\hline Mean $\theta:$ & \pm 0.24 & & \pm 0.67 \\
\hline
\end{tabular}


Table 5.6: Summary of the low-rate dynamic (advancing) contact angles measured by ADSA$\mathrm{P}$ on a poly (propene-alt $-N$-( $n$-hexyl)maleimide) copolymer surface

\begin{tabular}{lcc}
\hline liquid & $\begin{array}{c}\text { surface tension } \\
\gamma_{L \nu}\left(\mathrm{mJ} / \mathrm{m}^{2}\right)\end{array}$ & $\begin{array}{c}\text { contact angle } \\
\theta \text { (deg.) }\end{array}$ \\
\hline cis-decalin & 32.32 & 28.81 \\
2, 5-dichlorotoluene & 34.64 & $\theta \uparrow$ as $R \uparrow\left(29^{\circ} \rightarrow 37^{\circ}\right)$ \\
ethyl cinnamate & 37.17 & $\theta \downarrow$ and $\gamma_{k \nu} \downarrow$ as $R \uparrow\left(66^{\circ} \rightarrow 56^{\circ}\right)$ \\
dibenzylamine & 40.80 & $\theta \downarrow$ and $R \uparrow\left(39^{\circ} \rightarrow 34^{\circ}\right)$ \\
DMSO & 42.68 & $\theta \uparrow$ and $\gamma_{L \nu} \downarrow$ as $R \uparrow\left(40^{\circ} \rightarrow 65^{\circ}\right)$ \\
1-bromonaphthalene & 44.31 & $\theta \uparrow$ and $\gamma_{l \nu} \downarrow$ as $R \uparrow\left(40^{\circ} \rightarrow 60^{\circ}\right)$ \\
diethylene glycol & 44.68 & \\
ethylene glycol & 47.55 & $\theta \uparrow$ as $R \uparrow\left(67^{\circ} \rightarrow 70^{\circ}\right)$ \\
diiodomethane & 49.98 & slip/stick $\left(88^{\circ} \rightarrow 96^{\circ}\right)$ \\
2,2'-thiodiethanol & 53.77 & slip/stick $\left(68^{\circ} \rightarrow 90^{\circ}\right)$ \\
formamide & 59.08 & formamide dissolved the polymer on contact \\
glycerol & 65.02 & \\
water & 72.70 & \\
\hline
\end{tabular}


Table 5.7: Comparison between the advancing contact angles (deg.) measured by ADSA-P and a goniometer on the poly(propene-alt- $N$-( $n$-propyl)maleimide) surface

\begin{tabular}{|c|c|c|}
\hline \multirow[t]{2}{*}{ liquid } & \multicolumn{2}{|c|}{ poly(propene-alt $-N$-( $n$-propyl)maleimide) } \\
\hline & ADSA-P & goniometer \\
\hline 1-bromonaphthalene & 30.75 & 33.0 \\
\hline diethylene glycol & $\theta \uparrow$ as $R \uparrow\left(45^{\circ} \rightarrow 49^{\circ}\right)$ & 51.0 \\
\hline ethylene glycol & $\theta \uparrow$ as $R \uparrow\left(54^{\circ} \rightarrow 57^{\circ}\right)$ & 58.5 \\
\hline diiodomethane & slip/stick $\left(45^{\circ} \rightarrow 80^{\circ}\right)$ & 95.0 \\
\hline 2,2'-thiodiethanol & 54.04 & 55.5 \\
\hline formamide & $\theta \downarrow$ and $\gamma_{h} \downarrow$ as $R \uparrow\left(62^{\circ} \rightarrow 54^{\circ}\right)$ & 50.0 \\
\hline glycerol & 70.67 & 70.0 \\
\hline water & 77.51 & 75.0 \\
\hline
\end{tabular}


Table 5.8: Comparison between the advancing contact angles (deg.) measured by ADSA-P and a goniometer on the poly(propene-alt- $N$-( $n$-hexyl)maleimide) surface

\begin{tabular}{|c|c|c|}
\hline \multirow[t]{2}{*}{ liquid } & \multicolumn{2}{|c|}{ poly(propene-alt- $N$-( $n$-hexyl)maleimide) } \\
\hline & ADSA-P & goniometer \\
\hline cis-decalin & 28.81 & 28.0 \\
\hline 2,5-dichlorotoluene & $\theta \uparrow$ as $R \uparrow\left(29^{\circ} \rightarrow 37^{\circ}\right)$ & 60.0 \\
\hline ethyl cinnamate & $\theta \downarrow$ and $\gamma_{l \nu} \downarrow$ as $R \uparrow\left(66^{\circ} \rightarrow 56^{\circ}\right)$ & 67.0 \\
\hline dibenzylamine & $\theta \downarrow$ and $R \uparrow\left(39^{\circ} \rightarrow 34^{\circ}\right)$ & 41.0 \\
\hline DMSO & $\theta \uparrow$ and $\gamma_{v} \downarrow$ as $R \uparrow\left(40^{\circ} \rightarrow 65^{\circ}\right)$ & 58.0 \\
\hline 1-bromonaphthalene & $\theta \uparrow$ and $\gamma_{l \nu} \downarrow$ as $R \uparrow\left(40^{\circ} \rightarrow 60^{\circ}\right)$ & 75.0 \\
\hline diethylene glycol & 61.04 & 59.5 \\
\hline ethylene glycol & $\theta \uparrow$ as $R \uparrow\left(67^{\circ} \rightarrow 70^{\circ}\right)$ & 69.0 \\
\hline diiodomethane & slip/stick $\left(88^{\circ} \rightarrow 96^{\circ}\right)$ & 98.0 \\
\hline 2,2'-thiodiethanol & slip/stick $\left(68^{\circ} \rightarrow 90^{\circ}\right)$ & 91.0 \\
\hline formamide & formamide dissolved the polymer on contact & $-\ldots$ \\
\hline glycerol & 82.83 & 80.5 \\
\hline water & 92.26 & 92.0 \\
\hline
\end{tabular}




\section{CHAPTER 6}

\section{UNIVERSALITY OF THE CONTACT ANGLE PATTERNS}

It should be noted that, in addition to ADSA-P, the capillary rise at a vertical plate technique $[100,101,103]$ is also suitable for the determination of low-rate dynamic contact angles. Since the capillary rise at a vertical plate technique has been automated [103] to perform various dynamic advancing and receding contact angle measurements at immersion speeds ranging from 0.008 to $0.9 \mathrm{~mm} / \mathrm{min}$, measurements can be and have been performed $[100,101]$ under dynamic conditions closely resembling those in the ADSA-P experiments. Only contact angle results meeting the stipulations established in connection with ADSA in Chapter 5 will be considered below.

In several instances, the capillary rise technique has been employed on relatively inert and well-prepared surfaces: FC-721-coated mica [101], heat-pressed Teflon FEP [101], hexatriacontane [51,104], and cholesteryl acetate $[51,105]$. The FC-721 and FEP surfaces were prepared, respectively, by a dip-coating technique and a heat-pressing technique [68]. Hexatriacontane and cholesteryl acetate were produced by vapour deposition in a vacuum $[51,104,105]$; the surface quality was found to be so good that there was no contact angle hysteresis when water was used. It has been found that the contact angles determined from ADSA-P and the capillary rise at a vertical plate technique are virtually identical for the same solid-liquid 
systems $[100,101]$.

Figure 6.1 illustrates the dynamic contact angles for various polymers measured by the capillary rise technique and those by ADSA-P in Chapter 5: FC-721-coated mica [101], FC-722-coated mica [95] and -coated silicon wafer [106], FC-725coated silicon wafer [107], heat-pressed Teflon FEP [101], hexatriacontane [51,104], cholesteryl acetate [51,105], poly(propene-alt- $N$-( $n$-hexyl)maleimide) [77,108], PnBMA [109], PS [110], poly(styrene-(hexyl/10-carboxydecyl 90:10)-maleimide) [111], P(MMA/nBMA) [112], poly(propene-alt- $N$-(n-propyl)maleimide) $[77,108]$, PMMA [113], and poly(propene-alt- $N$-methylmaleimide) [106]. It can be seen that the values of $\gamma_{l \nu} \cos \theta$ change systematically with $\gamma_{l \nu}$ in a very regular fashion, from the hydrophobic hydrocarbon surfaces to the hydrophilic poly(propene-alt-Nmethylmaleimide) surface, and that the patterns are independent of the experimental technique on the one hand and liquid structure on the other. The regularity of the contact angle patterns is remarkable. Thus, one can change the contact angle, and because of Young's equation, the solid-liquid interfacial tension, by the simple mechanism of changing either the liquid or the solid. Obviously, these experimental results suggest that $\gamma_{\nu} \cos \theta$ depends only on $\gamma_{\nu}$ and $\gamma_{s \nu}$. Because of Young's equation, $\gamma_{s l}$ can be expressed as a function of only $\gamma_{L \nu}$ and $\gamma_{s v}$, allowing a search for an equation in the form

$$
\gamma_{s l}=F\left(\gamma_{t v}, \gamma_{s v}\right)
$$

This is called an equation-of-state relation as a relation involving intensive 
properties [114]. It should be noted that equations of this form have been in the literature for a long time, e.g., Antonow's [115] and Berthelot's [116] rules.

In the next section, several reasons for the minor scatter of some data points along $\gamma_{l \nu} \cos \theta$ vs. $\gamma_{l \nu}$ curves will be addressed.

\subsection{Reasons of deviation from smoothness}

As Figure 6.1 stands, on one and the same solid surface, there are minor deviations of some contact angle data from the curves and one might wish to argue that intermolecular forces could still have some independent effects on the contact angles. This question will be addressed in this section, by focusing on the contact angle data of three chemically similar methacrylate polymers.

Figure 6.2 shows a plot of $\gamma_{\nu} \cos \theta$ vs. $\gamma_{\nu}$ curves for the PnBMA, $\mathrm{P}(\mathrm{MMA} / n \mathrm{BMA})$, and PMMA polymers. As can be seen in this figure, there are slight deviations of the data points from the curves; however, it is not apparent that these deviations are systematic and are caused by any independent effects of intermolecular forces on the contact angles: For example, in the case of 3pyridylcarbinol with $\gamma_{l v}$ of about $48.0 \mathrm{~mJ} / \mathrm{m}^{2}$, the data point on the PMMA curve appears to be slightly higher, while the point on the $\mathrm{P}(\mathrm{MMA} / n \mathrm{BMA})$ is slightly lower and the one for PnBMA slightly higher again. There is no evidence for any systematic variation, for this and other liquids. Clearly, if there were a deviation due to specific intermolecular forces, one would, at the most, expect a monotonous change of the deviation when going from PMMA to $\mathrm{P}(\mathrm{MMA} / n \mathrm{BMA})$ to $\mathrm{P} n \mathrm{BMA}$. 
To keep matters in perspective, it has to be realized that the curves in Figure 6.2 would have to be considered smooth if a conventional goniometer technique with $\pm 2^{\circ}$ contact angle accuracy would have been used. Further, the fact that an equilibrium spreading pressure $\pi_{e}$

$$
\pi_{e}=\gamma_{s}-\gamma_{s v}
$$

of as low as $1 \mathrm{~mJ} / \mathrm{m}^{2}$ would easily contribute to such a variation should not be overlooked: On one and the same solid surface, $\gamma_{s v}$ is expected to be constant when vapour adsorption is negligible; however, if vapour adsorption of liquids does play a role, then $\gamma_{s v}$ can be different from liquid to liquid on one and the same solid surface. The answer to the question of whether or not vapour adsorption has an effect on the contact angle patterns in Figure 6.2 (and similar figures) would require general criteria to distinguish this from all other effects, such as swelling of the solid surface. As Figure 6.2 stands, it does not appear that vapour adsorption plays a significant role in the contact angles presented here; otherwise, one would expect such an effect to manifest itself as random variations of the contact angles, rather than the remarkable regularity. Nevertheless, minor adsorption which causes the equilibrium spreading pressure $\pi_{e}$ to vary by as much as $1 \mathrm{~mJ} / \mathrm{m}^{2}$ has been considered possible for low-energy solid surfaces [117].

Although the liquids and solids (polymers) selected in this thesis are of high purity, e.g. > 99\% (cf. Tables 3.1 and 5.1), minute impurities presented in either the liquids or the solids are unavoidable and finding liquids and solids (polymers) which 
contain absolutely no impurities is unrealistic. There is no guarantee that such matters could not have caused the apparent minor deviations of the points in Figure 6.2. It is worth mentioning that even very minor swelling of the polymer or creeping of the liquid could easily introduce a slight deviation of some points away from such curves. Therefore, only after considering all such possibilities would the need arise for explanations in terms of direct effects of intermolecular forces [45]. 


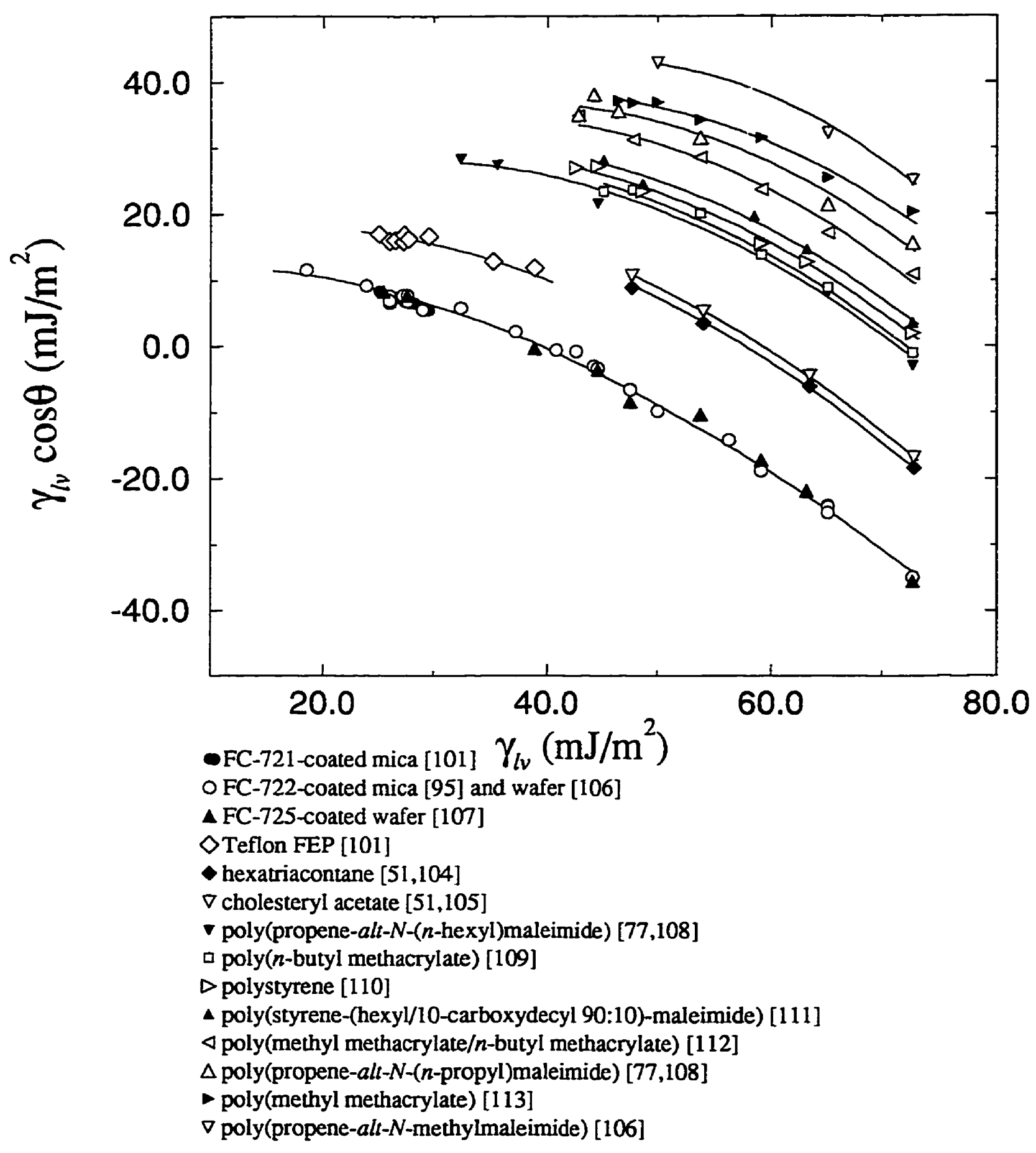

Figure 6.1 $\gamma_{l \nu} \cos \theta$ vs. $\gamma_{l \nu}$ for various solid surfaces. 


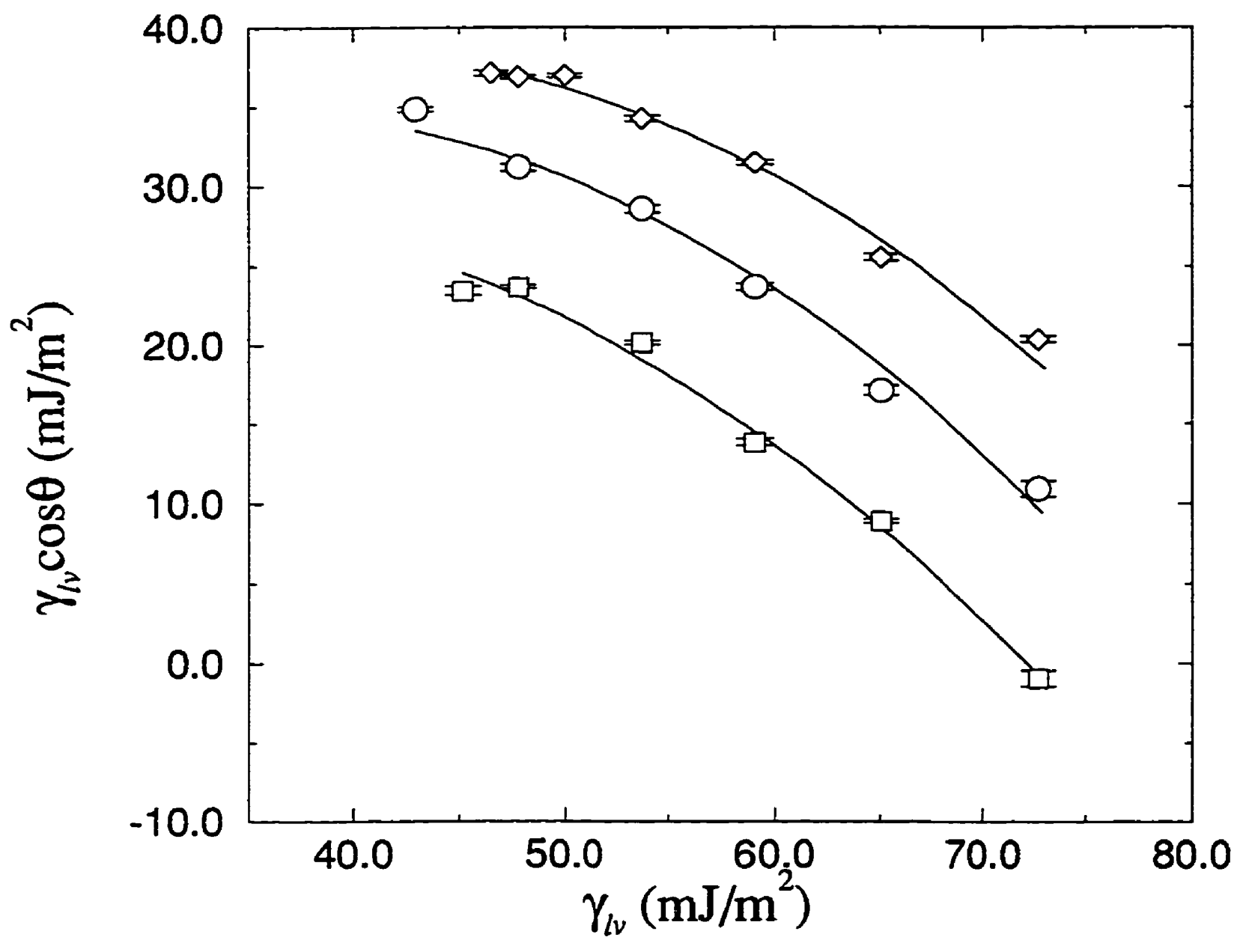

$\square$ poly ( $n$-butyl methacrylate)

Opoly(methyl methacrylate/n-butyl methacrylate)

$\diamond$ poly(methyl methacrylate)

Figure $6.2 \gamma_{l \nu} \cos \theta$ vs. $\gamma_{l \nu}$ for three methacrylate polymer-coated silicon wafer surfaces. The contact angles are dynamic contact angles by ADSA-P. Results suggest that $\gamma_{k} \cos \theta$ changes smoothly with $\gamma_{k}$ for a given solid surface. Changing the solid surface from the hydrophobic PnBMA surface to the relatively hydrophilic PMMA surface and hence the solid surface tensions $\left(\gamma_{s v}\right)$ shifts the curves in a very regular manner. Thus, $\gamma_{l v} \cos \theta$ depends only on $\gamma_{l v}$ and $\gamma_{s v}$; because of Young's equation, $\gamma_{s l}$ is a function of only $\gamma_{l v}$ and $\gamma_{s v}$. 


\section{CHAPTER 7}

\section{CRITERIA FOR CALCULATIONS OF SURFACE ENERGETICS}

In Chapter 5 and Appendices B-I, it has been shown that there exist a large number of contact angle complexities which prevent use of the measurements for energetic calculations. To arrive at the curves shown in Figure 6.1, several assumptions already mentioned in Chapter 1 were used to eliminate the meaningless contact angles. However, there remains one last assumption which has not been used and discussed: the constancy of $\gamma_{s v}$ going from liquid to liquid. It will be apparent in this chapter that such an assumption is indeed needed for energetic calculations; the importance of the various underlying assumptions in the determination of solid surface tensions will be discussed in detail. They will be addressed further in Chapter 8 , in conjunction with the surface tension component approaches $[11,15$ 17].

\subsection{Accepted Assumptions for Calculations of Surface Energetics}

For the sake of ease of reference, the assumptions listed in Chapter 1 are repeated here: 
(1) All approaches rely on the validity and applicability of Young's equation for surface energetics from experimental contact angles.

(2) Surfactant solutions or mixtures of liquids should not be used, since they would introduce complications due to preferential adsorption.

(3) The values of $\gamma_{l v}, \gamma_{s v}$, (and $\gamma_{s l}$ ) are assumed to be constant during the experiment, i.e. there should be no physical or chemical reaction between a solid and a liquid.

(4) The liquid surface tensions of the testing liquids should be higher than the anticipated solid surface tension.

(5) The values of $\gamma_{s v}$ going from liquid to liquid are also assumed to be constant, i.e. independent of the liquids used.

(1) It has to be realized that Young's equation

$$
\gamma_{l \nu} \cos \theta_{Y}=\gamma_{s v}-\gamma_{s l}
$$

is the only thermodynamic relation to interrelate the three surface tensions, $\gamma_{l v}, \gamma_{s v}$, $\gamma_{s l}$, with the experimental contact angle $\theta$. Therefore, the expectation of the applicability of Young's equation has to be fulfilled. As in the case of slip/stick of the three-phase contact line shown in Chapter 5 (Figure 5.9), Young's equation cannot be applicable: Since $\gamma_{l v}, \gamma_{s v}$, and $\gamma_{s l}$ are material properties and are expected to be constant, Young's equation implies a unique contact angle. Thus, contact 
angles from slip/stick of the three-phase contact line have to be discarded.

(2) Obviously, contact angle interpretation of surfactant solutions or mixtures of liquids is expected to be more complicated than that of the pure liquid. It has been found that if one measures contact angles of mixture solutions on one and the same solid surface, scatter, or patterns different from those in plots of the type in Figure 6.1 would arise [118]. Thermodynamically, such systems have three degrees of freedom [72-75]. The additional degree of freedom comes from the effect of an additional liquid component. While Young's equation may still be applicable in this case, no contact angle approach as yet allows the determination of solid surface tensions from such angles. Therefore, pure liquids are always used in contact angle measurements. However, even if this is the case, one has to ensure that $\gamma_{k}$ remains constant during the experiment. In an example shown earlier in Chapter 5 (Figure 5.7), polymer dissolution occurs, causing the liquid surface tension to differ from that of the pure liquid. This reflects the fact that the presumed pure liquid has been changed to a mixture of liquid/polymer solution. If a conventional goniometer technique had been used instead, the change in the operative $\gamma_{l \nu}$ might not be detected. Such goniometer measurements would inevitably reflect a solid-liquid system with a changed $\gamma_{l v}$, rather than the $\gamma_{l \nu}$ of the presumed pure liquid. Thus, contact angle interpretation from such angles would be in error. 
(3) If a chemical/physical reaction takes place, any of $\gamma_{l v}, \gamma_{s v}$, and $\gamma_{s l}$ could change during the experiment, and because of Young's equation (1.1), the contact angle $\theta$ would also change. Therefore, changes in $\theta$ suggest that at least one of $\gamma_{l v}$, $\gamma_{s v}$, and $\gamma_{s l}$ is changing. In an example shown in Chapter 5 (Figure 5.8), the contact angle increases as the drop front advances with essentially constant $\gamma_{l v}$. While there is no reason to question the applicability of Young's equation, $\gamma_{s l}$ is suspected to change: from Young's equation, if $\gamma_{l v}$ and $\gamma_{s v}$ are constant, changes in $\theta$ must be a consequence of a change in $\gamma_{s l}$. While such cases might be very interesting in a different context, they have to be discarded because our goal is to deduce solid surface tension from the simpliest possible situations.

(4) If $\gamma_{l \nu}=\gamma_{s v}$ or $\gamma_{l v}<\gamma_{s v}$, complete wetting occurs, or a change in $\gamma_{s v}$ induced by the solid/liquid contact (autophobicity). In order to illustrate this, a plot of $\gamma_{l} \cos \theta$ vs. $\gamma_{k v}$ is shown in Figure 7.1 for a PET surface. In this figure, liquids having surface tensions less than that of the anticipated PET surface tension are included, i.e. $\gamma_{l \nu}<$ $\gamma_{s \nu}$. As can be seen, the values of $\gamma_{l \nu} \cos \theta$ increase as $\gamma_{l \nu}$ decreases, reaching a global maximum. Further decrease in $\gamma_{l \nu}$ causes the data point to fall on a straight line. Thus, the liquid surface tensions of the testing liquids should be higher than that of the anticipated solid surface tension, by the appropriate choice of the liquids. Another possible effect of $\gamma_{l \nu}<\gamma_{s v}$ is liquid adsorption, which could cause $\gamma_{s v}$ to be different from liquid to liquid (see Chapter 6, section 6.1). Therefore, the testing liquids used in this study were selected to fulfill the condition $\gamma_{L}>\gamma_{s \nu}$. 
(5) One last assumption which has not been used to identify meaningful contact angles in Chapter 5 and Appendices B-I is the assumption of the constancy of $\gamma_{s v}$ going from liquid to liquid. This assumption is needed for reasons of procedure. Between the three variables, $\gamma_{l v}, \gamma_{s v}$, and $\gamma_{s l}$, only $\gamma_{l v}$ is measurable; an additional measurable quantity is, however, the contact angle $\theta$ which can be interrelated to these quantities by Young's equation. Therefore, it is impossible to study the direct effect of changing $\gamma_{l \nu}$ on a second (non-measurable) quantity, $\gamma_{s l}$, through $\theta$, unless the third (non-measurable) quantity, $\gamma_{s v}$, is kept constant. This can be readily achieved by measuring contact angles of different liquids on one and the same solid surface. Thus, $\gamma_{s v}$ has to be assumed constant from one liquid to the next, along the curves in plots of the type in Figure 6.1. Otherwise, interpretation of the data showing implicitly the effect of changes of $\gamma_{l v}$ on $\gamma_{s l}$ would not be possible. The assumption of constant $\gamma_{s \nu}$ will be used to deduce solid surface tensions from contact angles in Chapter 8.

\subsection{Experimental Criteria}

The experimental results in Chapter 5 illustrate that there are three apparent contact angle complexities;

(1) slip/stick of the three-phase contact line;

(2) contact angle increases/decreases as the drop front advances; and 
(3) liquid surface tension changes as the drop front advances.

These contact angles should not be used for the determination of solid surface tensions. With respect to the first point, slip/stick of the three-phase contact line indicates that Young's equation is not applicable. Increase/decrease in the contact angle and decrease in the liquid surface tension as the drop front advances violate the expectation of no physical/chemical reaction. Therefore, when the experimental contact angles and liquid surface tensions are not constant, they should be disregarded. However, the question arises as to whether the reverse is true, i.e. whether constancy of $\theta$ and $\gamma_{h}$ in the dynamic measurements described in Chapter 5 will always guarantee that the above contact angle assumptions are fulfilled. This question will be explored below.

In practice, many solids are not truly inert with respect to many liquids; even swelling of fluorocarbon surfaces by alkanes has been reported [54]. For example, if swelling of a solid surface occurs quickly upon the contact with a liquid as the drop front advances, $\theta$ will change to reflect the changed energetics. If the time scale of such an effect is much less than that of the contact angle measurements, $\theta$ could reflect the changed $\gamma_{s l}$. This might result in a rather constant contact angle, although the energetics would have changed. If this mechanism would not affect the liquid, $\gamma_{l v}$ would remain constant, i.e. be independent of time. However, such constant contact angles would reflect only the energetics of the already swollen solid surface. Further, one and the same solid surface could swell differently by different test 
liquids in an unknown manner. This effect would manifest itself in scatter of the plots of $\gamma_{l \nu} \cos \theta$ vs. $\gamma_{l \nu}$ because

$$
\gamma_{s l} \neq F\left(\gamma_{k v}, \gamma_{s v}\right)
$$

In this case, a systematic study of the effect of surface energetics are not possible since the energetics have changed in an unknown, more complex manner. Obviously, such angles would have to be disregarded even if the measured liquid surface tensions and contact angles are constant because the assumption of no chemical/physical reaction would have been violated. Unfortunately, the strategies employed here will not allow identification of such matters, and it remains a possibility that such effects contribute to the minor deviations of some data points from a smooth curve.

An example for this more complex pattern is self-assembled monolayers (SAMs), which have been widely used to produce monolayer surfaces of different chemical compositions and wettabilities $[119,120]$. For this type of surfaces, it is expected that penetration of liquids into the SAMs is inevitable; different liquids would have different effects on such surfaces. Because penetration of liquid is expected to occur almost instantly as the liquid contacts the solid, the observed advancing angle might reflect a $\gamma_{s l}$ value caused by a modification of the solid surface.

Low-rate dynamic contact angles of water on a octadecanethiol $\left(\mathrm{HS}\left(\mathrm{CH}_{2}\right)_{17} \mathrm{CH}_{3}\right) \mathrm{SAM}$ on a gold substrate are shown in Figure 7.2. It can be seen 
that the advancing contact angles and liquid surface tension are quite constant. A plot of $\gamma_{l \nu} \cos \theta$ vs. $\gamma_{l \nu}$ of various liquids for this surface is shown in Figure 7.3 (solid symbols). These contact angles were determined dynamically by ADSA-P in another study, not related to this thesis $[99,121]$. Contrary to the patterns shown in Figures 2.1, 5.4, 5.10-5.17, 6.1, and 6.2, no smooth curve results in Figure 7.3. The reason for the difference in pattern is believed to be the effect of liquid penetration into the monolayer SAMs. Such mechanism is believed to be absent or negligible for the relatively thick polymer films used in Chapter 5.

It is instructive to compare this contact angle pattern with that obtained from the hexatriacontane surface (also plotted in Figure 7.3). Since both surfaces are expected to consist entirely of $\mathrm{CH}_{3}$ groups, their solid surface tensions should be similar; one would then expect the two contact angle patterns to be essentially the same. However, the hexatriacontane data follow a smooth curve. From the point of view of surface energetics, the only difference for the two surfaces is that the SAM is a monolayer, whereas the hexatriacontane is a relatively thick crystallized surface. Obviously, it is the effect of liquid penetration and possible contact with the substrate of the SAMs which causes $\gamma_{s i}$ to change in a pattern different from that which would prevail in the absence of liquid penetration. In this case, there is no reason to question the validity and applicability of Young's equation; however, different liquids are expected to penetrate differently even on one and the same solid surface (in an unknown manner) and hence the energetics could be very different from liquid to liquid. Since nothing is known about the changed energetics and the 
systems have violated the assumption of no physical reaction, use of these contact angles in any contact angle approach naively could be meaningless [122]. Although the interpretation of contact angles on SAMs in terms of surface energetics could be misleading, wettability studies of SAMs can be very interesting [123]. 


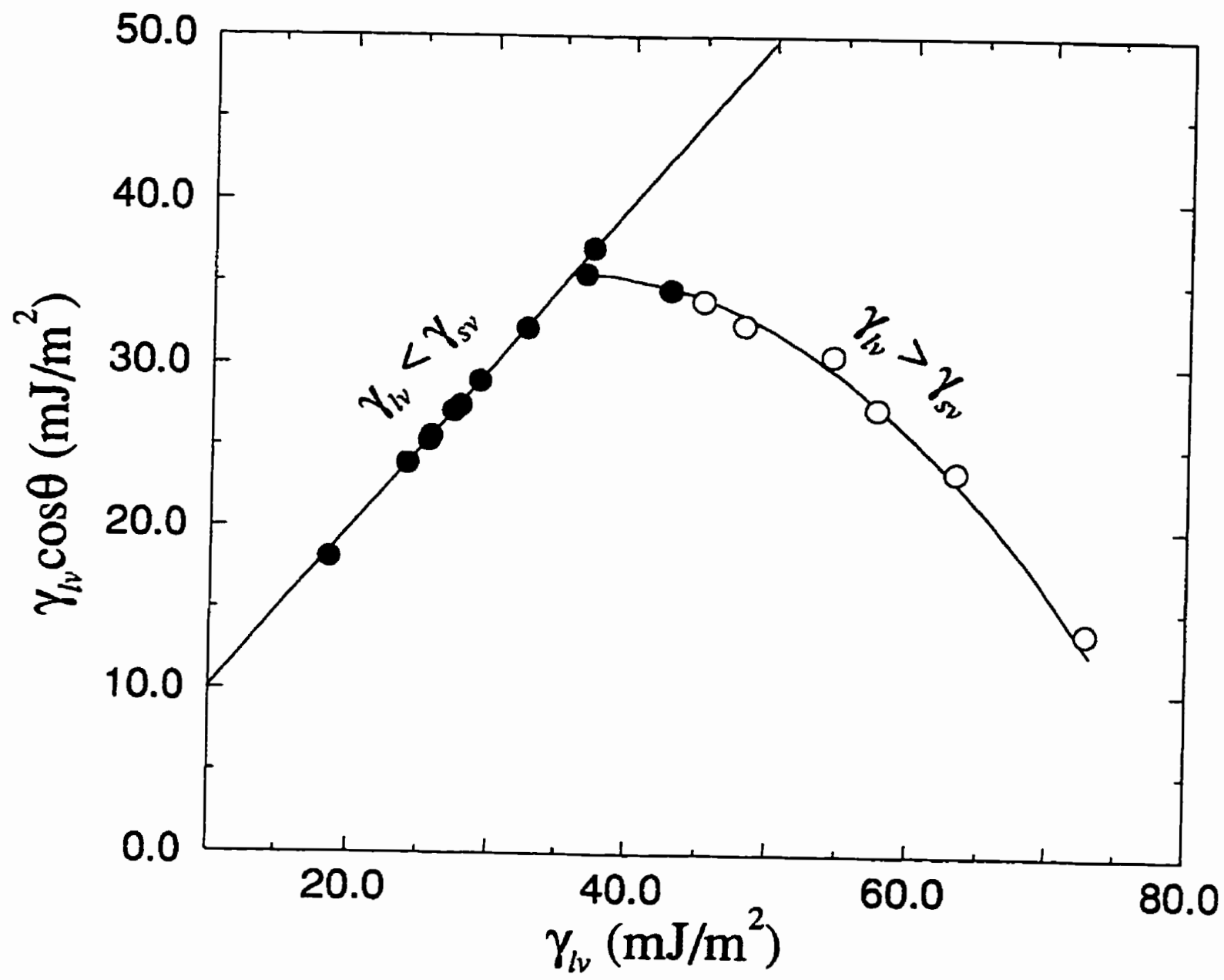

OPET [68]

OPET [21]

Figure 7.1 $\gamma_{l v} \cos \theta$ vs. $\gamma_{l}$ for a PET surface. 
water on

octadecanethiol $\left(\mathrm{HS}\left(\mathrm{CH}_{2}\right)_{17} \mathrm{CH}_{3}\right) \mathrm{SAM}$ on gold

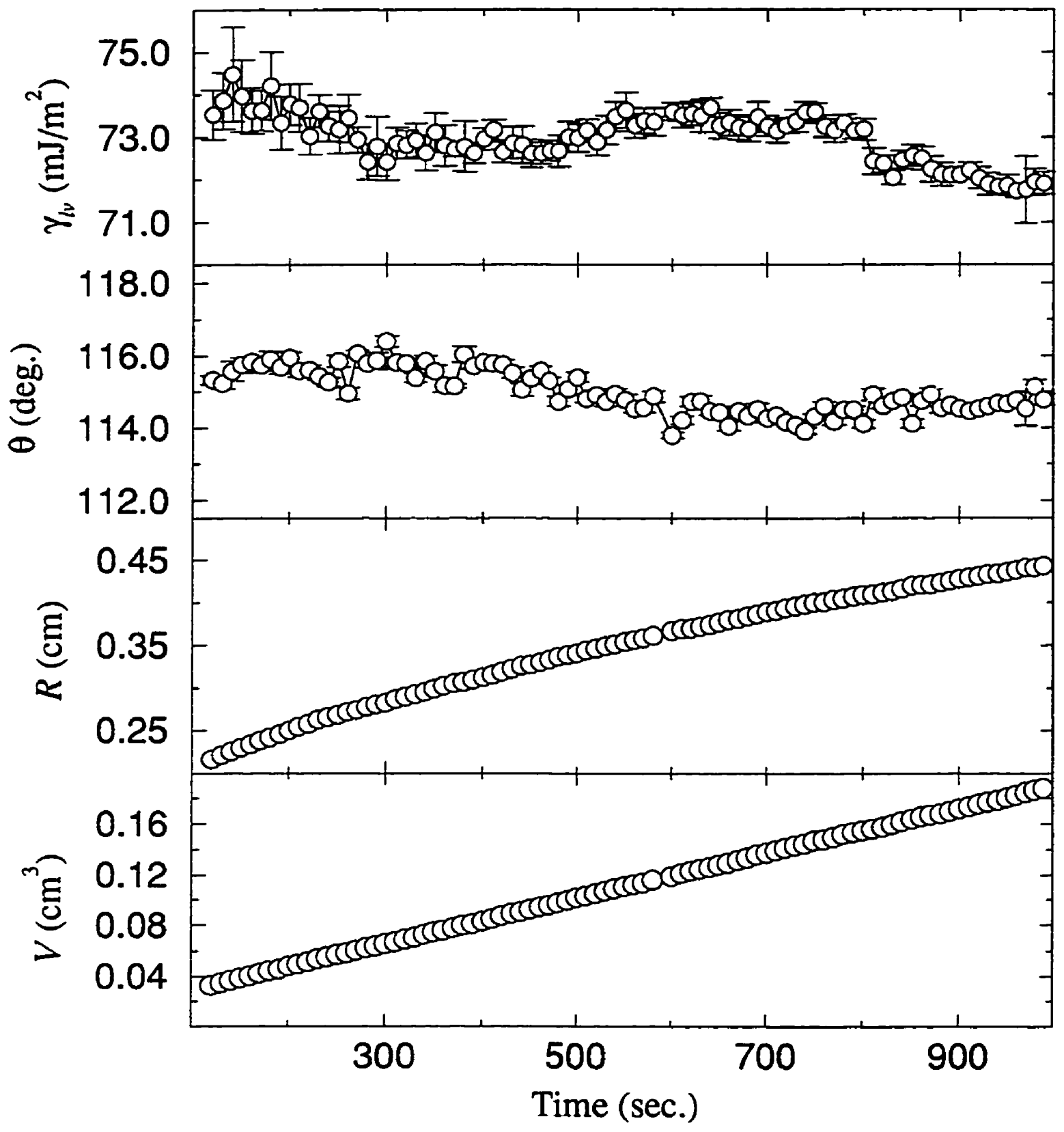

Figure 7.2 Low-rate dynamic contact angles of water on a octadecanethiol ( $\left.\mathrm{HS}\left(\mathrm{CH}_{2}\right) \mathrm{CH}_{3}\right) \mathrm{SAM}$ on gold substrate. 


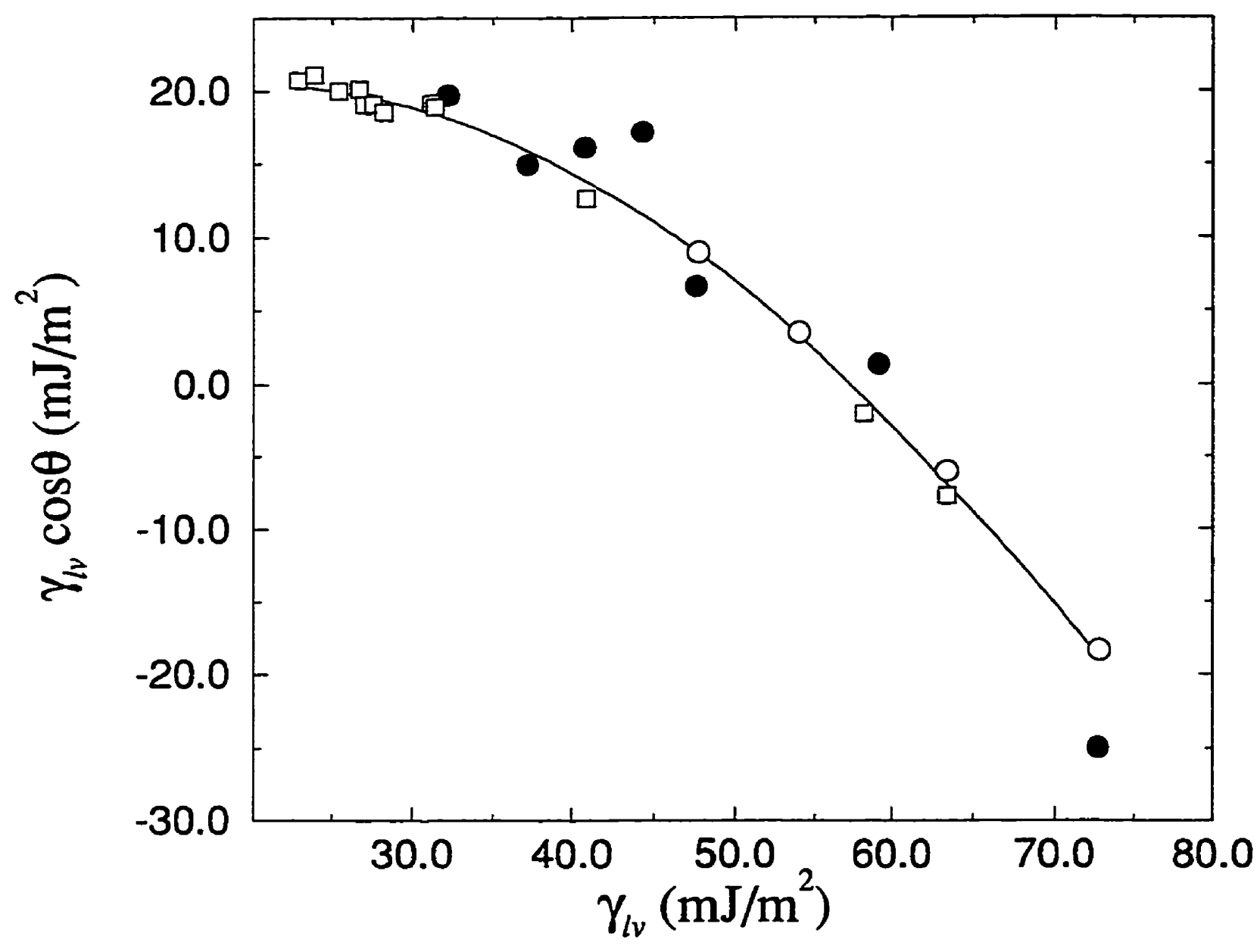

Ooctadecanethiol $\left(\mathrm{HS}\left(\mathrm{CH}_{2}\right)_{17} \mathrm{CH}_{3}\right)$ SAM on gold पhexatriacontane [125], from Table 9.1

O hexatriacontane [51,104], from Table 8.4

Figure $7.3 \gamma_{l \nu} \cos \theta$ vs. $\gamma_{l \nu}$ for a octadecanethiol $\left(\mathrm{HS}\left(\mathrm{CH}_{2}\right) \mathrm{CH}_{3}\right)$ SAM on a gold substrate and a hexatriacontane surface. 


\section{CHAPTER 8}

\section{CONTACT ANGLE INTERPRETATION}

The calculation of solid surface tension $\gamma_{s v}$ from the contact angle of a liquid of surface tension $\gamma_{l v}$ starts with Young's equation, Eq.(1.1). Of the four quantities in Young's equation, only $\gamma_{k}$ and $\theta$ are readily measurable. Thus, in order to determine $\gamma_{s v}$, further information is necessary. Conceptually, an obvious approach is to seek one more relation among the parameters of Eq.(1.1), such as an equation-of-state relation, of the form of Eq.(2.3) which is now known to exist from experimental facts. The simultaneous solution of Eqs.(1.1) and (2.3) would solve the problem.

Historically, the interpretation of contact angles in terms of solid surface energetics started with the pioneering work of Zisman and co-workers [10,124-131]; the key observation they made was that for a given solid the measured contact angles did not vary randomly as the liquid was varied; rather, $\cos \theta$ changed smoothly with the liquid surface tension $\gamma_{l v}$ within a band in a fashion that suggested a straight-line relationship.

Subsequent to Zisman's work, two major schools of thought evolved: one is the surface tension component approach [11,15-17]; the other is the equation of state approach [12-14]. The former approach stipulates that $\gamma_{s l}$ depends not only on $\gamma_{v}$ and $\gamma_{s v}$, but also on the specific intermolecular forces; the latter approach is based on an equation-of-state relation which has been shown to exist from the experimental 
results in Figures $2.1,5.4,5.10-5.17,6.1$, and 6.2. In order to test the validity of each approach, accurate experimental contact angle data are required.

From the experimental results shown in Figures 2.1, 5.4, 5.10-5.17, 6.1, and 6.2, the curves for all solid surfaces with very different chemical properties are effectively very smooth, suggesting that intermolecular forces do not have any additional and independent effects on the contact angles. This point has been addressed in Chapters 5 and 6. Thus, the surface tension component approaches contradict these experimental results; nevertheless, they will be briefly discussed and tested in the next section.

\subsection{Surface Tension Component Approaches}

\subsubsection{Fowkes approach}

The approach of surface tension components was pioneered by Fowkes [11]. He postulated that the total surface tension can be expressed as a sum of different surface tension components, each of which arises due to a specific type of intermolecular forces:

$$
\gamma=\gamma^{d}+\gamma^{h}+\gamma^{d i}+\cdots
$$

where $\gamma, \gamma^{d}, \gamma^{h}$, and $\gamma^{d i}$ are, respectively, the total surface tension, dispersive surface tension component, and surface tension components due to hydrogen and dipole-dipole bonding. Equation (8.1) is often rearranged into 


$$
\gamma=\gamma^{d}+\gamma^{n}
$$

i.e. the total surface tension $\gamma$ is a sum of only the dispersive $\gamma^{d}$ and non-dispersive $\gamma^{n}$ surface tension components. The former is claimed to result from molecular interaction due to London forces, the latter from all other interactions due to nonLondon forces. A geometric mean relationship was postulated both of the solidliquid and liquid-liquid interfacial tensions:

$$
\gamma_{12}=\gamma_{1}+\gamma_{2}-2\left[\gamma_{1}^{d} \gamma_{2}^{d}\right)^{1 / 2}
$$

For solid-liquid systems, combining Eq.(8.3) with Young's equation yields

$$
\gamma_{l} \cos \theta_{Y}=-\gamma_{l}+2\left[\gamma_{s}^{d} \gamma_{l}^{d}\right]^{1 / 2}
$$

Typically, experimental contact angles of different liquids with known $\gamma_{l}^{d}$ on a dispersive solid surface $\left(\gamma_{s}=\gamma_{s}^{d}\right)$ are employed to determine the surface tension of a solid. In these procedures, the applicability of Young's equation and the constancy of solid surface tension from liquid to liquid stated in Chapter 7 (section 7.1 ) are, obviously, implied.

The Fowkes approach, Eq.(8.3) and hence Eq.(8.4), can be easily tested using the contact angle results in Chapter 5 (Table 5.2). For simplicity, two liquids of nearly the same surface tension but very different intermolecular forces are selected on the FC-722-coated mica surface; the polar (non-dispersive) liquid is 1-pentanol $\left(\gamma_{l}=26.0 \mathrm{~mJ} / \mathrm{m}^{2}\right)$ and the dispersive one is trans-decalin $\left(\gamma_{l}=\gamma_{l}^{d}=27.2 \mathrm{~mJ} / \mathrm{m}^{2}\right)$. 
From Eq.(8.4), the $\gamma_{s}\left(=\gamma_{s}^{d}\right)$ value determined using the contact angle $\left(73.4^{\circ}\right)$ of trans-decalin is $11.2 \mathrm{~mJ} / \mathrm{m}^{2}$. Since 1-pentanol is a polar liquid, $\gamma_{l}^{d}$ is expected to be very different (smaller) than the total surface tension $\gamma_{l}$; assuming for the moment that dispersion force contributes $75 \%$ to the total surface tension of 1 -pentanol. This corresponds to $\gamma_{l}^{d}=19.5 \mathrm{~mJ} / \mathrm{m}^{2}$ for $\gamma_{l}=26.0 \mathrm{~mJ} / \mathrm{m}^{2}$. From the experimental contact angle $\left(73.0^{\circ}\right)$ of 1-pentanol, Eq.(8.4) predicts the $\gamma_{s}$ value to be $14.5 \mathrm{~mJ} / \mathrm{m}^{2}$. This value is almost $30 \%$ larger than that calculated using trans-decalin; a $\gamma_{s}$ value of $11.2 \mathrm{~mJ} / \mathrm{m}^{2}$ would imply $\gamma_{l}^{d}$ of 1-pentanol to be $25.2 \mathrm{~mJ} / \mathrm{m}^{2}$. This is clearly absurd: 1-pentanol would have to be classified as a non-polar liquid, i.e. $\gamma_{l} \approx \gamma_{l}^{d}$. Similar calculations can be performed for other dispersive/non-dispersive liquid pairs, with similar results. This result simply illustrates the fact that the perceived "surface tension components" in Fowkes' sense do not reflect physical reality. In principle, this is obvious from the experimental results that $\gamma_{l} \cos \theta$ changes smoothly with $\gamma_{l}$, independent of intermolecular forces and liquid structure. Thus, the basic postulate of the Fowkes approach is false and any generalization of this approach must suffer from the same deficiency.

\subsubsection{Owens-Wendt-Kaelble approach}

Owens and Wendt [15] extended Fowkes' concept to cases where both dispersion and hydrogen bonding forces may operate. They regarded the surface tension as being composed of two components such that 


$$
\gamma=\gamma^{d}+\gamma^{h}
$$

where $\gamma^{h}$ denotes the component of surface tension due to both hydrogen bonding and dipole-dipole interactions. They postulated

$$
\gamma_{s l}=\gamma_{s}+\gamma_{l}-2 \sqrt{\gamma_{s}^{d} \gamma_{l}^{d}}-2 \sqrt{\gamma_{s}^{h} \gamma_{l}^{h}}
$$

Combining this equation with Young's equation yields

$$
\gamma_{l}\left(1+\cos \theta_{Y}\right)=2 \sqrt{\gamma_{s}^{d} \gamma_{l}^{d}}+2 \sqrt{\gamma_{s}^{h} \gamma_{l}^{h}}
$$

Nearly at the same time, Kaelble [78] also published a very similar equation in terms of dispersion and polar forces. Thus, Eq.(8.7) is often called the Owens-WendtKaelble equation.

Clearly, the applicability of Young's equation discussed in Chapter 7 (section 7.1) is implied in Eq.(8.8). Since Eq.(8.8) contains two unknowns ( $\gamma_{s}^{d}$ and $\left.\gamma_{s}^{h}\right)$ of the solid, it is suggested to use contact angle measurements of at least two different liquids on one and the same solid surface, by solving two simultaneous equations. Such procedures also imply constancy of the solid surface tension from liquid to liquid; if the operative solid surface tension is not constant from one liquid to the next, simultaneous solution of different equations (from contact angles of different liquids) would be meaningless.

Equation (8.8) can be easily tested using the contact angles of trans-decalin and 1-pentanol on the FC-722 surface (in Table 5.2). Assuming the polarity of the (dispersive) FC-722 surface to be unknown and that $\gamma_{l}^{d}$ of 1-pentanol to be again 
$19.5 \mathrm{~mJ} / \mathrm{m}^{2}$, two simultaneous equations can be used to determine the two unknowns $\left(\gamma_{s}^{d}\right.$ and $\left.\gamma_{s}^{h}\right)$ from the experimental contact angles of 1-pentanol and trans-decalin. Equation (8.8) predicts $\gamma_{s}^{d}$ and $\gamma_{s}^{h}$ to be, respectively, $11.2 \mathrm{~mJ} / \mathrm{m}^{2}$ and $0.6 \mathrm{~mJ} / \mathrm{m}^{2}$. Since diiodomethane is claimed to be a dispersive liquid $[16,17]\left(\gamma_{l}=\gamma_{l}^{d}=50.0\right.$ $\left.\mathrm{mJ} / \mathrm{m}^{2}\right)$ and water is a non-dispersive liquid [11] $\left(\gamma_{l}=72.7 \mathrm{~mJ} / \mathrm{m}^{2}\right.$ and $\gamma_{l}^{d}=21.8$ $\mathrm{mJ} / \mathrm{m}^{2}$ ), two additional simultaneous equations can be obtained by insertion of the experimental contact angles from Table 5.2. This procedure yields $\gamma_{s}^{d}$ and $\gamma_{s}^{h}$ to be $8.1 \mathrm{~mJ} / \mathrm{m}^{2}$ and $2.8 \mathrm{~mJ} / \mathrm{m}^{2}$, respectively. Clearly, different choices of the liquid pairs yield different surface tension components of the solid surface: if nothing were known about the dispersive property of the FC-722 surface, Eq.(8.8) would have predicted this dispersive surface to be non-dispersive; the relative magnitudes would depend on the choice of the liquid pairs. Similar calculations can be performed for other pairs of liquids, with similar results.

\subsubsection{Lifshitz - van der Waals / Acid-Base (van Oss) Approach}

The Lifshitz - van der Waals / acid-base (van Oss) approach $[16,17]$ was claimed to be a generalization of the Fowkes approach, by considering perceived acid-base interactions at the interface. van Oss et al. divided the surface tension into different perceived components, i.e. the so-called Lifshitz-van der Waals $(L W)$, acid $(+)$, and base (-) components, such that the total surface tension is given by 


$$
\gamma_{i}=\gamma_{i}^{L W}+2 \sqrt{\gamma_{i}^{+} \gamma_{i}^{-}}
$$

where $i$ denotes either the solid or liquid phase. The interfacial tension was postulated both of solid-liquid and liquid-liquid systems as

$$
\gamma_{12}=\gamma_{1}+\gamma_{2}-2\left[\gamma_{1}^{L W} \gamma_{2}^{L W}\right]^{1 / 2}-2\left[\gamma_{1}^{+} \gamma_{2}^{-}\right]^{1 / 2}-2\left[\gamma_{1}^{-} \gamma_{2}^{+}\right]^{1 / 2}
$$

For solid-liquid systems, combining Eq.(8.10) with Young's equation yields

$$
\gamma_{l}\left(1+\cos \theta_{Y}\right)=2\left[\gamma_{l}^{L W} \gamma_{s}^{L W}\right]^{1 / 2}+2\left[\gamma_{l}^{+} \gamma_{s}^{-}\right]^{1 / 2}+2\left[\bar{\gamma}_{l}^{-} \gamma_{s}^{+}\right]^{1 / 2}
$$

Equation (8.11) is often used to determine the solid surface tension components $\left(\gamma_{s}^{L W}, \gamma_{s}^{+}\right.$, and $\left.\overline{\gamma_{s}}\right)$ from contact angles, using three simultaneous equations by inserting properties of calibration liquids. These procedures also imply the applicability of Young's equation and constancy of the solid surface tension from one liquid to the next, as discussed in Chapter 7 (section 7.1). The failure of this approach can be easily illustrated, by employing the postulated liquid surface tension components from van Oss et al. $[16,17]$ and experimental contact angles of liquid triplets; three simultaneous equations of Eq.(8.11) (from contact angles of three different polar liquids) will yield the three unknown solid properties. Table 8.1 illustrates the solid surface tension components of the FC-721-coated mica surface [132]. It can be seen that the calculated $\gamma_{s}$ value varies from -30.0 to $107.0 \mathrm{~mJ} / \mathrm{m}^{2}$, depending on the choice of the liquid triplets; the resulting "surface tension components" vary by a very large margin. However, it was recently suggested [133] 
that at least one non-polar liquid should be used for the above calculations, such as 1-bromonaphthalene. It is the contention of the proponents of this acid-base approach that 1-bromonaphthalene is a non-polar compound. No reason was given for the necessity of including a non-polar liquid. For this reason, the solid surface tension components of the same surface were recalculated using 1bromonaphthalene and shown in Table 8.2. Again, the calculated $\gamma_{s}$ values are not consistent, varying from -35.6 to $9.5 \mathrm{~mJ} / \mathrm{m}^{2}$. If nothing were known about the properties of the non-polar FC-721 surface, and if only a small number of measurements were available, this approach would predict all kinds of different molecular properties: non-polar, monopolar, bipolar acidic and basic as well as "negative" solid and solid-liquid interfacial tensions. The reason that the scatter of the results is not as bad as those in Table 8.1 is due to the use of Berthelot's rule, see later. Clearly, this approach just as erroneous as the earlier surface tension component approaches.

\subsection{Equation of State Approach}

In this and the following sections, an equation of state approach will be discussed, as such a relation has been inferred from the experimental results in Chapters 5 and 6. In the literature, two well-known equation-of-state relations are Antonow's [115] and Berthelot's [116] rules.

\subsubsection{Antonow's Rule}


An old equation of state is that of Antonow [115]. Antonow's rule relates $\gamma_{s t}$ with $\gamma_{b v}$ and $\gamma_{s v}$ for solid-liquid systems in the following simple manner:

$$
\gamma_{s l}=\left|\gamma_{t v}-\gamma_{s v}\right|
$$

This equation, although never having been derived in any fashion, appears in the literature from time to time. Combining this relation with Young's equation gives

$$
\cos \theta_{Y}=-1+2 \frac{\gamma_{s v}}{\gamma_{l v}}
$$

Thus, assuming, for the sake of the argument, the validity of Eq.(8.12), $\gamma_{s v}$ can be determined when $\gamma_{h \nu}$ and $\theta_{Y}$ are known. Once $\gamma_{s v}$ is known, $\gamma_{s l}$ can be found either from Young's equation or from Eq.(8.13).

\subsubsection{Berthelot's (Geometric Mean) Combining Rule}

Another equation-of-state relation can be obtained from the Berthelot combining rule [116]. Unlike Antonow's rule, Berthelot's rule has a theoretical background, based on molecular interactions of like pairs: From the London theory of dispersion $[134,135]$, the long range dispersion energy function for two identical molecules is given by

$$
U_{\mathrm{disp}}=\frac{C_{6}}{r^{6}}
$$

where $C_{6}$ is a negative constant, so that the energy contribution is attractive. A more 
general form [135] of the long range dispersion energy function including electrostatic and induction interactions can be expressed as

$$
U_{\text {disp }}=\frac{C_{6}}{r^{6}}+\frac{C_{8}}{r^{8}}+\frac{C_{10}}{r^{10}}+\cdots
$$

where $C_{8}$ and $C_{10}$ are all negative constants. It can be shown $[134,135]$ that the energy coefficient $C_{6}$ for two identical molecules can be expressed as

$$
C_{6}=-\frac{3}{4} \frac{E_{I} \alpha^{2}(0)}{\left(4 \pi \varepsilon_{0}\right)^{2}}
$$

where $\varepsilon_{0}$ is the permittivity of free space, $\alpha(0)$ is the static polarizability, and $E_{I}$ is the ionization energy.

From Eq.(8.16), the dispersion energy coefficient of a pair of molecules of species $i$ is given by

$$
C_{6}^{i i}=-\frac{3}{4} \frac{E_{I_{i}} \alpha_{i}^{2}(0)}{\left(4 \pi \varepsilon_{0}\right)^{2}}
$$

and similarly, for a pair of molecules of species $j$

$$
C_{6}^{j j}=-\frac{3}{4} \frac{E_{I_{j}} \alpha_{j}^{2}(0)}{\left(4 \pi \varepsilon_{0}\right)^{2}}
$$

It has been shown [135] that the interaction $C_{6}^{i j}$ between two dissimilar molecules $i$ and $j$ can be related by the following expression: 


$$
C_{6}^{i j}=-\frac{3}{2} \frac{E_{I_{i}} E_{I_{j}}}{E_{I_{i}}+E_{I_{j}}} \frac{\alpha_{i}(0) \alpha_{j}(0)}{\left(4 \pi \varepsilon_{0}\right)^{2}}
$$

Because the ionization energies vary only slightly from molecule from molecule, i.e., $E_{I_{i}}=E_{I_{j}}$, the dispersion energy coefficient $C_{6}^{i j}$ of Eq.(8.19) can be written in terms of $C_{6}^{i i}$ and $C_{6}^{j j}$ as

$$
C_{6}^{i j}=\sqrt{C_{6}^{i i} C_{6}^{j j}}
$$

This relation indeed forms the basis of the Berthelot (geometric mean) combining rule [116]:

$$
\varepsilon_{i j}=\sqrt{\varepsilon_{i i} \varepsilon_{j j}}
$$

where $\varepsilon_{i j}$ is the potential energy parameter (well depth) of unlike-pair interactions; $\varepsilon_{i i}$ and $\varepsilon_{j j}$ are the potential energy parameters (well depth) of like-pair interactions.

Thermodynamically, a relation of the free energy of adhesion per unit area of a solid-liquid pair is equal to the work required to separate an unit area of the solidliquid interface [136]:

$$
W_{s l}=\gamma_{l v}+\gamma_{s v}-\gamma_{s t}
$$

From the geometric mean combining rule (i.e. the Berthelot rule, Eq.(8.21)), the free energy of adhesion $W_{s l}$ can be approximated in terms of the free energy of cohesion of the solid, $W_{s s}$, and the free energy of cohesion of the liquid, $W_{l l}$ $[116,135,137,138]$, i.e. 


$$
W_{s l}=\sqrt{W_{l l} W_{s s}}
$$

By the definitions $W_{l l}=2 \gamma_{l}$ and $W_{s s}=2 \gamma_{s v}$, Eq.(8.23) becomes

$$
W_{s l}=2 \sqrt{\gamma_{l} \gamma_{s v}}
$$

By combining Eq.(8.24) with Eq.(8.22), the solid-liquid interfacial tension $\gamma_{s l}$ can be written as

$$
\gamma_{s l}=\gamma_{l v}+\gamma_{s v}-2 \sqrt{\gamma_{l v} \gamma_{s v}}=\left(\sqrt{\gamma_{l v}}-\sqrt{\gamma_{s v}}\right)^{2}
$$

Combining this equation with Young's equation yields

$$
\cos \theta_{Y}=-1+2 \sqrt{\frac{\gamma_{s v}}{\gamma_{l \nu}}}
$$

Thus, the solid-vapour surface tension can be determined when experimental (Young) contact angle and liquid-vapour surface tension are known.

The question then arises as to what to expect when such an equation-of-state relation, in conjunction with Young's equation, is used to calculate solid surface tensions. As discussed before, there is one immediate criterion that the results obtained with this equation (or, for that matter, any other equation) must satisfy: when measuring contact angles with a number of liquids on a low-energy solid, the solid-vapour surface tension $\gamma_{s v}$ is expected to be constant, independent of the liquid surface tension $\gamma_{l \nu}$. In other words, the different pairs of $\theta$ and $\gamma_{l \nu}$ for one and the same solid should yield sensibly constant values of $\gamma_{s v}$. Therefore, this simple 
assumption should hold when contact angles are measured. The $\gamma_{s v}$ values obtained from Eqs.(8.13) and (8.26) are given in Table 8.3 for the FC-722-coated mica. It can be seen that the $\gamma_{s v}$ values obtained from Antonow's and Berthelot's rule are not constant; rather, the former tends to increase as $\gamma_{k}$ increases; the latter tends to decrease as $\gamma_{\nu}$ increases.

As mentioned above, Antonow's rule does not have a theoretical basis. But, in the theory of intermolecular interactions and the theory of mixtures, combining rules are used to evaluate the parameters of unlike-pair interactions in terms of those of the like interactions $[139,140]$. However, as for many other combining rules, the Berthelot rule [116], i.e., Eq.(8.21), is only a useful approximation and does not provide a secure basis for the understanding of unlike-pair interactions. For the interactions between two very dissimilar types of molecules or materials, where there is an apparent difference between $\varepsilon_{i i}$ and $\varepsilon_{j j}$, it has been demonstrated $[44,141]$ that the geometric mean combining rule generally overestimates the strength of the unlike-pair interaction, i.e. the geometric mean value is too large an estimate. Clearly, this is why the geometric mean combining rule does not work for situations of large differences $\left|W_{l l}-W_{s s}\right|$ or $\left|\gamma_{l \nu}-\gamma_{s v}\right|$, as can be seen in Table 8.3. This fact is indeed well-known $[46-49,135]$.

In general, $\varepsilon_{s l}$, the minimum of the solid-liquid interaction potential, is often expressed in the following manner [45-49]:

$$
\varepsilon_{s l}=g\left(\sigma_{s} / \sigma_{l}\right) \sqrt{\varepsilon_{s s} \varepsilon_{l l}}
$$


where $\varepsilon_{s s}$ and $\varepsilon_{l l}$ are, respectively, the minima in the solid-solid and liquid-liquid potentials; $\sigma_{s}$ and $\sigma_{l}$ are the appropriate core diameters for the molecules of the solid and liquid, respectively. It should be noted that many other forms of $g\left(\sigma_{s} / \sigma_{l}\right)$ have been suggested. For example, Matyushov and Schmid [49] proposed

$$
g\left(\sigma_{s} / \sigma_{l}\right)=\left[\frac{4 \sigma_{s} / \sigma_{l}}{\left(1+\sigma_{s} / \sigma_{l}\right)^{2}}\right]^{3}
$$

and Sullivan [48] set

$$
g\left(\sigma_{s} / \sigma_{l}\right)=\frac{1}{4}\left[1+\frac{\sigma_{s}}{\sigma_{l}}\right]^{2}
$$

in attempts to give a better representation of solid-liquid interactions from solid-solid and liquid-liquid interactions. In general, such functions are normalized such that $g\left(\sigma_{s} / \sigma_{l}\right)=1$ when $\sigma_{s}=\sigma_{l}$. In this case, they revert to Berthelot's geometric mean combining rule, Eq.(8.21).

In the next section, we shall discuss a modification of Berthelot's rule, leading to an equation of state approach for solid-liquid interfacial tensions.

\subsubsection{Equation of State Approach: Modified Berthelot's Rule}

In the study of mixtures $[139,140]$, it has become common practice to introduce a factor $\left(1-K_{i j}\right)$ to the geometric mean combining rule, 


$$
\varepsilon_{i j}=\left(1-K_{i j}\right) \sqrt{\varepsilon_{i i} \varepsilon_{j j}}
$$

where $K_{i j}$ is an empirical parameter quantifying deviations from the geometric mean combining rule. Since the geometric mean combining rule overestimates the strength of the unlike-pair interactions, the modifying factor $\left(1-K_{i j}\right)$ should be a decreasing function of the difference $\varepsilon_{i i}-\varepsilon_{j j}$ and be equal to unity when the difference $\varepsilon_{i i}-\varepsilon_{j j}$ is zero.

On the basis of this thought, $\mathrm{Li}$ et al. [142] have considered a modified combining rule of the form

$$
\varepsilon_{i j}=\sqrt{\varepsilon_{i i} \varepsilon_{j j}} e^{-\alpha\left(\varepsilon_{\ddot{u}}-\varepsilon_{i j}\right)^{2}}
$$

where $\alpha$ is an empirical constant; the square of the difference $\left(\varepsilon_{i i}-\varepsilon_{j j}\right)$, rather than the difference itself, reflects the symmetry of this combining rule, and hence the anticipated symmetry of the equation of state. Correspondingly, for the cases of large differences $\left|W_{l l}-W_{s s}\right|$ or $\left|\gamma_{l v}-\gamma_{s v}\right|$, the combining rule for the free energy of adhesion of a solid-liquid pair can be written as

$$
W_{s l}=\sqrt{W_{l l} W_{s s}} e^{-\alpha\left(W_{u}-W_{s s}\right)^{2}}
$$

or, more explicitly, by using $W_{l l}=2 \gamma_{v}$ and $W_{s s}=2 \gamma_{s v}$,

$$
W_{s l}=2 \sqrt{\gamma_{l \nu} \gamma_{s v}} e^{-\beta\left(\gamma_{h}-\gamma_{s}\right)^{2}}
$$

In the above, $\alpha$ and $\beta$ are as yet unknown constants. Clearly, when the values of $\gamma_{l}$ and $\gamma_{s v}$ are close to each other, Eq.(8.33) reverts to Eq.(8.24), the geometric mean 
combining rule. By combining Eq.(8.33) with Eq.(8.22), an equation of state for interfacial tensions can be written as

$$
\gamma_{s l}=\gamma_{l \nu}+\gamma_{s \nu}-2 \sqrt{\gamma_{L \nu} \gamma_{s \nu}} e^{-\beta\left(\gamma_{L}-\gamma_{s}\right)^{2}}
$$

Combining Eq.(8.34) with Young's equation yields

$$
\cos \theta_{Y}=-1+2 \sqrt{\frac{\gamma_{s \nu}}{\gamma_{L \nu}}} e^{-\beta\left(\gamma_{\nu}-\gamma_{N \nu}\right)^{2}}
$$

Thus, the solid surface tensions can be determined from experimental (Young) contact angles and liquid surface tensions when $\beta$ is known. Obviously, for a given set of $\gamma_{h}$ and $\theta$ data measured on one and the same type of solid surface, the constant $\beta$ and $\gamma_{s v}$ values can be determined by a least-square analysis technique $[68,143,144]$. Starting out with arbitrary values for $\gamma_{s v}$ and $\beta$, iterative procedures can be used to identify that pair of $\gamma_{s v}$ and $\beta$ values which provides the best fit of the experimental data to the set of experimental $\gamma_{l v}$ and $\theta_{Y}$ pairs belonging to one and the same solid surface. From the experimental contact angles on the FC-721-coated mica, heat-pressed Teflon FEP, and poly(ethylene terephthalate) PET surfaces, an averaged $\beta$ value of $0.0001247\left(\mathrm{~m}^{2} / \mathrm{mJ}\right)^{2}$ was obtained $[14,68]$

The $\gamma_{s v}$ values calculated from Eq.(8.35) are given in Table 8.4, for the solid surfaces shown in Figure 6.1. It can be seen that the $\gamma_{s v}$ values calculated from the equation of state approach $[14,68]$ are quite constant, essentially independent of the choice of the liquids. This reconfirms the validity of the approach to determine solid 
surface tensions from contact angles.

It should be noted that the above calculations were based on a constant $\beta$ value of $0.0001247\left(\mathrm{~m}^{2} / \mathrm{mJ}\right)^{2}$. Alternatively, the $\gamma_{s v}$ values of various solids can be determined by the two-variable least-square analysis $[68,143,144]$, by assuming $\gamma_{s v}$ and $\beta$ in Eq.(8.35) to be constant as described above. This leads to a $\beta$ value and a $\gamma_{s \nu}$ value for every given solid surface. The results, together with those obtained using the $\beta$ value of $0.0001247\left(\mathrm{~m}^{2} / \mathrm{mJ}\right)^{2}$, are given in Table 8.5 . It is evident that there is good agreement between the $\gamma_{s v}$ values determined from the two strategies, and the slight difference in the $\beta$ values have very little effect on the calculated $\gamma_{s v}$ values. In Table 8.5 , since the $\beta$ values do not appear to change systematically with the solid surface (and hence $\gamma_{s \nu}$ ), a weighted $\beta$ value can be calculated. Alternatively, the statistical analysis described in Appendix A can be used to decide whether or not averaging of $\beta$ over $\gamma_{s v}$ is allowed. This procedure yields a correlation coefficient $r_{\text {cal }}$ of 0.477 for the 14 observations in Table 8.5. A tabulated correlation coefficient $r_{t a b}$ at $99 \%$ is 0.623 . Since, $r_{c a l}<r_{t a b}$, there is no correlation between $\beta$ and $\gamma_{s v}$ at $99 \%$ confidence. Thus, averaging of $\beta$ is allowed. Remarkably, this procedure together with the new experimental data yield a weighted $\beta$ value of $0.0001234\left(\mathrm{~m}^{2} / \mathrm{mJ}\right)^{2}$, which is in excellent agreement with that $(\beta=0.0001247$ $\left.\left(\mathrm{m}^{2} / \mathrm{mJ}\right)^{2}\right)$ obtained by $\mathrm{Li}$ et al. [68] from only three solid surfaces not considered here. 
It should be noted that other forms of the modified Berthelot's rule can also be used, as long as they are capable of describing the experimental contact angle patterns in Figures 2.1, 5.4, 5.10-5.17, 6.1, and 6.2. A different form of the modified Berthelot's rule will be proposed and discussed in Appendix $\mathrm{J}$, which yields essentially the same $\gamma_{s v}$ values as Eq.(8.35) does. 
Table 8.1. Calculated solid surface tension components for FC-721 using three simultaneous equations of van Oss approach, Eq.(8.11), from the contact angles of three polar liquids

\begin{tabular}{lcccc}
\hline & $\begin{array}{c}\left(\gamma_{s}^{L W}\right)^{1 / 2} \\
\left(\mathrm{~mJ} / \mathrm{m}^{2}\right)\end{array}$ & $\begin{array}{c}\left(\gamma_{s}^{+}\right)^{1 / 2} \\
\left(\mathrm{~mJ} / \mathrm{m}^{2}\right)\end{array}$ & $\begin{array}{c}\left(\gamma_{s}^{-}\right)^{1 / 2} \\
\left(\mathrm{~mJ}^{2} / \mathrm{m}^{2}\right)\end{array}$ & $\begin{array}{c}\gamma_{s} \\
\left(\mathrm{~mJ}^{2} / \mathrm{m}^{2}\right)\end{array}$ \\
\hline Fo-Gl-Wa & 2.56 & 0.46 & 0.87 & 7.38 \\
Fo-GI-DM & 2.33 & 1.30 & -1.60 & 1.27 \\
Fo-Gl-EG & 2.08 & 2.17 & -4.23 & -14.02 \\
Fo-Wa-DM & 7.08 & -4.07 & 1.24 & 40.12 \\
Fo-Wa-EG & 1.14 & 1.90 & 0.75 & 4.15 \\
Fo-DM-EG & 1.66 & 2.05 & -2.00 & -5.44 \\
Gl-Wa-DM & 3.38 & -0.10 & 0.68 & 11.31 \\
Gl-Wa-EG & 9.96 & -4.72 & -0.78 & 106.6 \\
Gl-DM-EG & 0.87 & 3.23 & -4.76 & -30.0 \\
Wa-DM-EG & 2.39 & 0.97 & 0.53 & 6.73 \\
\hline
\end{tabular}

DM: dimethyl sulfoxide (DMSO); EG:ethylene glycol; FO:formamide; Gl:glycerol; Wa: water 
Table 8.2. Calculated solid surface tension components for FC-721 using three simultaneous equations of van Oss approach, Eq.(8.11), from the contact angles of one non-polar and two polar liquids

\begin{tabular}{lcccc}
\hline & $\begin{array}{c}\left(\gamma_{s}^{L W}\right)^{1 / 2} \\
\left(\mathrm{~mJ} / \mathrm{m}^{2}\right)\end{array}$ & $\begin{array}{c}\left(\gamma_{s}^{+}\right)^{1 / 2} \\
\left(\mathrm{~mJ}^{2} / \mathrm{m}^{2}\right)\end{array}$ & $\begin{array}{c}\left(\gamma_{s}\right)^{1 / 2} \\
\left(\mathrm{~mJ} / \mathrm{m}^{2}\right)\end{array}$ & $\begin{array}{c}\gamma_{s} \\
\left(\mathrm{~mJ}^{2} / \mathrm{m}^{2}\right)\end{array}$ \\
\hline Fo-Gl-Br & 9.07 & -1.10 & 5.58 & -3.21 \\
Fo-Wa-Br & 9.07 & 0.02 & 0.90 & 9.11 \\
Fo-DM-Br & 9.07 & 0.53 & -1.19 & 7.81 \\
Fo-EG-Br & 9.07 & 2.44 & -9.16 & -35.63 \\
Gl-Wa-Br & 9.07 & 1.60 & 0.76 & 9.31 \\
Gl-DM-Br & 9.07 & 0.39 & -0.13 & 8.97 \\
Gl-EG-Br & 9.07 & 1.36 & -3.82 & -1.32 \\
Wa-DM-Br & 9.07 & 0.30 & 0.63 & 9.45 \\
Wa-EG-Br & 9.07 & 0.50 & 0.42 & 9.49 \\
DM-EG-Br & 9.07 & 0.04 & 2.70 & 9.29 \\
\hline
\end{tabular}

DM: dimethyl sulfoxide (DMSO); EG:ethylene glycol; FO:formamide; Gl:glycerol; Wa: water, $\mathrm{Br}$ : 1-bromonaphthalene 
Table 8.3: Calculated $\gamma_{s v}$ values $\left(\mathrm{mJ} / \mathrm{m}^{2}\right)$ of the FC-722-coated mica surface from Antonow's and Berthelot's rules. The contact angles are low-rate dynamic angles measured by ADSA-P.

\begin{tabular}{|c|c|c|c|c|}
\hline \multirow[t]{2}{*}{ liquid } & \multirow{2}{*}{$\begin{array}{c}\gamma_{t v} \\
\left(\mathrm{~mJ} / \mathrm{m}^{2}\right)\end{array}$} & \multirow{2}{*}{$\begin{array}{c}\theta \\
\text { (deg.) }\end{array}$} & \multicolumn{2}{|c|}{$\gamma_{s v}$} \\
\hline & & & $\begin{array}{c}\text { Antonow's rule, } \\
\text { Eq.(8.13) }\end{array}$ & $\begin{array}{c}\text { Berthelot's rule, } \\
\text { Eq.(8.26) }\end{array}$ \\
\hline decane & 23.88 & 67.36 & 16.5 & 11.5 \\
\hline 1-pentanol & 26.01 & 72.95 & 16.8 & 10.9 \\
\hline trans-decalin & 27.19 & 73.38 & 17.5 & 11.2 \\
\hline hexadecane & 27.62 & 75.94 & 17.2 & 10.7 \\
\hline 1-decanol & 28.99 & 78.84 & 17.3 & 10.3 \\
\hline cis-decalin & 32.32 & 79.56 & 19.1 & 11.3 \\
\hline ethyl cinnamate & 37.17 & 86.54 & 19.7 & 10.5 \\
\hline dibenzylamine & 40.80 & 90.70 & 20.1 & 10.0 \\
\hline dimethyl sulfoxide (DMSO) & 42.68 & 90.95 & 21.0 & 10.3 \\
\hline 1-bromonaphthalene & 44.31 & 93.81 & 20.7 & 9.7 \\
\hline diethylene glycol & 44.68 & 94.22 & 20.7 & 9.6 \\
\hline ethylene glycol & 47.55 & 97.87 & 20.5 & 8.9 \\
\hline diiodomethane & 49.98 & 101.18 & 20.1 & 8.1 \\
\hline 2,2'-thiodiethanol & 56.26 & 104.56 & 21.1 & 7.9 \\
\hline formamide & 59.08 & 108.49 & 20.2 & 6.9 \\
\hline glycerol & 65.02 & 111.73 & 20.5 & 6.5 \\
\hline water & 72.70 & 118.69 & 18.9 & 4.9 \\
\hline
\end{tabular}


Table 8.4: Summary of the dynamic contact angles of various solids by ADSA-P and capillary rise techniques. The $\gamma_{s v}$ values $\left(\mathrm{mJ} / \mathrm{m}^{2}\right)$ were calculated from the equation of state approach.

\begin{tabular}{|c|c|c|c|c|}
\hline \multirow[t]{2}{*}{ solid surface/technique } & \multirow[t]{2}{*}{ liquid } & \multirow{2}{*}{$\begin{array}{c}\gamma_{\nu \nu} \\
\left(\mathrm{mJ} / \mathrm{m}^{2}\right)\end{array}$} & \multirow{2}{*}{$\begin{array}{c}\theta \\
\text { (deg.) }\end{array}$} & \multirow{2}{*}{$\frac{\gamma_{s v}}{\text { equation-of- }} \begin{array}{c}\text { state, Eq. }(8.35) \\
\text { sta }\end{array}$} \\
\hline & & & & \\
\hline \multirow{8}{*}{$\begin{array}{l}\text { FC-721-coated mical } \\
\text { capillary rise }[101]\end{array}$} & dodecane & 25.03 & 70.4 & 11.7 \\
\hline & 2-octanol & 26.00 & 73.5 & 11.3 \\
\hline & tetradecane & 26.50 & 73.5 & 11.6 \\
\hline & 1-octanol & 27.28 & 75.1 & 11.5 \\
\hline & hexadecane & 27.31 & 75.6 & 11.3 \\
\hline & 1-hexadecene & 27.75 & 74.0 & 12.0 \\
\hline & 1-decanol & 28.29 & 76.6 & 11.5 \\
\hline & 1-dodecanol & 29.53 & 79.2 & 11.3 \\
\hline \multirow{12}{*}{$\begin{array}{l}\text { FC-722-coated mica/ } \\
\text { ADSA-P [95] }\end{array}$} & decane & 23.88 & 67.36 & 11.9 \\
\hline & 1-pentanol & 26.01 & 72.95 & 11.5 \\
\hline & trans-decalin & 27.19 & 73.38 & 11.9 \\
\hline & hexadecane & 27.62 & 75.94 & 11.4 \\
\hline & 1-decanol & 28.99 & 78.84 & 11.2 \\
\hline & cis-decalin & 32.32 & 79.56 & 12.4 \\
\hline & ethyl cinnamate & 37.17 & 86.54 & 12.2 \\
\hline & dibenzylamine & 40.80 & 90.70 & 12.2 \\
\hline & $\begin{array}{l}\text { dimethyl sulfoxide } \\
\text { (DMSO) }\end{array}$ & 42.68 & 90.95 & 12.9 \\
\hline & 1-bromonaphthalene & 44.31 & 93.81 & 12.4 \\
\hline & diethylene glycol & 44.68 & 94.22 & 12.4 \\
\hline & ethylene glycol & 47.55 & 97.87 & 12.1 \\
\hline
\end{tabular}




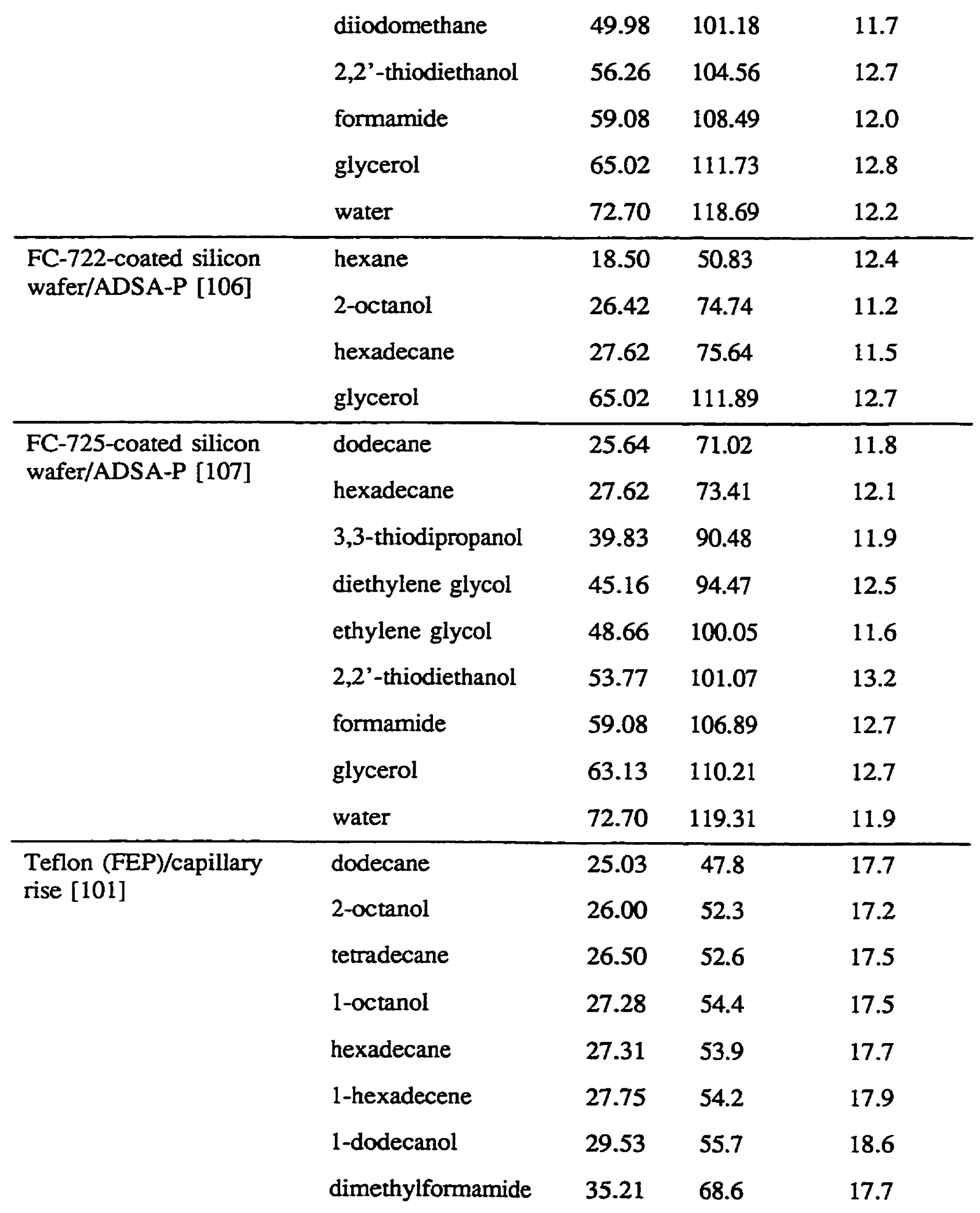




\begin{tabular}{|c|c|c|c|c|}
\hline & methyl salicylate & 38.85 & 72.2 & 18.4 \\
\hline \multirow{4}{*}{$\begin{array}{l}\text { hexatriacontane/capillary } \\
\text { rise }[51,104]\end{array}$} & ethylene glycol & 47.7 & 79.2 & 20.3 \\
\hline & 2,2'-thiodiethanol & 54.0 & 86.3 & 20.3 \\
\hline & glycerol & 63.4 & 95.4 & 20.6 \\
\hline & water & 72.8 & 104.6 & 20.3 \\
\hline \multirow{4}{*}{$\begin{array}{l}\text { cholesteryl acetate/ } \\
\text { capillary rise }[51,105]\end{array}$} & ethylene glycol & 47.7 & 77.0 & 21.3 \\
\hline & 2,2'-thiodiethanol & 54.0 & 84.3 & 21.3 \\
\hline & glycerol & 63.4 & 94.0 & 21.3 \\
\hline & water & 72.8 & 103.3 & 21.1 \\
\hline \multirow{5}{*}{$\begin{array}{l}\text { poly(propene-alt }-N-(n- \\
\text { hexyl)maleimide)/ } \\
\text { ADSA-P }[77,108]\end{array}$} & cis-decalin & 32.32 & 28.81 & 28.5 \\
\hline & triacetin & 35.52 & 39.45 & 28.3 \\
\hline & diethylene glycol & 44.68 & 61.04 & 26.7 \\
\hline & glycerol & 65.02 & 82.83 & 28.6 \\
\hline & water & 72.70 & 92.26 & 27.8 \\
\hline \multirow{6}{*}{$\begin{array}{l}\text { poly(n-butyl methacrylate) } \\
\text { /ADSA-P [109] }\end{array}$} & diethylene glycol & 45.16 & 58.73 & 28.0 \\
\hline & 3-pyridylcarbinol & 47.81 & 60.30 & 29.2 \\
\hline & 2,2'-thiodiethanol & 53.77 & 68.00 & 29.4 \\
\hline & formamide & 59.08 & 76.41 & 28.5 \\
\hline & glycerol & 65.02 & 82.11 & 29.0 \\
\hline & water & 72.70 & 90.73 & 28.7 \\
\hline \multirow[t]{5}{*}{$\begin{array}{l}\text { polystyrene/ADSA-P } \\
{[110]}\end{array}$} & $\begin{array}{l}\text { dimethyl sulfoxide } \\
\text { (DMSO) }\end{array}$ & 42.68 & 50.67 & 29.7 \\
\hline & diethylene glycol & 44.68 & 52.41 & 30.5 \\
\hline & ethylene glycol & 48.66 & 61.20 & 29.3 \\
\hline & formamide & 59.08 & 74.76 & 29.4 \\
\hline & glycerol & 63.11 & 78.38 & 30.0 \\
\hline
\end{tabular}




\begin{tabular}{|c|c|c|c|c|}
\hline & water & 72.70 & 88.42 & 30.2 \\
\hline \multirow{5}{*}{$\begin{array}{l}\text { poly(styrene-(hexyl/10- } \\
\text { carboxydecyl 90:10)- } \\
\text { maleimide)/ADSA-P } \\
\text { [111] }\end{array}$} & diethylene glycol & 45.16 & 51.32 & 31.3 \\
\hline & ethylene glycol & 48.66 & 59.72 & 30.2 \\
\hline & formamide & 58.45 & 70.28 & 31.4 \\
\hline & glycerol & 63.13 & 76.51 & 31.0 \\
\hline & water & 72.70 & 87.13 & 31.0 \\
\hline \multirow{6}{*}{$\begin{array}{l}\text { poly(methyl methacrylate/ } \\
n \text {-butyl methacrylate)/ } \\
\text { ADSA-P [112] }\end{array}$} & 1-iodonaphthalene & 42.92 & 35.67 & 35.7 \\
\hline & 3-pyridylcarbinol & 47.81 & 49.22 & 34.2 \\
\hline & 2,2'-thiodiethanol & 53.77 & 57.84 & 34.6 \\
\hline & formamide & 59.08 & 66.33 & 34.0 \\
\hline & glycerol & 65.02 & 74.72 & 33.3 \\
\hline & water & 72.70 & 81.33 & 34.6 \\
\hline \multirow{6}{*}{$\begin{array}{l}\text { poly(propene-alt- } N-(n- \\
\text { propyl)maleimide)/ } \\
\text { ADSA-P }[77,108]\end{array}$} & 1-iodonaphthalene & 42.92 & 35.19 & 35.9 \\
\hline & 1-bromonaphthalene & 44.31 & 30.75 & 38.6 \\
\hline & 1,3-diiodopropane & 46.51 & 39.98 & 37.1 \\
\hline & 2,2'-thiodiethanol & 53.77 & 54.04 & 36.5 \\
\hline & glycerol & 65.02 & 70.67 & 35.7 \\
\hline & water & 72.70 & 77.51 & 37.0 \\
\hline \multirow{7}{*}{$\begin{array}{l}\text { poly(methyl methacrylate) } \\
\text { /ADSA-P [113] }\end{array}$} & 1,3-diiodopropane & 46.51 & 36.95 & 38.3 \\
\hline & 3-pyridylcarbinol & 47.81 & 39.47 & 38.4 \\
\hline & diiodomethane & 49.98 & 42.25 & 39.0 \\
\hline & 2,2'-thiodiethanol & 53.77 & 50.35 & 38.3 \\
\hline & formamide & 59.08 & 57.73 & 38.6 \\
\hline & glycerol & 65.02 & 66.84 & 37.9 \\
\hline & water & 72.70 & 73.72 & 39.3 \\
\hline
\end{tabular}




\begin{tabular}{llccc}
\hline $\begin{array}{l}\text { poly(propene-alt- } N \text {-methyl } \\
\text { maleimide)/ADSA-P }\end{array}$ & diiodomethane & 49.98 & 30.71 & 43.7 \\
{$[106]$} & glycerol & 65.02 & 60.25 & 41.7 \\
& water & 72.70 & 69.81 & 41.8 \\
\hline
\end{tabular}


Table 8.5: Averaged $\gamma_{s v}$ values reproduced from Table 8.4; the $\gamma_{s v}\left(\mathrm{~mJ} / \mathrm{m}^{2}\right)$ and $\beta\left(\mathrm{m}^{2} / \mathrm{mJ}\right)^{2}$ values determined by a two-variable least-square fit are also given

\begin{tabular}{|c|c|c|c|c|}
\hline \multirow[t]{2}{*}{ solid surface/technique } & \multirow{2}{*}{$\begin{array}{l}\text { \# of } \\
\text { system }\end{array}$} & \multirow{2}{*}{$\frac{\text { Table } 8.4}{\gamma_{s v}^{\ddagger}}$} & \multicolumn{2}{|c|}{ least-square fit } \\
\hline & & & $\beta$ & $\gamma_{s v}$ \\
\hline FC-721-coated mica/capillary rise [101] & 8 & $11.5 \pm 0.2$ & 0.000124 & 11.7 \\
\hline FC-722-coated mica/ADSA-P [95] & 17 & $12.1 \pm 0.3$ & & \\
\hline FC-722-coated silicon wafer/ADSA-P [106] & 4 & $12.0 \pm 1.1$ & 0.000111 & 11.0 \\
\hline FC-725-coated silicon wafer/ADSA-P [107] & 9 & $12.3 \pm 0.4$ & 0.000114 & 11.9 \\
\hline Teflon FEP/capillary rise [101] & 9 & $17.8 \pm 0.3$ & 0.000142 & 18.0 \\
\hline hexatriacontane/capillary rise $[51,104]$ & 4 & $20.4 \pm 0.2$ & 0.000124 & 20.3 \\
\hline cholesteryl acetate/capillary rise $[51,105]$ & 4 & $21.3 \pm 0.2$ & 0.000128 & 21.5 \\
\hline $\begin{array}{l}\text { poly(propene-alt- } N \text {-( } n \text {-hexyl)maleimide)/ } \\
\text { ADSA-P }[77,108]\end{array}$ & 5 & $28.0 \pm 1.0$ & 0.000122 & 27.9 \\
\hline poly(n-butyl methacrylate)/ADSA-P [109] & 6 & $28.8 \pm 0.5$ & 0.000124 & 28.8 \\
\hline polystyrene/ADSA-P [110] & 6 & $29.9 \pm 0.5$ & 0.000120 & 29.7 \\
\hline $\begin{array}{l}\text { poly(styrene-(hexyl/10-carboxydecyl } \\
\text { 90:10)-maleimide)/ADSA-P [111] }\end{array}$ & 5 & $31.0 \pm 0.6$ & 0.000120 & 30.8 \\
\hline $\begin{array}{l}\text { poly(methyl methacrylate/ } n \text {-butyl } \\
\text { methacrylate)/ADSA-P [112] }\end{array}$ & 6 & $34.4 \pm 0.8$ & 0.000136 & 34.7 \\
\hline $\begin{array}{l}\text { poly(propene-alt- } N \text {-( } n \text {-propyl)maleimide)/ } \\
\text { ADSA-P }[77,108]\end{array}$ & 6 & $36.8 \pm 1.1$ & 0.000133 & 36.9 \\
\hline poly(methyl methacrylate)/ADSA-P [113] & 7 & $38.5 \pm 0.4$ & 0.000113 & 38.3 \\
\hline $\begin{array}{l}\text { poly(propene-alt } N \text {-methylmaleimide)/ } \\
\text { ADSA-P [106] }\end{array}$ & 3 & $42.4 \pm 2.8$ & 0.000167 & 43.4 \\
\hline
\end{tabular}

terror limits are $95 \%$ confidence limits 


\section{CHAPTER 9}

\section{APPLICATIONS}

There is an abundance of contact angle data in the literature which were obtained from static measurements, and are hence of unknown status. In this Chapter, the equation of state approach for solid-liquid interfacial tensions $[14,68]$ described in Chapter 8 will be employed to evaluate literature contact angle data; Zisman's contact angle data will be used as an illustration. The predictive power of the equation of state approach will also be discussed.

\subsection{Evaluation of Existing Contact Angle Data}

As shown in Chapter 5, goniometer contact angle data may contain a mixture of meaningful and meaningless angles. If one neglects the goniometer angles shown to be meaningless in the low-rate dynamic contact angle study by ADSA-P, smooth curves emerge. The question then arises as to whether one should neglect completely the literature contact angle data and repeat all measurements using a dynamic procedure such as ADSA-P, or whether some of the data can be salvaged. This question will be explored in this section, using Zisman's contact angle data.

The rationale is as follows. After discarding all those measurements which violate the basic assumptions, the low-rate dynamic contact angle measurements yielded contact angles which fell on smooth curves, such as those in Figures 2.1, 5.4, 
5.10-5.17, 6.1, and 6.2. Assuming that this would also have happened in the systems studied in the laboratory of Zisman [10], we propose to discard those contact angle data which do not sensibly fall on a smooth curve. The equation of state approach can be used to evaluate these data by generating a series of theoretical constant $\gamma_{s v}$ curves, in plots of $\gamma_{L \nu} \cos \theta$ vs. $\gamma_{s v}$. Figure 9.1 shows these theoretical curves generated by the equation of state approach, i.e. Eq.(8.35), from $\gamma_{s v}=16.0 \mathrm{~mJ} / \mathrm{m}^{2}$ to $\gamma_{s v}=45.0 \mathrm{~mJ} / \mathrm{m}^{2}$ in $1.0 \mathrm{~mJ} / \mathrm{m}^{2}$ increments; each curve represents a constant $\gamma_{s v}$ value and hence a hypothetical solid surface. Thus, if goniometer contact angle data are plotted in this graph, it can be decided how well data for any one solid fall onto an individual curve.

Figure 9.2 shows the contact angle data of Zisman and coworkers for the 80:20 tetrafluoroethylene-chlorotrifluoroethylene [124], 50:50 tetrafluoroethylene-ethylene [124] and nylon $(6,6)$ [127] surfaces, as well as the theoretical curves from Figure 9.1. In Figure 9.2, the data points for the 50:50 tetrafluoroethylene-ethylene surface fall consistently close to the theoretical constant $\gamma_{s v}$ curve of $27.0 \mathrm{~mJ} / \mathrm{m}^{2}$. However, considerable scatter is apparent for the other two surfaces. If $\pm 1.0 \mathrm{~mJ} / \mathrm{m}^{2}$ is selected as the allowable error, contact angle data which deviate away from a theoretical $\gamma_{s v}$ curve by more than $\pm 1.0 \mathrm{~mJ} / \mathrm{m}^{2}$ can be disregarded. Following these procedures, it was found that 7 of the 22 data for the $80: 20$ tetrafluoroethylenechlorotrifluoroethylene surface are clearly outside this error band and, similarly, 3 out of 7 data for the nylon $(6,6)$ surface; these data are rejected. Figure 9.3 shows 
these disregarded contact angle data in solid symbols. The above procedure was also applied to the goniometer data of several more solid surfaces from Zisman et al.: perfluorocapric acid [128], perfluorocaprylic acid [128], 17-(perfluoroheptyl)heptadecanoic acid [131], perfluorocaproic acid [131], 17-(perfluoropentyl)heptadecanoic acid [131], 17-(perfluoropropyl)-heptadecanoic acid [131], hexatriacontane [125], n-octadecylamine [126], stearic acid [130], 60:40 tetrafluoroethylene and chlorotrifluoroethylene [124], polychlorotrifluoroethylene [124], and polyvinyl fluoride [129]. The contact angles falling to $\pm 1.0 \mathrm{~mJ} / \mathrm{m}^{2}$ on smooth theoretical $\gamma_{s v}$ curves are given in Table 9.1, together with the calculated $\gamma_{s v}$ values from the equation of state approach $[14,68]$. It can be seen that the calculated $\gamma_{s v}$ values for these surfaces are indeed quite constant. The average $\gamma_{s v}$ values and the 95\% confidence limits are summarized in Table 9.2. Thus, contact angles can indeed be used for the determination of solid surface tensions and literature contact angles do not have to be discarded completely.

In principle, the above procedures can be automated by constructing a leastsquare objective function [143] to calculate the deviation of all contact angle data away from a theoretical curve generated by a given $\gamma_{s v}$ value. The best fitted constant $\gamma_{s \nu}$ curve can be used to discriminate against data which are clearly above and below the curve within a band, e.g., $\pm 1.0 \mathrm{~mJ} / \mathrm{m}^{2}$. The automation of these procedures is beyond the scope of this work. 


\subsection{Predictive Power of the Equation of State Approach}

In Table 8.4, experimental contact angles of a large number of liquids have been summarized. In this section, the predictive power of the equation of state approach will be illustrated simply by predicting from a single contact angle measurement on one and the same solid surface all the other contact angles measured.

For example, if the surface tension $\left(\gamma_{l v}=23.9 \mathrm{~mJ} / \mathrm{m}^{2}\right)$ and contact angle $(\theta=$ $67.4^{\circ}$ ) of decane on a FC-722-coated mica surface are chosen (from Table 8.4), the equation of state approach [14,68], Eq.(8.35), yields a $\gamma_{s v}$ value of $11.9 \mathrm{~mJ} / \mathrm{m}^{2}$. From this $\gamma_{s v}$ value, Eq.(8.35) can generate a series of contact angles for different values of $\gamma_{l v}$. These procedures are employed to produce a set of hypothetical contact angles corresponding to the surface tensions of the other liquids on the FC722 surface. The predicted contact angle results are given in Table 9.3. In all cases, the predicted and measured contact angles agree well, certainly within the usual error limit given in the literature as $\pm 2^{\circ}$.

Conversely, a series of hypothetical $\gamma_{k}$ values for different experimental contact angle values can also be generated from a single decane contact angle measurement. The predicted $\gamma_{v}$ values are also shown in Table 9.3 for the FC-722coated surface; it can be seen that the deviations between the predicted and measured values vary from $\pm 0.1 \mathrm{~mJ} / \mathrm{m}^{2}$ to $\pm 2.0 \mathrm{~mJ} / \mathrm{m}^{2}$ : While these deviations are somewhat outside the experimental error limits, there is no evidence of any 
systematic variation. The question whether these variations are artifacts or not would require further study. Similar calculations can be performed for other solid surfaces, with similar results. From a single contact angle measurement on one and the same solid surface, the equation of state approach $[14,68]$ is capable of predicting the contact angles of different liquids as well as the liquid surface tensions. 


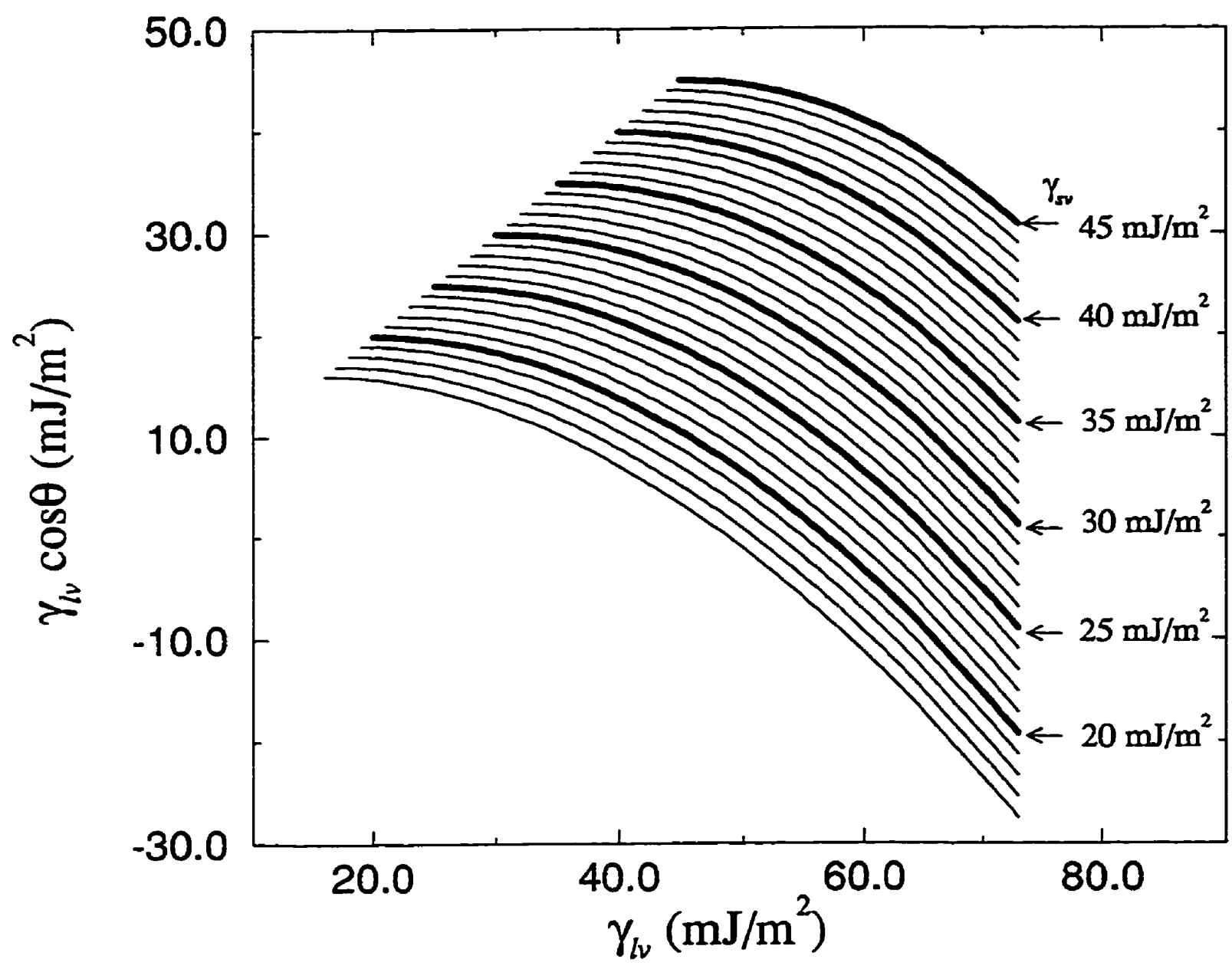

Figure $9.1 \gamma_{l v} \cos \theta$ vs. $\gamma_{l}$ generated from the equation-of-state approach, Eq. (8.35), from $\gamma_{s v}=16.0 \mathrm{~mJ} / \mathrm{m}^{2}$ to $\gamma_{s v}=45.0 \mathrm{~mJ} / \mathrm{m}^{2}$, in $1.0 \mathrm{~mJ} / \mathrm{m}^{2}$ increments. 


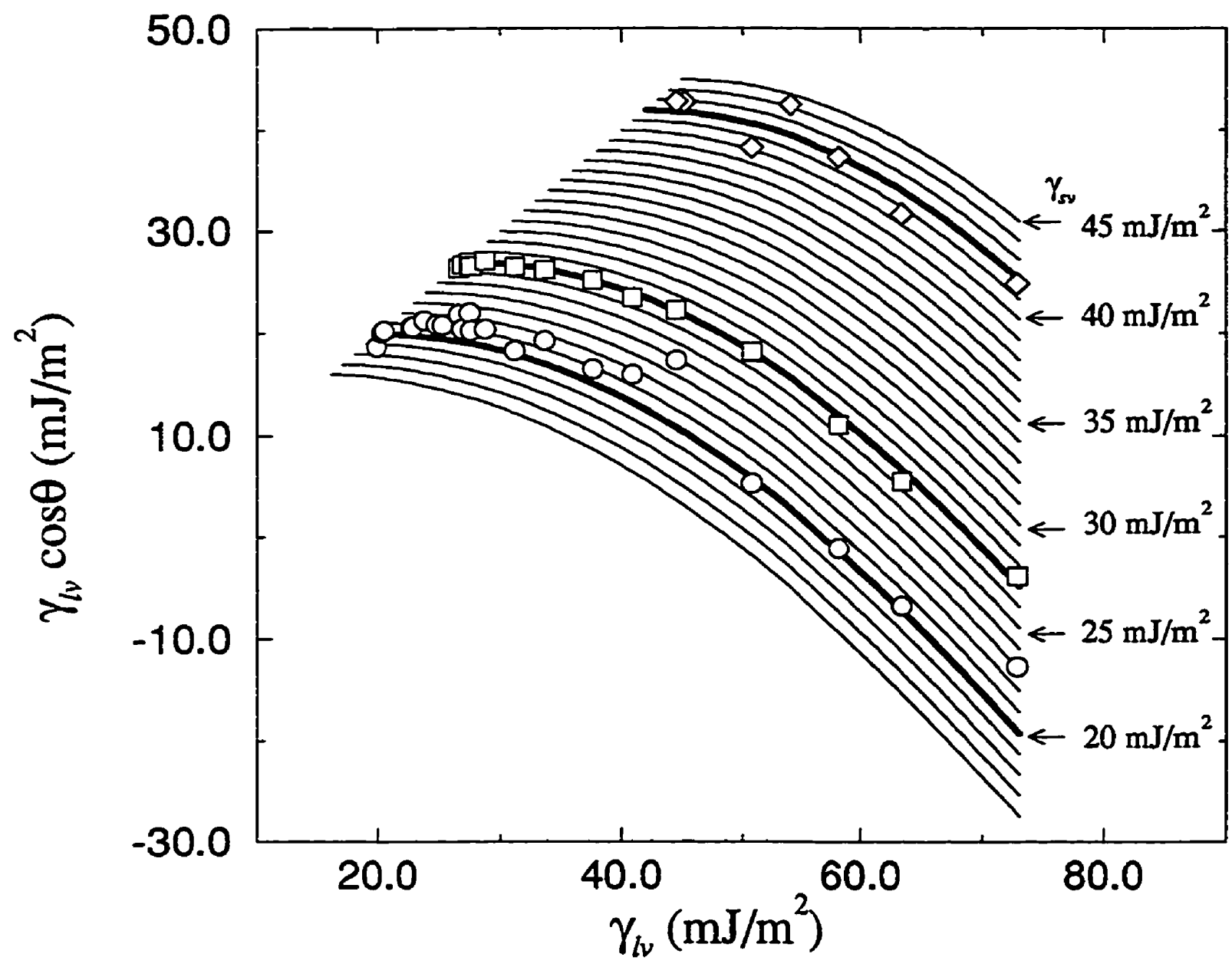

O 80:20 tetrafluoroethylene and chlorotrifluoroethylene $\square$ 50:50 tetrafluoroethylene and ethylene $\diamond$ nylon $(6,6)$

Figure $9.2 \gamma_{L \nu} \cos \theta$ vs. $\gamma_{l_{\nu}}$ for Zisman's data on 80:20 tetrafluoroethylene and chlorotrifluoroethylene, 50:50 tetrafluoroethylene and ethylene, and nylon $(6,6)$ surfaces, as well as the theoretical constant $\gamma_{s v}$ curves from Figure 9.1. 


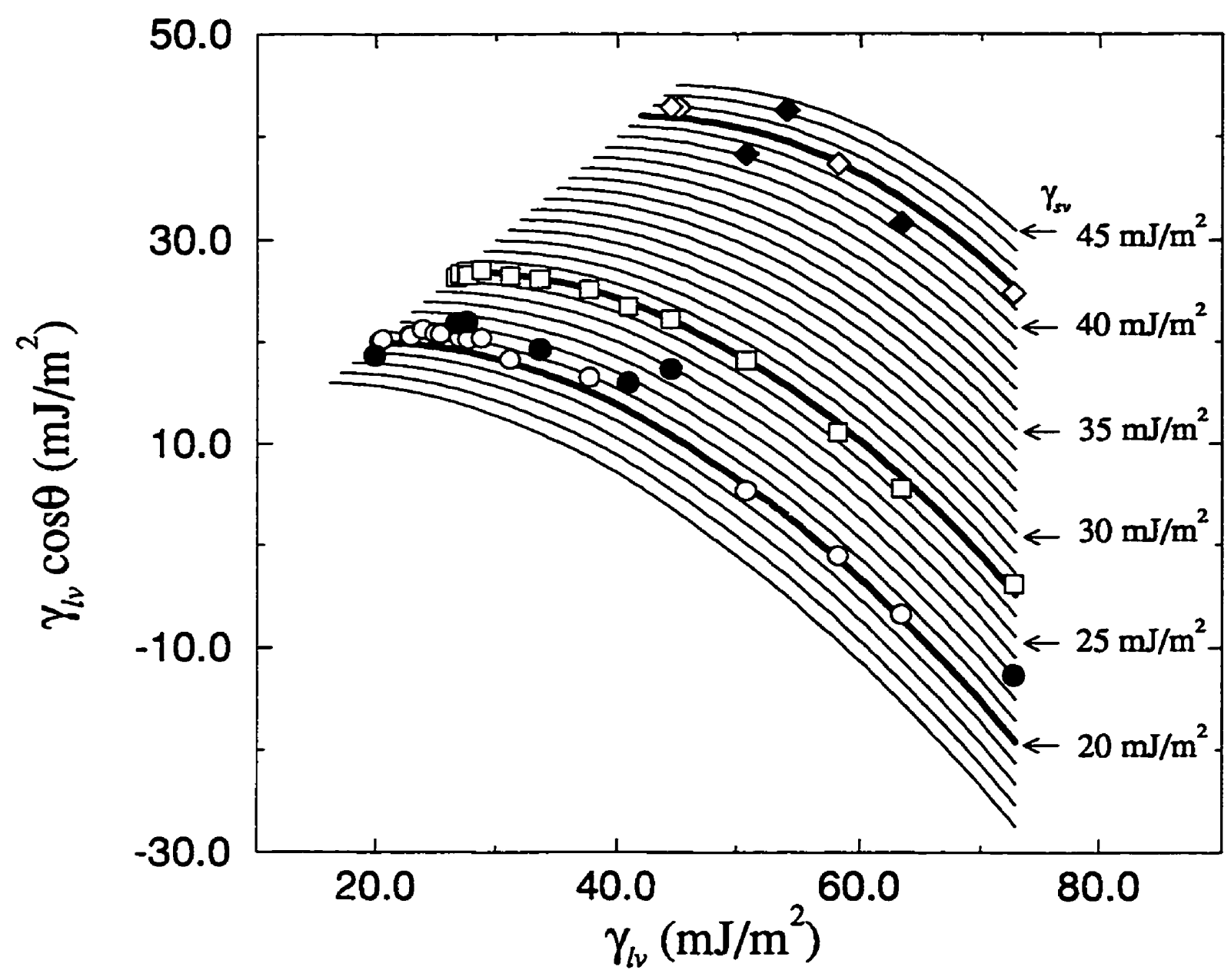

O 80:20 tetrafluoroethylene and chlorotrifluoroethylene $\square$ 50:50 tetrafluoroethylene and ethylene $\diamond$ nylon $(6,6)$

Figure $9.3 \gamma_{l v} \cos \theta$ vs. $\gamma_{l v}$ for Zisman's data on 80:20 tetrafluoroethylene and chlorotrifiuoroethylene, 50:50 tetrafluoroethylene and ethylene, and nylon $(6,6)$ surfaces Contact angle data which are clearly outside a constant $\gamma_{s v}$ curve by more than $\pm 1.0 \mathrm{~mJ} / \mathrm{m}^{2}$ are discarded (solid symbols). 
Table 9.1: Summary of the static contact angles of various solids from Zisman et al. by a conventional goniometer technique. The $\gamma_{s v}$ values $\left(\mathrm{mJ} / \mathrm{m}^{2}\right)$ were calculated from the equation of state approach

\begin{tabular}{|c|c|c|c|c|}
\hline \multirow[t]{2}{*}{ solid surface } & \multirow[t]{2}{*}{ liquid } & \multirow{2}{*}{$\begin{array}{c}\gamma_{l v} \\
\left(\mathrm{~mJ} / \mathrm{m}^{2}\right)\end{array}$} & \multirow{2}{*}{$\begin{array}{c}\theta \\
\text { (deg.) }\end{array}$} & \multirow{2}{*}{ 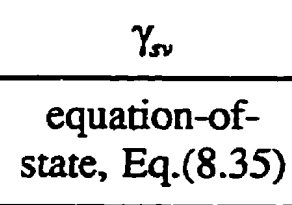 } \\
\hline & & & & \\
\hline \multirow{9}{*}{$\begin{array}{l}\text { perfluorocapric } \\
\text { acid }^{\dagger}[128]\end{array}$} & octane & 21.8 & 64.5 & 11.5 \\
\hline & decane & 23.9 & 69.5 & 11.3 \\
\hline & dodecane & 25.4 & 73.0 & 11.2 \\
\hline & tetradecane & 26.7 & 75.0 & 11.2 \\
\hline & hexadecane & 27.6 & 77.0 & 11.1 \\
\hline & bis(2-ethylhexyl)sebacate & 31.1 & 80.0 & 11.8 \\
\hline & $t$-butylnaphthalene & 33.7 & 84.5 & 11.5 \\
\hline & tetrachlorobiphenyl & 44.2 & 93.5 & 12.5 \\
\hline & diiodomethane & 50.8 & 99.5 & 12.7 \\
\hline \multirow{8}{*}{$\begin{array}{l}\text { perfluorocaprylic } \\
\operatorname{acid}^{\dagger}[129]\end{array}$} & octane & 21.8 & 59.0 & 12.8 \\
\hline & decane & 23.9 & 64.5 & 12.6 \\
\hline & dodecane & 25.4 & 66.0 & 13.1 \\
\hline & tetradecane & 26.7 & 68.8 & 13.0 \\
\hline & hexadecane & 27.6 & 71.8 & 12.6 \\
\hline & bis(2-ethylhexyl)sebacate & 31.1 & 74.0 & 13.7 \\
\hline & $t$-butylnaphthalene & 33.7 & 80.0 & 12.9 \\
\hline & tetrachlorobiphenyl & 44.2 & 91.0 & 13.5 \\
\hline \multirow{4}{*}{$\begin{array}{l}\text { 17-(perfluoro- } \\
\text { heptyl)-hepta- } \\
\text { decanoic acid } \\
{[131]}\end{array}$} & heptane & 20.3 & 52 & 13.4 \\
\hline & octane & 21.8 & 57 & 13.2 \\
\hline & decane & 23.9 & 64 & 12.8 \\
\hline & undecane & 24.7 & 64 & 13.2 \\
\hline
\end{tabular}




\begin{tabular}{|c|c|c|c|c|}
\hline & dodecane & 25.4 & 66 & 13.1 \\
\hline & tridecane & 25.9 & 68 & 12.8 \\
\hline & tetradecane & 26.7 & 70 & 12.6 \\
\hline & 2-octanol & 26.7 & 68 & 13.2 \\
\hline & 1-octanol & 27.8 & 68 & 13.8 \\
\hline & squalane & 29.5 & 77 & 12.0 \\
\hline & pentaerythritol tetracaproate & 30.4 & 77 & 12.4 \\
\hline & bis-(2-ethylhexyl)sebacate & 31.1 & 78 & 12.4 \\
\hline & bis-(2-ethylhexyl)phthalate & 31.3 & 78 & 12.5 \\
\hline & $t$-butylnaphthalene & 33.7 & 78 & 13.6 \\
\hline & tricresyl phosphate & 40.9 & 90 & 12.5 \\
\hline & tetrachlorobiphenyl & 44.2 & 93 & 12.7 \\
\hline & ethylene glycol & 47.7 & 98 & 12.1 \\
\hline & formamide & 58.2 & 105 & 13.2 \\
\hline & water & 72.7 & 115 & 14.3 \\
\hline \multirow{6}{*}{$\begin{array}{l}\text { perfluorocaproic } \\
\text { acid }^{\ddagger}[131]\end{array}$} & octane & 21.8 & 59.0 & 12.8 \\
\hline & decane & 23.9 & 64.5 & 12.6 \\
\hline & dodecane & 25.4 & 66.0 & 13.1 \\
\hline & tetradecane & 26.7 & 68.8 & 13.0 \\
\hline & hexadecane & 27.6 & 71.8 & 12.6 \\
\hline & $t$-butylnaphthalene & 33.7 & 77.0 & 13.9 \\
\hline \multirow{5}{*}{$\begin{array}{l}\text { 17-(perfluoro- } \\
\text { pentyl)-hepta- } \\
\text { decanoic acid } \\
{[131]}\end{array}$} & octane & 21.8 & 50 & 14.9 \\
\hline & decane & 23.9 & 57 & 14.6 \\
\hline & dodecane & 25.4 & 61 & 14.4 \\
\hline & tetradecane & 26.7 & 65 & 14.1 \\
\hline & dicyclohexyl & 32.8 & 72 & 15.2 \\
\hline
\end{tabular}




\begin{tabular}{|c|c|c|c|c|}
\hline & $t$-butylnaphthalene & 33.7 & 73 & 15.3 \\
\hline & ethylene glycol & 47.7 & 92 & 14.6 \\
\hline & diiodomethane & 50.8 & 94 & 15.1 \\
\hline \multirow{11}{*}{$\begin{array}{l}\text { 17-(perfluoro- } \\
\text { propyl)-hepta- } \\
\text { decanoic acid } \\
{[131]}\end{array}$} & octane & 20.2 & 23 & 17.1 \\
\hline & decane & 23.9 & 48 & 16.9 \\
\hline & dodecane & 25.4 & 52 & 16.9 \\
\hline & tridecane & 25.9 & 51 & 17.5 \\
\hline & tetradecane & 26.7 & 55 & 16.9 \\
\hline & hexadecane & 27.6 & 59 & 17.5 \\
\hline & squalene & 29.5 & 62 & 16.6 \\
\hline & pentaerythritol tetracaproate & 30.4 & 62 & 17.2 \\
\hline & $t$-butylnaphthalene & 33.7 & 68 & 17.1 \\
\hline & ethylene glycol & 47.7 & 84 & 18.1 \\
\hline & formamide & 58.2 & 97 & 17.1 \\
\hline \multirow{12}{*}{$\begin{array}{l}80: 20 \text { tetrafluoro- } \\
\text { ethylene and } \\
\text { chlorotrifluoro- } \\
\text { ethylene [124] }\end{array}$} & heptane & 20.3 & 8 & 20.1 \\
\hline & di(n-propyl) ether & 20.5 & 8 & 20.3 \\
\hline & di(n-butyl) ether & 22.8 & 25 & 20.7 \\
\hline & nonane & 22.9 & 26 & 20.7 \\
\hline & decane & 23.9 & 27 & 21.4 \\
\hline & $\operatorname{di}(n$-amyl) ether & 24.9 & 33 & 21.1 \\
\hline & dodecane & 25.4 & 35 & 21.1 \\
\hline & $\operatorname{di}(n$-heptyl) ether & 27.0 & 41 & 21.0 \\
\hline & $\operatorname{di}(n$-octyl) ether & 27.7 & 43 & 21.0 \\
\hline & benzene & 28.8 & 45 & 21.2 \\
\hline & di(2-ethylhexyl)phthalene & 31.2 & 54 & 20.3 \\
\hline & benzyl phenylundecanoate & 37.7 & 64 & 20.9 \\
\hline
\end{tabular}




\begin{tabular}{|c|c|c|c|c|}
\hline & ... l & 500 & 01 & 107 \\
\hline & formamide & 58.2 & 91 & 20.2 \\
\hline & glycerol & 63.4 & 96 & 20.2 \\
\hline \multirow{12}{*}{$\begin{array}{l}\text { hexatriacontane } \\
\text { [125] }\end{array}$} & nonane & 22.9 & 25 & 20.8 \\
\hline & decane & 23.9 & 28 & 21.2 \\
\hline & dodecane & 25.4 & 38 & 20.4 \\
\hline & tetradecane & 26.7 & 41 & 20.7 \\
\hline & di(n-heptyl) ether & 27.0 & 45 & 19.9 \\
\hline & hexadecane & 27.6 & 46 & 20.1 \\
\hline & $n$-heptylic acid & 28.3 & 49 & 19.8 \\
\hline & di(2-ethylhexyl)phthalate & 31.2 & 52 & 20.9 \\
\hline & carbon disulfide & 31.4 & 53 & 20.7 \\
\hline & tricresyl phosphate & 40.9 & 72 & 19.6 \\
\hline & formamide & 58.2 & 92 & 19.6 \\
\hline & glycerol & 63.4 & 97 & 19.7 \\
\hline \multirow{10}{*}{$\begin{array}{l}n \text {-octadecylamine } \\
{[126]}\end{array}$} & di(n-butyl) ether & 22.8 & 9 & 22.5 \\
\hline & nonane & 22.9 & 13 & 22.3 \\
\hline & decane & 23.9 & 18 & 22.8 \\
\hline & dodecane & 25.4 & 30 & 22.2 \\
\hline & tetradecane & 26.7 & 34 & 22.4 \\
\hline & $\operatorname{di}(n$-heptyl) ether & 27.0 & 34 & 22.7 \\
\hline & hexadecane & 27.6 & 38 & 22.2 \\
\hline & di (n-octyl) ether & 27.7 & 36 & 22.8 \\
\hline & di(2-ethylhexyl)adipate & 30.2 & 45 & 22.3 \\
\hline & $\begin{array}{l}\text { 1,6-hexamethylene glycol } \\
\text { di-2-ethylhexanoate }\end{array}$ & 30.2 & 44 & 22.6 \\
\hline
\end{tabular}




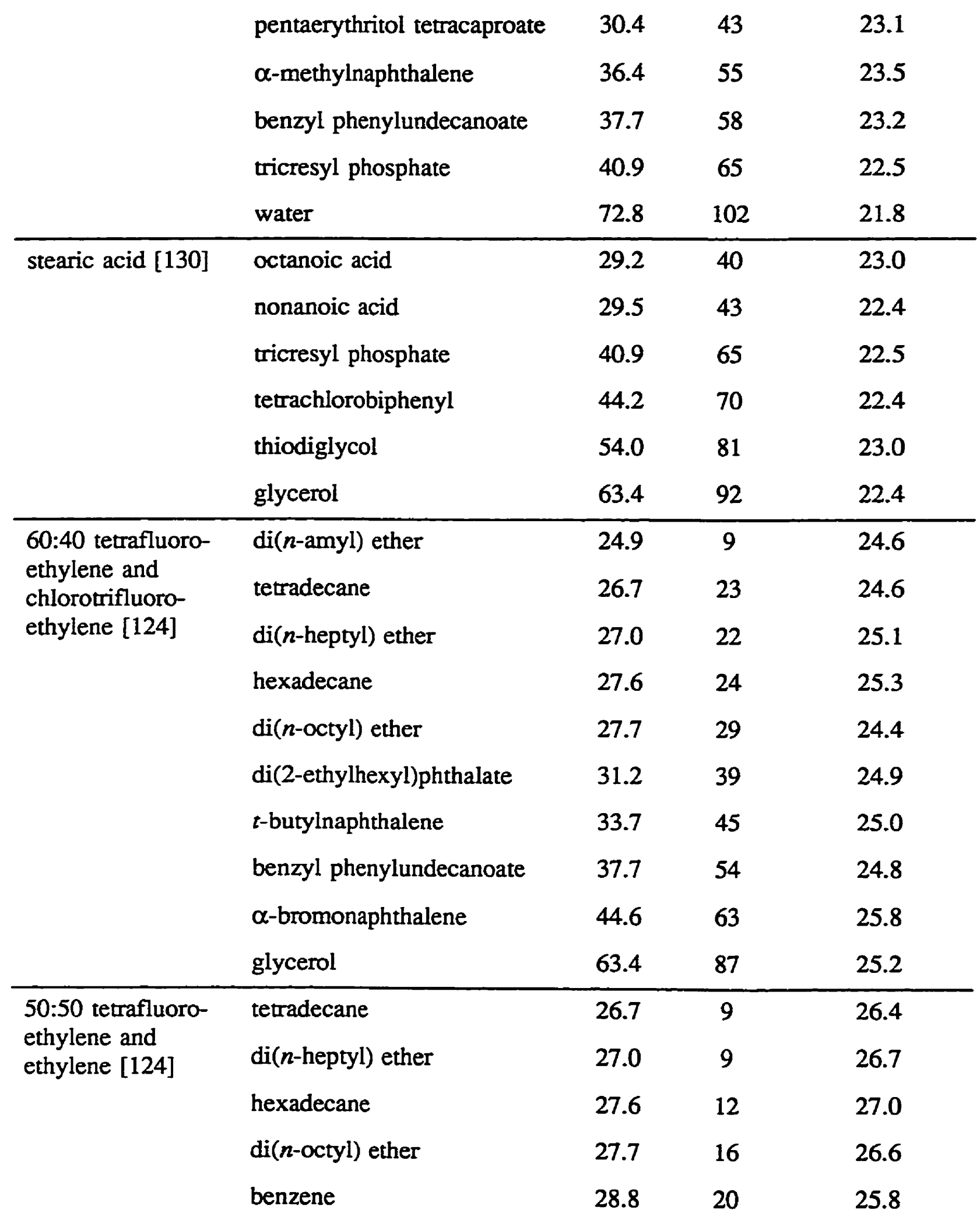




\begin{tabular}{|c|c|c|c|c|}
\hline & di(2-ethylhexyl)phthalate & 31.2 & 32 & 26.8 \\
\hline & $t$-butylnaphthalene & 33.7 & 39 & 26.9 \\
\hline & benzyl phenylundecanoate & 37.7 & 48 & 27.0 \\
\hline & tricresyl phophate & 40.9 & 55 & 26.6 \\
\hline & $\alpha$-bromonaphthalene & 44.6 & 60 & 27.1 \\
\hline & diiodomethane & 50.8 & 69 & 27.0 \\
\hline & formamide & 58.2 & 79 & 26.5 \\
\hline & glycerol & 63.4 & 85 & 26.4 \\
\hline & water & 72.8 & 93 & 27.4 \\
\hline \multirow{5}{*}{$\begin{array}{l}\text { polychlorotri- } \\
\text { fluoroethylene } \\
{[124]}\end{array}$} & di(2-ethylhexyl)phthalate & 31.2 & 6 & 31.0 \\
\hline & benzyl phenylundecanoate & 37.7 & 37 & 30.8 \\
\hline & tricresyl phosphate & 40.9 & 44 & 31.0 \\
\hline & diiodomethane & 50.8 & 82 & 29.4 \\
\hline & water & 72.8 & 90 & 29.2 \\
\hline \multirow{5}{*}{$\begin{array}{l}\text { polyvinyl fluoride } \\
\text { [129] }\end{array}$} & benzyl phenylendecanoate & 37.7 & 17 & 36.1 \\
\hline & tricresyl phosphate & 40.9 & 28 & 36.1 \\
\hline & diiodomethane & 50.8 & 49 & 36.6 \\
\hline & glycerol & 63.4 & 66 & 37.2 \\
\hline & water & 72.8 & 80 & 35.5 \\
\hline \multirow[t]{4}{*}{ nylon $(6,6)[127]$} & $\alpha$-bromonaphthalene & 44.6 & 16 & 42.9 \\
\hline & aroclor 1242 & 45.3 & 19 & 42.9 \\
\hline & formamide & 58.2 & 50 & 41.9 \\
\hline & water & 72.8 & 70 & 41.7 \\
\hline
\end{tabular}

'contact angles were estimated from graphs 
Table 9.2: Averaged $\gamma_{s v}$ values from Table 9.1 (Zisman's data) calculated from the equation of state approach

\begin{tabular}{|c|c|c|}
\hline \multirow[t]{2}{*}{ solid surface } & \multicolumn{2}{|c|}{$\begin{array}{c}\text { Eq. }(8.35), \text { using } \\
\beta=0.0001247\left(\mathrm{~m}^{2} / \mathrm{mJ}\right)^{2}\end{array}$} \\
\hline & $\begin{array}{l}\gamma_{s v} \text { from } \\
\text { Table } 9.1^{\ddagger}\end{array}$ & $\begin{array}{l}\text { \# of } \\
\text { system }\end{array}$ \\
\hline perfluorocapric acid ${ }^{\dagger}[128]$ & $11.6 \pm 0.5$ & 9 \\
\hline perfluorocaprylic acid ${ }^{\dagger}[128]$ & $12.7 \pm 0.5$ & 8 \\
\hline 17-(perfluoroheptyl)-heptadecanoic acid [131] & $12.9 \pm 0.3$ & 19 \\
\hline perfluorocaproic acid ${ }^{\dagger}[131]$ & $13.0 \pm 0.5$ & 6 \\
\hline 17-(perfluoropentyl)-heptadecanoic acid [131] & $14.8 \pm 0.4$ & 8 \\
\hline 17-(perfluoropropyl)-heptadecanoic acid [131] & $17.2 \pm 0.3$ & 11 \\
\hline $80: 20$ tetrafluoroethylene and chlorotrifluoroethylene [124] & $20.8 \pm 0.3$ & 15 \\
\hline hexatriacontane [125] & $20.3 \pm 0.4$ & 12 \\
\hline$n$-octadecylamine [126] & $22.6 \pm 0.2$ & 15 \\
\hline stearic acid [130] & $22.6 \pm 0.3$ & 6 \\
\hline 60:40 tetrafluoroethylene and chlorotrifluoroethylene [124] & $25.0 \pm 0.3$ & 10 \\
\hline 50:50 tetrafluoroethylene and ethylene [124] & $26.7 \pm 0.2$ & 14 \\
\hline polychlorotrifluoroethylene [124] & $30.3 \pm 1.1$ & 5 \\
\hline polyvinyl fluoride [129] & $36.4 \pm 0.8$ & 5 \\
\hline nylon $(6,6)[127]$ & $42.4 \pm 0.9$ & 4 \\
\hline
\end{tabular}

${ }^{\dagger}$ contact angle data were estimated from graphs

†error limits are $95 \%$ confidence limits 
Table 9.3: Comparison between the measured and predicted contact angles and liquid surface tensions on a FC-722-coated mica

\begin{tabular}{lcccc}
\hline liquid & \multicolumn{2}{c}{$\theta$ (deg.) } & \multicolumn{2}{c}{$\gamma_{l v}\left(\mathrm{~mJ} / \mathrm{m}^{2}\right)$} \\
\cline { 2 - 5 } & $\begin{array}{c}\text { measured } \\
\text { in Table 8.4 }\end{array}$ & $\begin{array}{c}\text { predicted } \\
\text { from } \\
\text { Eq.(8.35) }\end{array}$ & $\begin{array}{c}\text { measured in } \\
\text { Table 8.4 }\end{array}$ & $\begin{array}{c}\text { predicted } \\
\text { from } \\
\text { Eq.(8.35) }\end{array}$ \\
\hline decane & 67.36 & $-\ldots .-$ & 23.88 & $-\cdots--$ \\
1-pentanol & 72.95 & 71.4 & 26.01 & 26.8 \\
trans-decalin & 73.38 & 73.4 & 27.19 & 27.2 \\
hexadecane & 75.94 & 74.2 & 27.62 & 28.6 \\
1-decanol & 78.84 & 76.4 & 28.99 & 30.4 \\
cis-decalin & 79.56 & 81.3 & 32.32 & 31.3 \\
ethyl cinnamate & 86.54 & 87.4 & 37.17 & 36.6 \\
dibenzylamine & 90.70 & 91.5 & 40.80 & 40.2 \\
dimethyl sulfoxide (DMSO) & 90.95 & 93.5 & 42.68 & 40.4 \\
1-bromonaphthalene & 93.81 & 95.2 & 44.31 & 43.3 \\
diethylene glycol & 94.22 & 95.6 & 44.68 & 43.5 \\
ethylene glycol & 97.87 & 98.4 & 47.55 & 47.0 \\
diiodomethane & 101.18 & 100.7 & 49.98 & 50.5 \\
2,2'-thiodiethanol & 104.56 & 106.3 & 56.26 & 54.4 \\
formamide & 108.49 & 108.7 & 59.08 & 59.0 \\
glycerol & 111.73 & 113.5 & 65.02 & 62.9 \\
water & 118.69 & 119.3 & 72.70 & 71.9 \\
\hline & & & & \\
\hline
\end{tabular}

${ }^{\dagger}$ based on a $\gamma_{s v}$ value of $11.9 \mathrm{~mJ} / \mathrm{m}^{2}$ calculated from the contact angle of decane 


\section{CHAPTER 10 \\ CONCLUSIONS}

The main contributions of this thesis are as follows. This work illustrates clearly that obtaining meaningful contact angles for the determination of solid surface tensions relies heavily on how contact angles are measured and whether or not the widely made assumptions have been violated. Experimental procedures and criteria for measuring and interpreting meaningful contact angles have been developed. The apparent discrepancy in terms of the contact angle patterns in the literature have been explained. A large amount of meaningful contact angle data was also generated on various solid surfaces. Experimental unique curves of $\gamma_{k} \cos \theta$ vs. $\gamma_{l v}$ were obtained. The widely used surface tension component approaches $[11,15-$ $17,78,79]$ were shown to contradict these experimental contact angle patterns. The new contact angle data established in this thesis provide experimental foundation for future development of the equation of state approach for solid surface tensions; a new formulation of such an approach which allows the determination of solid surface tensions has been developed.

The conclusions of this work are summarized as follows.

(1) Contact angle phenomena are complicated. 
(2) Considerable care is required in the preparation of solid surfaces for contact angle measurements.

(3) Circumspection is necessary in the decision whether or not experimental contact angles can be used in conjunction with Young's equation.

(4) Caution should be exercised when measuring and interpreting static advancing contact angles using a goniometer technique.

(5) Contact angles from a conventional goniometer-sessile drop technique may produce contact angles which violate the basic assumptions made in all surface energetics approaches, e.g. constancy of $\gamma_{s \nu}$.

(6) Low-rate dynamic contact angle measurement from ADSA-P allows one to distinguish meaningful contact angles from meaningless ones.

(7) The values of $\gamma_{l \nu} \cos \theta$ in general change smoothly and systematically with $\gamma_{l \nu}$, signaling constant $\gamma_{s v}$. Because of Young's equation, $\gamma_{s l}$ can be expressed as a function of $\gamma_{l \nu}$ and $\gamma_{s \nu}$.

(8) The solid surface tension $\gamma_{s v}$ can be obtained from the equation of state approach for solid-liquid interfacial tensions.

(9) The predictive power of the equation of state approach is remarkable: From a single contact angle measurement on one and the same solid surface, it is capable of predicting the contact angles $\theta$ for different $\gamma_{h}$ values as well as the $\gamma_{l v}$ for different $\theta$ values. 


\section{CHAPTER 11}

\section{PERSPECTIVE}

A look at the likely future of research on contact angles and surface energetics will benefit from a view back, particularly at persistent obstacles to progress. There are three key attitudes which have hampered progress immensely:

(1) Contact angles are simple quantities which can be readily measured and interpreted by anybody, requiring no particular skill, methodology, or knowledge.

(2) Contact angle measurements show hysteresis. Hence, experimental contact angles are not equilibrium values, and therefore nothing useful can be learned from contact angle studies.

(3) Contact angles contain readily accessible information about intermolecular forces.

All of these propositions are false. With respect to the first proposition, the present thesis shows how misleading conventional contact angle measurements on sessile drops can be.

The second proposition, while false, is the most difficult to refute. Operationally, the key question is not whether a contact angle is an equilibrium contact angle, but whether it can be used in conjunction with Young's equation. For 
instance, contact angle hysteresis caused by a modest degree of surface heterogeneity does not make Young's equation inapplicable. Furthermore, it is clear from the systems examined here that contact with a liquid will often affect the solid surface. This does not preclude the possibility that the advancing contact angle is the equilibrium angle; rather this equilibrium cannot be reached from "the other side", i.e. under receding conditions, because the solid surface is now different. Furthermore, it is difficult to see how the smooth curves of, e.g., Figures 2.1, 5.4, $5.10-5.17,6.1$, and 6.2 could arise if the contact angle data do not contain surface energetic meaning.

Finally, the widely held view expressed in the third proposition is demonstrably false, from curves like those in Figures 2.1, 5.4, 5.10-5.17, 6.1, and 6.2. For a given solid, the contact angle depends only on the liquid surface tension, not directly on the intermolecular forces which give rise to these surface tensions. Referring to the curve for FC-721 in Figure 2.1, the fact that methanol falls on the same smooth curve as hexane and decane would imply that the polar component of surface tension of methanol is zero, i.e. methanol would have to be classified as non-polar, which is clearly absurd.

While the first and third propositions have been dealt with extensively in this thesis, the answer to the question of contact angle hysteresis in the second proposition would require further study. 


\section{CHAPTER 12}

\section{FUTURE WORK}

The present state of knowledge is well summarized in the equation of state approach outlined above. The approach can be used to good advantage in numerous applications, including interfacial phenomena of powders [25,27]. Nevertheless, there remain many unsolved questions relating to the measurement and interpretation of contact angles.

(1) While vapour adsorption does not appear to play a significant role in the contact angle data presented here, it is quite possible that it could enter the picture for more hydrophilic surfaces, particularly if $\gamma_{l v} \approx \gamma_{s v}$ or $\gamma_{l v}<\gamma_{s v}$, i.e. cases which were excluded in the present study. While adsorption may produce contact angle patterns different from those shown in Figures 2.1, 5.4, 5.10-5.17, 6.1 , and 6.2, this would not necessarily imply that Young's equation is not applicable or that contact angle approaches might not be feasible. The answer to these questions would require general criteria to distinguish the effect of vapour adsorption on the contact angles from all other effects.

(2) Recently, self-assembled monolayers (SAMs) have been widely used to produce surfaces of different chemical compositions and wettabilities. However, it is believed that penetration of liquid into the SAMs is inevitable. Given that two solids having the same solid surface tensions and that a specific 
liquid may penetrate into one solid but not the other, the contact angles on the two chemically identical surfaces can be different: one would due to pure energetic effects, and the other to the effects of the changed energetics and liquid penetration. In the latter case, attempts [122] to interpet surface energetics from contact angle approaches naively, e.g. by means of the above equation of state approach, could be misleading (cf. Chapter 7, Figure 7.3).

(3) It is well-known that roughness affects the experimentally observed contact angles. However, there are as yet no general criteria to quantify roughness and at what level of smoothness surface topography has no longer an effect on the contact angle. The answer to such questions will have to involve considerations of line tension [59] and the contortions of three-phase lines.

(4) It is still an open question of whether or not $\beta$ in Eq.(8.35) is a "universal" constant, i.e. independent of the solid surface. Such a question can be addressed only after an even larger body of accurate contact angle data on various solids has been generated.

(5) In the experimental patterns of Figures $2.1,5.4,5.10-5.17,6.1$, and 6.2 , it was found that liquid properties, i.e. intermolecular forces, do not act independently on the contact angles. Indeed, this is supported by recent studies $[45,48]$ using the theory of molecular interactions. Further development or modeling of this molecular theory or any other sound theory should allow a better understanding of contact angles and contribute to the present debate about contact angle interpretation. 
(6) While the slip/stick contact angle patterns, e.g., of that shown in Figure 5.9 and similar patterns cannot be used to determine surface energetics, they are still very interesting and worth investigating.

(7) Routine production of systems which are free of contact angle hysteresis might be considered an important goal. It is firmly believed that all that would be produced is further confirmation of the contact angle story presented here. It is expected that more benefits can be obtained from the much simpler systematic study of receding contact angles of available systems, using concepts and procedures described above.

(8) Some of the contact angle data presented here show deviations from a smooth curve which, while inside the widely accepted global accuracy of $\pm 2^{\circ}$, are somewhat outside the error limits of the ADSA measurements. The question whether these deviations are artifacts or whether they reflect physical reality needs further study. 


\section{REFERENCES}

1. B.V. Derjaguin, V.M. Muller and Y.P. Toporov, J. Colloid Interface Sci., 73 (1980) 293.

2. K.L. Johnson, K. Kendall and A.D. Roberts, Proc. Roy. Soc. (London), A324 (1971) 301.

3. V.M. Muller, Yushchenko, V.S. and B.V. Derjaguin, J. Colloid Interface Sci., 92 (1983) 92.

4. A. Fogden and L.R. White, J. Colloid Interface Sci., 138 (1990) 414.

5. R.M. Pashley, P.M. McGuiggan, R.G. Horn and B.W. Ninham, J. Colloid Interface Sci., 126 (1988), 569.

6. H.K. Christenson, J. Phys. Chem., 90 (1986) 4.

7. P.M. Claesson, C.E. Blom, P.C. Horn and B.W. Ninham, J. Colloid Interface Sci., 114 (1986) 234.

8. P.M. Pashley, P.M. McGuiggan and R.M. Pashley, Colloids Surf., 27 (1987) 277.

9. R.M. Pashley, P.M. McGuiggan, B.W. Ninham and D.F. Evans, Science, 229 (1985) 1088.

10. W.A. Zisman, "Contact Angle, Wettability and Adhesion" in Advances in Chemistry Series, Vol. 43; American Chemical Society: Washington, D.C., (1964).

11. F.M. Fowkes, Ind. Eng. Chem. 12 (1964) 40.

12. O. Driedger, A.W. Neumann and P.J. Sell, Kolloid-Z. Z. Polym. 201 (1965) 52. 
13. A.W. Neumann, R.J. Good, C.J. Hope and M. Sejpal, J. Colloid Interface Sci. 49 (1974) 291.

14. J.K. Spelt and D. Li, "The Equation of State Approach to Interfacial Tensions" in Applied Surface Thermodynamics, A.W. Neumann, J.K. Spelt, Eds., Marcel Dekker Inc.: New York, 1996; pp 239-292.

15. D.K. Owens and R.C. Wendt, J. Appl. Polym. Sci. 13 (1969) 1741.

16. C.J. van Oss, M.K. Chaudhury and R.J. Good, Chem. Revs. 88 (1988) 927.

17. R.J. Good and C.J. van Oss, "The Modern Theory of Contact Angles and the Hydrogen Bond Components of Surface Energies" in Modern Approaches to Wettability: Theory and Applications, M. Schrader, G. Loeb., Eds.; Plenum Press: New York, 1992; pp 1-27.

18. H.G. Bruil, Colloid Polym. Sci., 252 (1974) 32.

19. G.D. Cheever, J. Coat Technol., 55 (1983) 53.

20. H.W. Kilau, Colloids Surf., 26 (1983) 217.

21. K. Grundke, T. Bogumil, T. Gietzelt, H.-J. Jacobasch, D.Y. Kwok and A.W. Neumann, Progr. Colloid Polym. Sci., 101 (1996) 58.

22. E.I. Vargha-Butler, T.K. Zubovits, D.R. Absolom and A.W. Neumann, Dispersion Sci. Technol., 6(3) (1985) 357.

23. E.I. Vargha-Butler, E. Moy and A.W. Neumann, Colloids Surf., 24 (1987) 315.

24. E.I. Vargha-Butler, T.K. Zubovits, D.R. Absolom and A.W. Neumann, Chem. Eng. Commun., 33 (1985) 255.

25. D. Li and A.W. Neumann, "Wettability and Surface Tension of Particles" in Applied Surface Thermodynamics, A.W. Neumann, J.K. Spelt, Eds.; Marcel Dekker Inc.: New York, 1996; pp 509-556.

26. S.N. Omenyi and A.W. Neumann, J. Appl. Phys., 47 (1976) 3956. 
27. D. Li and A.W. Neumann, "Behavior of Particles at Solidification Fronts" in Applied Surface Thermodynamics, A.W. Neumann, J.K. Spelt, Eds.; Marcel Dekker Inc.: New York, 1996; pp 557-628.

28. A.E. Corte, J. Geophys. Res. 67 (1962) 1085.

29. P. Hoekstra and R.D. Miller, J. Colloid Interface Sci. 25 (1967) 166.

30. J. Cissé and G.F. Bolling, J. Crystal Growth 10 (1971) 67.

31. J. Cissé and G.F. Bolling, J. Crystal Growth 11 (1971) 25.

32. A.M. Zubko, V.G. Lobonov and V.V. Nikonova, Sov. Phys. Crystallogr. 18 (1973) 239.

33. K.H. Chen and W.R. Wilcox, J. Crystal Growth 40 (1977) 214.

34. D.W. Fuerstenau and M.C. Williams, Colloids Surfaces 22 (1987) 87.

35. D.W. Fuerstenau and M.C. Williams, Part. Characterization 4 (1987) 7.

36. D.W. Fuerstenau and M.C. Williams, Int. J. Mineral Process 20 (1987) 153.

37. D.W. Fuerstenau, M.C. Williams, K.S. Narayanan, J.L. Diao and R.H. Urbina, Energy and Fuels 2 (1988) 237.

38. D.W. Fuerstenau, J. Diao and J. Hanson, Energy and Fuels 4 (1990) 34.

39. S.J. Hemingway, J.R. Henderson and J.R. Rowlinson, Faraday Symp. Chem. Soc. 16 (1981) 33.

40. R. Guermeur, F. Biquard and C. Jacolin, J. Chem. Phys. 82 (1985) 2040.

41. B.S. Carey, L.E. Scriven and H.T. Davis, AICHE J. 26 (1980) 705.

42 E. Moy and A.W. Neumann, "Theoretical Approaches for Estimating SolidLiquid Interfacial Tensions" in Applied Surface Thermodynamics, A.W. Neumann, J.K. Spelt, Eds.; Marcel Dekker Inc.: New York, 1996; pp 333-378. 
43. H.C. Hamaker, Physica 4 (1937) 1058.

44. J.N. Israelachvili, Proc. R. Soc. London. A. 331 (1972) 39.

45. A.E. van Giessen, D.J. Bukman and B. Widom, J. Colloid Interface Sci. 192 (1997) 257.

46. T.M. Reed, J. Phys. Chem. 55 (1955) 425.

47. B.E.F. Fender and G.D. Halsey, Jr., J. Chem. Phys. 36 (1962) 1881.

48. D.E. Sullivan, J. Chem. Phys. 74(4) (1981) 2604.

49. D.V. Matyushov and R. Schmid, J. Chem. Phys. 104(21) (1996) 8627.

50. T. Young, Philos. Trans. R. Soc. London 95 (1805) 65.

51. A.W. Neumann, Adv. Colloid Interface Sci. 4 (1974) 105.

52. D. Li and A.W. Neumann, "Thermodynamic Status of Contact Angles" in Applied Surface Thermodynamics, A.W. Neumann, J.K. Spelt, Eds.; Marcel Dekker Inc.: New York, 1996; pp 109-168.

53. A. Marmur, Colloids Surf. A 116 (1996) 25.

54. R.V. Sedev, J.G. Petrov and A.W. Neumann, J. Colloid Interface Sci. 180 (1996) 36.

55. R.N. Wenzel, Ind. Eng. Chem. 28 (1936) 988.

56. A.B.D. Cassie, Discuss. Faraday Soc. 3 (1948) 11.

57. S. Baxer and A.B.D. Cassie, J. Text. Inst. 36:T (1945) 67.

58. A.B.D. Cassie and S. Baxter, Trans. Faraday Soc. 40 (1944) 546.

59. J. Gaydos and A.W. Neumann, "Line Tension in Multiphase Equilibrium Systems" in Applied Surface Thermodynamics, A.W. Neumann, J.K. Spelt, Eds., Marcel Dekker Inc.: New York, 1996; pp 169-238. 
60. C.J. van Oss, L. Ju, M.K. Chaudhury and R.J. Good, J. Colloid Interface Sci. 128 (1989) 313.

61. C.J. van Oss, M.K. Chaudhury and R.J. Good, J Chromatography 391 (1987) 53.

62. C.J. van Oss, M.K. Chaudhury and R.J. Good, Sep. Sci. Technol. 24 (1989) 15.

63. R.J. Good, N.R. Srivatsa, M. Islam, H.T.L. Huang and C.J. van Oss, J. Adhes. Sci. Technol. 4(8) (1990) 607.

64. C.J. van Oss, R.J. Good and H.J. Busscher, J. Disp. Sci. Technol. 11(1) (1990) 75.

65. J.O. Naim and C.J. van Oss, Immunological Invest. 21(7) (1992) 649.

66. A.W. Neumann and R.J. Good, "Experimental Methods" in Surface and Colloid Surface, R.J. Good, R.R. Stomberg, Eds., Vol. 11, Plenum Press: New York, 1979; pp 31-91.

67. J.K. Spelt and E.I. Vargha-Butler, "Contact Angle and Liquid Surface Tension Measurements: General Procedures and Techniques" in Applied Surface Thermodynamics, A.W. Neumann, J.K. Spelt, Eds., Marcel Dekker Inc.: New York, 1996; pp 379-411.

68. D. Li and A.W. Neumann, J. Colloid Interface Sci. 148 (1992) 190.

69. D. Li, M. Xie and A.W. Neumann, Colloid Polym. Sci. 271 (1993) 573.

70. D.Y. Kwok, D. Li and A.W. Neumann, Colloids Surf. A. 89 (1994) 181.

71. C.A. Ward and A.W. Neumann, J. Colloid Interface Sci. 49 (1974) 286.

72. R. Defay, "Etude Thermodynamique de Ia Tension Superficielle"; Gauthier Villars: Paris, 1934.

73. R. Defay and I. Prigogine, "Surface Tension and Adsorption"; A. Bellemans (collab.), D.H. Everett (trans.), Longmans; Green \& Co.: London, 1954, p.222. 
74. D. Li, J. Gaydos and A.W. Neumann, Langmuir 5 (1989) 293.

75. D. Li and A.W. Neumann, Adv. Colloids Interface Sci. 49 (1994) 147.

76. U. Wienhold, Ph.D. Thesis, Martin-Luther-Universität Halle-Wittenberg, Germany, 1994.

77. D.Y. Kwok, T. Gietzelt, K. Grundke, H.-J. Jacobasch and A.W. Neumann, Langmuir 13 (1997) 2880.

78. D.H. Kaelble, J. Adhesion 2 (1970) 66.

79. S. Wu, in Adhesion and Adsorption of Polymers, L.-H. Lee, Ed., Plenum, New York, 1980; pp 53-65.

80. C.J. van Oss, R.J. Good and M.K. Chaudhury, Langmuir 4 (1988) 884.

81. Y. Rotenberg, L. Boruvka and A.W. Neumann, J. Colloid Interface Sci. 93 (1983) 169.

82. P. Cheng, D. Li, L. Boruvka, Y. Rotenberg and A.W. Neumann, Colloids Surf. 93 (1983) 169.

83. P. Cheng, Ph.D. Thesis, "Automation of Axisymmetric Drop Shape Analysis Using Digital Image Processing", University of Toronto, 1990.

84. S. Lahooti, O.I. del Rio, P. Cheng and A.W. Neumann, "Axisymmetric Drop Shape Analysis" in Applied Surface Thermodynamics, A.W. Neumann, J.K. Spelt, Eds., Marcel Dekker Inc.: New York, 1996; pp 441-507.

85. D.Y. Kwok, W. Hui and A.W. Neumann, Langmuir 11 (1995) 2669.

86. D.Y. Kwok, Y. Lee and A.W. Neumann, "Evaluation of the Lifshitz - van der Waals / Acid-Base Approach to Determine Interfacial Tensions: 2. Interfacial Tensions of Liquid-Liquid Systems", Langmuir (accepted for publication, Feb. 1998).

87. A. Voigt, O. Thiel, D. Williams, Z. Policova, W. Zingg and A.W. Neumann, Colloids Surf. 58 (1991) 315. 
88. S.S. Susnar, H.A. Hamza and A.W. Neumann, Colloids Surf. A. 89 (1994) 169.

89. D.Y. Kwok, M.A.Sc. Thesis, "Axisymmetric Drop Shape Analysis as a Film Balance", University of Toronto, 1994.

90. D.Y. Kwok, D. Vollhardt, R. Miller, D. Li and A.W. Neumann, Colloids Surf. A. 10 (1994) 51.

91. D.Y. Kwok, P. Chiefalo, B. Khorshiddoust, S. Lahooti, M.A. CabrerizoVilchez, O. del Rio and A.W. Neumann, "Determination of Ultra-Low Interfacial Tension by Axisymmetric Drop Shape Analysis" in Surfactant Adsorption and Surface Solubilization, R. Sharma, Ed., ACS Series 615; Washington, D.C., 1995, pp 374-386.

92. D.Y. Kwok, M.A. Cabrerizo-Vilchez, Y. Gomez, S.S. Susnar, O. del Rio, D. Vollhardt, R. Miller and A.W. Neumann, "Axisymmetric Drop Shape Analysis as a Method to Study Dynamic Interfacial Tensions" in Dynamic Properties of Interfaces and Association Structures, V. Pillai, D.O. Shah, Eds., AOCS Press; Champaign, IL, 1996; pp 278-296.

93. S.S. Susnar, P. Chen, O.I. del Rio and A.W. Neumann, Colloids Surf. A. 116 (1996) 181.

94. J.K. Spelt, D.R. Absolom and A.W. Neumann, Langmuir 2 (1986) 620.

95. D.Y. Kwok, R. Lin, M. Mui and A.W. Neumann, Colloids Surf. A. 116 (1996) 63.

96. J.F. Oliver, C. Huh and S.G. Mason, J. Colloid Interface Sci. 93 (1983) 169.

97. J.F. Oliver, C. Huh and S.G. Mason, Colloids Surf. 1 (1980) 79.

98. D. Duncan, D. Li, J. Gaydos and A.W. Neumann, J. Colloid Interface Sci. 169 (1995) 256.

99. A. Amirfazli, D.Y. Kwok, J. Gaydos and A.W. Neumann, "Line Tension Measurements Through Drop Size Dependence of Contact Angles", J. Colloid Interface Sci. (accepted for publication, March 1998). 
100. D.Y. Kwok, D. Li and A.W. Neumann, "Capillary Rise at a Vertical Plate as a Contact Angle Technique" in Applied Surface Thermodynamics, A.W. Neumann, J.K. Spelt, Eds., Marcel Dekker Inc.: New York, 1996; pp 413-440.

101. D.Y. Kwok, C.J. Budziak and A.W. Neumann, J. Colloid Interface Sci. 173 (1995) 143.

102. K. Grundke, P. Weidenhammer, P. Werner, R. Trinowitz, A. Janke, D.Y. Kwok, K. Pöschel, H.-J. Jacobasch and A.W. Neumann, (in preparation)

103. C.J. Budziak and A.W. Neumann, Colloids Surf. 43 (1990) 279.

104. G.H.E. Hellwig and A.W. Neumann, 5th Int. Congr. on Surface Activity, Section B, (1968) 687.

105. G.H.E. Hellwig and A.W. Neumann, Kolloid-Z. Z. Polym. 40 (1969) 229.

106. O.I. del Río, D.Y. Kwok, R. Wu, J.M. Alvarez and A.W. Neumann, "Contact Angle Measurements by Axisymmetric Drop Shape Analysis and an Automated Polynomial Fit Program" Colloid Surf. A (accepted for publication, June 1997).

107. D.Y. Kwok, C.N.C. Lam, A. Li, A. Leung, R. Wu, E. Mok and A.W. Neumann, "Measuring and Interpreting Contact Angles: A Complex Issue", Colloids Surf. A (accepted for publication, Dec. 1997).

108. D.Y. Kwok, C.N.C. Lam, A. Li, A. Leung and A.W. Neumann, "Low-Rate Dynamic Contact Angles on Non-Inert Poly(propene-alt- $N$-( $n$-alkyl)maleimide) Copolymers by an Automated Axisymmetric Drop Shape Analysis (ADSA-P)", Langmuir, 14 (1998) 2221.

109. D.Y. Kwok, A. Leung, A. Li, C.N.C. Lam, R. Wu and A.W. Neumann, "LowRate Dynamic Contact Angles on Poly( $n$-butyl methacrylate) and the Determination of Solid Surface Tensions", Colloid Polym. Sci. (accepted for publication, Jan. 1998).

110. D.Y. Kwok, C.N.C. Lam, A. Li, K. Zhu, R. Wu and A.W. Neumann, "LowRate Dynamic Contact Angles on Polystyrene and the Determination of Solid Surface Tensions", Polym. Eng. Sci. (accepted for publication, Jan. 1998). 
111. D.Y. Kwok, A. Li, C.N.C. Lam, R. Wu, T. Gietzelt, K. Grundke, H.-J. Jacobasch and A.W. Neumann, "Low-Rate Dynamic Contact Angles on Poly(styrene-(hexyl/10-carboxydecyl 90:10)-maleimide) and the Determination of Solid Surface Tensions" (to appear).

112. D.Y. Kwok, C.N.C. Lam, A. Li and A.W. Neumann, "Low-Rate Dynamic Contact Angles on Poly(methyl methacrylate/ $n$-butyl methacrylate) and the Determination of Solid Surface Tensions", J. Adhes. (accepted for publication, Feb. 1998).

113. D.Y. Kwok, A. Leung, C.N.C. Lam, A. Li, R. Wu and A.W. Neumann, "LowRate Dynamic Contact Angles on Poly(methyl methacrylate) and the Determination of Solid Surface Tensions", J. Colloid Interface Sci. (accepted for publication, April 1998).

114. H.B. Callen, Thermodynamics and an Introduction to Thermostatistics, 2nd Ed., John Wiley \& Sons, 1985.

115. G. Antonow, J. Chim. Phys. 5 (1907) 372.

116. D. Berthelot, Compt. rend. 1261703 (1898) 1857.

117. R.J. Good, in Adsorption at Interfaces, K.L Mittal, Ed., ACS Symposium Series, No. 8, American Chemical Society, D.C., 1975.

118. D. Li, C. Ng and A.W. Neumann, J. Adhes. Sci. Technol. 6 (1992) 601.

119. C.D. Bain, E.B. Troughton, Y. Tao, J. Eval, G.M. Whitesides and R.G. Nuzzo, J. Am. Chem. Soc. 111 (1989) 321.

120. C.D. Bain and G.M. Whitesides, Angew. Chem. Int. Ed. Engl. 28 (1989) 506.

121. A. Amirfazli, Ph.D. Thesis, University of Toronto (in preparation).

122. J. Drelich and J.D. Miller, J. Colloid Interface Sci. 167 (1994) 217.

123. G.S. Ferguson and G.M. Whitesides, "Thermal Reconstruction of the Functionalized Interface of Polyethylene Carboxylic Acid and Its Derivatives" in Modern Approaches to Wettability: Theory and Applications, M. Schrader, G. Loeb., Eds.; Plenum Press: New York, 1992; pp 143-177. 
124. H.W. Fox and W.A. Zisman, J. Phys. Chem. 7 (1952) 109.

125. H.W. Fox and W.A. Zisman, J. Colloid Sci. 7 (1952) 428.

126. E.G. Shafrin and W.A. Zisman, J. Colloid Sci. 7 (1952) 166.

127. A.H. Ellison and W.A. Zisman, J. Phys. Chem. 58 (1954) 503.

128. E.F. Hare, E.G. Shafrin and W.A. Zisman, J. Phys. Chem. 58 (1954) 236.

129. A.H. Ellison and W.A. Zisman, J. Phys. Chem. 58 (1954) 260.

130. E.G. Shafrin and W.A. Zisman, J. Phys. Chem. 61 (1957) 1046.

131. E.G. Shafrin and W.A. Zisman, J. Phys. Chem. 66 (1962) 740.

132. D.Y. Kwok, D. Li and A.W. Neumann, Langmuir 10 (1994) 1323.

133. W. Wu, R.F. Giese, Jr. and C.J. van Oss, Langmuir 11 (1995) 379.

134. F. London, Z. Phys. Chem. (B) 11 (1930) 222.

135. G.C. Maitland, M. Rigby, E.B. Smith and W.A. Wakeham, Intermolecular Forces: Their Origin and Determination, Clarendon Press, Oxford, 1981.

136. A. Dupré, "Théorie Mécanique de la Chaleur"; Gauthier-Villars: Paris, 1969.

137. L.A. Girifalco and R.J. Good, J. Phys. Chem. 61 (1957) 904.

138. R.J. Good and E. Elbing, Ind. Eng. Chem. 62(3) (1970) 72.

139. K.C. Chao and R.L. Robinson, Jr., Equation of State: Theories and Applications, ACS, Washington, D.C., 1986.

140. J.S. Rowlinson and F.L. Swinton, Liquids and Liquid Mixtures, Butterworth Scientific, London, 1981.

141. J. Kestin and E.A. Mason, AIP Conf. Proc. 11 (1973) 137. 
142. D. Li and A.W. Neumann, J. Colloid Interface Sci. 137 (1990) 304.

143. C. Lipson and N.J. Sheth, Statistical Design and Analysis of Engineering Experiments, McGraw-Hill Publishing Co., New York, 1973.

144. J.A. Mann, Jr., in Surface and Colloid Science, Vol. 13, E. Matijjevic, R.J. Good, Eds.; Plenum Press: New York, 1984, p.213. 


\section{APPENDIX A \\ STATISTICAL CRITERIA FOR AVERAGING \\ OF CONTACT ANGLE DATA}

In the analysis of experimental data, it is desirable to study whether correlation exists among variables and, if so, how one variable correlates (or associates) with the others. For example, one might ask what is the association between surface tension and temperature? Does one depend on the other, or are they unrelated? These situations are covered by correlation analysis [143]. In other situations, one may be interested in establishing the functional relationship among the variables, where regression analysis applies [143]. In the above example, one might ask, alternatively, what is the functional relationship between surface tension and temperature. However, a functional relationship must be assumed, a priori. Once the functional relationship is established between the independent and dependent variables, regression analysis can be used to determine how well this relation fits the experimental data. For example, regression analysis can be used to determine whether a straight line or a quadratic equation should be used to best describe the dependence of surface tension on the temperature.

For the purpose of deciding whether averaging of contact angles over time is allowed, correlation analysis is used since one does not have to assume a functional relationship between contact angle and time: All we want to know is whether the 
experimental contact angle is associated with time for a specific experiment, and if so, averaging is not allowed. A quantitative measure of the association between the variables is defined by the correlation coefficient, $r$. The range of $r$ can be from -1 to +1 , depending on the degree of association. For example, when $r=-1$, a perfect, but negative, correlation exists among the variables. Statistical tables [143] can be used to determine the significance of the calculated correlation coefficient, $r_{\text {cal }}$, from a sample at a certain confidence level. Such table provides the maximum values of $r_{t a b}$ which can be expected by chance alone when actually no correlation exists. In order to conclude at a given confidence level that correlation does exist, the calculated $r_{c a l}$ should exceed the tabulated value of $r_{t a b}$.

In Figure 5.8, the calculated correlation coefficient, $r_{\text {cal }}$, is found to be 0.935, where the tabulated correlation coefficient, $r_{t a b}$ at $99 \%$ confidence is found to be 0.29 (see Table A.1). Since $r_{c a l}=0.935 \gg r_{t a b}=0.29$, one can conclude that, at 99\% confidence, contact angle and time are strongly correlated. The positive value of $r_{c a l}$ indicates that contact angle and time are correlated positively. Thus, averaging of contact angles over time in Figure 5.8 is not allowed. Similar conclusions with similar results (see Table A.1) can be drawn for other liquids, where controversy might arise as to whether averaging is allowed, if only the experimental reasons discussed earlier in the paper are considered.

To prove the point, the correlation coefficient for water on poly(propene-alt- $N$ (n-propyl)maleimide) in Figure 5.5 was also calculated. The calculated correlation coefficient, $r_{c a l}$, is significantly less than that of the $r_{t a b}$ at $99 \%$ confidence (see 
Table A.1). Thus, one can conclude that, at $99 \%$ confidence, there is no correlation between the contact angle and time and averaging the contact angles over time is allowed. 
Table A.1: Summary of the correlation analysis to study whether or not averaging the contact angles over time is allowed for the solid-liquid system in Figures 5.5 and $\mathbf{5 . 8}$

\begin{tabular}{|c|c|c|c|c|}
\hline & $\begin{array}{c}\text { no. of } \\
\text { observations after } \\
R=0.48 \mathrm{~cm}\end{array}$ & $r_{\text {cal }}$ & $\begin{array}{l}r_{\text {tab }} \text { at } \\
99 \%\end{array}$ & $\begin{array}{l}\text { is averaging } \\
\text { allowed at } 99 \% \\
\text { confidence? }\end{array}$ \\
\hline \multicolumn{5}{|l|}{$\begin{array}{l}\text { poly }(\text { propene-alt }-N-(n- \\
\text { propyl)maleimide })\end{array}$} \\
\hline ethylene glycol in Figure 5.8 & 73 & 0.935 & 0.29 & no \\
\hline water in Figure 5.5 & 62 & -0.048 & 0.33 & yes \\
\hline
\end{tabular}




\section{APPENDIX B \\ LOW-RATE DYNAMIC CONTACT ANGLES \\ ON A FLUOROCARBON FC725-COATED \\ SULICON WAFER SURFACE}

Low-rate dynamic contact angles of 30 liquids on a FC-725-coated wafer surface are measured by an automated axisymmetric drop shape analysis - profile (ADSA-P). Surprisingly, results indicate that FC-725 behaves differently in some respects from what one would expect for non-polar surfaces: only 9 liquids yield essentially constant contact angles whereas the others show slip/stick contact angle behaviour. In the worst case, the contact angle increases from about $50^{\circ}$ to $160^{\circ}$ at essentially constant three-phase contact radius. These angles should be disregarded for the interpretation in terms of surface energetics since there is no guarantee that Young's equation is applicable.

\section{B.1 Materials (Solid Surfaces and Liquids)}

FC-725, a "Fluorad" brand conformal coating, available as a $2 \%$ solution from 3M (London, Ont.: I.D.\# 98-0211-1251-5) was used as supplied. The FC-725-coated surfaces were prepared by a dip-coating technique $[68,95]$ on cleaned and dried silicon wafer surfaces. Silicon wafers $<100>$ (Silicon Sense, Naschua, N.H., U.S.A.; thickness: $525 \pm 50$ micron) were selected as the substrate for the polymer coating. 
They were obtained as circular discs of about $10 \mathrm{~cm}$ diameter and were cut into rectangular shapes of about $2 \times 3 \mathrm{~cm}^{2}$. A hole of about $1 \mathrm{~mm}$ diameter was made, by using a diamond drill bit from Lunzer (New York, N.Y., U.S.A.; SMS-0.027), in the centre of each rectangular wafer surface before the cleaning procedures. Each rectangular wafer surface was first cleaned with ethanol (Commercial Alcohol Inc., Toronto; > 99\% purity from a 25L metal tank), acetone (BDH Inc., Toronto; $99.5 \%$ purity from a $4 \mathrm{~L}$ bottle), and then soaked in chromic acid for at least $24 \mathrm{hr}$. The cleaned wafer surfaces were rinsed with doubly-distilled water (deionized with a Sybron Barnstead MEGA-PURE system), and dried under a heat lamp before the copolymer coating. The experimental procedures have been described in Chapter 5 .

Thirty liquids were chosen in this study [107]. They are listed in Table B.1, together with the physical properties and surface tensions (measured at $23.0 \pm$ $\left.0.5^{\circ} \mathrm{C}\right)$.

\section{B.2 Results}

Of the 30 liquids used, only 9 liquids resulted in essentially constant contact angles: they are water, glycerol, formamide, 2,2'-thiodiethanol, ethylene glycol, diethylene glycol, 3,3'-thiodipropanol, hexadecane, and dodecane. They are summarized in Table B.2, at different rates of advancing, and each on a newly prepared surface.

The rest of the 21 liquids were found to behave similarly on the surface, largely with slip/stick behaviour. A summary of these complexities is given in Table B.3, 
together with the meaningful results from Table B.2; a total of more than 150 freshly prepared FC-725-coated wafers were prepared and used; more than 10,000 images were acquired and analyzed by ADSA-P. 
Table B.1: Suppliers and surface tensions of the liquids used for the contact angle measurements on a FC-725-coated silicon wafer surface. The surface tensions were measured at $23.0 \pm 0.5^{\circ} \mathrm{C}$

\begin{tabular}{|c|c|c|c|c|c|}
\hline liquid & supplier & $\%$ purity & $\begin{array}{l}\text { density } \\
\left(\mathrm{g} / \mathrm{cm}^{3}\right)\end{array}$ & $\begin{array}{l}\text { surface } \\
\text { tension } \gamma_{k v} \\
\left(\mathrm{~mJ} / \mathrm{m}^{2}\right)\end{array}$ & $\begin{array}{l}\text { no. of } \\
\text { drops }\end{array}$ \\
\hline decane & caledon & 99.98 & 0.730 & $23.88 \pm 0.008$ & 10 \\
\hline dodecane & aldrich & 99 & 0.749 & $25.64 \pm 0.03$ & 10 \\
\hline 1-pentanol & aldrich & $99+$ & 0.811 & $26.01 \pm 0.09$ & 10 \\
\hline trans-decalin & aldrich & 99 & 0.870 & $27.19 \pm 0.08$ & 10 \\
\hline hexadecane & aldrich & $99+$ & 0.773 & $27.62 \pm 0.005$ & 10 \\
\hline 1-decanol & aldrich & $99+$ & 0.829 & $28.99 \pm 0.004$ & 10 \\
\hline cis-decalin & aldrich & 99 & 0.897 & $32.32 \pm 0.01$ & 7 \\
\hline nitromethane & aldrich & $99+$ & 1.127 & $34.31 \pm 0.006$ & 10 \\
\hline 2,5-dichlorotoluene & aldrich & 98 & 1.254 & $34.64 \pm 0.003$ & 10 \\
\hline triacetin & fluka & $99+$ & 1.158 & $35.52 \pm 0.16$ & 10 \\
\hline ethyl cyanoacetate & aldrich & $98+$ & 1.063 & $36.01 \pm 0.04$ & 9 \\
\hline$N, N$-dimethylformamide & $\begin{array}{l}\text { sigma- } \\
\text { aldrich }\end{array}$ & $\begin{array}{l}99.9+ \\
\text { (HPLC) }\end{array}$ & 0.944 & $36.65 \pm 0.004$ & 9 \\
\hline ethyl cinnamate & aldrich & 99 & 1.049 & $37.17 \pm 0.02$ & 10 \\
\hline methyl salicylate & aldrich & $99+$ & 1.174 & $38.82 \pm 0.07$ & 10 \\
\hline 3,3'-thiodipropanol & aldrich & 98 & 1.092 & $39.83 \pm 0.20$ & 10 \\
\hline dibenzylamine & aldrich & 97 & 1.026 & $40.80 \pm 0.06$ & 9 \\
\hline $\begin{array}{l}\text { dimethyl sulfoxide } \\
\text { (DMSO) }\end{array}$ & $\begin{array}{l}\text { sigma- } \\
\text { aldrich }\end{array}$ & $\begin{array}{l}99.9 \\
\text { (HPLC) }\end{array}$ & 1.101 & $42.68 \pm 0.09$ & 10 \\
\hline 1-iodonaphthalene & aldrich & 99 & 1.740 & $42.92 \pm 0.03$ & 10 \\
\hline 1-bromonaphthalene & aldrich & 98 & 1.489 & $44.31 \pm 0.05$ & 7 \\
\hline diethylene glycol & aldrich & 99 & 1.118 & $45.16 \pm 0.05$ & 10 \\
\hline
\end{tabular}




\begin{tabular}{llllll} 
1,3-diiodopropane & aldrich & 99 & 2.576 & $46.51 \pm 0.13$ & 10 \\
3-pyridylcarbinol & aldrich & 98 & 1.124 & $47.81 \pm 0.03$ & 10 \\
ethanolamine & aldrich & $99+$ & 1.012 & $48.23 \pm 0.06$ & 10 \\
ethylene glycol & aldrich & $99+$ & 1.113 & $48.66 \pm 0.02$ & 10 \\
1,1,2,2-tetrabromoethane & aldrich & 98 & 2.967 & $49.29 \pm 0.05$ & 10 \\
diiodomethane & aldrich & 99 & 3.325 & $49.98 \pm 0.02$ & 10 \\
2,2'-thiodiethanol & aldrich & $99+$ & 1.221 & $53.77 \pm 0.03$ & 10 \\
formamide & aldrich & $99.5+$ & 1.134 & $59.08 \pm 0.01$ & 10 \\
glycerol & baker & 99.8 & 1.258 & $63.13 \pm 0.10$ & 10 \\
analyzed & & & & \\
water & LAST & $\begin{array}{l}\text { doubly } \\
\text { distilled }\end{array}$ & 0.997 & $72.7 \pm 0.09$ & 10 \\
\hline
\end{tabular}

${ }^{\dagger}$ Laboratory of Applied Surface Thermodynamics 
Table B.2: Low-rate dynamic (advancing) contact angles of different liquids on a FC-725coated silicon wafer surface. For each liquid, at least 5 and up to 10 different rates of advancing of the three-phase contact line were performed, each on a newly prepared solid surface. The error bars are $95 \%$ confidence limits

\begin{tabular}{|c|c|c|c|c|c|}
\hline \multicolumn{2}{|c|}{ water } & \multicolumn{2}{|c|}{ glycerol } & \multicolumn{2}{|c|}{ formamide } \\
\hline $\begin{array}{c}\text { rate } \\
(\mathrm{mm} / \mathrm{min} .)\end{array}$ & $\begin{array}{c}\theta \\
\text { (deg.) }\end{array}$ & $\begin{array}{c}\text { rate } \\
(\mathrm{mm} / \mathrm{min} .)\end{array}$ & $\begin{array}{c}\theta \\
\text { (deg.) }\end{array}$ & $\begin{array}{c}\text { rate } \\
(\mathrm{mm} / \mathrm{min} .)\end{array}$ & $\begin{array}{c}\boldsymbol{\theta} \\
\text { (deg.) }\end{array}$ \\
\hline 0.084 & 119.20 & 0.102 & 111.54 & 0.104 & 106.93 \\
\hline 0.095 & 119.13 & 0.105 & 111.08 & 0.121 & 107.67 \\
\hline 0.099 & 119.35 & 0.114 & 109.96 & 0.129 & 107.13 \\
\hline 0.136 & 119.38 & 0.117 & 109.94 & 0.141 & 106.26 \\
\hline 0.142 & 118.93 & 0.118 & 109.74 & 0.162 & 107.16 \\
\hline 0.158 & 119.21 & 0.127 & 109.89 & 0.163 & 106.64 \\
\hline 0.168 & 119.48 & 0.128 & 109.77 & 0.170 & 106.42 \\
\hline 0.207 & 119.76 & 0.129 & 109.97 & 0.195 & 106.89 \\
\hline -- & --- & 0.130 & 109.97 & ------ & -.-- \\
\hline Mean $\theta:$ & \pm 0.22 & & \pm 0.49 & & \pm 0.38 \\
\hline
\end{tabular}


Table B.2: (cont'd)

\begin{tabular}{|c|c|c|c|c|c|}
\hline \multicolumn{2}{|c|}{ 2,2'-thiodiethanol } & \multicolumn{2}{|c|}{ ethylene glycol } & \multicolumn{2}{|c|}{ diethylene glycol } \\
\hline $\begin{array}{c}\text { rate } \\
(\mathrm{mm} / \mathrm{min} .)\end{array}$ & $\begin{array}{c}\theta \\
\text { (deg.) }\end{array}$ & $\begin{array}{c}\text { rate } \\
(\mathrm{mm} / \mathrm{min} .)\end{array}$ & $\begin{array}{c}\theta \\
(\operatorname{deg} .)\end{array}$ & $\begin{array}{c}\text { rate } \\
(\mathrm{mm} / \mathrm{min} .)\end{array}$ & $\begin{array}{c}\theta \\
\text { (deg.) }\end{array}$ \\
\hline 0.159 & 100.66 & 0.181 & 100.05 & 0.121 & 94.04 \\
\hline 0.163 & 101.02 & 0.182 & 100.04 & 0.192 & 94.90 \\
\hline 0.164 & 101.19 & 0.183 & 100.38 & 0.202 & 94.16 \\
\hline 0.181 & 100.70 & 0.207 & 99.98 & 0.221 & 93.89 \\
\hline 0.184 & 100.76 & 0.253 & 99.78 & 0.226 & 94.84 \\
\hline 0.239 & 100.71 & 0.266 & 99.91 & 0.246 & 94.78 \\
\hline 0.250 & 101.35 & 0.297 & 100.07 & 0.260 & 94.69 \\
\hline 0.321 & 101.18 & 0.441 & 100.01 & ---.-- & -..- \\
\hline 0.354 & 101.58 & 0.536 & 100.13 & ---- & -...- \\
\hline 0.644 & 101.53 & 0.548 & 100.18 & ------ & -..-- \\
\hline Mean $\theta$ & \pm 0.25 & & \pm 0.12 & & \pm 0.39 \\
\hline
\end{tabular}


Table B.2: (cont'd)

\begin{tabular}{|c|c|c|c|c|c|}
\hline \multicolumn{2}{|c|}{ 3,3'-thiodipropanol } & \multicolumn{2}{|c|}{ hexadecane } & \multicolumn{2}{|c|}{ dodecane } \\
\hline $\begin{array}{c}\text { rate } \\
(\mathrm{mm} / \mathrm{min} .)\end{array}$ & $\begin{array}{c}\theta \\
\text { (deg.) }\end{array}$ & $\begin{array}{c}\text { rate } \\
(\mathrm{mm} / \mathrm{min} .)\end{array}$ & $\begin{array}{c}\theta \\
\text { (deg.) }\end{array}$ & $\begin{array}{c}\text { rate } \\
(\mathrm{mm} / \mathrm{min} .)\end{array}$ & $\begin{array}{c}\theta \\
\text { (deg.) }\end{array}$ \\
\hline 0.146 & 90.80 & 0.138 & 72.84 & 0.106 & 70.98 \\
\hline 0.153 & 90.07 & 0.159 & 74.46 & 0.152 & 71.38 \\
\hline 0.186 & 90.45 & 0.189 & 74.04 & 0.344 & 71.59 \\
\hline 0.187 & 90.65 & 0.177 & 73.84 & 0.434 & 70.10 \\
\hline 0.245 & 90.43 & 0.335 & 73.44 & 0.621 & 70.80 \\
\hline - & ---- & 0.355 & 73.29 & 0.691 & 70.88 \\
\hline --.-- & -ב-ב- & 0.311 & 72.88 & 0.769 & 71.34 \\
\hline - & -..-. & 0.756 & 72.45 & 0.788 & 71.11 \\
\hline Mean $\theta$ : & 0.34 & & \pm 0.57 & & \pm 0.39 \\
\hline
\end{tabular}


Table B.3: Summary of the low-rate dynamic (advancing) contact angles measured by ADSA$P$ on a FC-725-coated silicon wafer surface

\begin{tabular}{lll}
\hline liquid & $\begin{array}{c}\gamma_{l v} \\
\left(\mathrm{~mJ} / \mathrm{m}^{2}\right)\end{array}$ & \multicolumn{1}{c}{$\begin{array}{c}\theta \\
(\text { deg. })\end{array}$} \\
\hline decane & 23.88 & slip/stick $\left(50^{\circ} \rightarrow 160^{\circ}\right)$ \\
dodecane & 25.64 & $71.02 \pm 0.39$ \\
1-pentanol & 26.01 & slip/stick $\left(65^{\circ} \rightarrow 150^{\circ}\right)$ \\
trans-decalin & 27.19 & slip/stick $\left(75^{\circ} \rightarrow 130^{\circ}\right)$ \\
hexadecane & 27.62 & $73.41 \pm 0.57$ \\
1-decanol & 28.99 & slip/stick $\left(80^{\circ} \rightarrow 140^{\circ}\right)$ \\
cis-decalin & 32.32 & slip/stick $\left(70^{\circ} \rightarrow 120^{\circ}\right)$ \\
nitromethane & 34.31 & slip/stick $\left(70^{\circ} \rightarrow 140^{\circ}\right)$ \\
2,5-dichlorotoluene & 34.64 & slip/stick $\left(70^{\circ} \rightarrow 150^{\circ}\right)$ \\
triacetin & 35.53 & slip/stick $\left(85^{\circ} \rightarrow 130^{\circ}\right)$ \\
ethyl cyanoacetate & 36.01 & slip/stick $\left(90^{\circ} \rightarrow 150^{\circ}\right)$ \\
$N, N$-dimethylformamide & 36.65 & $\theta \downarrow \& \gamma_{l v} \downarrow$ as $R \uparrow\left(95^{\circ} \rightarrow 70^{\circ}\right)$ \\
ethyl cinnamate & 37.17 & slip/stick $\left(70^{\circ} \rightarrow 140^{\circ}\right)$ \\
methyl salicylate & 38.82 & slip/stick $\left(105^{\circ} \rightarrow 165^{\circ}\right)$ \\
3,3'-thiodipropanol & 39.83 & $90.48 \pm 0.34$ \\
dibenzylamine & 40.80 & slip/stick $\left(80^{\circ} \rightarrow 160^{\circ}\right)$ \\
dimethyl sulfoxide $(\mathrm{DMSO})$ & 42.68 & slip/stick $\left(90^{\circ} \rightarrow 100^{\circ}\right)$ \\
1-iodonaphthalene & 42.92 & slip/stick $\left(100^{\circ} \rightarrow 170^{\circ}\right)$ \\
1-bromonaphthalene & 44.31 & slip/stick $\left(80^{\circ} \rightarrow 160^{\circ}\right)$ \\
diethylene glycol & 45.16 & $94.47 \pm 0.39$ \\
1,3-diiodopropane & 46.51 & slip/stick $\left(95^{\circ} \rightarrow 135^{\circ}\right)$ \\
3-pyridylcarbinol & 47.81 & slip/stick $\left(95^{\circ} \rightarrow 115^{\circ}\right)$ \\
& &
\end{tabular}




\begin{tabular}{lll} 
ethanolamine & 48.23 & $\theta \downarrow \& \gamma_{l v} \downarrow$ as $R \uparrow\left(73^{\circ} \rightarrow 60^{\circ}\right)$ \\
ethylene glycol & 48.66 & $100.05 \pm 0.12$ \\
$1,1,2,2$-tetrabromoethane & 49.29 & slip/stick $\left(95^{\circ} \rightarrow 160^{\circ}\right)$ \\
diiodomethane & 49.98 & slip/stick $\left(98^{\circ} \rightarrow 123^{\circ}\right)$ \\
$2,2^{\prime}$-thiodiethanol & 53.77 & $101.07 \pm 0.25$ \\
formamide & 59.08 & $106.89 \pm 0.38$ \\
glycerol & 63.13 & $110.21 \pm 0.49$ \\
water & 72.70 & $119.31 \pm 0.22$ \\
\hline
\end{tabular}




\section{APPENDIX C \\ LOW-RATE DYNAMIC CONTACT ANGLES ON A POLY(n-BUTYL METHACRYLATE) SOLID SURFACE}

Low-rate dynamic contact angles of 22 liquids on a poly( $n$-butyl methacrylate) (PnBMA) polymer are measured by an automated axisymmetric drop shape analysis - profile (ADSA-P). It is found that 16 liquids yielded non-constant contact angles, and/or dissolved the polymer on contact. From the experimental contact angles of the remaining 6 liquids, it is found that the liquid-vapour surface tension times cosine of the contact angle changes smoothly with the liquid-vapour surface tension, i.e. $\gamma_{l v} \cos \theta$ depends only on $\gamma_{l v}$ for a given solid surface (or solid surface tension).

\section{C.1 Materials (Solid Surfaces and Liquids)}

Poly(n-butyl methacrylate) (PnBMA) was purchased from Polysciences (Warrington, P.A., U.S.A.; cat\# 02061) as a fine powder. A 2\% PnBMA/chloroform solution was prepared using chloroform (Sigma-Aldrich, 99.9+\% A.C.C. HPLC grade) as the solvent. Silicon wafers $<100>$ (Silicon Sense, Naschua, N.H., U.S.A.; thickness: $525 \pm 50$ micron) were selected as the substrate for the polymer coating. The PnBMA-coated surfaces were prepared by a solvent-casting technique on the dried silicon wafers inside Petri glass dishes (Canlab, Mississauga, Ont.: cat.\# D2005-1) overnight. The experimental procedures and solid surface preparations 
have been described in Chapter 5 .

Twenty two liquids were chosen in this study [109]. They are listed in Table C.1, together with the physical properties and surface tensions (measured at $23.0 \pm$ $\left.0.5^{\circ} \mathrm{C}\right)$.

\section{C.2 Results}

Of the 22 liquids used, it was found that only 6 liquids yielded usable contact angles. They are water, glycerol, formamide, 2,2'-thiodiethanol, 3-pyridylcarbinol, and diethylene glycol. The rest of the 16 liquids either dissolved the polymer on contact or yielded non-constant contact angles during the course of the experiments.

The reproducibility of all solid-liquid systems is very good. They are summarized in Table C.2 for the 6 liquids with usable contact angles, at different rates of advancing and each on a newly prepared surface. It should be noted that a total of more than 130 freshly prepared PnBMA-coated wafers were prepared and used; more than 10,000 images were acquired and analyzed by ADSA-P. A summary of the contact angle complexities is given in Table C.3, together with the meaningful results from Table C.2. 
Table C.1: Suppliers and surface tensions of the liquids used for the contact angle measurements on a poly ( $n$-butyl methacrylate) PnBMA-coated silicon wafer surface. The surface tensions were measured at $23.0 \pm 0.5^{\circ} \mathrm{C}$

\begin{tabular}{|c|c|c|c|c|c|}
\hline liquid & supplier & $\%$ purity & $\begin{array}{l}\text { density } \\
\left(\mathrm{g} / \mathrm{cm}^{3}\right)\end{array}$ & $\begin{array}{l}\text { surface } \\
\text { tension } \gamma_{k v} \\
\left(\mathrm{~mJ} / \mathrm{m}^{2}\right)\end{array}$ & $\begin{array}{l}\text { no. of } \\
\text { drops }\end{array}$ \\
\hline cis-decalin & aldrich & 99 & 0.897 & $32.32 \pm 0.01$ & 7 \\
\hline nitromethane & aldrich & $99+$ & 1.127 & $34.31 \pm 0.006$ & 10 \\
\hline 2,5-dichlorotoluene & aldrich & 98 & 1.254 & $34.64 \pm 0.003$ & 10 \\
\hline triacetin & fluka & $99+$ & 1.158 & $35.52 \pm 0.16$ & 10 \\
\hline ethyl cyanoacetate & aldrich & $98+$ & 1.063 & $36.01 \pm 0.04$ & 9 \\
\hline$N, N$-dimethylformamide & $\begin{array}{l}\text { sigma- } \\
\text { aldrich }\end{array}$ & $\begin{array}{l}99.9+ \\
\text { (HPLC) }\end{array}$ & 0.944 & $36.65 \pm 0.004$ & 9 \\
\hline ethyl cinnamate & aldrich & 99 & 1.049 & $37.17 \pm 0.02$ & 10 \\
\hline methyl salicylate & aldrich & $99+$ & 1.174 & $38.82 \pm 0.07$ & 10 \\
\hline dibenzylamine & aldrich & 97 & 1.026 & $40.80 \pm 0.06$ & 9 \\
\hline $\begin{array}{l}\text { dimethyl sulfoxide } \\
\text { (DMSO) }\end{array}$ & $\begin{array}{l}\text { sigma- } \\
\text { aldrich }\end{array}$ & $\begin{array}{l}99.9 \\
\text { (HPLC) }\end{array}$ & 1.101 & $42.68 \pm 0.09$ & 10 \\
\hline 1-iodonaphthalene & aldrich & 99 & 1.740 & $42.92 \pm 0.03$ & 10 \\
\hline 1-bromonaphthalene & aldrich & 98 & 1.489 & $44.31 \pm 0.05$ & 7 \\
\hline diethylene glycol & aldrich & 99 & 1.118 & $45.16 \pm 0.05$ & 10 \\
\hline 1,3-diiodopropane & aldrich & 99 & 2.576 & $46.51 \pm 0.13$ & 10 \\
\hline 3-pyridylcarbinol & aldrich & 98 & 1.124 & $47.81 \pm 0.03$ & 10 \\
\hline ethylene glycol & aldrich & $99+$ & 1.113 & $48.66 \pm 0.02$ & 10 \\
\hline 1,1,2,2-tetrabromoethane & aldrich & 98 & 2.967 & $49.29 \pm 0.05$ & 10 \\
\hline diiodomethane & aldrich & 99 & 3.325 & $49.98 \pm 0.02$ & 10 \\
\hline 2,2'-thiodiethanol & aldrich & $99+$ & 1.221 & $53.77 \pm 0.03$ & 10 \\
\hline formamide & aldrich & $99.5+$ & 1.134 & $59.08 \pm 0.01$ & 10 \\
\hline
\end{tabular}




\begin{tabular}{llllll} 
glycerol & $\begin{array}{l}\text { baker } \\
\text { analyzed }\end{array}$ & 99.8 & 1.258 & $63.13 \pm 0.10$ & 10 \\
water & LAST $^{+}$ & $\begin{array}{l}\text { doubly } \\
\text { distilled }\end{array}$ & 0.997 & $72.70 \pm 0.09$ & 10 \\
\hline
\end{tabular}

'Laboratory of Applied Surface Thermodynamics 
Table C.2: Low-rate dynamic (advancing) contact angles of different liquids on a poly $(n$-butyl methacrylate) PnBMA-coated silicon wafer surface. For each liquid, 6 different rates of advancing of the three-phase contact line were performed, each on a newly prepared solid surface. The error bars are $95 \%$ confidence limits

\begin{tabular}{cccccc}
\hline & \multicolumn{2}{c}{ glycerol } & \multicolumn{2}{c}{ formamide } \\
$\begin{array}{c}\text { rate } \\
\text { (mm/min.) }\end{array}$ & $\begin{array}{c}\theta \\
\text { (deg.) }\end{array}$ & $\begin{array}{c}\text { rate } \\
(\mathrm{mm} / \mathrm{min} .)\end{array}$ & $\begin{array}{c}\theta \\
\text { (deg.) }\end{array}$ & $\begin{array}{c}\text { rate } \\
(\mathrm{mm} / \mathrm{min} .)\end{array}$ & $\begin{array}{c}\theta \\
\text { (deg.) }\end{array}$ \\
\hline 0.130 & $91.66 \pm 0.35$ & 0.214 & $82.28 \pm 0.05$ & 0.214 & $76.65 \pm 0.04$ \\
0.131 & $91.70 \pm 0.35$ & 0.218 & $82.13 \pm 0.05$ & 0.223 & $75.86 \pm 0.04$ \\
0.164 & $90.42 \pm 0.23$ & 0.223 & $82.28 \pm 0.03$ & 0.239 & $76.86 \pm 0.06$ \\
0.225 & $90.39 \pm 0.12$ & 0.224 & $81.87 \pm 0.08$ & 0.254 & $76.97 \pm 0.07$ \\
0.358 & $89.92 \pm 0.12$ & 0.230 & $82.23 \pm 0.07$ & 0.266 & $75.43 \pm 0.05$ \\
0.479 & $90.31 \pm 0.08$ & 0.251 & $81.96 \pm 0.05$ & 0.283 & $76.68 \pm 0.07$ \\
\hline Mean $\theta:$ & $90.73 \pm 0.79$ & & $82.11 \pm 0.21$ & & $76.41 \pm 0.65$ \\
\hline
\end{tabular}


Table C.2: (cont'd)

\begin{tabular}{cccccc}
\hline \multicolumn{2}{c}{$2,2^{\prime}$-thiodiethanol } & \multicolumn{2}{c}{ 3-pyridylcarbinol } & \multicolumn{2}{c}{ diethylene glycol } \\
$\begin{array}{c}\text { rate } \\
\text { (mm/min.) }\end{array}$ & $\begin{array}{c}\theta \\
\text { (deg.) }\end{array}$ & $\begin{array}{c}\text { rate } \\
\text { (mm/min.) }\end{array}$ & $\begin{array}{c}\theta \\
\text { (deg.) }\end{array}$ & $\begin{array}{c}\text { rate } \\
\text { (mm/min.) }\end{array}$ & $\begin{array}{c}\theta \\
\text { (deg.) }\end{array}$ \\
\hline 0.229 & $68.01 \pm 0.03$ & 0.344 & $60.35 \pm 0.15$ & 0.332 & $59.14 \pm 0.08$ \\
0.238 & $68.12 \pm 0.05$ & 0.578 & $60.35 \pm 0.07$ & 0.380 & $58.97 \pm 0.09$ \\
0.284 & $68.33 \pm 0.06$ & 0.609 & $60.23 \pm 0.15$ & 0.381 & $58.76 \pm 0.14$ \\
0.315 & $67.88 \pm 0.03$ & 0.681 & $60.59 \pm 0.18$ & 0.449 & $59.16 \pm 0.04$ \\
0.427 & $67.98 \pm 0.07$ & 0.858 & $60.40 \pm 0.09$ & 0.451 & $58.83 \pm 0.03$ \\
0.643 & $67.69 \pm 0.08$ & 1.200 & $59.87 \pm 0.07$ & 0.503 & $57.52 \pm 0.16$ \\
\hline Mean $\theta:$ & $68.00 \pm 0.23$ & & $60.30 \pm 0.25$ & & $58.73 \pm 0.64$ \\
\hline
\end{tabular}


Table C.3: Summary of low-rate dynamic (advancing) contact angles measured by ADSA-P on a poly( $n$-butyl methacrylate) PnBMA-coated silicon wafer surface

\begin{tabular}{|c|c|c|}
\hline liquid & $\underset{\left(\mathrm{mJ} / \mathrm{m}^{2}\right)}{\gamma_{L_{v}}}$ & $\begin{array}{c}\theta \\
\text { (deg.) }\end{array}$ \\
\hline cis-decalin & 32.32 & $\theta \uparrow$ as $R \uparrow$ (and slips) $\left(25^{\circ} \rightarrow 55^{\circ}\right)$ \\
\hline nitromethane & 34.31 & slip/stick $\left(40^{\circ} \rightarrow 95^{\circ}\right)$ \\
\hline 2,5-dichlorotoluene & 34.64 & $\theta \downarrow$ as $R \uparrow\left(26^{\circ} \rightarrow 16^{\circ}\right)^{\dagger}$ \\
\hline triacetin & 35.53 & slip/stick $\left(40^{\circ} \rightarrow 54^{\circ}\right)$ \\
\hline ethyl cyanoacetate & 36.01 & slip/stick $\left(45^{\circ} \rightarrow 65^{\circ}\right)$ \\
\hline$N, N$-dimethylformamide & 36.65 & $\theta \downarrow$ as $R \uparrow\left(44^{\circ} \rightarrow 36^{\circ}\right)^{\dagger}$ \\
\hline ethyl cinnamate & 37.17 & $\theta \uparrow$ as $R \uparrow$ (and slips) $\left(35^{\circ} \rightarrow 65^{\circ}\right)$ \\
\hline methyl salicylate & 38.82 & $\theta \uparrow \downarrow$ as $R \uparrow\left(45^{\circ} \rightarrow 66^{\circ} \rightarrow 54^{\circ}\right)$ \\
\hline dibenzylamine & 40.80 & $\theta \uparrow \downarrow \& \gamma_{\nu v} \downarrow$ as $R \uparrow\left(32^{\circ} \rightarrow 41^{\circ} \rightarrow 38^{\circ}\right)$ \\
\hline dimethyl sulfoxide (DMSO) & 42.68 & slip/stick $\left(56^{\circ} \rightarrow 64^{\circ}\right)$ \\
\hline 1-iodonaphthalene & 42.92 & $\theta \uparrow$ as $R \uparrow$ (and slips) $\left(45^{\circ} \rightarrow 65^{\circ}\right)$ \\
\hline 1-bromonaphthalene & 44.31 & $\theta \uparrow \& \gamma_{k v} \downarrow$ as $R \uparrow\left(32^{\circ} \rightarrow 46^{\circ}\right)$ \\
\hline diethylene glycol & 45.16 & $58.73 \pm 0.64$ \\
\hline 1,3-diiodopropane & 46.51 & slip/stick $\left(40^{\circ} \rightarrow 75^{\circ}\right)$ \\
\hline ethylene glycol & 47.55 & $\theta \uparrow$ and $\gamma_{l v} \downarrow$ as $R \uparrow\left(67^{\circ} \rightarrow 73^{\circ}\right)$ \\
\hline 3-pyridylcarbinol & 47.81 & $60.30 \pm 0.25$ \\
\hline 1,1,2,2-tetrabromoethane & 49.29 & $\theta \uparrow \downarrow \& \gamma_{v v} \downarrow$ as $R \uparrow\left(40^{\circ} \rightarrow 65^{\circ} \rightarrow 56^{\circ}\right)$ \\
\hline diiodomethane & 49.98 & slip/stick $\left(60^{\circ} \rightarrow 100^{\circ}\right)$ \\
\hline 2,2'-thiodiethanol & 53.77 & $68.00 \pm 0.23$ \\
\hline formamide & 59.08 & $76.41 \pm 0.65$ \\
\hline glycerol & 65.02 & $82.11 \pm 0.21$ \\
\hline water & 72.70 & $90.73 \pm 0.79$ \\
\hline
\end{tabular}

'part of the polymer was observed to be removed after the experiment 


\section{APPENDIX D \\ LOW-RATE DYNAMIC CONTACT ANGLES ON A POLYSTYRENE SOLID SURFACE}

Low-rate dynamic contact angles of 13 liquids on a polystyrene polymer are measured by an automated axisymmetric drop shape analysis - profile (ADSA-P). It is found that 7 liquids yielded non-constant contact angles, and/or dissolved the polymer on contact. From the experimental contact angies of the other 6 liquids, it is found that the liquid-vapour surface tension times cosine of the contact angle changes smoothly with the liquid-vapour surface tension, i.e. $\gamma_{l \nu} \cos \theta$ depends only on $\gamma_{l}$ for a given solid surface (or solid surface tension).

\section{D.1 Materials (Solid Surfaces and Liquids)}

Polystyrene (PS) was purchased from Polysciences (Warrington, P.A., U.S.A.; cat\# 00574, MW 125,000-250,000, atatic beads). A 2\% PS/toluene solution was prepared using toluene (Sigma-Aldrich, 99.8\% HPLC grade) as the solvent. Silicon wafers $<100>$ (Silicon Sense, Naschua, N.H., U.S.A.; thickness: $525 \pm 50$ micron) were selected as the substrate for the polymer coating. The PS-coated surfaces were prepared by a solvent-casting technique on the dried silicon wafers inside Petri glass dishes (Canlab, Mississauga, Ont.: cat.\# D2005-1) overnight. The experimental procedures and solid surface preparations have been described in Chapter 5 . 
Thirteen liquids were chosen in this study [110]. They are shown in Table D.1, together with the physical properties and surface tensions (measured at $23.0 \pm$ $0.5^{\circ} \mathrm{C}$.

\section{D.2 Results}

Of the 13 liquids used, it was found that only 6 liquids yielded usable contact angles. They are water, glycerol, formamide, ethylene glycol, diethylene glycol, and dimethyl sulfoxide (DMSO). The rest of the 7 liquids either dissolved the polymer on contact or yielded non-constant contact angles during the course of the experiments.

The reproducibility of all solid-liquid systems is very good. They are summarized in Table D.2 for the 6 liquids with constant contact angles, at different rates of advancing and each on a newly prepared surface; a total of more than 70 freshly prepared PS-coated wafers were prepared and used; more than 4,000 images were acquired and analyzed by ADSA-P. A summary of the contact angle complexities is given in Table D.3, together with the meaningful results from Table D.2. 
Table D.1: Suppliers and surface tensions of the liquids used for the contact angle measurements on a polystyrene PS-coated silicon wafer surface. The surface tensions were measured at $23.0 \pm 0.5^{\circ} \mathrm{C}$

\begin{tabular}{|c|c|c|c|c|c|}
\hline liquid & supplier & $\%$ purity & $\begin{array}{l}\text { density } \\
\left(\mathrm{g} / \mathrm{cm}^{3}\right)\end{array}$ & $\begin{array}{c}\text { surface } \\
\text { tension } \gamma_{h} \\
\left(\mathrm{~mJ} / \mathrm{m}^{2}\right)\end{array}$ & $\begin{array}{l}\text { no. of } \\
\text { drops }\end{array}$ \\
\hline dibenzylamine & aldrich & 97 & 1.026 & $40.80 \pm 0.06$ & 9 \\
\hline $\begin{array}{l}\text { dimethyl sulfoxide } \\
\text { (DMSO) }\end{array}$ & $\begin{array}{l}\text { sigma- } \\
\text { aldrich }\end{array}$ & $\begin{array}{l}99.9 \\
\text { (HPLC) }\end{array}$ & 1.101 & $42.68 \pm 0.09$ & 10 \\
\hline 1-iodonaphthalene & aldrich & 99 & 1.740 & $42.92 \pm 0.03$ & 10 \\
\hline 1-bromonaphthalene & aldrich & 98 & 1.489 & $44.31 \pm 0.05$ & 7 \\
\hline diethylene glycol & aldrich & 99 & 1.118 & $44.68 \pm 0.03$ & 9 \\
\hline 1,3-diiodopropane & aldrich & 99 & 2.576 & $46.51 \pm 0.13$ & 10 \\
\hline 3-pyridylcarbinol & aldrich & 98 & 1.124 & $47.81 \pm 0.03$ & 10 \\
\hline ethylene glycol & aldrich & $99+$ & 1.113 & $48.66 \pm 0.02$ & 10 \\
\hline 1,1,2,2-tetrabromoethane & aldrich & 98 & 2.967 & $49.29 \pm 0.05$ & 10 \\
\hline diiodomethane & aldrich & 99 & 3.325 & $49.98 \pm 0.02$ & 10 \\
\hline formamide & aldrich & $99.5+$ & 1.134 & $59.08 \pm 0.01$ & 10 \\
\hline glycerol & $\begin{array}{l}\text { baker } \\
\text { analyzed }\end{array}$ & 99.8 & 1.258 & $63.13 \pm 0.10$ & 10 \\
\hline water & LAST $^{+}$ & $\begin{array}{l}\text { doubly } \\
\text { distilled }\end{array}$ & 0.997 & $72.70 \pm 0.09$ & 10 \\
\hline
\end{tabular}

'Laboratory of Applied Surface Thermodynamics 
Table D.2: Low-rate dynamic (advancing) contact angles of different liquids on a polystyrene PS-coated silicon wafer surface. For each liquid, at least 7 and up to 10 different rates of advancing of the three-phase contact line were performed, each on a newly prepared solid surface. The error bars are $95 \%$ confidence limits

\begin{tabular}{cccccc}
\hline \multicolumn{2}{c}{ water } & \multicolumn{2}{c}{ glycerol } & \multicolumn{2}{c}{ formamide } \\
$\begin{array}{c}\text { rate } \\
\text { (mm/min.) }\end{array}$ & $\begin{array}{c}\theta \\
\text { (deg.) }\end{array}$ & $\begin{array}{c}\text { rate } \\
(\mathrm{mm} / \mathrm{min} \text {.) }\end{array}$ & $\begin{array}{c}\theta \\
\text { (deg.) }\end{array}$ & $\begin{array}{c}\text { rate } \\
\text { (mm/min.) }\end{array}$ & $\begin{array}{c}\theta \\
\text { (deg.) }\end{array}$ \\
\hline 0.107 & $88.18 \pm 0.03$ & 0.128 & $78.40 \pm 0.05$ & 0.140 & $74.24 \pm 0.11$ \\
0.109 & $88.39 \pm 0.03$ & 0.158 & $78.25 \pm 0.05$ & 0.157 & $74.56 \pm 0.09$ \\
0.117 & $88.62 \pm 0.08$ & 0.165 & $78.48 \pm 0.08$ & 0.162 & $74.06 \pm 0.09$ \\
0.240 & $88.06 \pm 0.03$ & 0.166 & $78.58 \pm 0.04$ & 0.167 & $74.28 \pm 0.15$ \\
0.267 & $88.79 \pm 0.03$ & 0.175 & $78.58 \pm 0.04$ & 0.176 & $75.80 \pm 0.11$ \\
0.329 & $88.77 \pm 0.04$ & 0.260 & $78.80 \pm 0.06$ & 0.222 & $75.31 \pm 0.11$ \\
0.561 & $88.14 \pm 0.06$ & 0.424 & $77.92 \pm 0.09$ & 0.269 & $75.34 \pm 0.10$ \\
$\cdots$ & -- & 1.194 & $78.33 \pm 0.09$ & 0.455 & $74.35 \pm 0.13$ \\
-- & -- & 1.240 & $78.51 \pm 0.10$ & 0.800 & $74.98 \pm 0.07$ \\
$-\cdots$ & ---- & 1.262 & $77.91 \pm 0.13$ & 0.840 & $74.70 \pm 0.19$ \\
\hline Mean $\theta:$ & $88.42 \pm 0.28$ & & $78.38 \pm 0.20$ & & $74.76 \pm 0.41$ \\
\hline
\end{tabular}


Table D.2: (cont'd)

\begin{tabular}{|c|c|c|c|c|c|}
\hline \multicolumn{2}{|c|}{ ethylene glycol } & \multicolumn{2}{|c|}{ diethylene glycol } & \multicolumn{2}{|c|}{$\begin{array}{l}\text { dimethyl sulfoxide } \\
\text { (DMSO) }\end{array}$} \\
\hline $\begin{array}{c}\text { rate } \\
(\mathrm{mm} / \mathrm{min} .)\end{array}$ & $\begin{array}{c}\theta \\
\text { (deg.) }\end{array}$ & $\begin{array}{c}\text { rate } \\
(\mathrm{mm} / \mathrm{min} .)\end{array}$ & $\begin{array}{c}\theta \\
\text { (deg.) }\end{array}$ & $\begin{array}{c}\text { rate } \\
(\mathrm{mm} / \mathrm{min} .)\end{array}$ & $\begin{array}{c}\theta \\
\text { (deg.) }\end{array}$ \\
\hline 0.276 & $61.43 \pm 0.09$ & 0.404 & $53.21 \pm 0.07$ & 0.456 & $50.85 \pm 0.08$ \\
\hline 0.323 & $61.28 \pm 0.05$ & 0.488 & $51.92 \pm 0.08$ & 0.491 & $50.62 \pm 0.09$ \\
\hline 0.339 & $61.65 \pm 0.06$ & 0.460 & $51.94 \pm 0.07$ & 0.521 & $50.52 \pm 0.14$ \\
\hline 0.343 & $61.22 \pm 0.06$ & 0.500 & $52.01 \pm 0.32$ & 0.544 & $50.51 \pm 0.04$ \\
\hline 0.413 & $61.01 \pm 0.15$ & 0.609 & $53.51 \pm 0.08$ & 0.582 & $50.47 \pm 0.03$ \\
\hline 0.425 & $61.32 \pm 0.19$ & 0.887 & $51.93 \pm 0.27$ & 0.703 & $51.31 \pm 0.16$ \\
\hline 0.654 & $60.58 \pm 0.18$ & 1.118 & $51.89 \pm 0.31$ & 0.845 & $50.45 \pm 0.12$ \\
\hline 0.707 & $61.13 \pm 0.08$ & 1.150 & $53.41 \pm 0.16$ & 1.008 & $50.65 \pm 0.08$ \\
\hline ---- & -----.. & 1.163 & $51.83 \pm 0.23$ & (-ב-ב- & ----- \\
\hline Mean $\theta:$ & $61.20 \pm 0.26$ & & $52.41 \pm 0.61$ & & $50.67 \pm 0.24$ \\
\hline
\end{tabular}


Table D.3: Summary of low-rate dynamic (advancing) contact angles measured by ADSA-P on a polystyrene PS-coated silicon wafer surface

\begin{tabular}{lcc}
\hline liquid & $\begin{array}{c}\gamma_{L \nu} \\
\left(\mathrm{mJ} / \mathrm{m}^{2}\right)\end{array}$ & $\begin{array}{c}\theta \\
(\mathrm{deg})\end{array}$ \\
\hline dibenzylamine & 40.80 & slip/stick $\left(30^{\circ} \rightarrow 40^{\circ}\right)^{\dagger}$ \\
dimethyl sulfoxide (DMSO) & 42.68 & $50.67 \pm 0.24^{\circ}$ \\
1-iodonaphthalene & 42.92 & dissolved the polymer on contact \\
1-bromonaphthalene & 44.31 & slip/stick $\left(15^{\circ} \rightarrow 25^{\circ}\right)$ \\
diethylene glycol & 44.68 & $52.41 \pm 0.61^{\circ}$ \\
1,3-diiodopropane & 46.51 & slip/stick $\left(35^{\circ} \rightarrow 55^{\circ}\right)$ \\
3-pyridylcarbinol & 47.81 & slip/stick $\left(42^{\circ} \rightarrow 48^{\circ}\right)$ \\
ethylene glycol & 48.66 & $61.20 \pm 0.26^{\circ}$ \\
$1,1,2,2$-tetrabromoethane & 49.29 & dissolved the polymer on contact \\
diiodomethane & 49.98 & slip/stick $\left(40^{\circ} \rightarrow 60^{\circ}\right)$ \\
formamide & 59.08 & $74.76 \pm 0.41^{\circ}$ \\
glycerol & 63.13 & $78.38 \pm 0.20^{\circ}$ \\
water & 72.70 & $88.42 \pm 0.28^{\circ}$ \\
\hline
\end{tabular}

${ }^{\dagger}$ part of the polymer was observed to be removed after the experiment 


\section{APPENDIX E \\ LOW-RATE DYNAMIC CONTACT ANGLES ON A POLY(STYRENE-(HEXYL/10-CARBOXYDECYL 90:10)-MALEIMIDE) SOLID SURFACE}

Low-rate dynamic contact angles of 14 liquids on a poly(styrene-(hexyl/10carboxydecyl 90:10)-maleimide) $\mathrm{P}(\mathrm{S}(\mathrm{H} / \mathrm{C}$ 90:10)M) copolymer are measured by an automated axisymmetric drop shape analysis - profile (ADSA-P). It is found that 9 liquids yielded non-constant contact angles, and/or dissolved the polymer. From the experimental contact angles of the remaining 5 liquids, it is found that the liquidvapour surface tension times cosine of the contact angle changes smoothly with the liquid-vapour surface tension, i.e. $\gamma_{l \nu} \cos \theta$ depends only on $\gamma_{l \nu}$ for a given solid surface (or solid surface tension).

\section{E.1 Materials (Solid Surfaces and Liquids)}

Poly(styrene-(hexyl/10-carboxydecyl 90:10)-maleimide) P(S(H/C 90:10)M) was synthesized at the Institute of Polymer Research Dresden (Germany). A 2\% $\mathrm{P}(\mathrm{S}(\mathrm{H} / \mathrm{C}$ 90:10)M)/tetrahydrofuran solution was prepared using tetrahydrofuran (Sigma-Aldrich, $99.9+\%$ HPLC) as the solvent. Silicon wafers $\langle 100\rangle$ (Silicon Sense, Naschua, N.H., U.S.A.; thickness: $525 \pm 50$ micron) were selected as the substrate for the polymer coating. The $\mathrm{P}(\mathrm{S}(\mathrm{H} / \mathrm{C}$ 90:10)M)-coated surfaces were 
prepared by a solvent-casting technique on the dried silicon wafers inside Petri glass dishes (Canlab, Mississauga, Ont.: cat.\# D2005-1) overnight. The experimental procedures and solid surface preparations have been described in Chapter 5 .

Fourteen liquids were chosen in this study [111]. They are listed in Table E.1, together with the physical properties and surface tensions (measured at $23.0 \pm$ $\left.0.5^{\circ} \mathrm{C}\right)$.

\section{E.2 Results}

Of the 14 liquids used, it was found that only 5 liquids yielded usable contact angles. They are water, glycerol, formamide, ethylene glycol, and diethylene glycol. The remaining 9 liquids either yielded non-constant contact angles or dissolved the polymer during the course of the experiments.

The reproducibility of all solid-liquid systems is very good. They are summarized in Table E.2 for the 5 liquids with usable contact angles, at different rates of advancing and each on a newly prepared surface. It should be noted that a total of more than 80 freshly prepared $\mathrm{P}(\mathrm{S}(\mathrm{H} / \mathrm{C}$ 90:10)M)-coated wafers were prepared and used; more than 8,000 images were acquired and analyzed by ADSAP. A summary of the contact angle complexities is given in Table E.3, together with the meaningful results from Table E.2. 
Table E.1: Suppliers and surface tensions of the liquids used for the contact angle measurements on a poly(styrene-(hexyl/10-carboxydecyl 90:10)-maleimide) $\mathrm{P}(\mathrm{S}(\mathrm{H} / \mathrm{C}$ 90:10)M)-coated silicon wafer surface. The surface tensions were measured at $23.0 \pm 0.5^{\circ} \mathrm{C}$

\begin{tabular}{|c|c|c|c|c|c|}
\hline liquid & supplier & $\%$ purity & $\begin{array}{l}\text { density } \\
\left(\mathrm{g} / \mathrm{cm}^{3}\right)\end{array}$ & $\begin{array}{c}\text { surface } \\
\text { tension } \gamma_{\nu} \\
\left(\mathrm{mJ} / \mathrm{m}^{2}\right)\end{array}$ & $\begin{array}{l}\text { no. of } \\
\text { drops }\end{array}$ \\
\hline dibenzylamine & aldrich & 97 & 1.026 & $40.80 \pm 0.06$ & 9 \\
\hline $\begin{array}{l}\text { dimethyl sulfoxide } \\
\text { (DMSO) }\end{array}$ & $\begin{array}{l}\text { sigma- } \\
\text { aldrich }\end{array}$ & $\begin{array}{l}99.9 \\
\text { (HPLC) }\end{array}$ & 1.101 & $42.68 \pm 0.09$ & 10 \\
\hline 1-iodonaphthalene & aldrich & 99 & 1.740 & $42.92 \pm 0.03$ & 10 \\
\hline 1-bromonaphthalene & aldrich & 98 & 1.489 & $44.31 \pm 0.05$ & 7 \\
\hline diethylene glycol & aldrich & 99 & 1.118 & $45.16 \pm 0.05$ & 10 \\
\hline 1,3-diiodopropane & aldrich & 99 & 2.576 & $46.51 \pm 0.13$ & 10 \\
\hline 3-pyridylcarbinol & aldrich & 98 & 1.124 & $47.81 \pm 0.03$ & 10 \\
\hline ethylene glycol & aldrich & $99+$ & 1.113 & $48.66 \pm 0.02$ & 10 \\
\hline 1,1,2,2-tetrabromoethane & aldrich & 98 & 2.967 & $49.29 \pm 0.05$ & 10 \\
\hline diiodomethane & aldrich & 99 & 3.325 & $49.98 \pm 0.02$ & 10 \\
\hline 2,2'-thiodiethanol & aldrich & $99+$ & 1.221 & $53.77 \pm 0.03$ & 10 \\
\hline formamide & aldrich & $99.5+$ & 1.134 & $59.08 \pm 0.01$ & 10 \\
\hline glycerol & $\begin{array}{l}\text { baker } \\
\text { analyzed }\end{array}$ & 99.8 & 1.258 & $63.13 \pm 0.10$ & 10 \\
\hline water & $\mathrm{LAST}^{+}$ & $\begin{array}{l}\text { doubly } \\
\text { distilled }\end{array}$ & 0.997 & $72.70 \pm 0.09$ & 10 \\
\hline
\end{tabular}

'Laboratory of Applied Surface Thermodynamics 
Table E.2: Low-rate dynamic (advancing) contact angles of different liquids on a poly(styrene-(hexyl/10-carboxydecyl 90:10)-maleimide) $\mathrm{P}(\mathrm{S}(\mathrm{H} / \mathrm{C}$ 90:10)M)-coated silicon wafer surface. For each liquid, 7 different rates of advancing of the three-phase contact line were performed, each on a newly prepared solid surface. The error bars are $95 \%$ confidence limits

\begin{tabular}{cccccc}
\hline \multicolumn{2}{c}{ water } & \multicolumn{2}{c}{ glycerol } & \multicolumn{2}{c}{ formamide } \\
$\begin{array}{c}\text { rate } \\
\text { (mm/min.) }\end{array}$ & $\begin{array}{c}\theta \\
\text { (deg.) }\end{array}$ & $\begin{array}{c}\text { rate } \\
(\mathrm{mm} / \mathrm{min} .)\end{array}$ & $\begin{array}{c}\theta \\
\text { (deg.) }\end{array}$ & $\begin{array}{c}\text { rate } \\
(\mathrm{mm} / \mathrm{min} .)\end{array}$ & $\begin{array}{c}\theta \\
(\mathrm{deg} .)\end{array}$ \\
\hline 0.104 & $86.24 \pm 0.06$ & 0.144 & $76.87 \pm 0.03$ & 0.225 & $69.97 \pm 0.10$ \\
0.117 & $87.92 \pm 0.18$ & 0.177 & $75.80 \pm 0.02$ & 0.292 & $69.54 \pm 0.08$ \\
0.118 & $87.10 \pm 0.07$ & 0.208 & $76.32 \pm 0.04$ & 0.309 & $69.93 \pm 0.07$ \\
0.136 & $86.33 \pm 0.61$ & 0.469 & $76.47 \pm 0.07$ & 0.311 & $71.30 \pm 0.06$ \\
0.172 & $87.22 \pm 0.12$ & 0.683 & $76.38 \pm 0.05$ & 0.321 & $71.21 \pm 0.10$ \\
0.285 & $87.85 \pm 0.08$ & 0.988 & $76.96 \pm 0.09$ & 0.342 & $69.81 \pm 0.10$ \\
0.417 & $87.26 \pm 0.13$ & 1.347 & $76.78 \pm 0.12$ & 0.453 & $70.21 \pm 0.09$ \\
\hline Mean $\theta:$ & $87.13 \pm 0.61$ & & $76.51 \pm 0.37$ & & $70.28 \pm 0.64$ \\
\hline
\end{tabular}


Table E.2: (cont'd)

\begin{tabular}{cccc}
\hline \multicolumn{2}{c}{ ethylene glycol } & \multicolumn{2}{c}{ diethylene glycol } \\
$\begin{array}{c}\text { rate } \\
(\mathrm{mm} / \mathrm{min} .)\end{array}$ & $\begin{array}{c}\theta \\
(\mathrm{deg} .)\end{array}$ & $\begin{array}{c}\text { rate } \\
(\mathrm{mm} / \mathrm{min})\end{array}$ & $\begin{array}{c}\theta \\
(\mathrm{deg})\end{array}$ \\
\hline 0.215 & $59.63 \pm 0.05$ & 0.242 & $51.71 \pm 0.06$ \\
0.428 & $60.12 \pm 0.13$ & 0.244 & $51.72 \pm 0.09$ \\
0.482 & $59.43 \pm 0.10$ & 0.252 & $50.74 \pm 0.06$ \\
0.717 & $60.13 \pm 0.07$ & 0.290 & $51.40 \pm 0.24$ \\
0.973 & $60.09 \pm 0.11$ & 0.520 & $51.48 \pm 0.14$ \\
1.024 & $59.17 \pm 0.08$ & 0.835 & $51.26 \pm 0.12$ \\
1.103 & $59.45 \pm 0.09$ & 1.125 & $50.93 \pm 0.08$ \\
\hline Mean $\theta:$ & $59.72 \pm 0.36$ & & $51.32 \pm 0.35$ \\
\hline
\end{tabular}


Table E.3: Summary of the contact angle results on a poly(styrene-(hexyl/10-carboxydecyl 90:10)-maleimide) $\mathrm{P}(\mathrm{S}(\mathrm{H} / \mathrm{C}$ 90:10)M)-coated silicon wafer surface

\begin{tabular}{lcc}
\hline liquid & $\begin{array}{c}\gamma_{L v} \\
\left(\mathrm{~mJ} / \mathrm{m}^{2}\right)\end{array}$ & $\begin{array}{c}\theta \\
(\mathrm{deg} .)\end{array}$ \\
\hline dibenzylamine & 40.80 & $\theta \uparrow$ as $R \uparrow\left(35^{\circ} \rightarrow 43^{\circ}\right)^{\dagger}$ \\
dimethyl sulfoxide (DMSO) & 42.68 & $\theta \uparrow$ as $R \uparrow\left(45^{\circ} \rightarrow 80^{\circ}\right)^{\dagger+}$ \\
1-iodonaphthalene & 42.92 & slip/stick $\left(20^{\circ} \rightarrow 90^{\circ}\right)$ \\
1-bromonaphthalene & 44.31 & slip/stick $\left(30^{\circ} \rightarrow 130^{\circ}\right)$ \\
diethylene glycol & 45.16 & $51.32 \pm 0.35^{\circ}$ \\
1,3-diiodopropane & 46.51 & slip/stick $\left(40^{\circ} \rightarrow 80^{\circ}\right)$ \\
3-pyridylcarbinol & 47.81 & slip/stick $\left(32^{\circ} \rightarrow 60^{\circ}\right)$ \\
ethylene glycol & 48.66 & $59.72 \pm 0.36^{\circ}$ \\
1,1,2,2-tetrabromoethane & 49.29 & slip/stick $\left(35^{\circ} \rightarrow 100^{\circ}\right)$ \\
diiodomethane & 49.98 & slip/stick $\left(40^{\circ} \rightarrow 100^{\circ}\right)$ \\
2,2'-thiodiethanol & 53.77 & slip/stick $\left(60^{\circ} \rightarrow 80^{\circ}\right)$ \\
formamide & 58.45 & $70.28 \pm 0.64^{\circ}$ \\
glycerol & 63.13 & $76.51 \pm 0.37^{\circ}$ \\
water & 72.70 & $87.13 \pm 0.61^{\circ}$ \\
\hline
\end{tabular}

${ }^{\dagger}$ part of the polymer was observed to be removed after the experiment the drop periphery was not circular during the experiment due to dissolution 


\section{APPENDIX F \\ LOW-RATE DYNAMIC CONTACT ANGLES ON A \\ POLY(METHYL METHACRYLATE/n-BUTYL \\ METHACRYLATE) SOLID SURFACE}

Low-rate dynamic contact angles of 12 liquids on a poly(methyl methacrylate/n-butyl methacrylate) P(MMA/nBMA) copolymer are measured by an automated axisymmetric drop shape analysis - profile (ADSA-P). It is found that 6 liquids yield non-constant contact angles, and/or dissolve the polymer on contact. From the experimental contact angles of the remaining 6 liquids, it is found that the liquid-vapour surface tension times cosine of the contact angle changes smoothly with the liquid-vapour surface tension, i.e. $\gamma_{\nu} \cos \theta$ depends only on $\gamma_{\nu}$ for a given solid surface (or solid surface tension).

\section{F.1 Materials (Solid Surfaces and Liquids)}

Poly(methyl methacrylate/n-butyl methacrylate) P(MMA/nBMA) copolymer was purchased from Polysciences (Warrington, P.A., U.S.A.; cat\# 01922) as fine beads. A 2\% $\mathrm{P}(\mathrm{MMA} / n \mathrm{BMA}) /$ chloroform solution was prepared using chloroform (Sigma-Aldrich, $99.9+\%$ A.C.C. HPLC grade) as the solvent. Silicon wafers $<100>$ (Silicon Sense, Naschua, N.H., U.S.A.; thickness: $525 \pm 50$ micron) were selected as the substrate for the polymer coating. The $\mathrm{P}(\mathrm{MMA} / n \mathrm{BMA})$-coated surfaces were 
prepared by a solvent-casting technique on the dried silicon wafers inside Petri glass dishes (Canlab, Mississauga, Ont.: cat.\# D2005-1) overnight. The experimental procedures and solid surface preparations have been described in Chapter 5.

Twelve liquids were chosen in this study [112]. They are listed in Table F.1, together with the physical properties and surface tensions (measured at $23.0 \pm$ $0.5^{\circ} \mathrm{C}$.

\section{F.2 Results}

Of the 12 liquids used, it was found that only 6 liquids yielded usable contact angles. They are water, glycerol, formamide, 2,2'-thiodiethanol, 3-pyridylcarbinol, and 1-iodonaphthalene. The remaining 6 liquids either dissolved the polymer on contact or yielded non-constant contact angles during the course of the experiments.

The reproducibility of all solid-liquid systems is very good. They are summarized in Table F.2 for the 6 liquids with usable contact angles, at different rates of advancing and each on a newly prepared surface. It should be noted that a total of more than 70 freshly prepared $\mathrm{P}(\mathrm{MMA} / n \mathrm{BMA})$-coated wafers were prepared and used; more than 5,000 images were acquired and analyzed by ADSA-P. A summary of the contact angle complexities is given in Table F.3, together with the meaningful results from Table F.2. 
Table F.1: Suppliers and surface tensions of the liquids used for the contact angle measurements on a poly(methyl methacrylate/n-butyl methacrylate) P(MMA/nBMA)-coated silicon wafer surface. The surface tensions were measured at $23.0 \pm 0.5^{\circ} \mathrm{C}$

\begin{tabular}{llllcc}
\hline liquid & supplier & \% purity & $\begin{array}{c}\text { density } \\
\left(\mathrm{g} / \mathrm{cm}^{3}\right)\end{array}$ & $\begin{array}{c}\text { surface } \\
\text { tension } \gamma_{\mathrm{V}} \\
\left(\mathrm{m} J / \mathrm{m}^{2}\right)\end{array}$ & $\begin{array}{c}\text { no. of } \\
\text { drops }\end{array}$ \\
\hline dibenzylamine & aldrich & 97 & 1.026 & $40.80 \pm 0.06$ & 9 \\
$\begin{array}{l}\text { dimethyl sulfoxide } \\
\text { (DMSO) }\end{array}$ & $\begin{array}{l}\text { sigma- } \\
\text { aldrich }\end{array}$ & $\begin{array}{l}99.9 \\
(\mathrm{HPLC})\end{array}$ & 1.101 & $42.68 \pm 0.09$ & 10 \\
1-iodonaphthalene & aldrich & 99 & 1.740 & $42.92 \pm 0.03$ & 10 \\
1-bromonaphthalene & aldrich & 98 & 1.489 & $44.31 \pm 0.05$ & 7 \\
1,3-diiodopropane & aldrich & 99 & 2.576 & $46.51 \pm 0.13$ & 10 \\
3-pyridylcarbinol & aldrich & 98 & 1.124 & $47.81 \pm 0.03$ & 10 \\
1,1,2,2-tetrabromoethane & aldrich & 98 & 2.967 & $49.29 \pm 0.05$ & 10 \\
diiodomethane & aldrich & 99 & 3.325 & $49.98 \pm 0.02$ & 10 \\
2,2'-thiodiethanol & aldrich & $99+$ & 1.221 & $53.77 \pm 0.03$ & 10 \\
formamide & aldrich & $99.5+$ & 1.134 & $59.08 \pm 0.01$ & 10 \\
glycerol & baker & 99.8 & 1.258 & $65.02 \pm 0.04$ & 8 \\
& analyzed & & & & 10 \\
water & LAST & $\begin{array}{l}\text { doubly } \\
\text { distilled }\end{array}$ & 0.997 & $72.70 \pm 0.09$ & 10 \\
\hline
\end{tabular}

'Laboratory of Applied Surface Thermodynamics 
Table F.2: Low-rate dynamic (advancing) contact angles of different liquids on a poly(methyl methacrylate/n-butyl methacrylate) P(MMA/nBMA)-coated silicon wafer surface. For each liquid, at least 5 and up to 10 different rates of advancing of the three-phase contact line were performed, each on a newly prepared solid surface. The error bars are $95 \%$ confidence limits

\begin{tabular}{|c|c|c|c|c|c|}
\hline \multicolumn{2}{|c|}{ water } & \multicolumn{2}{|c|}{ glycerol } & \multicolumn{2}{|c|}{ formamide } \\
\hline $\begin{array}{c}\text { rate } \\
(\mathrm{mm} / \mathrm{min} .)\end{array}$ & $\begin{array}{c}\theta \\
\text { (deg.) }\end{array}$ & $\begin{array}{c}\text { rate } \\
(\mathrm{mm} / \mathrm{min} .)\end{array}$ & $\begin{array}{c}\theta \\
\text { (deg.) }\end{array}$ & $\begin{array}{c}\text { rate } \\
(\mathrm{mm} / \mathrm{min} .)\end{array}$ & $\begin{array}{c}\theta \\
\text { (deg.) }\end{array}$ \\
\hline 0.265 & $82.67 \pm 0.07$ & 0.321 & $75.65 \pm 0.06$ & 0.424 & $65.70 \pm 0.07$ \\
\hline 0.300 & $82.86 \pm 0.07$ & 0.358 & $74.53 \pm 0.05$ & 0.425 & $66.58 \pm 0.04$ \\
\hline 0.333 & $82.89 \pm 0.13$ & 0.359 & $75.04 \pm 0.07$ & 0.441 & $66.62 \pm 0.06$ \\
\hline 0.348 & $80.35 \pm 0.05$ & 0.409 & $74.67 \pm 0.07$ & 0.456 & $66.64 \pm 0.04$ \\
\hline 0.423 & $80.24 \pm 0.04$ & 0.456 & $73.46 \pm 0.07$ & 0.466 & $66.47 \pm 0.05$ \\
\hline 0.562 & $80.29 \pm 0.04$ & 0.682 & $74.48 \pm 0.04$ & 0.809 & $66.07 \pm 0.12$ \\
\hline 0.568 & $80.94 \pm 0.05$ & 0.702 & $74.52 \pm 0.09$ & 0.812 & $67.12 \pm 0.13$ \\
\hline 0.578 & $81.42 \pm 0.07$ & 0.822 & $74.79 \pm 0.04$ & 0.874 & $65.71 \pm 0.15$ \\
\hline 0.603 & $81.53 \pm 0.24$ & -.... & --.-- & 0.964 & $66.02 \pm 0.14$ \\
\hline 0.693 & $80.06 \pm 0.08$ & -..--.. & $-\cdots$ & -...-. & -..--- \\
\hline Mean $\theta$ : & $81.33 \pm 0.80$ & & $74.72 \pm 0.59$ & & $66.33 \pm 0.37$ \\
\hline
\end{tabular}


Table F.2: (cont'd)

\begin{tabular}{|c|c|c|c|c|c|}
\hline \multicolumn{2}{|c|}{ 2,2'-thiodiethanol } & \multicolumn{2}{|c|}{ 3-pyridylcarbinol } & \multicolumn{2}{|c|}{ 1-iodonaphthalene } \\
\hline $\begin{array}{c}\text { rate } \\
\text { (mm/min.) }\end{array}$ & $\begin{array}{c}\theta \\
\text { (deg.) }\end{array}$ & $\begin{array}{c}\text { rate } \\
(\mathrm{mm} / \mathrm{min} .)\end{array}$ & $\begin{array}{c}\theta \\
\text { (deg.) }\end{array}$ & $\begin{array}{c}\text { rate } \\
(\mathrm{mm} / \mathrm{min} .)\end{array}$ & $\begin{array}{c}\theta \\
\text { (deg.) }\end{array}$ \\
\hline 0.313 & $57.51 \pm 0.18$ & 0.516 & $48.91 \pm 0.09$ & 0.201 & $36.01 \pm 0.35$ \\
\hline 0.331 & $58.46 \pm 0.07$ & 0.576 & $48.98 \pm 0.08$ & 0.382 & $35.28 \pm 0.23$ \\
\hline 0.491 & $58.48 \pm 0.05$ & 0.850 & $49.57 \pm 0.14$ & 0.552 & $35.92 \pm 0.14$ \\
\hline 0.505 & $57.31 \pm 0.04$ & 0.866 & $48.88 \pm 0.07$ & 0.601 & $35.04 \pm 0.19$ \\
\hline 0.562 & $57.84 \pm 0.05$ & 0.895 & $49.77 \pm 0.17$ & 0.870 & $36.28 \pm 0.10$ \\
\hline 0.625 & $58.36 \pm 0.10$ & ----- & -.-- & 0.904 & $36.48 \pm 0.09$ \\
\hline 0.629 & $57.22 \pm 0.06$ & $-\cdots$ & ------ & 0.920 & $35.37 \pm 0.19$ \\
\hline 0.896 & $57.56 \pm 0.12$ & -.-- & ------- & 0.929 & $35.24 \pm 0.16$ \\
\hline -.---- & ----- & & -...-- & 0.930 & $35.92 \pm 0.40$ \\
\hline ----- & ---- & ----- & ----- & 1.139 & $35.18 \pm 0.12$ \\
\hline Mean $\theta$ : & $57.84 \pm 0.44$ & & $49.22 \pm 0.52$ & & $35.67 \pm 0.36$ \\
\hline
\end{tabular}


Table F.3: Summary of the contact angle results on a poly(methyl methacrylate/ $n$-butyl methacrylate) $\mathrm{P}(\mathrm{MMA} / n \mathrm{BMA})$-coated silicon wafer surface

\begin{tabular}{lcc}
\hline liquid & $\begin{array}{c}\gamma_{\nu} \\
\left(\mathrm{mJ} / \mathrm{m}^{2}\right)\end{array}$ & $\begin{array}{c}\theta \\
\text { (deg.) }\end{array}$ \\
\hline dibenzylamine & 40.80 & dissolved the copolymer on contact \\
dimethyl sulfoxide (DMSO) & 42.68 & $\theta \uparrow \downarrow$ as $R \uparrow\left(46^{\circ} \rightarrow 56^{\circ} \rightarrow 51^{\circ}\right)^{\dagger}$ \\
1-iodonaphthalene & 42.92 & $35.67 \pm 0.36$ \\
1-bromonaphthalene & 44.31 & $\theta \downarrow \& \gamma_{h} \downarrow$ as $R \uparrow\left(27^{\circ} \rightarrow 23^{\circ}\right)^{\dagger}$ \\
1,3-diiodopropane & 46.51 & slip/stick $\left(15^{\circ} \rightarrow 55^{\circ}\right)^{\dagger}$ \\
3-pyridylcarbinol & 47.81 & $49.22 \pm 0.52$ \\
1,1,2,2-tetrabromoethane & 49.29 & dissolved the copolymer on contact \\
diiodomethane & 49.98 & slip/stick $\left(45^{\circ} \rightarrow 75^{\circ}\right)$ \\
2,2'-thiodiethanol & 53.77 & $57.84 \pm 0.44$ \\
formamide & 59.08 & $66.33 \pm 0.37$ \\
glycerol & 65.02 & $74.72 \pm 0.59$ \\
water & 72.70 & $81.33 \pm 0.80$ \\
\hline
\end{tabular}

'part of the copolymer was observed to be removed after the experiment 


\section{APPENDIX G \\ LOW-RATE DYNAMIC CONTACT ANGLES ON A POLY(METHYL METHACRYLATE) SOLID SURFACE}

Low-rate dynamic contact angles of 9 liquids on a poly(methyl methacrylate) (PMMA) polymer were measured by an automated axisymmetric drop shape analysis - profile (ADSA-P). It was found that 2 liquids dissolved the polymer on contact. From the experimental contact angles of the other seven polar and non-polar liquids, it was found that the liquid-vapour surface tension times cosine of the contact angle changes smoothly with the liquid-vapour surface tension, i.e. $\gamma_{\nu} \cos \theta$ depends only on $\gamma_{\nu}$ for a given solid surface (or solid surface tension).

\section{G.1 Materials (Solid Surfaces and Liquids)}

Poly(methyl methacrylate) (PMMA) was purchased from Polysciences, Warrington, P.A. U.S.A., (cat\# 04553, MW 75,000) as 200 micron beads. A $2 \%$ PMMA/chloroform solution was prepared using chloroform (Sigma-Aldrich, $99.9+\%$ A.C.C. HPLC grade) as the solvent. Silicon wafers $<100>$ (Silicon Sense, Naschua, N.H., U.S.A.; thickness: $525 \pm 50$ micron) were selected as the substrate for the polymer coating. The PMMA-coated surfaces were prepared by a solventcasting technique on the dried silicon wafers inside Petri glass dishes (Canlab, Mississauga, Ont.: cat.\# D2005-1) overnight. The experimental procedures and solid 
surface preparations have been described in Chapter 5 .

Nine liquids were chosen in this study [113]. They are listed in Table G.1, together with the physical properties and surface tensions (measured at $23.0 \pm$ $\left.0.5^{\circ} \mathrm{C}\right)$.

\section{G.2 Results}

Two liquids were found to dissolve the PMMA-coated wafer on contact, resulting in very irregular and flat drops. They are 1,1,2,2-tetrabromoethane and ethanolamine. Indeed, it was observed that the PMMA-coated film was partly removed after the experiments, in the contact area between the liquids and PMMA. The rest of the 7 liquids all yield essentially constant contact angles.

The reproducibility of all solid-liquid systems is very good. They are summarized in Table G.2 for the 7 liquids with essentially constant contact angles, at different rates of advancing and each on a newly prepared surface. It should be noted that a total of more than 70 freshly prepared PMMA-coated wafers were prepared and used; more than 5,000 images were acquired and analyzed by ADSA-P. 
Table G.1: Suppliers and surface tensions of the liquids used for the contact angle measurements on a poly (methyl methacrylate) PMMA-coated silicon wafer surface. The surface tensions were measured at $23.0 \pm 0.5^{\circ} \mathrm{C}$

\begin{tabular}{llllll}
\hline liquid & supplier & $\%$ purity & $\begin{array}{c}\text { density } \\
\left(\mathrm{g} / \mathrm{cm}^{3}\right)\end{array}$ & $\begin{array}{c}\text { surface } \\
\text { tension } \gamma_{\psi_{w}} \\
\left(\mathrm{~mJ} / \mathrm{m}^{2}\right)\end{array}$ & $\begin{array}{c}\text { no. of } \\
\text { drops }\end{array}$ \\
\hline 1,3-diiodopropane & aldrich & 99 & 2.576 & $46.51 \pm 0.13$ & 10 \\
3-pyridylcarbinol & aldrich & 98 & 1.124 & $47.81 \pm 0.03$ & 10 \\
ethanolamine & aldrich & $99+$ & 1.012 & $48.23 \pm 0.06$ & 10 \\
1,1,2,2-tetrabromoethane & aldrich & 98 & 2.967 & $49.29 \pm 0.05$ & 10 \\
diiodomethane & aldrich & 99 & 3.325 & $49.98 \pm 0.02$ & 10 \\
2,2'-thiodiethanol & aldrich & $99+$ & 1.221 & $53.77 \pm 0.03$ & 10 \\
formamide & aldrich & $99.5+$ & 1.134 & $59.08 \pm 0.01$ & 10 \\
glycerol & baker & 99.8 & 1.258 & $65.02 \pm 0.04$ & 8 \\
& analyzed & & & & 10 \\
water & LAST & $\begin{array}{l}\text { doubly } \\
\text { distilled }\end{array}$ & 0.997 & $72.70 \pm 0.09$ & 10 \\
\hline
\end{tabular}

'Laboratory of Applied Surface Thermodynamics 
Table G.2: Low-rate dynamic (advancing) contact angles of different liquids on a poly(methyl methacrylate) PMMA-coated silicon wafer surface. For each liquid, at least 8 and up to 10 different rates of advancing of the three-phase contact line were performed, each on a newly prepared solid surface. The error bars are $95 \%$ confidence limits

\begin{tabular}{cccccc}
\hline \multicolumn{2}{c}{ water } & \multicolumn{2}{c}{ glycerol } & \multicolumn{2}{c}{ formamide } \\
$\begin{array}{c}\text { rate } \\
\text { (mm/min.) }\end{array}$ & $\begin{array}{c}\theta \\
\text { (deg.) }\end{array}$ & $\begin{array}{c}\text { rate } \\
\text { (mm/min.) }\end{array}$ & $\begin{array}{c}\theta \\
\text { (deg.) }\end{array}$ & $\begin{array}{c}\text { rate } \\
\text { (mm/min.) }\end{array}$ & $\begin{array}{c}\theta \\
\text { (deg.) }\end{array}$ \\
\hline 0.260 & $73.67 \pm 0.03$ & 0.161 & $66.57 \pm 0.02$ & 0.188 & $57.51 \pm 0.03$ \\
0.261 & $73.57 \pm 0.04$ & 0.168 & $66.77 \pm 0.10$ & 0.217 & $57.58 \pm 0.06$ \\
0.291 & $74.73 \pm 0.04$ & 0.204 & $66.83 \pm 0.03$ & 0.238 & $58.22 \pm 0.06$ \\
0.330 & $73.29 \pm 0.04$ & 0.207 & $66.14 \pm 0.04$ & 0.240 & $57.63 \pm 0.05$ \\
0.338 & $73.91 \pm 0.03$ & 0.252 & $67.61 \pm 0.03$ & 0.271 & $57.51 \pm 0.03$ \\
0.347 & $73.81 \pm 0.03$ & 0.264 & $67.17 \pm 0.06$ & 0.283 & $58.04 \pm 0.10$ \\
0.356 & $73.45 \pm 0.04$ & 0.368 & $66.51 \pm 0.02$ & 0.285 & $57.83 \pm 0.05$ \\
0.368 & $73.60 \pm 0.06$ & 0.401 & $66.28 \pm 0.10$ & 0.294 & $57.44 \pm 0.07$ \\
0.661 & $73.70 \pm 0.08$ & 0.549 & $67.27 \pm 0.08$ & 0.314 & $58.03 \pm 0.05$ \\
0.730 & $73.48 \pm 0.08$ & 0.998 & $67.20 \pm 0.18$ & 0.341 & $57.74 \pm 0.05$ \\
\hline Mean $\theta:$ & $73.72 \pm 0.28$ & & $66.84 \pm 0.34$ & & $57.73 \pm 0.21$ \\
\hline
\end{tabular}


Table G.2: (cont'd)

\begin{tabular}{|c|c|c|c|c|c|}
\hline \multicolumn{2}{|c|}{$2,2^{\prime}$-thiodiethanol } & \multicolumn{2}{|c|}{ diiodomethane } & \multicolumn{2}{|c|}{ 3-pyridylcarbinol } \\
\hline $\begin{array}{c}\text { rate } \\
\text { (mm/min.) }\end{array}$ & $\begin{array}{c}\theta \\
\text { (deg.) }\end{array}$ & $\begin{array}{c}\text { rate } \\
(\mathrm{mm} / \mathrm{min} .)\end{array}$ & $\begin{array}{c}\theta \\
\text { (deg.) }\end{array}$ & $\begin{array}{c}\text { rate } \\
\text { (mm/min.) }\end{array}$ & $\begin{array}{c}\theta \\
\text { (deg.) }\end{array}$ \\
\hline 0.281 & $50.10 \pm 0.05$ & 0.428 & $42.67 \pm 0.07$ & 0.330 & $39.66 \pm 0.03$ \\
\hline 0.300 & $50.35 \pm 0.04$ & 0.471 & $42.72 \pm 0.10$ & 0.342 & $39.47 \pm 0.05$ \\
\hline 0.420 & $50.00 \pm 0.06$ & 0.493 & $42.17 \pm 0.10$ & 0.354 & $39.26 \pm 0.02$ \\
\hline 0.443 & $50.20 \pm 0.04$ & 0.510 & $41.62 \pm 0.09$ & 0.366 & $39.22 \pm 0.02$ \\
\hline 0.505 & $51.73 \pm 0.10$ & 0.521 & $42.45 \pm 0.09$ & 0.375 & $39.75 \pm 0.04$ \\
\hline 0.921 & $50.01 \pm 0.04$ & 0.561 & $42.29 \pm 0.05$ & 0.380 & $39.37 \pm 0.02$ \\
\hline 0.939 & $50.48 \pm 0.11$ & 0.581 & $41.98 \pm 0.06$ & 0.395 & $39.79 \pm 0.03$ \\
\hline 1.025 & $50.11 \pm 0.18$ & 0.798 & $42.07 \pm 0.15$ & 0.435 & $39.47 \pm 0.03$ \\
\hline 1.131 & $50.37 \pm 0.08$ & ---- & - & 0.491 & $38.73 \pm 0.04$ \\
\hline 1.218 & $50.14 \pm 0.10$ & -...- & --.--- & 0.716 & $39.97 \pm 0.03$ \\
\hline Mean $\theta$ : & $50.35 \pm 0.37$ & & $42.25 \pm 0.31$ & & $39.47 \pm 0.25$ \\
\hline
\end{tabular}


Table G.2: (cont'd)

\begin{tabular}{|c|c|}
\hline \multicolumn{2}{|c|}{ 1,3-diiodopropane } \\
\hline $\begin{array}{c}\text { rate } \\
(\mathrm{mm} / \mathrm{min} .)\end{array}$ & $\begin{array}{c}\theta \\
\text { (deg.) }\end{array}$ \\
\hline 0.541 & $36.67 \pm 0.05$ \\
\hline 0.545 & $37.15 \pm 0.05$ \\
\hline 0.547 & $36.87 \pm 0.05$ \\
\hline 0.619 & $36.42 \pm 0.04$ \\
\hline 0.635 & $37.16 \pm 0.04$ \\
\hline 0.747 & $36.84 \pm 0.07$ \\
\hline 0.872 & $35.86 \pm 0.18$ \\
\hline 0.883 & $37.03 \pm 0.07$ \\
\hline 1.161 & $37.56 \pm 0.07$ \\
\hline 1.244 & $37.94 \pm 0.10$ \\
\hline Mean $\theta:$ & $36.95 \pm 0.41$ \\
\hline
\end{tabular}




\section{APPENDIX H \\ LOW-RATE DYNAMIC CONTACT ANGLES ON \\ POLY(PROPENE-alt-N-(n-ALKYL)MALEIMIDE) \\ SOLID SURFACES}

Low-rate dynamic contact angles of 10 new liquids on poly(propene-alt- $N$ - $(n-$ alkyl)maleimide) copolymers are reported. It is found that only 3 liquids yield usable contact angles: triacetin on poly(propene-alt- $N$-( $n$-hexyl)maleimide), and 1,3diiodopropane and 1-iodonaphthalene on poly(propene-alt- $N$-( $n$-propyl)maleimide). The remaining liquids either dissolve the polymer on contact or yield non-constant contact angles during the course of the experiments. Plotting the meaningful angles together with the results obtained from previous studies reconfirms that the product of liquid-vapour surface tension and cosine of the contact angle $\gamma_{l v} \cos \theta$ is a function only of the liquid-vapour $\gamma_{l v}$ and solid-vapour $\gamma_{s v}$ surface tensions. In addition, finding liquids that yield meaningful contact angles is not an easy task, especially on these non-inert surfaces.

\section{H.1 Materials (Solid Surfaces and Liquids)}

poly(propene-alt- $N$ - $(n$-hexyl)maleimide) and poly(propene-alt- $N-(n-$ propyl)maleimide) were synthesized at the Institute of Polymer Research Dresden (Germany). The chemical structure of these copolymers has been described in Figure 
3.1. Silicon wafers $<100>$ (Silicon Sense, Naschua, N.H., U.S.A.; thickness: $525 \pm$ 50 micron) were selected as the substrate for the polymer coating.

The new liquids used are listed in Table $H .1$ with the liquid-yapour surface tensions measured at $23.0 \pm 0.5^{\circ} \mathrm{C}$. They are 1,1,2,2-tetrabromoethane, ethanolamine, 3-pyridylcarbinol, 1,3-diiodopropane, 1-iodonaphthalene,methyl salicylate, $N, N$-dimethylformamide, ethyl cyanoacetate, triacetin, and nitromethane. Details with respect to solid surface preparation, and experimental procedures have been described in Chapter 5 .

\section{H.2 Results}

It was found [108] that only three liquids yielded usable contact angles: triacetin on poly(propene-alt- $N$-( $n$-hexyl)maleimide), and 1,3-diiodopropane and 1iodonaphthalene on poly(propene-alt- $N$-( $n$-propyl)maleimide). They are summarized in Table H.2. The remaining liquids either dissolved the polymer on contact or yielded non-constant contact angles during the course of the experiments, as given in Table H.3, together with the results from Table H.2. 
Table H.1: Suppliers and surface tensions of the liquids used for the contact angle measurements on poly(propene-alt- $N$-( $n$-propyl)maleimide)- and poly(propene-alt- $N$ - $(n-$ hexyl)maleimide)-coated silicon wafer surfaces. The surface tensions were measured at $\mathbf{2 3 . 0}$ $\pm 0.5^{\circ} \mathrm{C}$

\begin{tabular}{llllcc}
\hline liquid & supplier & $\%$ purity & $\begin{array}{c}\text { density } \\
\left(\mathrm{g} / \mathrm{cm}^{3}\right)\end{array}$ & $\begin{array}{c}\text { surface } \\
\text { tension } \gamma_{h} \\
\left(\mathrm{~m} / \mathrm{m}^{2}\right)\end{array}$ & $\begin{array}{c}\text { no. of } \\
\text { drops }\end{array}$ \\
\hline nitromethane & aldrich & $99+$ & 1.127 & $34.31 \pm 0.006$ & 10 \\
triacetin & fluka & $99+$ & 1.158 & $35.52 \pm 0.16$ & 10 \\
ethyl cyanoacetate & aldrich & $98+$ & 1.063 & $36.01 \pm 0.04$ & 9 \\
$N, N$-dimethylformamide & sigma- & $99.9+$ & 0.944 & $36.65 \pm 0.004$ & 10 \\
& aldrich & $($ HPLC) & & & 10 \\
methyl salicylate & aldrich & $99+$ & 1.174 & $38.82 \pm 0.07$ & 10 \\
1,3-diiodopropane & aldrich & 99 & 2.576 & $46.51 \pm 0.13$ & 10 \\
3-pyridylcarbinol & aldrich & 98 & 1.124 & $47.81 \pm 0.03$ & 10 \\
ethanolamine & aldrich & $99+$ & 1.012 & $48.23 \pm 0.06$ & 10 \\
1,1,2,2-tetrabromoethane & aldrich & 98 & 2.967 & $49.29 \pm 0.05$ & 10 \\
\hline
\end{tabular}

'Laboratory of Applied Surface Thermodynamics 
Table H.2: Low-rate dynamic (advancing) contact angles of different liquids on poly(propenealt- $N$-( $n$-hexyl)maleimide)- and poly(propene-alt- $N$-( $n$-propyl)maleimide)-coated silicon wafer surfaces. For each liquid, at least 4 and up to 6 different rates of advancing of the three-phase contact line were performed, each on a newly prepared solid surface. The error bars are $95 \%$ confidence limits

\begin{tabular}{|c|c|c|c|c|c|}
\hline \multicolumn{2}{|c|}{$\begin{array}{c}\text { poly(propene-alt }-N-(n- \\
\text { hexyl)maleimide) } \\
\text { triacetin }\end{array}$} & \multicolumn{4}{|c|}{ poly(propene-alt- $N$-( $n$-propyl)maleimide) } \\
\hline $\begin{array}{c}\text { rate } \\
\text { (mm/min.) }\end{array}$ & $\begin{array}{c}\theta \\
(\operatorname{deg} .)\end{array}$ & $\begin{array}{c}\text { rate } \\
(\mathrm{mm} / \mathrm{min} .)\end{array}$ & $\begin{array}{c}\theta \\
\text { (deg.) }\end{array}$ & $\begin{array}{c}\text { rate } \\
(\mathrm{mm} / \mathrm{min} .)\end{array}$ & $\begin{array}{c}\theta \\
\text { (deg.) }\end{array}$ \\
\hline 0.128 & 39.79 & 0.620 & 40.42 & 0.829 & 35.23 \\
\hline 0.198 & 39.61 & 0.701 & 40.36 & 0.843 & 35.34 \\
\hline 0.366 & 39.83 & 0.721 & 39.88 & 0.910 & 35.22 \\
\hline 0.429 & 38.58 & 0.766 & 39.71 & 0.914 & 34.96 \\
\hline 0.464 & 39.50 & 0.775 & 39.42 & -n- & $-\cdots$ \\
\hline 0.627 & 39.41 & 1.013 & 40.06 & --- & $-\cdots$ \\
\hline Mean $\theta:$ & $39.45 \pm 0.48$ & \multicolumn{2}{|c|}{$39.98 \pm 0.40$} & \multicolumn{2}{|c|}{$35.19 \pm 0.26$} \\
\hline
\end{tabular}


Table H.3: Summary of the contact angle results for the 10 liquids on poly(propene-alt- $N$ - $(n-$ hexyl)maleimide)- and poly(propene-alt- $N$-( $n$-propyl)maleimide)-coated silicon wafer surfaces

\begin{tabular}{|c|c|c|c|}
\hline & & $\begin{array}{l}\text { poly(propene-alt }-N-(n- \\
\text { hexyl)maleimide) }\end{array}$ & $\begin{array}{l}\text { poly(propene-alt- } N-(n- \\
\text { propyl)maleimide) }\end{array}$ \\
\hline liquids & $\begin{array}{c}\gamma_{\nu v} \\
\left(\mathrm{~mJ} / \mathrm{m}^{2}\right)\end{array}$ & $\begin{array}{c}\theta \\
\text { (deg.) }\end{array}$ & $\begin{array}{c}\theta \\
\text { (deg.) }\end{array}$ \\
\hline 1,1,2,2-tetrabromoethane & 49.29 & $\theta \downarrow$ as $R \uparrow\left(46^{\circ} \rightarrow 30^{\circ}\right)$ & $\begin{array}{l}\text { dissolved the polymer } \\
\text { on contact }\end{array}$ \\
\hline ethanolamine & 48.23 & $\theta \downarrow$ as $R \uparrow\left(42^{\circ} \rightarrow 38^{\circ}\right)$ & $\begin{array}{l}\text { dissolved the polymer } \\
\text { on contact }\end{array}$ \\
\hline 3-pyridylcarbinol & 47.81 & $\theta \downarrow$ as $R \uparrow\left(47^{\circ} \rightarrow 41^{\circ}\right)$ & $\theta \downarrow$ as $R \uparrow\left(39^{\circ} \rightarrow 36^{\circ}\right)$ \\
\hline 1,3-diiodopropane & 46.51 & $\begin{array}{l}\text { dissolved the polymer } \\
\text { on contact }\end{array}$ & $39.98 \pm 0.40$ \\
\hline 1-iodonaphthalene & 42.92 & $\theta \downarrow$ as $R \uparrow\left(28^{\circ} \rightarrow 23^{\circ}\right)$ & $35.19 \pm 0.26$ \\
\hline methyl salicylate & 38.82 & $\begin{array}{l}\text { dissolved the polymer } \\
\text { on contact }\end{array}$ & \\
\hline$N, N$-dimethylformamide & 36.65 & $\begin{array}{l}\text { dissolved the polymer } \\
\text { on contact }\end{array}$ & - \\
\hline ethyl cyanoacetate & 36.01 & $\theta \uparrow$ as $R \uparrow\left(20^{\circ} \rightarrow 32^{\circ}\right)$ & - \\
\hline triacetin & 35.52 & $39.45 \pm 0.48$ & - \\
\hline nitromethane & 34.31 & $\begin{array}{l}\text { dissolved the polymer } \\
\text { on contact }\end{array}$ & ------- \\
\hline
\end{tabular}




\section{APPENDIX I}

\section{LOW-RATE DYNAMIC CONTACT ANGLES ON A POLY(PROPENE-alt-N-METHYLMALEIMIDE) SOLID SURFACE}

\section{I.1 Materials (Solid Surfaces and Liquids)}

Poly(propene-alt- $N$-methylmaleimide) copolymer was synthesized at the Institute of Polymer Research Dresden (Germany) by polymer analogous reactions of alternating poly(propene-maleic anhydride) copolymer with methyl-amine. The chemical structure of the poly(propene-alt- $N$-methylmaleimide) copolymer has been described before (for $m=0$ in Figure 3.1). Silicon wafers $<100\rangle$ (Silicon Sense, Naschua, N.H., U.S.A.; thickness: $525 \pm 50$ micron) were selected as the substrate for the polymer coating. The poly(propene-alt- $N$-methylmaleimide)-coated surfaces were prepared by a solvent-casting technique on the dried silicon wafers inside Petri glass dishes (Canlab, Mississauga, Ont.: cat.\# D2005-1) overnight. The experimental procedures and solid surface preparations have been described in Chapter 5.

Seven liquids are used for the contact angle experiments [106]: they are ethanolamine, 1,1,2,2-tetrabromoethane, diiodomethane, 2,2'-thiodiethanol, formamide, glycerol, and water. The physical properties and surface tensions of these liquids are shown in Table I.1. 


\section{I.2 Results}

It was found that only water, glycerol, and diiodomethane yielded essentially constant contact angles. They are summarized in in Table I.2. The remaining liquids either dissolved the polymer on contact or yield non-constant contact angles, as given in Table I.3. 
Table I.1: Suppliers and surface tensions of the liquids used for the contact angle measurements on a poly(propene-alt- $N$-methylmaleimide)-coated silicon wafer surface. The surface tensions were measured at $23.0 \pm 0.5^{\circ} \mathrm{C}$

\begin{tabular}{llllcc}
\hline liquid & supplier & \% purity & $\begin{array}{c}\text { density } \\
\left(\mathrm{g} / \mathrm{cm}^{3}\right)\end{array}$ & $\begin{array}{c}\text { surface } \\
\text { tension } \gamma_{L v} \\
\left(\mathrm{~m} / / \mathrm{m}^{2}\right)\end{array}$ & $\begin{array}{c}\text { no. of } \\
\text { drops }\end{array}$ \\
\hline ethanolamine & aldrich & $99+$ & 1.012 & $48.23 \pm 0.06$ & 10 \\
1,1,2,2-tetrabromoethane & aldrich & 98 & 2.967 & $49.29 \pm 0.05$ & 10 \\
diiodomethane & aldrich & 99 & 3.325 & $49.98 \pm 0.02$ & 10 \\
2,2'-thiodiethanol & aldrich & $99+$ & 1.221 & $53.77 \pm 0.03$ & 10 \\
formamide & aldrich & $99.5+$ & 1.134 & $59.08 \pm 0.01$ & 10 \\
glycerol & $\begin{array}{l}\text { baker } \\
\text { analyzed }\end{array}$ & 99.8 & 1.258 & $65.02 \pm 0.04$ & 8 \\
water & LAST & doubly & 0.997 & $72.70 \pm 0.09$ & 10 \\
\hline
\end{tabular}


Table I.2. Low-rate dynamic (advancing) contact angles of different liquids on a poly(propene-alt- $N$-methylmaleimide)-coated silicon wafer surface. For each liquid, at least 5 and up to 6 different rates of advancing of the three-phase contact line were performed, each on a newly prepared solid surface. The error bars are $95 \%$ confidence limits

\begin{tabular}{cccccc}
\hline \multicolumn{2}{c}{ water } & \multicolumn{2}{c}{ glycerol } & \multicolumn{2}{c}{ diiodomethane } \\
$\begin{array}{c}\text { rate } \\
\text { (mm/min.) }\end{array}$ & $\begin{array}{c}\theta \\
\text { (deg.) }\end{array}$ & $\begin{array}{c}\text { rate } \\
\text { (mm/min.) }\end{array}$ & $\begin{array}{c}\theta \\
\text { (deg.) }\end{array}$ & $\begin{array}{c}\text { rate } \\
\text { (mm/min.) }\end{array}$ & $\begin{array}{c}\theta \\
\text { (deg.) }\end{array}$ \\
\hline 0.146 & $69.22 \pm 0.04$ & 0.219 & $60.73 \pm 0.04$ & 0.480 & $29.78 \pm 0.14$ \\
0.158 & $70.23 \pm 0.07$ & 0.253 & $59.67 \pm 0.06$ & 0.527 & $31.19 \pm 0.18$ \\
0.183 & $69.69 \pm 0.06$ & 0.256 & $60.28 \pm 0.04$ & 0.669 & $30.43 \pm 0.19$ \\
0.208 & $69.95 \pm 0.06$ & 0.297 & $60.11 \pm 0.06$ & 0.789 & $31.48 \pm 0.20$ \\
0.314 & $69.56 \pm 0.10$ & 0.409 & $60.44 \pm 0.10$ & 0.813 & $30.69 \pm 0.35$ \\
0.341 & $70.19 \pm 0.10$ & 0.527 & $60.25 \pm 0.08$ & $-\ldots$ & $\ldots$ \\
\hline Mean $\theta:$ & $69.81 \pm 0.41$ & & $60.25 \pm 0.37$ & & $30.71 \pm 0.83$ \\
\hline
\end{tabular}


Table I.3. Summary of contact angle results on a poly(propene-alt- $N$-methylmaleimide)-coated silicon wafer surface

\begin{tabular}{lcc}
\hline liquid & $\begin{array}{c}\text { surface tension } \\
\left(\mathrm{mJ} / \mathrm{m}^{2}\right)\end{array}$ & $\begin{array}{c}\text { contact angle } \\
\text { (deg.) }\end{array}$ \\
\hline ethanolamine & 48.23 & dissolved the polymer on contact \\
1,1,2,2-tetrabromoethane & 49.29 & dissolved the polymer on contact \\
diiodomethane & 49.98 & $30.71 \pm 0.83$ \\
2,2'-thiodiethanol & 53.77 & $\theta \downarrow$ and $\gamma_{\nu} \uparrow$ as $R \uparrow\left(36^{\circ} \rightarrow 32^{\circ}\right)$ \\
formamide & 59.08 & $\theta \downarrow$ and $\gamma_{\nu} \downarrow$ as $R \uparrow\left(44^{\circ} \rightarrow 41^{\circ}\right)$ \\
glycerol & 65.02 & $60.25 \pm 0.37$ \\
water & 72.80 & $69.81 \pm 0.41$ \\
\hline
\end{tabular}




\section{APPENDIX J}

\section{ALTERNATIVE FORMULATION OF AN EQUATION OF STATE APPROACH FOR SOLID SURFACE TENSIONS}

In the study of mixtures $[139,140]$, it has become common practice to introduce a factor $\left(1-K_{i j}\right)$ to the geometric mean combining rule,

$$
\varepsilon_{i j}=\left(1-K_{i j}\right) \sqrt{\varepsilon_{i i} \varepsilon_{j j}}
$$

where $K_{i j}$ is an empirical parameter quantifying deviations from the geometric mean combining rule. In the theory of molecular interactions of solids and liquids, $\varepsilon_{s l}$ is often written in the following form:

$$
\varepsilon_{s l}=g\left(\sigma_{s} / \sigma_{l}\right) \sqrt{\varepsilon_{s s} \varepsilon_{l l}}
$$

where $\varepsilon_{s s}$ and $\varepsilon_{l l}$ are, respectively, the minima in the solid-solid and liquid-liquid potentials; $\sigma_{s}$ and $\sigma_{l}$ are the appropriate core diameters for the molecules of the solid and liquid, respectively. The use of the $g\left(\sigma_{s} / \sigma_{f}\right)$ function in Eq.(8.27) is again to quantify the deviation from Berthelot's rule for unlike-pair molecular interactions. As is well-known from experimental and theoretical studies $[44,135,139,141]$, the geometric mean combining rule generally overestimates the strength of the unlikepair interactions; thus, the modifying factor $\left(1-K_{i j}\right)$ should be a decreasing function of the difference $\varepsilon_{i i}-\varepsilon_{j j}$ and should equal to unity when the difference $\left(\varepsilon_{i i}-\varepsilon_{j j}\right)$ tends towards zero. 
On the basis of this thought, a different modifying factor similar to $\left(1-K_{i j}\right)$ is considered:

$$
1-\kappa_{1}\left(\varepsilon_{i i}-\varepsilon_{j j}\right)^{2}
$$

so that $\left(1-\kappa_{1}\left(\varepsilon_{i i}-\varepsilon_{j j}\right)^{2}\right)$ is also a decreasing function of the difference $\left(\varepsilon_{i i}-\varepsilon_{j j}\right)$ and is equal to unity when $\varepsilon_{i i}=\varepsilon_{j j}$. Thus, Eq.(8.30) can then be written as

$$
\varepsilon_{i j}=\left(1-\kappa_{1}\left(\varepsilon_{i i}-\varepsilon_{j j}\right)^{2}\right) \sqrt{\varepsilon_{i i} \varepsilon_{j j}}
$$

where $\kappa_{1}$ is an unknown constant; the square of the difference $\left(\varepsilon_{i i}-\varepsilon_{j j}\right)$, rather than the difference itself, reflects the symmetry of this combining rule, and hence the anticipated symmetry of the equation of state. Because the free energy is directly proportional to the energy parameter $\varepsilon[137,138]$, i.e. $W \propto \varepsilon$, and for the cases of large differences $\left|W_{l l}-W_{s s}\right|$ or $\left|\gamma_{l v}-\gamma_{s v}\right|$, the combining rule for the free energy of adhesion of a solid-liquid pair can be written as

$$
W_{s l}=\left(1-\alpha_{1}\left(W_{l l}-W_{s s}\right)^{2}\right) \sqrt{W_{l l} W_{s s}}
$$

where $\alpha_{1}$ is an empirical constant which is in general different from $\kappa_{1}$ in Eq.(J.2); more explicitly, by using $W_{u}=2 \gamma_{l v}$ and $W_{s s}=2 \gamma_{s v}$,

$$
W_{s l}=2\left(1-\beta_{1}\left(\gamma_{l v}-\gamma_{s v}\right)^{2}\right) \sqrt{\gamma_{l v} \gamma_{s v}}
$$

In the above, $\alpha_{1}$ and $\beta_{1}\left(=4 \alpha_{1}\right)$ are as yet unknown constants. Clearly, when the values of $\gamma_{l v}$ and $\gamma_{s v}$ are close to each other, Eq.(J.4) reverts to the geometric mean 
combining rule. By combining Eq.(J.4) with Eq.(8.22), an alternative equation of state for solid-liquid interfacial tensions can be written as

$$
\gamma_{s l}=\gamma_{l v}+\gamma_{s v}-2 \sqrt{\gamma_{l v} \gamma_{s v}}\left(1-\beta_{1}\left(\gamma_{l v}-\gamma_{s v}\right)^{2}\right)
$$

Combining Eq.(J.5) with Young's equation yields

$$
\cos \theta_{Y}=-1+2 \sqrt{\frac{\gamma_{s v}}{\gamma_{l v}}}\left(1-\beta_{1}\left(\gamma_{l v}-\gamma_{s v}\right)^{2}\right)
$$

The question then becomes whether this combining rule fits well the experimental contact angle patterns shown earlier. Obviously, for a given set of $\gamma_{l v}$ and $\theta$ data measured on one and the same type of solid surface, the constant $\beta_{1}$ and $\gamma_{s \nu}$ values can be determined by a two-variable least-square analysis technique $[68,143,144]$. Starting out with arbitrary values for $\gamma_{s v}$ and $\beta_{l}$, iterative procedures can be used to identify that pair of $\gamma_{s v}$ and $\beta_{1}$ values which provides the best fit of the experimental data to the set of experimental $\gamma_{l \nu}$ and $\theta_{Y}$ pairs belonging to one and the same solid surface. Figures J.1-J.6 show the best-fitted curves of Eq.(J.6) onto the experimental contact angle data for several solid surfaces previously considered. It can be seen that Eq.(J.6) fits these experimental data very well. The results of such a least-square analysis are summarized in Table J.1. Since the $\beta_{1}$ values do not appear to show any dependence on the solid surfaces, a weighted mean $\beta_{1}$ can be obtained. This yields $\beta_{1}=0.0001057\left(\mathrm{~m}^{2} / \mathrm{mJ}\right)^{2}$. A comparison between the $\gamma_{s v}$ values for various solid surfaces obtained from the two equation of state formulations is also given in Table J.1. It can be seen that the $\gamma_{s v}$ values obtained from the two formulations (equations) 
are virtually identical. Since the form of Eq.(J.2) is similar to Eq.(8.30), insight about molecular interactions of unlike pairs can be gained; the rationale is as follows.

Knowing $\beta_{1}=0.0001057\left(\mathrm{~m}^{2} / \mathrm{mJ}\right)^{2}$, the present form of the combining rule for the free energy of adhesion, Eq.(J.3), can be written as

$$
W_{s l}=\left(1-0.0000264\left(W_{l l}-W_{s s}\right)^{2}\right) \sqrt{W_{l l} W_{s s}}
$$

where $\alpha_{1}=\beta_{1} / 4=0.0000264\left(\mathrm{~m}^{2} / \mathrm{m} J\right)^{2}$. Since $W \propto \varepsilon$ and if $W \approx k \varepsilon$, a combining rule for the energy parameter can be derived:

$$
\varepsilon_{s l}=\left(1-0.0000264 k^{2}\left(\varepsilon_{l l}-\varepsilon_{s s}\right)^{2}\right) \sqrt{\varepsilon_{l l} \varepsilon_{s s}}
$$

where $k$ is a proportionality constant.

Although the proportionality constant $k$ is unknown at the moment, Eq.(J.8) should, in principle, be able tell us something about the molecular interactions between unlike solid-liquid pairs. In the study of molecular interactions between solids and liquids through, e.g., the Lennard-Jones solid-fluid potential $[45,48,49,135]$, a combining rule is always required to represent the interactions of unlike pairs of molecules $\varepsilon_{i j}$ from those of like pairs, $\varepsilon_{i i}$ and $\varepsilon_{j j}$. However, the exact form of the combining rule for solid-liquid energy potential is often uncertain owing to the fact that estimating solid-liquid interfacial tensions directly is a difficult task and hence any specific (proposed) form of the combining rule cannot be easily tested and verified. As Eq.(J.8) stands, information about unlike molecular interactions can 
be inferred when the proportionality constant $k$ is known. It should be realized that Eq.(J.2) can be formulated for $k$ to drop out, e.g. by normalization. This procedure is beyond the scope of this thesis. 


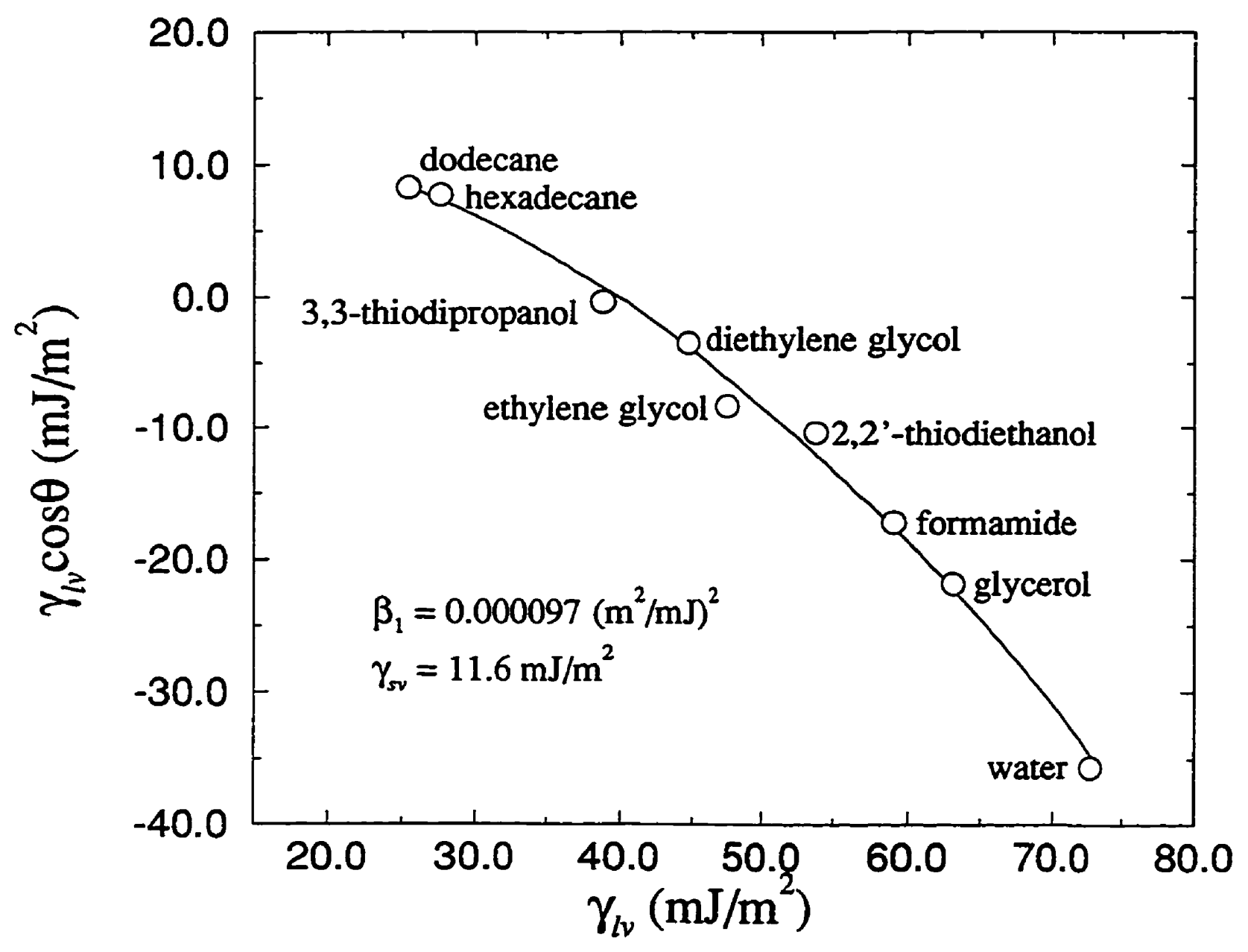

OFC-725-coated silicon wafer surface

Figure J.1 $\gamma_{l \nu} \cos \theta$ vs. $\gamma_{\nu}$ for a FC-725-coated silicon wafer surface. The curve is a best fit of Eq.(J.6) to the experimental data. 


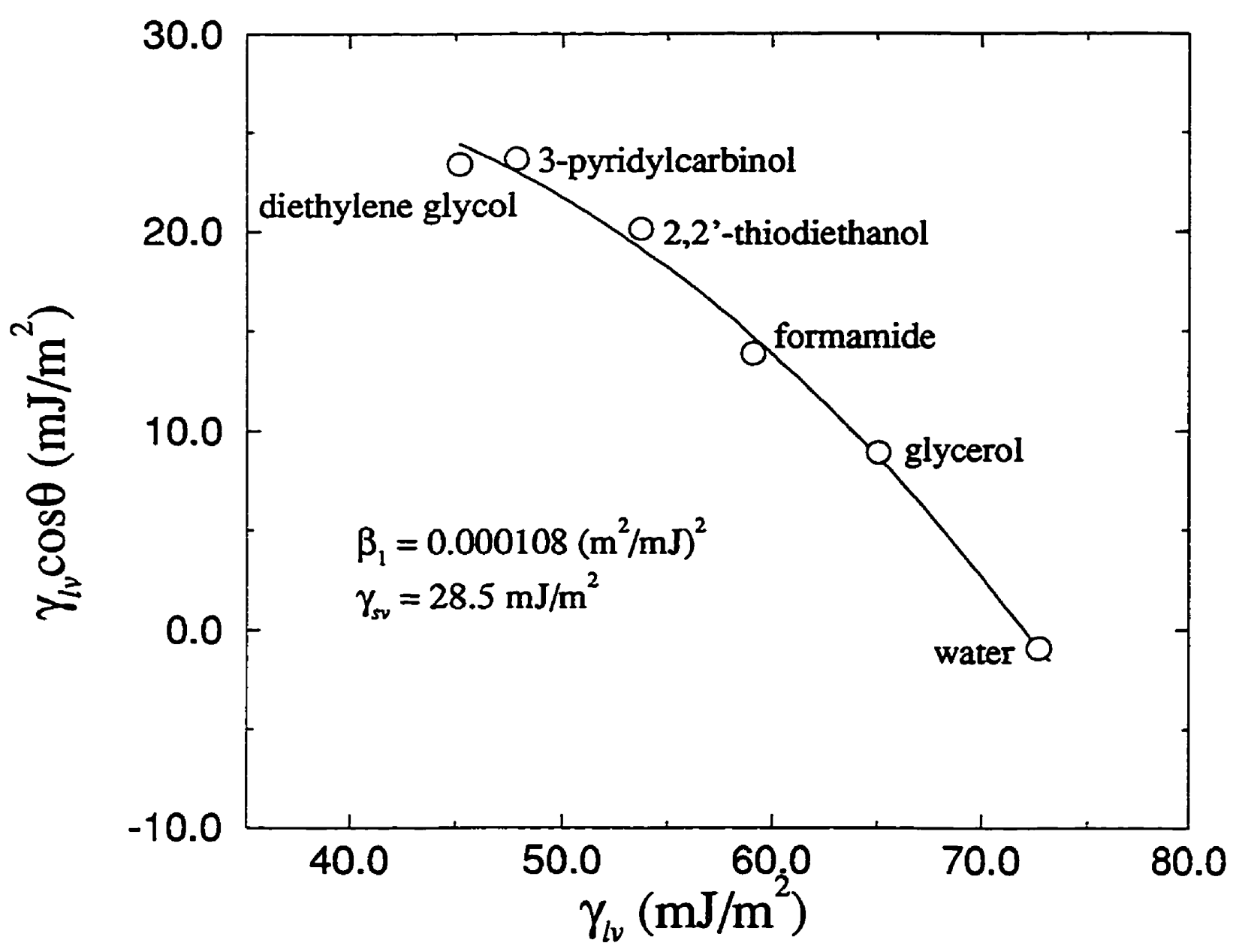

Opoly(n-butyl methacrylate) PnBMA

Figure J.2 $\gamma_{l \nu} \cos \theta$ vs. $\gamma_{l \nu}$ for a poly( $n$-butyl methacrylate) PnBMA-coated silicon wafer surface. The curve is a best fit of Eq.(J.6) to the experimental data. 


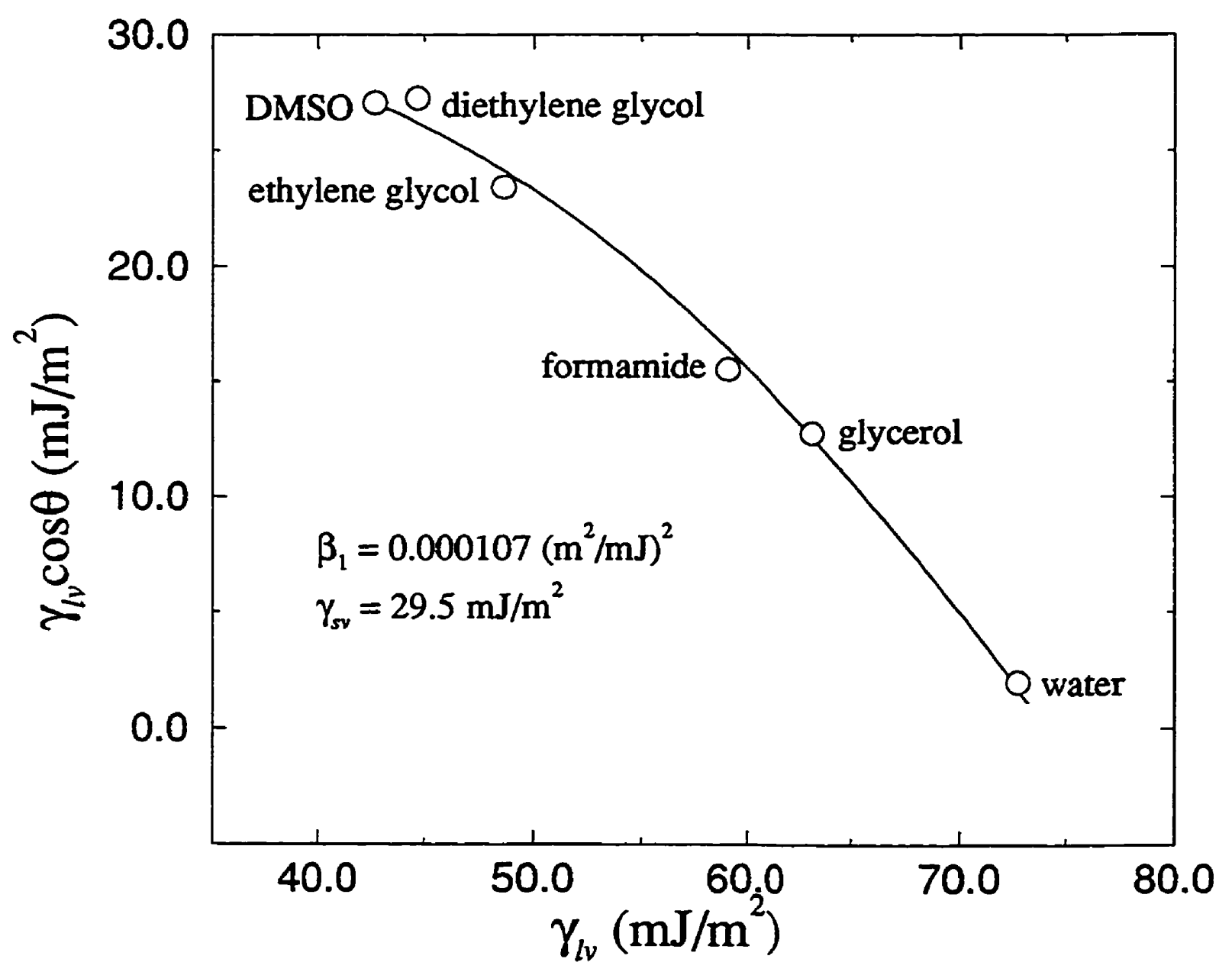

Opolystyrene PS

Figure J.3 $\gamma_{l} \cos \theta$ vs. $\gamma_{l}$ for a polystyrene PS-coated silicon wafer surface. The curve is a best fit of Eq.(J.6) to the experimental data. 


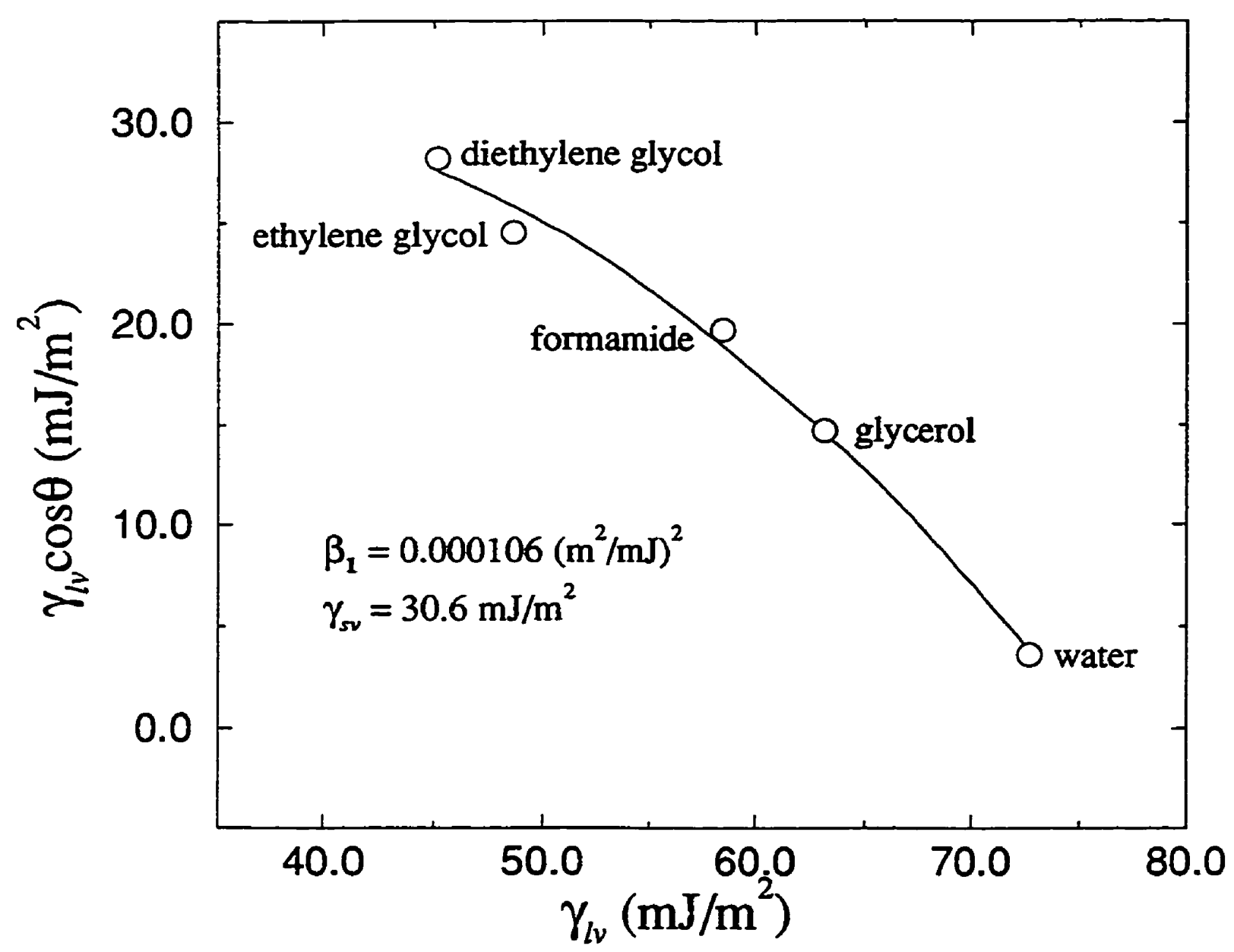

Opoly(styrene-(hexyl/10-carboxydecyl 90:10)-maleimide)

Figure J.4 $\gamma_{L} \cos \theta$ vs. $\gamma_{L}$ for a poly(styrene-(hexyl/10-carboxydecyl 90:10)maleimide)-coated silicon wafer surface. The curve is a best fit of Eq.(J.6) to the experimental data. 


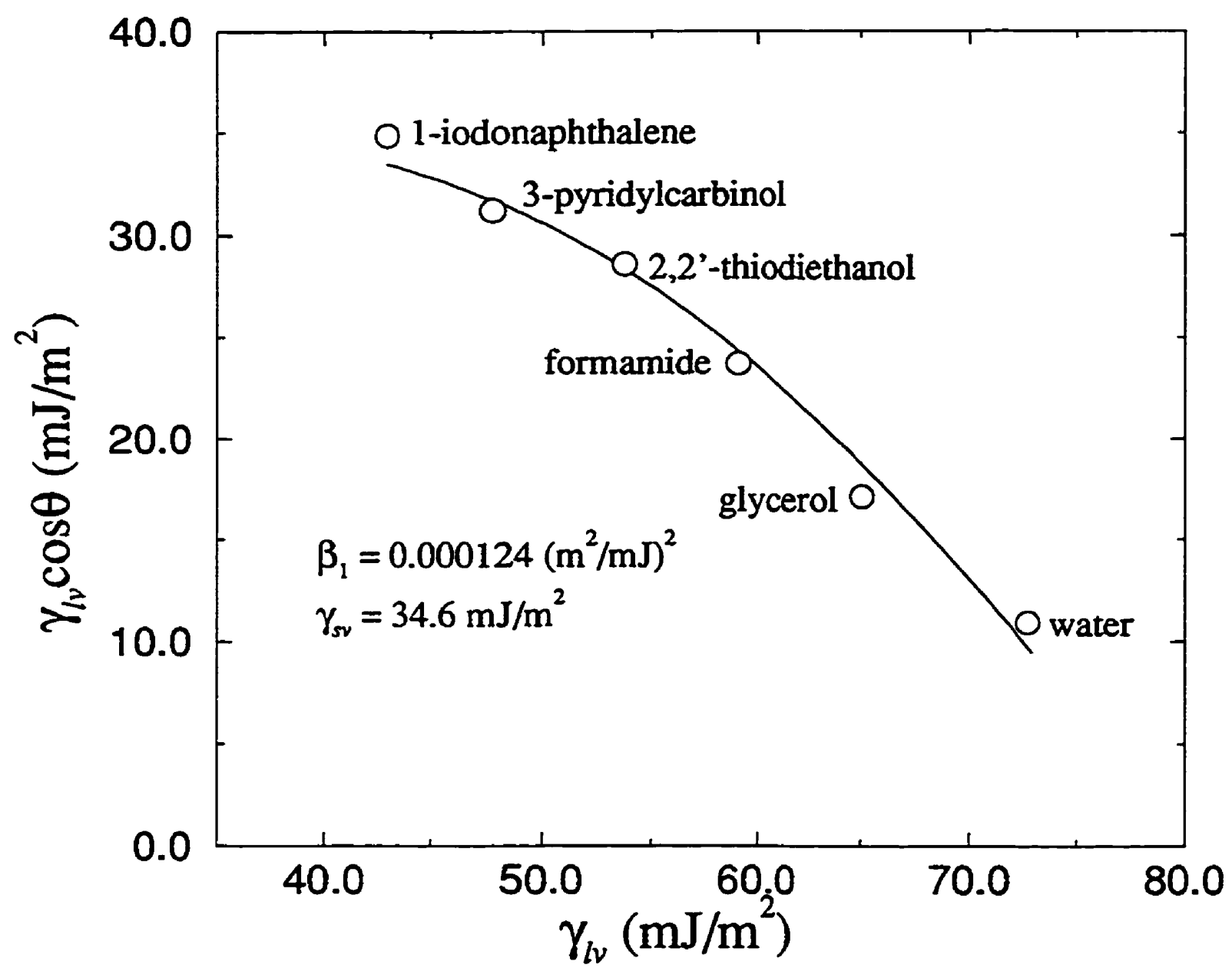

O poly(methyl methacrylate/n-butyl methacrylate)

Figure J.5 $\gamma_{l v} \cos \theta$ vs. $\gamma_{l}$ for a poly (methyl methacrylate/ $n$-butyl methacrylate) P(MMA/nBMA)-coated silicon wafer surface. The curve is a best fit of Eq.(J.6) to the experimental data. 


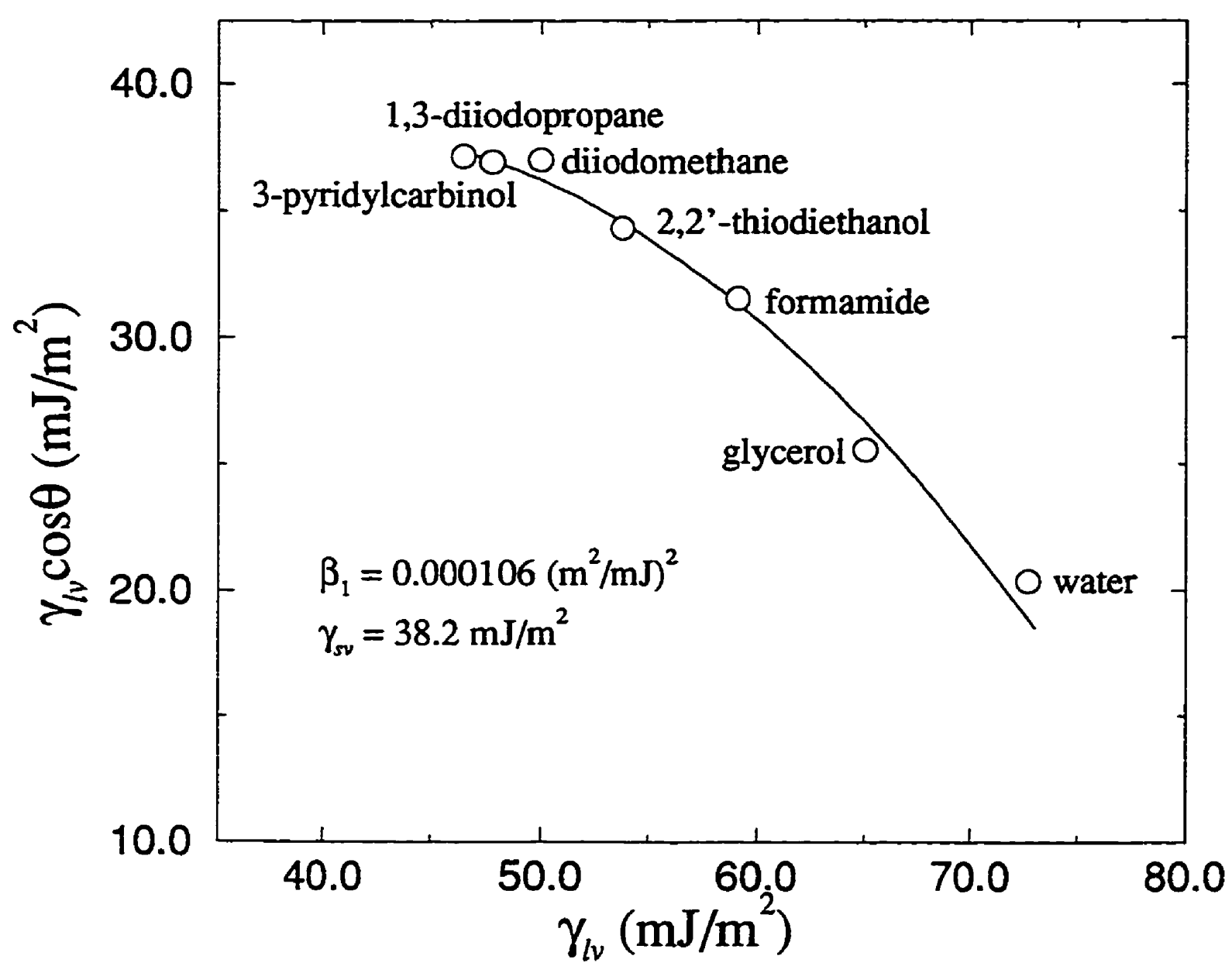

O poly(methyl methacrylate) PMMA

Figure J.6 $\gamma_{l \nu} \cos \theta$ vs. $\gamma_{\nu \nu}$ for a poly(methyl methacrylate) PMMA-coated silicon wafer surface. The curve is a best fit of Eq.(J.6) to the experimental data. 
Table J.1: $\gamma_{s v}\left(\mathrm{~mJ} / \mathrm{m}^{2}\right)$ and $\beta\left(\mathrm{m}^{2} / \mathrm{mJ}\right)^{2}$ values determined by a two-variable least-square fit for the two equation-of-state formulations

\begin{tabular}{|c|c|c|c|c|c|}
\hline \multirow[t]{2}{*}{ solid surface/technique } & \multirow[b]{2}{*}{$\begin{array}{c}\text { \# of } \\
\text { system }\end{array}$} & \multicolumn{2}{|c|}{ Eq.(8.35) } & \multicolumn{2}{|c|}{ Eq.(J.6) } \\
\hline & & $\boldsymbol{\beta}$ & $\gamma_{s v}$ & $\beta_{1}$ & $\gamma_{s v}$ \\
\hline FC-721-coated mica/capillary rise [101] & 8 & 0.000124 & 11.7 & 0.000097 & 11.7 \\
\hline FC-722-coated mica/ADSA-P [95] & 17 & & & & \\
\hline $\begin{array}{l}\text { FC-722-coated silicon wafer/ADSA-P } \\
{[106]}\end{array}$ & 4 & 0.000111 & 11.8 & 0.000092 & 11.6 \\
\hline $\begin{array}{l}\text { FC-725-coated silicon wafer/ADSA-P } \\
\text { [107] }\end{array}$ & 9 & 0.000114 & 11.9 & 0.000092 & 11.6 \\
\hline Teflon FEP/capillary rise [101] & 9 & 0.000142 & 18.0 & 0.000118 & 17.8 \\
\hline hexatriacontane/capillary rise $[51,104]$ & 4 & 0.000124 & 20.3 & 0.000100 & 19.7 \\
\hline $\begin{array}{l}\text { cholesteryl acetate/capillary rise } \\
{[51,105]}\end{array}$ & 4 & 0.000128 & 21.5 & 0.000104 & 20.9 \\
\hline $\begin{array}{l}\text { poly(propene-alt- } N \text {-( } n \text {-hexyl)maleimide) } \\
\text { /ADSA-P/ }[77,108]\end{array}$ & 5 & 0.000122 & 27.9 & 0.000109 & 27.8 \\
\hline $\begin{array}{l}\text { poly(n-butyl methacrylate)/ADSA-P } \\
\text { [109] }\end{array}$ & 6 & 0.000124 & 28.8 & 0.000108 & 28.5 \\
\hline polystyrene/ADSA-P [110] & 6 & 0.000120 & 29.7 & 0.000107 & 29.5 \\
\hline $\begin{array}{l}\text { poly(styrene-(hexyl/10-carboxydecyl } \\
\text { 90:10)-maleimide)/ADSA-P [111] }\end{array}$ & 5 & 0.000120 & 30.8 & 0.000106 & 30.6 \\
\hline $\begin{array}{l}\text { poly(methyl methacrylate/n-butyl } \\
\text { methacrylate)/ADSA-P [112] }\end{array}$ & 6 & 0.000136 & 34.7 & 0.000124 & 34.6 \\
\hline $\begin{array}{l}\text { poly(propene-alt- } N-(n- \\
\text { propyl)maleimide)/ADSA-P }[77,108]\end{array}$ & 6 & 0.000133 & 36.9 & 0.000123 & 36.9 \\
\hline $\begin{array}{l}\text { poly(methyl methacrylate)/ADSA-P } \\
\text { [113] }\end{array}$ & 7 & 0.000113 & 38.3 & 0.000106 & 38.2 \\
\hline $\begin{array}{l}\text { poly(propene-alt- } N \text {-methylmaleimide)/ } \\
\text { ADSA-P [106] }\end{array}$ & 3 & 0.000167 & 43.4 & 0.000155 & 43.3 \\
\hline
\end{tabular}




\section{IMAGE EVALUATION \\ TEST TARGET (QA-3)}
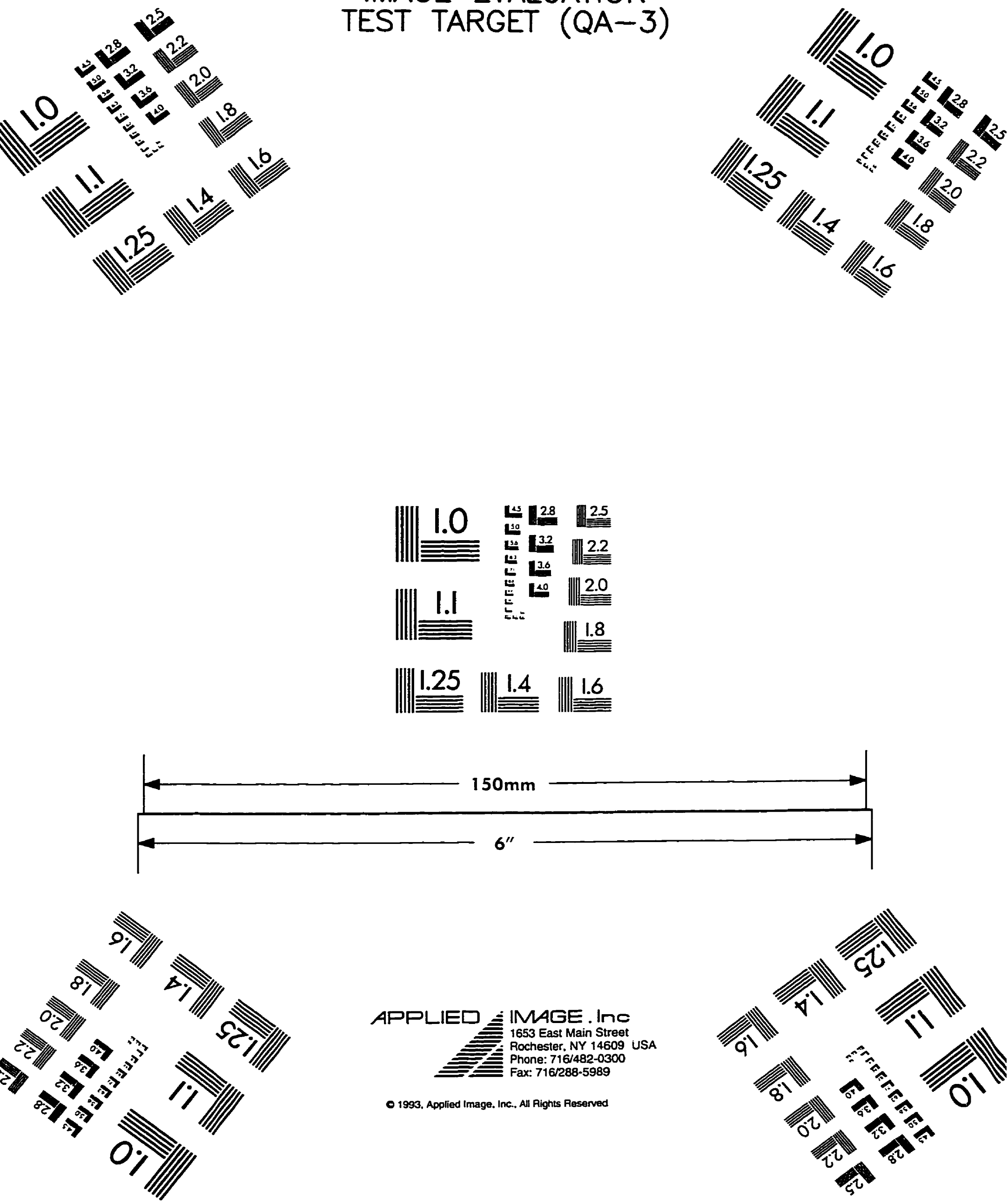

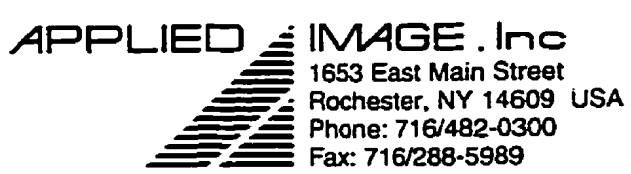

- 1993. Applied Image. Inc. All Rights Reserved

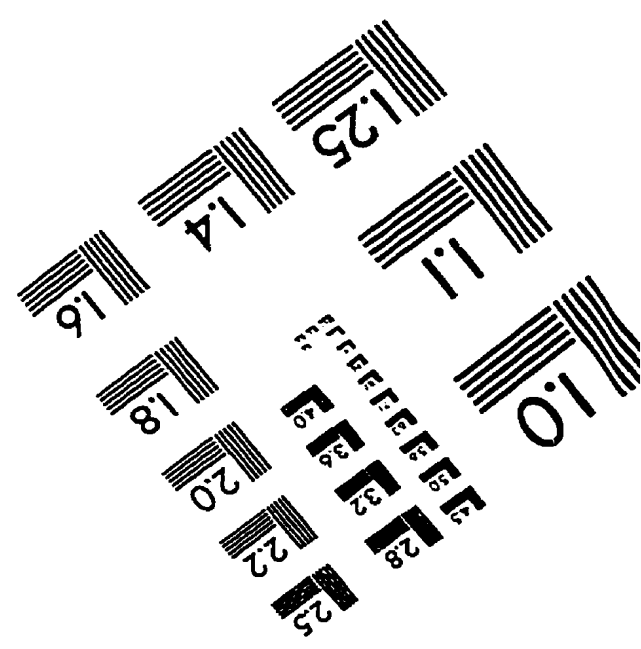

